\title{
1 A Review on Removal of Elemental Mercury from Flue Gas 2 Using Advanced Oxidation Process: Chemistry and Process
}

\author{
Yangxian Liu*, a and Yusuf G. Adewuyi*,b
}

b. Chemical, Biological and Bioengineering Department, North Carolina Agricultural and Technical State University, Greensboro, North Carolina 27411, USA

*Corresponding authors. Tel.: +86 51188743612; fax: +86 51188745824. E-mail: liuyx1984@126.com (Y.X. Liu).

Tel.: (336) 334-7564 or (336) 285 3651. Fax: (336) 334-7904. E-mail: adewuyi@ncat.edu. (Y.G. Adewuyi)

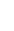

ABSTRACT: Mercury emission from combustion sources has become a great public concern due to its hazards for human health and ecosystem. Although a large number of $\mathrm{Hg}^{0}$ removal technologies already have been developed, none of them can obtain large-scale applications due to various technical and economic issues. Therefore, more efforts are needed to develop cost-effective $\mathrm{Hg}^{0}$ removal technologies. Advanced oxidation technologies (AOTs) are defined as those technologies that can generate mainly the hydroxyl radical $(\cdot \mathrm{OH})$ with high oxidation potential and other reactive oxygen species including superoxide anion radical $\left(\mathrm{O}_{2}{ }^{-}\right)$, hydrogen peroxide $\left(\mathrm{H}_{2} \mathrm{O}_{2}\right)$ and singlet oxygen, by various environmentally benign physical or chemical processes. In the past two decades, AOTs have gained an extensive attention research and successful applications in water treatment and soil remediation, as well as in flue gas purification for multipollutant treatment. In recent years, an increasing attention has been paid to the removal of $\mathrm{Hg}^{0}$ in flue gas using AOTs due to the excellent prospects of this technology. To date, the four main AOTs for removing $\mathrm{Hg}^{0}$ in flue gas include plasma $\mathrm{AOTs}$, $\mathrm{TiO}_{2}$ photocatalytic AOTs, photochemical AOTs and activated oxidant AOTs. While these AOTs have shown excellent prospects for removing $\mathrm{Hg}^{0}$ in flue gas, a number of technical issues need to be resolved before they are amenable 
to industrial applications. This article provides the first comprehensive review of the progress and recent developments of these four AOTs for removing $\mathrm{Hg}^{0}$ in flue gas, with emphasis on the chemistry and processes involved. The effects of the main flue gas components and process parameters on $\mathrm{Hg}^{0}$ removal using these AOTs are summarized. The reaction products, mechanism, kinetics, reactor types and process flow systems, and impacts on of $\mathrm{Hg}^{0}$ removal are also comprehensively reviewed, with insights into the challenges for large-scale applications. This review is intended to advance our understanding and outline directions for future developments of this research field.

Keywords: $\mathrm{Hg}^{0}$ removal; advanced oxidation technologies (AOTs); plasma; $\mathrm{TiO}_{2}$ photocatalytic; photochemical; activated oxidant

\section{Contents}

1. Introduction, .4

1.1 An overview of technologies for $\mathrm{Hg}^{0}$ from removal from flue gas...........................

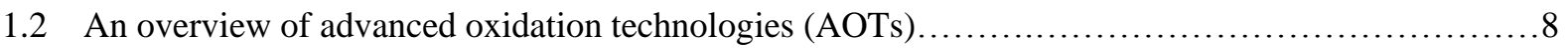

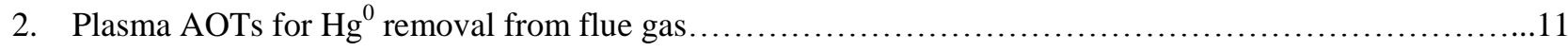

2.1 Overview of plasma AOTs for $\mathrm{Hg}^{0}$ removal from flue gas.

2.4 Products and mechanism of $\mathrm{Hg}^{0}$ removal using non-thermal plasma.....

2.5 Kinetics of $\mathrm{Hg}^{0}$ removal using non-thermal plasma.

2.6 Non-thermal plasma reactor and process flow for $\mathrm{Hg}^{0}$ removal

3. $\mathrm{TiO}_{2}$ photocatalytic AOTs for $\mathrm{Hg}^{0}$ removal from flue gas. 43 
4.2 Dry photochemical AOTs for $\mathrm{Hg}^{0}$ removal. 


\section{Introduction}

\subsection{An overview of technologies for $\mathrm{Hg}^{0}$ removal from flue gas}

Mercury emission from combustion sources such as coal-fired boilers, municipal waste combustors and

medical waste incinerators, which accounts for more than $90 \%$ of all anthropogenic mercury emissions, has become a great public concern due to its high toxicity, environmental persistency, bioaccumulation and detrimental effects on human health and ecosystem (Yang et al.2011; Stolle et al. 2014; Reddy et al.2012). Depending on combustion conditions and flue gas chemistry, mercury exists in three forms in typical flue gas: elemental mercury $\left(\mathrm{Hg}^{0}\right)$, oxidized mercury $\left(\mathrm{Hg}^{2+}\right)$ and particulate-bound mercury $\left(\mathrm{Hg}^{\mathrm{p}}\right)(\mathrm{Cheng}$ et al.2014; Chi et 
For example, $\mathrm{Hg}^{2+}$ can be removed with high efficiency using existing wet flue gas desulfurization (WFGD) equipments due to its high water-solubility. $\mathrm{Hg}^{\mathrm{p}}$ can be easily captured from flue gas, along with fly ash particles, in electrostatic precipitators (ESPs) and/or baghouses (Rodríguez-Pérez et al. 2013; Wang et al. 2014a). However, $\mathrm{Hg}^{0}$ is very difficult to remove from flue gas by existing air pollution control devices (APCD) because of its high volatility at room temperature and low solubility in water (Rodríguez-Pérez et al. 2013; Wang et al. 2014a). Therefore, developing effective $\mathrm{Hg}^{0}$ control methods is currently an important area of research focus and need in the field of energy and environmental protection. Over the past few decades, a number of both dry and wet $\mathrm{Hg}^{0}$ control technologies, including adsorption removal (Yang et al. 2007; Zheng et al. 2012; Chiu et al. 2014; Klasson et al. 2014; Tan et al. 2012; Zhao et al. 2010; Fuente-Cuesta et al. 2012; De et al. 2013; Than et al. 2011; Rupp et al. 2014; Shu et al. 2011; Ren et al. 2006; Shen et al. 2014), catalytic oxidation (Gao et al. 2013; Xu et al. 2014; Zhao et al. 2014a; Wiatros-Motyka et al. 2013; Li et al. 2013; Zhang et al. 2014a; Chen et al. 2014; Hou et al. 2014; Li et al. 2014; Xu et al. 2015; Zhang et al. 2014b), advanced oxidation (An et al. 2014a; Wang et al. 2010; Shan et al. 2009; Zhou et al. 2011; Tan et al. 2010; Fang et al. 2013; Granite et al. 2002; Liu et al. 2014a; Xu et al. 2008; Liu et al. 2014b; Lu et al. 2007; Zhao et al. 2014a; Zhao et al. 2014b; Martinez et al. 2007) and traditional chemical oxidation technologies (Wang et al. 2007; Fang et al. 2012; Hutson et al. 2008; Zhao et al. 2013; Zhao et al. 2013; Barnea et al. 2013; Cheng et al. 2014; Liu et al. 2010a; Stergaršek et al. 2010; Vaart et al. 2011), have been developed. The detailed classification of $\mathrm{Hg}^{0}$ removal technologies from flue gas is further described in Figure 1.

Adsorption removal technologies can effectively remove $\mathrm{Hg}^{0}$ in flue gas by initially converting $\mathrm{Hg}^{0}$ to $\mathrm{Hg}^{\mathrm{p}}$, which is subsequently captured by existing ESPs and/or baghouses (Yang et al. 2007). At present, the exploration and development of high performance and inexpensive adsorbents are the key research initiatives and directions in this field (Yang et al. 2007). As shown in Figure 1, a large number of adsorbents, including modified and 
111 supported adsorbents have been developed and reported in the literature to remove $\mathrm{Hg}^{0}$ in flue gas in the past two 112 decades (Yang et al. 2007; Zheng et al. 2012; Chiu et al. 2014; Klasson et al. 2014; Tan et al. 2012; Zhao et al. 113 2010; Fuente-Cuesta et al. 2012; De et al. 2013; Tan et al. 2011; Rupp et al. 2014; Shu et al. 2013; Ren et al. 2006;

114 Shen et al. 2014). Some researchers have also published several detailed and in-depth reviews on the subject. For 115 example, Yang et al. 2007, Reddy et al.2012 and Liu et al.2008 reviewed the recent development of adsorbents for 116 capturing mercury in coal-fired boiler flue gas. Hower et al. 2010, Ahmaruzzaman et al. 2010 and Wilcox et 117 al.2012 reported mercury capture by fly ash in coal-fired power plants. Pavlish et al.2003 published an overview 118 and reported on recent developments in mercury control technologies for coal-fired power plants. Zheng et al. 1192012 provided a general review of mercury removal technologies from flue gas from cement production 120 processes. 


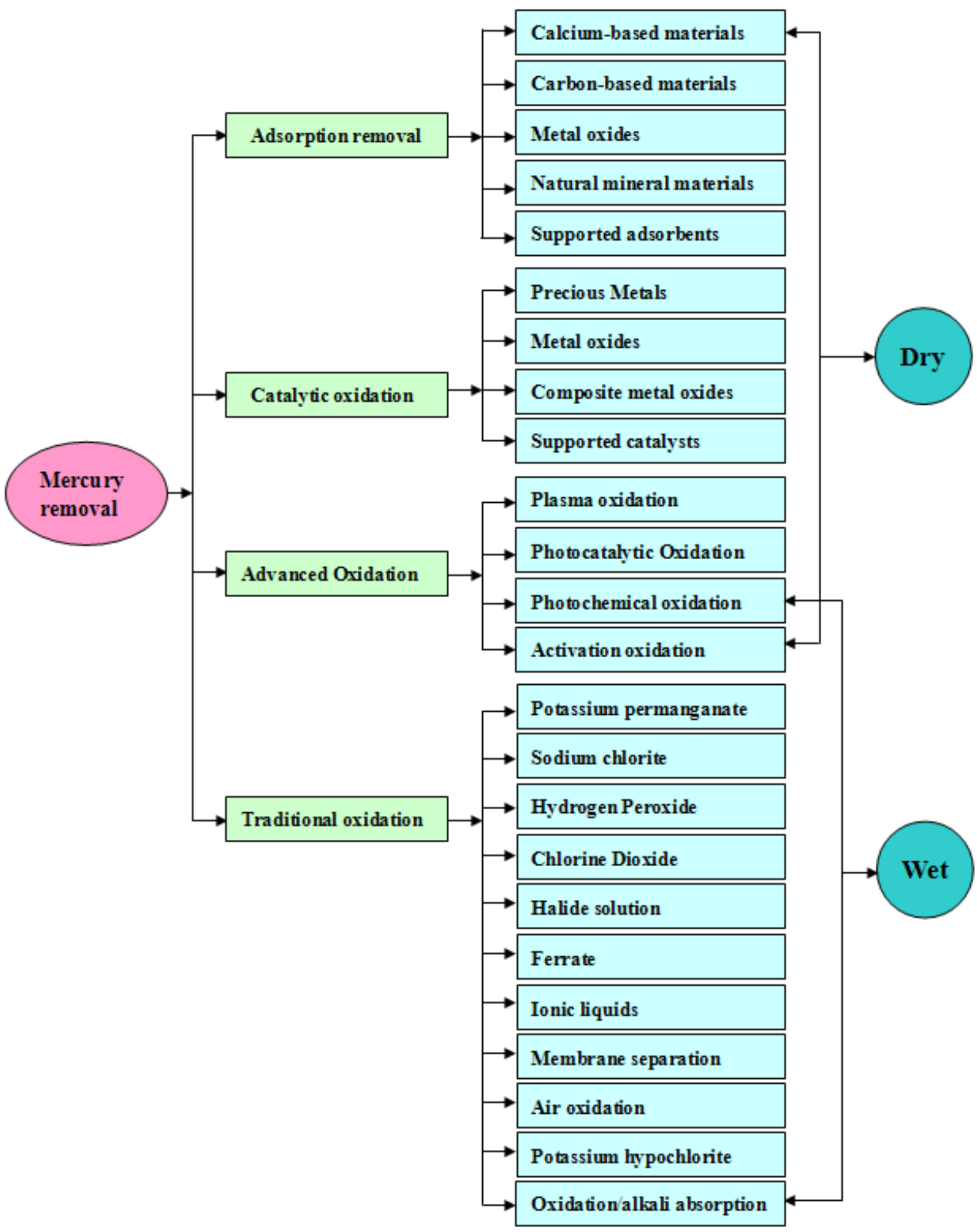

Figure 1. The detailed classification of $\mathrm{Hg}^{0}$ from flue gas removal technology

In recent years, catalytic oxidation removal technologies of $\mathrm{Hg}^{0}$ from flue gas has also received a great deal 
to oxidize $\mathrm{Hg}^{0}$ to $\mathrm{Hg}^{2+}$ in a simplified and low cost process (Gao et al. 2013; Xu et al. 2014). Work in this area currently focuses on the development of cost-effective and highly reliable catalysts. A large number of mercury oxidation catalysts, mainly including precious metals, metal oxides, composite metal oxides and their modified or supported catalysts, had been developed to remove $\mathrm{Hg}^{0}$ in flue gas (Gao et al. 2013; Xu et al. 2014; Zhao et al. 2014a; Wiatros-Motyka et al. 2013; Li et al. 2013; Zhang et al. 2014a; Chen et al. 2014; Hou et al. 2014; Li et al. 2014; Xu et al. 2015), and are reported in recent comprehensive reviews. Wilcox et al.2012, Dranga et al.2012, Reddy et al.2012 and Presto et al.2006 respectively reviewed the new developments in $\mathrm{Hg}^{0}$ oxidation catalysts. Adsorption and catalytic oxidation technologies have shown good prospects in laboratory studies, but the catalysts still require further improvements for use in future industrial applications due to their low stability and reliability, lack of effective regeneration method, and high costs of application. In addition, traditional chemical oxidation and separation methods such as $\mathrm{KMnO}_{4}, \mathrm{NaClO}_{2}, \mathrm{O}_{3}, \mathrm{ClO}_{2}, \mathrm{KClO}$, ferrate; and ionic liquids, air, halide and membrane separations have been used to remove gaseous $\mathrm{Hg}^{0}$ in various reactor types (Wang et al. 2007; Fang et al. 2012; Hutson et al. 2008; Zhao et a.l 2013a; Zhao et a.l 2013b; Barnea et al. 2013; Cheng et al. 2014; Liu et al. 2013; Stergaršek et al. 2010; Vaart et al. 2011). Besides, some oxidants are also added to common calcium-based and urea-based wet flue gas desulfurization (WFGD) equipment to enhance removal of $\mathrm{Hg}^{0}$ in flue gas (Presto et al. 2006; Fang et al. 2014; Zhong 1008; Zhao et al. 2008). However, these technologies are still unable to obtain commercial applications due to a variety of unsolved problems such as high cost, secondary pollution of products applications. or low removal efficiency (Liu et al. 2014a; Liu et al. 2014c). Therefore, more research efforts are needed to develop more cost-effective technologies for $\mathrm{Hg}^{0}$ removal from flue gas, which are capable of large-scale

\subsection{An overview of advanced oxidation technologies (AOTs)}


radicals $(\cdot \mathrm{OH})$ by various physical or chemical methods (Liu et al. 2011a). The redox potentials of some common oxidants under acidic conditions are summarized in Table 1 . It can be seen from Table 1 that $\cdot \mathrm{OH}$ is a very strong oxidant (second only to fluorine) in nature and therefore, capable of almost complete oxidation of most pollutants in nature (Liu et al. 2011a; Serpone et al. 2010; Josepha et al. 2009; Ayoub et al. 2010; Feng et al. 2013; Sharma et al. 2012). Hence, the oxidation reaction processes induced by $\cdot \mathrm{OH}$ has almost no secondary pollutants since the

Table 1. Redox potentials of several common oxidants under acidic conditions (Liu et al. 2011a; Portland et al. 1934).

\begin{tabular}{lcccccccccc}
\hline Category & $\mathrm{F}_{2}$ &. $\mathrm{OH}$ & $\mathrm{SO}_{4}{ }^{-}$ &. $\mathrm{O}_{2}^{-}$ & $\mathrm{K}_{2} \mathrm{FeO}_{4}$ & $\mathrm{~K}_{2} \mathrm{~S}_{2} \mathrm{O}_{8}$ & $\mathrm{O}_{3}$ &. $\mathrm{O}$ & $\mathrm{H}_{2} \mathrm{O}_{2}$ \\
\hline Potential (V) & 2.87 & 2.80 & 2.67 & 2.21 & 2.20 & 2.08 & 2.08 & 2.05 & 1.76 \\
\hline Category & $\mathrm{KMn}$ & $\mathrm{NaClO}_{2}$ & $\mathrm{HO}_{2} \cdot$ & $\mathrm{NaClO}$ & $\mathrm{NaClO}_{3}$ & $\mathrm{Cl}_{2}$ & $\mathrm{KCr}_{2} \mathrm{O}_{7}$ & $\mathrm{O}_{2}$ & $\mathrm{ClO}_{2}$ \\
& $\mathrm{O}_{4}$ & & & & & & & & & \\
\hline Potential (V) & 1.70 & 1.64 & 1.51 & 1.49 & 1.47 & 1.36 & 1.36 & 1.23 & 1.19 \\
\hline
\end{tabular}
pollution concerns, an increasing attention also has been paid to flue gas purification technologies using AOTs, 

have shown excellent prospects for removing $\mathrm{Hg}^{0}$ in flue gas, there are still a number of technical issues to be resolved before they are ready for large-scale industrial applications. This article provides the first comprehensive review of the major research progress on these four AOTs for removing $\mathrm{Hg}^{0}$ in flue gas, and the effects of major flue gas components, and process parameters on $\mathrm{Hg}^{0}$ removal are summarized. The reaction products and mechanism, kinetics, reactor types and process flow of $\mathrm{Hg}^{0}$ removal using these four AOTs are comprehensively reviewed and discussed. Finally, some unresolved issues and challenges, and future research directions of $\mathrm{Hg}^{0}$ 


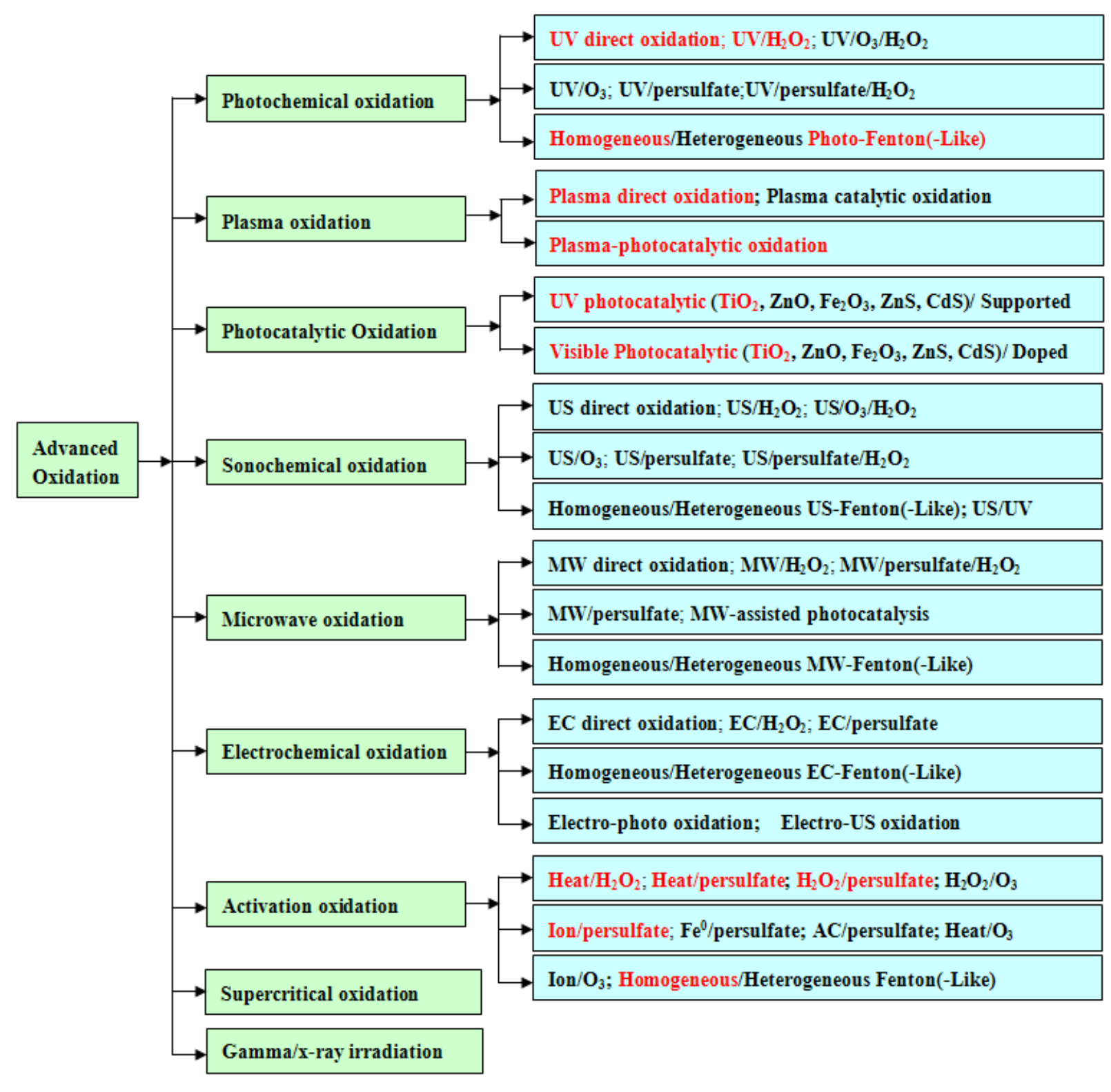

Figure 2. Common AOTs in the field of water treatment, soil remediation and flue gas purification

\section{Plasma AOTs for removing $\mathrm{Hg}^{\mathrm{0}}$ in flue gas}

\subsection{Overview of plasma $\mathrm{AOT}$ for removing $\mathrm{Hg}^{0}$ in flue gas}

Plasma is an ionized gas which is in its fourth state unlike the other three states of matters (solid, liquid and 

ionization. In these methods, gas discharge is recognized as the most effective way, and has been widely used in scientific research and industrial applications (Bogaerts et al. 2002; Chang et al. 2002). Depending on the differences in the generating methods, plasma can of several types, but generally can be divided into thermal equilibrium state plasma (or high-temperature plasma) and non-thermal equilibrium state plasma (or low-temperature plasma) based on the state of thermodynamic equilibrium (or particle temperature) (Bogaerts et al. 2002; Chang et al. 2002; Tendero et al. 2006; Kogelschatz et al. 2004; McAdams et al. 2001; Li et al. 2014a).

Of the two, non-thermal equilibrium state plasma (NTP) can be further divided into two types consisting of thermal plasma (or quasi-equilibrium plasma) and cold plasma (or non quasi-equilibrium plasma) (Bogaerts et al. 2002; Chang et al. 2002; Tendero et al. 2006; Kogelschatz et al. 2004; McAdams et al. 2001; Li et al. 2014a). Specific classification of plasma technology is further summarized in Figure 3.

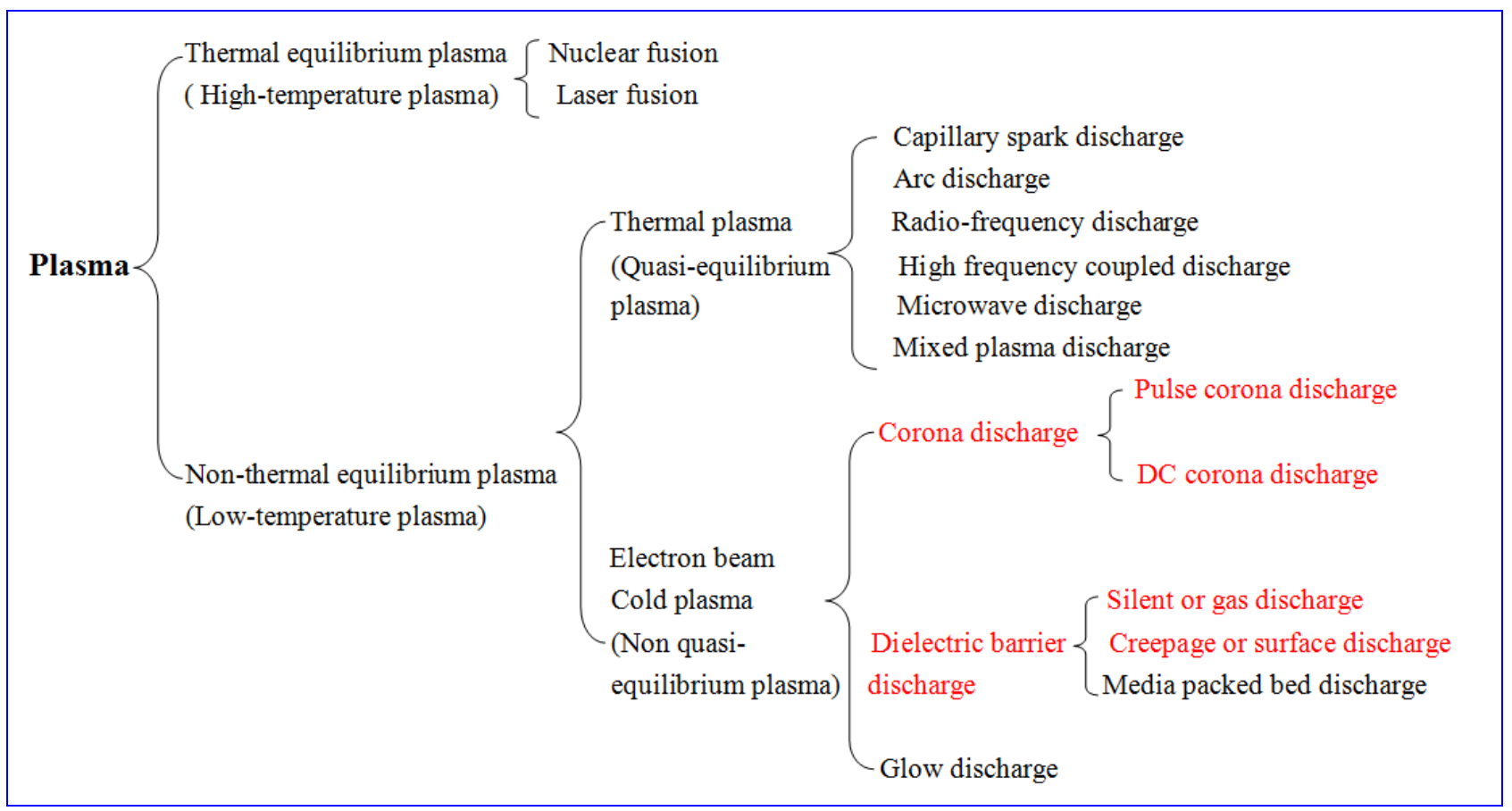

Figure 3. Specific classification of plasma technology. 
Li et al. 2014a). The electron beam method was the first used for flue gas purification. In 1970s, Kawamura et al. $1979,1980,1981$ used electron beam irradiation to remove $\mathrm{SO}_{2}$ and $\mathrm{NO}_{\mathrm{x}}$ from flue gas in a pilot plant facility with processing capacity of $10000 \mathrm{Nm}^{3} / \mathrm{h}$, In the few decades following, other world-wide investigators have carried out relevant research, and established more pilot plants and demonstration projects (Frank et al. 1995; Chmielewski et al. 1992; Chmielewski et al. 2007; Norman et al. 1992; Chmielewski et al. 2003; Basfar et al. 2008; Licki et al. 2003). These studies have demonstrated that electron beam irradiation could remove $\mathrm{SO}_{2}$ and $\mathrm{NO}_{\mathrm{x}}$ in flue gas with efficiencies of more than $95 \%$ and 80\%, respectively (Frank et al. 1995; Chmielewski et al. 1992; Chmielewski et al. 2007; Norman et al. 1992; Chmielewski et al. 2003). The electron beam irradiation can obtain high removal efficiencies of pollutants, but it also has several deficiencies such as high energy consumption and costs, short life of electron gun as well as complex system, which limit its commercial applications (Kogelschatz er al. 2003; Park et al. 1999; Yan et al. 1999). Many researchers subsequently developed corona discharge plasma and dielectric barrier discharge plasma to remove $\mathrm{SO}_{2}, \mathrm{NO}_{\mathrm{x}}$, VOCs, etc. in flue gas, and obtained good results (Kogelschatz er al. 2003; Park et al. 1999; Yan et al. 1999; Tas et al.1997; Takaki et al. 1999; Chang et al. 1992; Penetrante et al. 1996; Ma et al. 2002; Sun et al. 1996; Dhali et al. 1991; Evans et al. 1991; Koutsospyros et al. 2005; Mok et al. 2002; Yoshida et al. 2009; Mok et al. 1999). Compared to electron beam radiation, corona discharge plasma and dielectric barrier discharge plasma have lower energy consumption and more reliable equipment, and are hence, recognized as more promising flue gas purification technologies (Mok et al. 1999; Chang et al. 2003). In the past two decades, a large number of studies related to removals of $\mathrm{SO}_{2}$, $\mathrm{NO}_{\mathrm{x}}, \mathrm{H}_{2} \mathrm{~S}$ and VOCs in flue gas using corona discharge plasma and dielectric barrier discharge plasma have been reported (Kogelschatz er al. 2003; Park et al. 1999; Yan et al. 1999; Tas et al.1997; Takaki et al. 1999; Chang et al. 1992; Penetrante et al. 1996; Ma et al. 2002; Sun et al. 1996; Dhali et al. 1991; Evans et al. 1991; Koutsospyros et al. 2005; Mok et al. 2002; Yoshida et al. 2009; Mok et al. 1999; Mok et al. 1999; Chang et al. 2003). In addition, 
Masuda et al. 1987, Urabe et al. 1988 and Helfritch et al 1996 and 1998 successfully reported for the first time, the use of pulse-corona discharge plasma for the oxidative removal of $\mathrm{Hg}^{0}$ in flue gas. Based on these studies, $\mathrm{Hg}^{0}$ removal technologies using various plasma discharge processes were further developed by many researchers, and some other plasma discharge processes such as dielectric barrier discharge (DBD), including typical DBD, surface discharge and packed-bed discharge, as well as DC corona discharge were also used for removal of $\mathrm{Hg}^{0}$ in flue gas (Liang et al. 2002; Xu et al. 2009; Wang et al. 2009; Ko et al. 2008a; Ko et al. 2008b; Ko et al. 2008c; Byun et al. 2008; Byun et al. 2011a; Chen et al. 2006; Jeong et al. 2007; Byun et al. 2011b; Bo et al. 2009; Tang et al. 2008; Wang et al. 2011; Lin et al.2011; Yang et al. 2012a; Yang et al.2014b; An et al. 2014b; Wu et al. 1996).

\subsection{Effects of process parameters on $\mathrm{Hg}^{0}$ removal using non-thermal plasma}

Related studies (Liang et al. 2002; Mannava et al. 2004; Xu et al. 2009; Wang et al. 2009; Ko et al. 2008a; Ko et al. 2008b; Ko et al. 2008c; Byun et al. 2008; Byun et al. 2011a; Chen et al. 2006; Jeong et al. 2007; Byun et al. 2011b; Bo et al. 2009; Tang et al. 2008; Wang et al. 2011; Lin et al.2011; Yang et al. 2012a; Yang et al.2014a; An et al. 2014a; Wu et al. 1996) have reported that oxidation process of $\mathrm{Hg}^{0}$ in flue gas using non-thermal plasma is affected by various process parameters. To better understand and grasp the key process parameters of $\mathrm{Hg}^{0}$ oxidation using non-thermal plasma, in the next sections, the effects of several process parameters on $\mathrm{Hg}^{0}$ oxidation using non-thermal plasma will be reviewed and discussed.

\subsubsection{Effects of supplied voltage or specific energy density}

Corona discharge plasma and dielectric barrier discharge (DBD) plasma are often generated artificially by gas discharge (Tendero et al. 2006; Kogelschatz et al. 2004), thus energy input is regarded as a key parameter for plasma discharge process. Supplied voltage (SV) and specific energy density (SED), as two important indicators, are often used to characterize the number of input energy. In plasma discharge process, various active species, including $\cdot \mathrm{OH}, \mathrm{O}_{3}, \cdot \mathrm{O}$, etc., are generated by high-energy electrons impacting with flue gas components $\left(\mathrm{N}_{2}, \mathrm{O}_{2}\right.$, 
$\mathrm{H}_{2} \mathrm{O}$ and $\mathrm{CO}_{2}$ ) (Chang et al.2002; Tendero et al.2006; Kogelschatz et al.2004; McAdams et al.2011; Li et al. 2014). Relevant studies (An et al.2014a; Byun et al.2008; Yang et al.2012a; Yang et al.2012b) showed that removal of $\mathrm{Hg}^{0}$ in flue gas was mainly achieved by oxidations of these active substances such as $\cdot \mathrm{OH}, \mathrm{O}_{3}$ and $\cdot \mathrm{O}$ produced by plasma discharge process. With increasing SV or SED, the number of generated high-energy electrons will increase, which also will raise the yield of these active substances (An et al.2014a; Byun et al.2008; Yang et al.2012a; Yang et al.2012b), thereby promoting removal of $\mathrm{Hg}^{0}$. Wang et al 2010, Jeong et al. 2007 and Lin et al. 2010 investigated the effects of SV on $\mathrm{Hg}^{0}$ oxidation using DBD plasma, and all of them found that $\mathrm{Hg}^{0}$ removal efficiency dramatically increased with increasing SV. Wang et al. 2011 studied the effects of SV on $\mathrm{Hg}^{0}$ oxidation using different discharge modes, including positive pulsed corona discharge, negative/positive DC discharge and $12 \mathrm{kHz} \mathrm{AC}$ discharge, and their results showed that under different discharge modes, $\mathrm{Hg}^{0}$ removal efficiencies still increase with increasing SV. Yang et al.2012a also obtained similar results using a combined plasma- $\mathrm{TiO}_{2}$ photocatalysis process.

Furthermore, the effects of SED on $\mathrm{Hg}^{0}$ removal are also studied by several researchers. Chen et al.2006 and Ko et al.2008 investigated the effects of SED on $\mathrm{Hg}^{0}$ oxidation in a DBD reactor, and their results showed that with increasing SED, $\mathrm{Hg}^{0}$ conversion greatly increased. The effects of SED on $\mathrm{Hg}^{0}$ oxidation using positive pulsed corona discharge and negative/positive DC discharge were also tested by Ko et al.2008 and Wang et al.2011, respectively, and their results indicated that with increasing SED, $\mathrm{Hg}^{0}$ conversion greatly increased. An et al. 2014a and 2014b also studied the effects of SED on $\mathrm{Hg}^{0}$ oxidation in a surface discharge plasma (SDP) reactor and a SDP reactor inserted in simulated flue duct, respectively, and they also found that $\mathrm{Hg}^{0}$ conversion rate greatly increased with increasing SED. Based on the above results, it can be seen that there is a positive relationship between SV/SED and $\mathrm{Hg}^{0}$ oxidation efficiency. However, it is also noteworthy that increasing SV or SED can effectively raise $\mathrm{Hg}^{0}$ oxidation efficiency, but the power consumption of the system also increases 
accordingly. Therefore, it is necessary to maintain an optimal value between $\mathrm{Hg}^{0}$ oxidation efficiency and system power consumption in future industrial application.

\subsubsection{Effect of pulse frequency}

Pulse frequency is an important parameter for pulse discharge plasma process. Xu et al.2009 studied the effects of pulse frequency on $\mathrm{Hg}^{0}$ oxidation efficiency in a positive DC reactor, and their results indicated that $\mathrm{Hg}^{0}$ oxidation efficiency increased almost linearly with increasing pulse frequency. Liang et al.2002 also found that $\mathrm{Hg}^{0}$ removal efficiencies increased with increasing pulse frequency in a prototype electrostatic precipitators (ESPs). Masuda et al.1987 also observed a similar trend in $\mathrm{Hg}^{0}$ removal efficiency using a pulse discharge process. In a pulse discharge plasma system, the relationship between the total discharge energy of system and pulse frequency can be described by the following equation (1) (Bo et al. 2009),

$$
S E D=\frac{\tau \cdot f \cdot P_{0}}{V}
$$

where SED is the specific energy density of system, $\mathrm{J} / \mathrm{L} ; \tau$ is the residence time, s; $f$ is the pulse frequency, Hz; $P_{0}$ is the input energy of single pulse, $\mathrm{W}$; and $V$ is the gas flow rate, $\mathrm{L} / \mathrm{s}$.

It can be seen from the equation (1) that with increase of pulse frequency, the SED will increase, thus the yield of active species $\left(\cdot \mathrm{OH}, \mathrm{O}_{3}, \mathrm{O} \cdot\right.$, etc.) will increase as well. $\mathrm{Hg}^{0}$ oxidation efficiency primarily depends on the yield of these active species, and as a result, it increases with increasing pulse frequency.

\subsubsection{Effects of discharge polarity, power supply and reactor structure}

Related studies (An et al.2014a; Wang et al.2009; Bo et al.2009; Wang et al. 2011; An et al.2014b) reported that different discharge polarities and power supplies will result in different yields and concentration distributions of active substances and electrons in plasma reactor, and even under the same discharge polarity and power supply, the yield and concentration distribution of active substances and electrons also have significant differences with the changes of the plasma reactor structure. As we mentioned earlier, $\mathrm{Hg}^{0}$ oxidation mainly depends on the yield 
of active substances in plasma discharge process, thus it is very necessary to discuss the effects of discharge polarity, power supply and plasma reactor structure on $\mathrm{Hg}^{0}$ oxidation.

\section{(1) Discharge polarity and power supply}

Wang et al. 2009 studied the effects of power supply modes on $\mathrm{Hg}^{0}$ oxidation in a link tooth wheel-cylinder reactor energized by different high voltage power supplies. The results showed that $\mathrm{Hg}^{0}$ oxidation efficiency and $\mathrm{O}_{3}$ production of negative DC corona discharge were much higher than those of positive DC corona and AC corona discharge with the same supplied voltages. $\mathrm{O}_{3}$ has been widely considered to be one of the most effective active substances for $\mathrm{Hg}^{0}$ oxidation in plasma discharge process (An et al.2014a; Liang et al.2002; Wang et al. 2009; Byun et al. 2011a; Byun et al. 2011b; Wang et al. 2011; An et al.2014b), thus the authors inferred that this difference in $\mathrm{Hg}^{0}$ oxidation efficiency may be attributed to the different $\mathrm{O}_{3}$ production under different power supply modes. Liang et al. 2002 also studied the effects of three power supply modes, including positive DC corona discharge, negative DC corona discharge and pulse corona discharge, on $\mathrm{Hg}^{0}$ oxidation in prototype electrostatic precipitators (ESPs), and their results showed that the order of $\mathrm{Hg}^{0}$ oxidation efficiency was negative DC corona energization > positive DC corona energization > pure pulse corona energization. The results of Masuda et al.1987 ndicated that for $\mathrm{Hg}^{0}$ oxidation, there was no performance difference between positive and negative polarity for the temperature up to $200^{\circ} \mathrm{C}$, but at $300^{\circ} \mathrm{C}$ and higher, the negative polarity performed better. Byun et al. 2011b also examined the effect of polarity on $\mathrm{Hg}^{0}$ oxidation via a pulsed corona discharge (PCD) reactor, and found that the positive PCD showed a higher $\mathrm{Hg}^{0}$ oxidation than the negative one at the same applied voltage, but there was no difference in $\mathrm{Hg}^{0}$ oxidation at the same SED.

It is obvious from these studies that, there is a contradiction on the effects of positive and negative polarities on $\mathrm{Hg}^{0}$ oxidation between the results of Liang et al. and other investigators. The results of Byun et al. 2011a showed that $\mathrm{Hg}^{0}$ oxidation efficiency increased from $10 \%$ to $70 \%$ with increasing the reaction time at a fixed SED 
by the autocatalytic role of $\mathrm{Hg}^{2+}$, as an active site, attached to the reactor surface. Therefore, Byun et al.2011a suggested that the results of Liang et al. might have not considered the effect of surface catalytic reaction of $\mathrm{Hg}^{2+}$ on $\mathrm{Hg}^{0}$ removal, thereby resulting in this difference. Wang et al.2011 investigated the effects of discharge polarity (positive and negative DC corona discharge) under the same SED on $\mathrm{Hg}^{0}$ oxidation and $\mathrm{O}_{3}$ formation, and they found that the outlet concentration of $\mathrm{O}_{3}$ and $\mathrm{Hg}^{0}$ oxidation efficiency using positive DC corona discharge were significantly higher than those using negative DC corona discharge at a fixed SED. Wang et al.2011 urther investigated the reasons for this difference by photographing the images of positive and negative DC corona discharge at same conditions as shown in Figure 4.
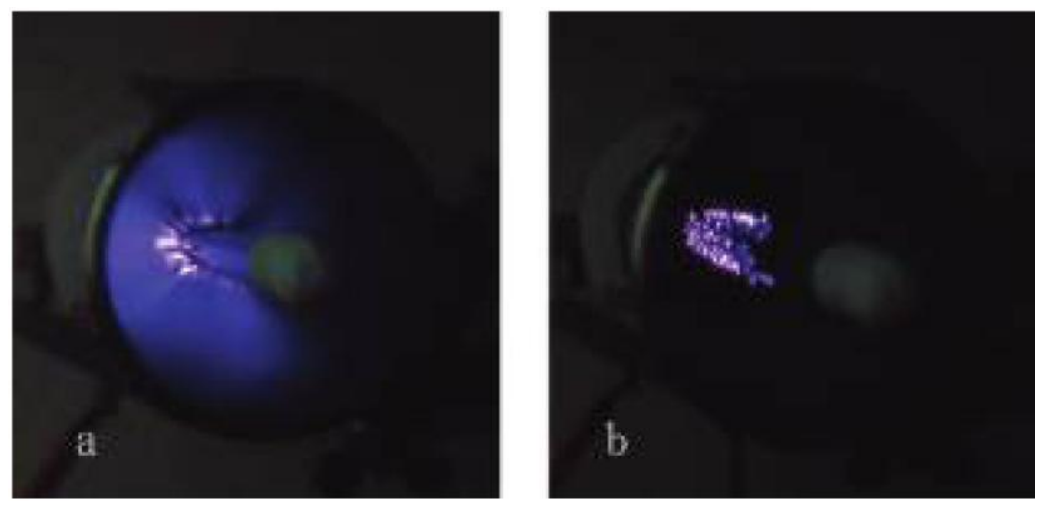
corona across the entire inter-electrode space, while only the glow corona can be observed in the vicinity of discharge tooth tine for negative DC discharge with the same applied voltage. The streamer corona discharge exhibits higher chemical activity than the glow corona discharge due to a relatively larger ionized region (Gasparik et al. 2000). Therefore, this difference between positive and negative polarities was mainly attributed to the relatively higher chemical activity of positive polarity as compared to the negative one. Besides, an optical spectrum measurement by Jani et al.1999 lso indicated that the average electron-energy induced by positive discharge was obviously higher than that by negative discharge for the same energy consumption. Under a 
positive discharge mode, the stronger electric-field intensity will increase the yields of high-energy electrons, which also will enhance the dissociation of $\mathrm{O}_{2}$ and $\mathrm{H}_{2} \mathrm{O}$ to produce more active substances, thereby showing a better $\mathrm{Hg}^{0}$ oxidation.

\section{(2) Reactor structure}

Wang et al.2011 studied the effects of discharge tooth wheel number on $\mathrm{Hg}^{0}$ oxidation in a link tooth wheel-cylinder reactor using a negative DC corona discharge, and they found that increasing the number of discharge tooth wheels resulted in a higher $\mathrm{Hg}^{0}$ oxidation. The authors speculated that this result may be attributed to the fact that a specific injection energy, corresponding to the yield of high energy electrons and active substances, was proportional to the number of tooth wheels. Thus $\mathrm{Hg}^{0}$ oxidation was enhanced by increasing the number of tooth wheels. Xu et al.2009 studied the effects of the electrode number on $\mathrm{Hg}^{0}$ oxidation using a positive pulsed corona discharge, and they found that $\mathrm{Hg}^{0}$ oxidation efficiency increased approximately linearly with increasing electrode number. They hypothesized that increasing electrode number could extend the length of pulsed corona discharge area, producing more high-energy electrons and active substances in plasma reactor, and thereby enhancing $\mathrm{Hg}^{0}$ oxidation.

Liang et al.2002 tested the performance of a two-stage discharge mode for $\mathrm{Hg}^{0}$ removal in a prototype electrostatic precipitators (ESPs) (the first stage (upstream) was supplied with pulse voltage to oxidize $\mathrm{Hg}^{0}$ by plasma reactions, while the second stage with DC voltage was used to generate a high drift field.), and the results showed that $\mathrm{Hg}^{0}$ oxidation efficiency using this kind of two-stage energization mode was higher than that under positive DC corona energization and pulse corona energization, but lower than that under negative DC corona energization. An et al.2014a developed a non-thermal plasma (NTP) injection approach to oxidize $\mathrm{Hg}^{0}$ in flue gas. In their studies, a surface discharge plasma (SDP) reactor was inserted in a simulated flue duct, and was used to generate and inject active species into simulated flue gas. The differences of "injection approach", also called 
"indirect oxidation", and "direct oxidation" in $\mathrm{Hg}^{0}$ oxidation efficiency and energy consumption were evaluated by the authors, and the results indicated that the "injection approach" or "indirect oxidation" has higher $\mathrm{Hg}^{0}$ removal efficiency and lower energy consumption than "direct oxidation" under the same conditions.

\subsubsection{Effects of residence time}

Residence time is an important parameter for chemical reaction and reactor design. Jeong et al.2007 studied the effects of residence time on $\mathrm{Hg}^{0}$ oxidation using a DBD reactor under different voltages. The results indicated that $\mathrm{Hg}^{0}$ oxidation was significantly enhanced with increasing residence time. $\mathrm{Xu}$ et al.2009 found that $\mathrm{Hg}^{0}$ oxidation efficiency significantly increased with increasing residence time (below 6s), but almost remained constant when residence time exceeded $6 \mathrm{~s}$ in a positive DC reactor. Appropriately increasing residence time will raise the probabilities of collision between active substances and contaminant molecules, thereby enhancing the reaction process. However, an excessive residence time is unnecessary because, not only will it not further increase $\mathrm{Hg}^{0}$ removal efficiency, but also will result in an excessive large reactor volume and high costs.

\subsubsection{Effects of $\mathrm{Hg}^{0}$ inlet concentration}

$\mathrm{Hg}^{0}$ inlet concentration often changes from a few $\mu \mathrm{g} / \mathrm{m}^{3}$ to a few hundred $\mu \mathrm{g} / \mathrm{m}^{3}$ depending on the different fuels and combustion conditions. Jeong et al.2007 tested the effects of $\mathrm{Hg}^{0}$ inlet concentration on $\mathrm{Hg}^{0} \mathrm{oxidation} \mathrm{in}$ a DBD reactor, and they found that increasing $\mathrm{Hg}^{0}$ inlet concentration was not conducive to $\mathrm{Hg}^{0}$ oxidation. $\mathrm{Xu}$ et al.2009 and An et al.2014b also obtained similar results in a positive DC reactor and a SDP reactor, respectively. However, Liang et al.2002 btained the opposite results, which indicated that $\mathrm{Hg}^{0}$ oxidation efficiencies significantly increased with increasing $\mathrm{Hg}^{0}$ inlet concentration under four kinds of discharge modes, including positive DC corona discharge, negative DC corona discharge, pulse corona discharge as well as the combination of pulse corona discharge and negative DC corona discharge, in a prototype electrostatic precipitators (ESPs).

\subsection{Effects of flue gas components on $\mathrm{Hg}^{0}$ removal using non-thermal plasma}



burning a low-sulfur eastern bituminous coal is often a complex mixture of several gas components, which typically consists of 5-7\% $\mathrm{H}_{2} \mathrm{O}, 3-4 \% \mathrm{O}_{2}, 15-16 \% \mathrm{CO}_{2}, 1$ ppb total $\mathrm{Hg}, 20$ ppm $\mathrm{CO}, 10$ ppm hydrocarbons, 100 ppm $\mathrm{HCl}, 800$ ppm $\mathrm{SO}_{2}, 10 \mathrm{ppm} \mathrm{SO}_{3}, 500 \mathrm{ppm} \mathrm{NO}_{\mathrm{x}}$, and the balance $\mathrm{N}_{2}$. These flue gas components are found to have obvious impact on plasma discharge process (mainly affecting the yield and concentration distribution of active substances and electrons as well as energy utilization efficiency of the system), thereby further interfering with the oxidation of $\mathrm{Hg}^{0}$ in flue gas as reported by several investigators (An et al.2014a; Wang et al.2010; Liang et al.2002; Wang et al.2009; Byun et al.2011a; Byun et al. 2011b; Wang et al.2011; An et al. 2014b).

\subsubsection{Effects of $\mathrm{O}_{2}$}

$\mathrm{O}_{2}$ is one of the main component in coal-fired flue gas, and is often considered as the important precursor of the active substances such as $\cdot \mathrm{O}$ and $\mathrm{O}_{3}$ in most of advanced oxidation reactions. Thus its content often has a significant impact on $\mathrm{Hg}^{0}$ oxidation using non-thermal plasma. The effects of $\mathrm{O}_{2}$ on $\mathrm{Hg}^{0}$ oxidation in a DBD reactor were investigated by Wang et al. 2010 and Lin et al.2010 respectively, and their results showed that $\mathrm{Hg}^{0}$ oxidation was greatly strengthened with increasing $\mathrm{O}_{2}$ concentration. An et al. 2014a also tested the effects of $\mathrm{O}_{2}$ concentration on $\mathrm{Hg}^{0}$ oxidation in a SDP reactor inserted in simulated flue duct, and the results indicated that $\mathrm{Hg}^{0}$ plasma- $\mathrm{TiO}_{2}$ photocatalysis reactor. The generation of active species such as $\mathrm{O}_{3}, \cdot \mathrm{O}, \cdot \mathrm{OH}$, etc. in non-thermal plasma discharge process via high-energy electrons impacting on $\mathrm{O}_{2}$ molecules in the flue gas can be described by reactions (2)-(6) (An et al. 2014a; Wang et al. 2010; Lin et al. 2010).

$$
\mathrm{O}_{2}(g)+\mathrm{e} \rightarrow \cdot \mathrm{O}\left({ }^{3} \mathrm{P}\right)(g)+\cdot \mathrm{O}\left({ }^{1} \mathrm{D}\right)(g)+\mathrm{e}
$$


402 It is obvious from these reactions that increase in $\mathrm{O}_{2}$ levels in flue gas leads to increased generation of active

403

404

405

406

407

408

409

410

411

412

species and enhances $\mathrm{Hg}^{0}$ oxidation.

\subsubsection{Effects of $\mathrm{H}_{2} \mathrm{O}$}

In advanced oxidation reactions, $\mathrm{H}_{2} \mathrm{O}$ is often the precursor of $\cdot \mathrm{OH}$ radical in various reactions (An et al. 2014a; Wang et al. 2010). Wang et al. 2010 found that $\mathrm{Hg}^{0}$ oxidation was increased by adding single $\mathrm{H}_{2} \mathrm{O}$ in a DBD reactor. An et al. 2014a investigated the effects of $\mathrm{H}_{2} \mathrm{O}$ in a SDP reactor inserted in simulated flue duct, and their results showed that adding $4 \%$ and $6 \% \mathrm{H}_{2} \mathrm{O}$ made $\mathrm{Hg}^{0}$ oxidation efficiency increased from $81 \%$ to $86 \%$ and 89\%, respectively. Lin et al.2010 and Yang et al. 2012a and 2012b also obtained similar positive results in a DBD reactor and a combined plasma- $\mathrm{TiO}_{2}$ photocatalysis reactor, respectively. $\cdot \mathrm{OH}$ will be generated in plasma discharge process through high-energy electrons impacting on $\mathrm{H}_{2} \mathrm{O}$ molecules, and it is an effective $\mathrm{Hg}^{0}$ oxidant in a variety of advanced oxidation reactions (An et al. 2014a; Wang et al. 2010; Lin et al.2010; Yang et al. 2012a). The related process can be described by reactions (7)-(11) (An et al. 2014a; Wang et al. 2010; Lin et al.2010; Yang et al. 2012a).

$$
\begin{aligned}
& \mathrm{H}_{2} \mathrm{O}(g)+\mathrm{e} \rightarrow \cdot \mathrm{OH}(g)+\cdot \mathrm{H}(g)+\mathrm{e} \\
& \mathrm{Hg}(g)+\cdot \mathrm{OH}(g) \rightarrow \mathrm{HgOH}(g) \\
& \mathrm{HgOH}(g)+\cdot \mathrm{OH}(g) \rightarrow \mathrm{Hg}(\mathrm{OH})_{2}(g) \\
& \mathrm{HgOH}(g)+\mathrm{O}_{2}(g) \rightarrow \mathrm{HgO}(g)+\mathrm{HO}_{2} \cdot(g) \\
& \mathrm{Hg}(\mathrm{OH})_{2}(g) \rightarrow \mathrm{HgO}(g)+\mathrm{H}_{2} \mathrm{O}(g)
\end{aligned}
$$

However, the results of An et al.2014b indicated that $\mathrm{H}_{2} \mathrm{O}$ inhibited $\mathrm{Hg}^{0}$ oxidation in a SDP reactor. An et al.2014b showed that $\mathrm{H}_{2} \mathrm{O}$ inhibition of $\mathrm{O}_{3}$ generation was responsible for the antagonistic effect of $\mathrm{H}_{2} \mathrm{O}$ on $\mathrm{Hg}^{0}$ 
oxidation. The results of $\mathrm{Ko}$ et al. 2008 found that $\mathrm{Hg}^{0}$ oxidation was hardly affected by $\mathrm{H}_{2} \mathrm{O}$ in a DBD reactor. The authors speculated that the hydroxides of mercury were very likely to re-decompose back to $\mathrm{Hg}^{0}$ at high temperature because they were very unstable even at room temperature. The results of Goodsite et al. 2004 which were based on quantum chemical calculations showed that the lifetime of $\mathrm{HgOH}$ is only $280 \mu$ s at $25^{\circ} \mathrm{C}$, consistent with the speculation of Ko et al. 2008.

\subsubsection{Effects of $\mathrm{HCl}$}

During the combustion process, chlorine always exists in coal or waste materials, and eventually will be converted into the gaseous $\mathrm{HCl}$ ( $\mathrm{Li}$ et al. 2003). Although $\mathrm{HCl}$ has a low concentration (about $100 \mathrm{ppm}$ ) in flue gas, it has a significant impact on $\mathrm{Hg}^{0}$ oxidation using non-thermal plasma (An et al. 2014a; Wang et al. 2010). The results of Wang et al. 2010 in a DBD reactor showed that with $30 \mathrm{ppm}$ of $\mathrm{HCl}$ added into the gas stream, $\mathrm{Hg}^{0}$ conversion rate gradually increased from $43.2 \%$ to $70.6 \%$ within $30 \mathrm{~min}$, and with further increase from from 30 ppm to $60 \mathrm{ppm}, \mathrm{Hg}^{0}$ conversion rate dramatically increased from $70.6 \%$ to $96.8 \%$ just within 15 min. Ko et al. 2008 and 2009 studied the effects of $\mathrm{HCl}$ on $\mathrm{Hg}^{0}$ oxidation in a DBD reactor and a pulsed corona discharge (PCD) reactor, and their results showed that $\mathrm{Hg}^{0}$ oxidation was promoted by adding $\mathrm{HCl}$ in two plasma reactors. An et al. 2014a and Yang et al. 2012a obtained similar results in a SDP reactor inserted in simulated flue duct and a combined plasma- $\mathrm{TiO}_{2}$ photocatalysis reactor, respectively. Other researchers (An et al. 2014a; Wang et al. 2010; Li et al. 2003) studied the mechanism of $\mathrm{HCl}$ effects on $\mathrm{Hg}^{0}$ oxidation, and suggested that the additional formation of $\mathrm{Cl}$ and $\mathrm{HOCl}$ was the main reason for the enhanced oxidation of $\mathrm{Hg}^{0}$ through the following series of elementary reactions (12)-(24).

$$
\begin{aligned}
& \mathrm{HCl}(g)+\mathrm{e} \rightarrow \cdot \mathrm{H}(g)+\mathrm{Cl} \cdot(g)+\mathrm{e} \\
& \mathrm{HCl}(g)+\cdot \mathrm{OH}(g) \rightarrow \mathrm{H}_{2} \mathrm{O}(g)+\mathrm{Cl} \cdot(g) \\
& \mathrm{Cl} \cdot(g)+\cdot \mathrm{OH}(g) \rightarrow \mathrm{HOCl}(g)
\end{aligned}
$$




$$
\mathrm{Cl} \cdot(g)+\mathrm{Cl} \cdot(g) \rightarrow \mathrm{Cl}_{2}(g)
$$

\subsubsection{Effects of $\mathrm{SO}_{2}$} through reactions (25)-(27) (An et al. 2014a; Wang et al. 2010), hindering $\mathrm{Hg}^{0}$ conversion.

$$
\mathrm{SO}_{2}(g)+\cdot \mathrm{O}(g) \rightarrow \mathrm{SO}_{3}(g)
$$

$$
\mathrm{SO}_{2}(g)+\mathrm{O}_{3}(g) \rightarrow \mathrm{SO}_{3}(g)+\mathrm{O}_{2}(g)
$$

$$
\mathrm{SO}_{2}(g)+\cdot \mathrm{OH}(g)+\mathrm{M} \rightarrow \mathrm{OHSO}_{2}(g)+\mathrm{M}
$$

On the other hand, Wang et al. 2009 showed that $\mathrm{Hg}^{0}$ oxidation efficiency increased with addition of $\mathrm{SO}_{2}$ in a 
negative DC reactor. The product $\mathrm{HgO}$ of $\mathrm{Hg}^{0}$ oxidation will be consumed by $\mathrm{OHSO}_{2}(\mathrm{~g})$ produced in reaction (27) as shown in reactions (28) and (29), which promote $\mathrm{Hg}^{0}$ oxidation by changing the chemical equilibrium of $\mathrm{Hg}^{0}$ oxidized by $\cdot \mathrm{O}$ and $\mathrm{O}_{3}$ (Wang et al. 2009).

$$
\begin{aligned}
& \mathrm{OHSO}_{2}(g)+\mathrm{O}_{2}(g) \rightarrow \mathrm{SO}_{3}(g)+\mathrm{HO}_{2} \cdot(g) \\
& \mathrm{HgO}(g)+\mathrm{SO}_{3}(g) \rightarrow \mathrm{HgSO}_{4}(g)
\end{aligned}
$$

Also, An et al. 2014a and 2014b showed that increasing $\mathrm{SO}_{2}$ concentration had little effects on $\mathrm{Hg}^{0}$ oxidation in a SDP reactor and a SDP reactor inserted in simulated flue duct, respectively. The authors suggested that both $\cdot \mathrm{O}$ and $\mathrm{O}_{3}$ were the main oxidizers of $\mathrm{Hg}^{0}$ removal, while $\cdot \mathrm{OH}$ was the main oxidizer of $\mathrm{SO}_{2}$ removal. Therefore, the consumption of $\cdot \mathrm{O}$ and $\mathrm{O}_{3}$ by reacting with $\mathrm{SO}_{2}$ is very minor due to the low reaction rates, and as a result, $\mathrm{SO}_{2}$ has little effects on $\mathrm{Hg}^{0}$ oxidation. Hence, it should be noted that $\mathrm{SO}_{2}$ shows very complex effects on $\mathrm{Hg}^{0}$ oxidation using different plasma reactors, and require further mechanistic studies.

\subsubsection{Effects of NO}

The effects of $\mathrm{NO}$ on $\mathrm{Hg}^{0}$ oxidation using plasma discharge processes as studied by several researchers show consistent results. Wang et al. 2010 investigated the effects of $\mathrm{NO}$ on $\mathrm{Hg}^{0}$ oxidation in a DBD reactor, and found $\mathrm{Hg}^{0}$ oxidation greatly diminished by the presence of NO. Wang et al. 2009 also showed that $\mathrm{Hg}^{0}$ oxidation efficiency greatly decreased with increased NO concentration in a negative DC corona discharge reactor. An et al. 2014a and 2014b and Ko et al. 2008 also obtained similar results in a SDP reactor, a SDP reactor inserted in simulated flue duct as well as a typical DBD reactor, respectively. The authors hypothesized that the observed results are likely attributed to the fact that NO can consume active oxidants in competition with $\mathrm{Hg}^{0}$, and hence, reducing its conversion as in reactions (30)-(33) (An et al. 2014a; Wang et al. 2010; Ko et al. 2008; An et al. 2014b).

$$
\mathrm{NO}(g)+\cdot \mathrm{O}(g) \rightarrow \mathrm{NO}_{2}(g)
$$




$$
\mathrm{NO}_{2}(g)+\cdot \mathrm{OH}(g) \rightarrow \mathrm{HNO}_{3}(g)
$$

491

Wang et al. 2009 demonstrated the validity of these reactions in a study which simultaneously detected $\mathrm{NO}$ and $\mathrm{O}_{3}$ in the exhaust gas and showed $\mathrm{O}_{3}$ concentration significantly decreased while $\mathrm{NO}_{2}$ dramatically increased from the oxidation of NO.

\subsubsection{Effects of $\mathrm{CO}_{2}$}

In the typical coal-fired flue gas from a coal-fired utility burning a low-sulfur eastern bituminous coal, the volume fraction of $\mathrm{CO}_{2}$ is up to $15-16 \%$ (Granite et al. 2002), which is the second largest component after $\mathrm{N}_{2}$. Related results confirmed (Wang et al. 2009; Lin et al. 2010) that the high-energy electrons from plasma discharge process can effectively decompose $\mathrm{CO}_{2}$ by breaking the molecular bond in $\mathrm{CO}_{2}$. Hence, studying the impact of $\mathrm{CO}_{2}$ on $\mathrm{Hg}^{0}$ oxidation is essential for future applications of this technology. Wang et al. 2009 tudied the effect of $\mathrm{CO}_{2}$ on $\mathrm{Hg}^{0}$ removal in a negative DC corona reactor, and their results indicated that $\mathrm{CO}_{2}$ greatly weakened $\mathrm{Hg}^{0}$ oxidation. For example, at $10 \mathrm{kV}$ of supplied voltage, $\mathrm{Hg}^{0}$ oxidation efficiency roughly decreased from $67.8 \%$ to $17.5 \%$ with the addition of $12 \% \mathrm{CO}_{2}$. The results of Lin et al. 2010 also indicated that with the additions of $4.5 \%$ and $7.5 \% \mathrm{CO}_{2}$ into $\mathrm{N}_{2} / \mathrm{O}_{2} / \mathrm{Hg}^{0}$ gas stream, $\mathrm{Hg}^{0}$ oxidation efficiency reduced from $97.4 \%$ to $96.6 \%$ and $89.7 \%$, respectively. Chen et al. 2006 suggested that $\cdot \mathrm{O}$ will be generated by the electron-impact dissociation of $\mathrm{CO}_{2}$ in plasma discharge process through reaction (34), which will provide more active species, $\cdot \mathrm{O}$ for $\mathrm{Hg}^{0}$ oxidation.

$$
\mathrm{CO}_{2}(g)+\mathrm{e} \rightarrow \mathrm{CO}(g)+\cdot \mathrm{O}(g)+\mathrm{e}
$$

However, some other investigators have also argued that although the electron-impact dissociation of $\mathrm{CO}_{2} \mathrm{created}$ more $\cdot \mathrm{O}$, it was negligible since the dissociation rate of $\mathrm{CO}_{2}$ was 4-5 orders of magnitude lower than that of $\mathrm{O}_{2}$. This dissociation of $\mathrm{CO}_{2}$ consumed a lot of high-energy electrons and meanwhile, strengthened the reducing 
atmosphere by generating the reducing gas CO (Wang et al. 2009; Lin et al. 2010), which was not conducive to

$511 \mathrm{Hg}^{0}$ oxidation. Based on the existing results, the latter view seems closer to the experimental results to date.

512

\subsubsection{Synergistic effects of mixing gas components}

As mentioned earlier, the components of actual coal-fired flue gas are very complex, thus studying the influence of any single fuel gas component on $\mathrm{Hg}^{0}$ oxidation is not adequate for future developments of these potential technologies for eventual industrial applications. Some researchers preliminarily studied the effects of multi-components on $\mathrm{Hg}^{0}$ oxidation using plasma discharge process. Chen et al. 2006 tested the effects of single $\mathrm{H}_{2} \mathrm{O}$, coexisting $\mathrm{O}_{2}$ and $\mathrm{H}_{2} \mathrm{O}$ as well as coexisting $\mathrm{CO}_{2}, \mathrm{O}_{2}$ and $\mathrm{H}_{2} \mathrm{O}$ on $\mathrm{Hg}^{0}$ oxidation using a DBD process. The results showed that on the average only $18 \% \mathrm{Hg}^{0}$ average conversion was achieved by adding single $\mathrm{H}_{2} \mathrm{O}, \mathrm{but}^{\mathrm{H}} \mathrm{Hg}^{0}$ obtained a complete conversion with the joint addition of $\mathrm{O}_{2}$ and $\mathrm{H}_{2} \mathrm{O}$, and a $80 \%$ conversion with the joint addition of $\mathrm{CO}_{2}, \mathrm{O}_{2}$ and $\mathrm{H}_{2} \mathrm{O}$, respectively, indicating the synergetic effects of presence of these multi-components. The results of Wang et al. 2010 showed that compared to the positive effect of adding single $\mathrm{H}_{2} \mathrm{O}$ or $\mathrm{O}_{2}$, there was a more complex effect on $\mathrm{Hg}^{0}$ oxidation in a DBD reactor with the joint addition of $\mathrm{O}_{2}$ and $\mathrm{H}_{2} \mathrm{O}$. For example, $\mathrm{Hg}^{0}$ oxidation rate had a significant increase followed by a quick decline with continuously increase of $\mathrm{H}_{2} \mathrm{O}$ content in the presence of $\mathrm{O}_{2}$. The authors suggested that adding a small amount of $\mathrm{H}_{2} \mathrm{O}$ could improve $\mathrm{Hg}^{0}$ oxidation by generating more $\cdot \mathrm{OH}$. However, when the excess $\mathrm{H}_{2} \mathrm{O}$ was added, the excess $\mathrm{H}_{2} \mathrm{O}$ also consumed $\mathrm{O}_{3}$ and $\cdot \mathrm{O}$ by competing with $\mathrm{Hg}^{0}$ through reactions (35)-(38). The active species, $\mathrm{O}_{3}$ and $\cdot \mathrm{O}$, are considered as more effective active substances than $\cdot \mathrm{OH}$ for $\mathrm{Hg}^{0}$ oxidation (An et al. 2014a; Wang et al. 2010). Hence, the addition of excess $\mathrm{H}_{2} \mathrm{O}$ resulted in the remarkable decrease in $\mathrm{Hg}^{0}$ conversion.

$$
\mathrm{H}_{2} \mathrm{O}(g)+\mathrm{O}_{3}(g) \rightarrow \mathrm{H}_{2} \mathrm{O}_{2}(g)+\mathrm{O}_{2}(g)
$$

$$
\mathrm{H}_{2} \mathrm{O}_{2}(g) \rightarrow \cdot \mathrm{OH}(g)+\cdot \mathrm{OH}(g)
$$


Ko et al. 2008 nvestigated the synergistic influence of $\mathrm{HCl}$ and $\mathrm{H}_{2} \mathrm{O}$ on $\mathrm{Hg}^{0}$ oxidation using a DBD process, and their results showed that only adding $\mathrm{H}_{2} \mathrm{O}$ almost had no effect on $\mathrm{Hg}^{0}$ oxidation, but when $\mathrm{HCl}$ was also added to the flue gas stream, the addition of $\mathrm{H}_{2} \mathrm{O}$ clearly accelerated $\mathrm{Hg}^{0}$ oxidation. Related results (An et al. 2014a; Wang et al. 2010; Lin et al. 2010; Yang et al. 2012a; Yang et al. 2012b) demonstrated that $\cdot \mathrm{OH}$ could be generated in plasma discharge process by high-energy electrons impacting on the $\mathrm{H}_{2} \mathrm{O}$ molecules. The $\mathrm{Cl}_{2}$ present following reaction (39).

$$
\mathrm{Cl}_{2}(g)+\cdot \mathrm{OH}(g) \leftrightarrow \mathrm{Cl} \cdot(g)+\mathrm{HOCl}(g)
$$

541 The generated $\mathrm{Cl}$. and $\mathrm{HOCl}$ are important reactive intermediates for enhancing $\mathrm{Hg}^{0}$ oxidation to produce $\mathrm{HgCl}$ by reactions (40) and (41) (An et al. 2014a; Lin et al. 2010; Yang et al. 2012; ; Yang et al. 2012b). atmosphere. Wang et al. 2010 evaluated the synergistic effects of coexisting $\mathrm{SO}_{2} / \mathrm{NO}$ and $\mathrm{CO}_{2} / \mathrm{O}_{2}$ gas streams on gas components of $\mathrm{O}_{2}, \mathrm{H}_{2} \mathrm{O}$, $\mathrm{NO}$ and $\mathrm{SO}_{2}$. However, when $20 \mathrm{ppm} \mathrm{HCl}$ was also added to in the mixed gas components, $\mathrm{Hg}^{0}$ oxidation efficiency singnificantly increased, but was still lower than that of adding single $\mathrm{O}_{2}$ alone. The results of Lin et al. 2010 found that compared to a single component such as $\mathrm{O}_{2}$ or $\mathrm{H}_{2} \mathrm{O}, \mathrm{Hg}^{0}$ oxidation efficiency using a DBD discharge process declined by of $20 \%$ on the average in $\mathrm{HCl} / \mathrm{N}_{2} / \mathrm{CO}_{2} / \mathrm{O}_{2} / \mathrm{H}_{2} \mathrm{O}$ complex $\mathrm{Hg}^{0}$ oxidation using positive and negative DC corona discharge process, and their results indicated that $\mathrm{Hg}^{0}$ 
oxidation was enhanced by adding $\mathrm{SO}_{2}$ alone, but the degree of enhancement was significantly reduced by further addition of NO into the gas stream. The authors speculated that the results were likely to be attributed to the fact that $\mathrm{O}_{2}$ was the main source of $\mathrm{O}_{3}$ and $\cdot \mathrm{O}$, thus increasing its concentrations was beneficial to $\mathrm{Hg}^{0}$ oxidation (An et al. 2014a; Wang et al. 2011). However, $\mathrm{NO}$ is an efficient scavenger of $\mathrm{O}_{3}$ and $\cdot \mathrm{O}$ (An et al. 2014a; Wang et al. 2011; Lin et al. 2010), thus increasing its concentrations was detrimental to $\mathrm{Hg}^{0}$ oxidation. To prove this theory, the authors further measured the $\mathrm{O}_{3}$ concentration along with $\mathrm{Hg}^{0}$ oxidation efficiency, and found that both increased with the increase of $\mathrm{O}_{2} / \mathrm{CO}_{2}$ ratio (Wang et al. 2011). In addition to these studies, the effects of some other flue gas components such as various particulate matters, $\mathrm{VOCs}, \mathrm{NO}_{2}, \mathrm{CO}, \mathrm{H}_{2} \mathrm{~S}$, alkali metal salts, etc., and their mechanisms on $\mathrm{Hg}^{0}$ oxidation using plasma discharge process require further in-depth evaluations.

\subsection{Products and mechanism of $\mathrm{Hg}^{0}$ removal using non-thermal plasma}

\subsubsection{Products of $\mathrm{Hg}^{0}$ removal using non-thermal plasma}

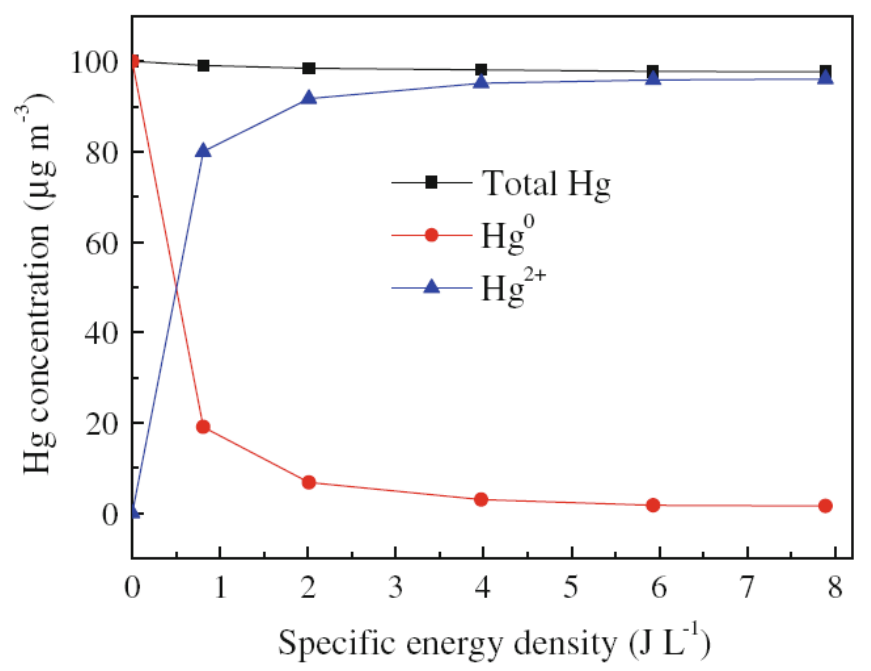

Figure 5. Content changes of different mercury components (An et al. 2014a).

An et al. 2014a and 2014b etermined the gaseous and solid products of $\mathrm{Hg}^{0}$ oxidation in a SDP reactor and a SDP reactor inserted in simulated flue duct using a mercury analyzer, X-ray photoelectron spectroscopy (XPS), electronic probe microanalysis (EPMA) and energy dispersive spectroscopy (EDS). The results showed that the concentration of $\mathrm{Hg}^{0}$ in flue gas exhibited a dramatic decrease, while the concentration of oxidized $\mathrm{Hg}$ in flue gas 

results. form of yellow deposits on the internal surface of the simulated flue duct. The changes in contents of different mercury species are depicted in Figure 5. The elements and elemental oxidation states of the deposited mercury species on the internal surface of simulated flue duct were determined by XPS, and the results are shown in Figure 6. It can be seen that the presence of $\mathrm{Hg} 4 \mathrm{f}$ was detected, and two typical peaks at 106.99 and $103.00 \mathrm{eV}$ for $\mathrm{Hg}$ $4 \mathrm{f}_{5 / 2}$ and $\mathrm{Hg} 4 \mathrm{f}_{7 / 2}$, respectively, suggested that $\mathrm{Hg}$ was possibly combined with oxygen (He et al. 2011). The authors (An et al. 2014a and 2014b) calculated the elemental contents and $\mathrm{Hg} / \mathrm{O}$ atomic ratio by the normalized peak areas of the Si 2p, $\mathrm{Hg} 4 \mathrm{f}$ and $\mathrm{O} 1$ s core level spectra, and they found that for the deposited mercury species, the atom ratio of $\mathrm{O}$ and $\mathrm{Hg}$ on the surface was observed to be approximately 1.01, suggesting that the deposited mercury species predominantly existed in the form of $\mathrm{HgO}$. Also, using EPMA, the authors (An et al. 2014a and 2014b) found the atomic ratio of $\mathrm{O}$ and $\mathrm{Hg}$ to be approximately 0.996 and 1.05, respectively, consistent with XPS

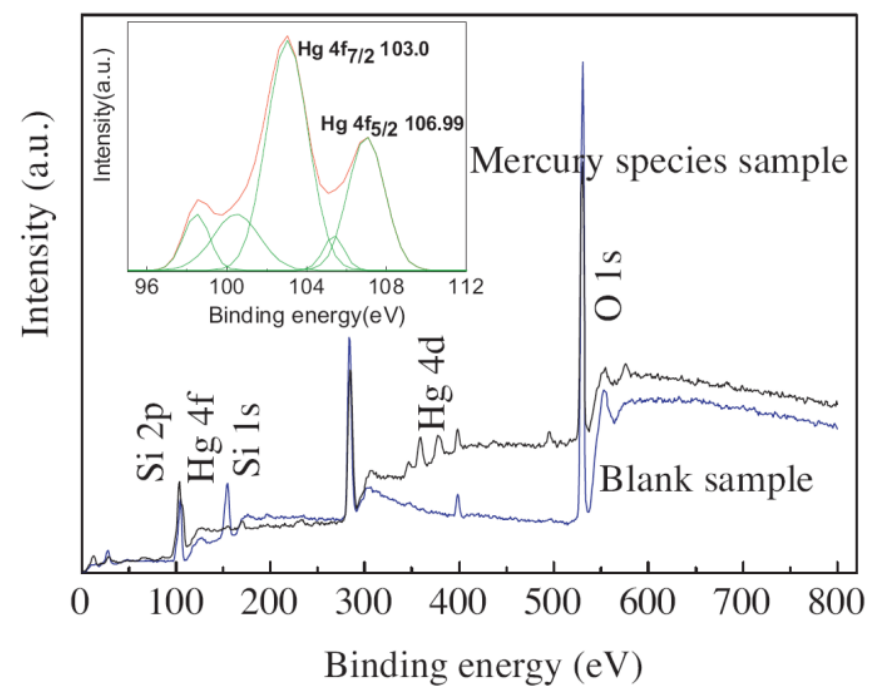

Figure 6. XPS spectra of deposited mercury species for NTP injection (An et al. 2014a). 
(a)
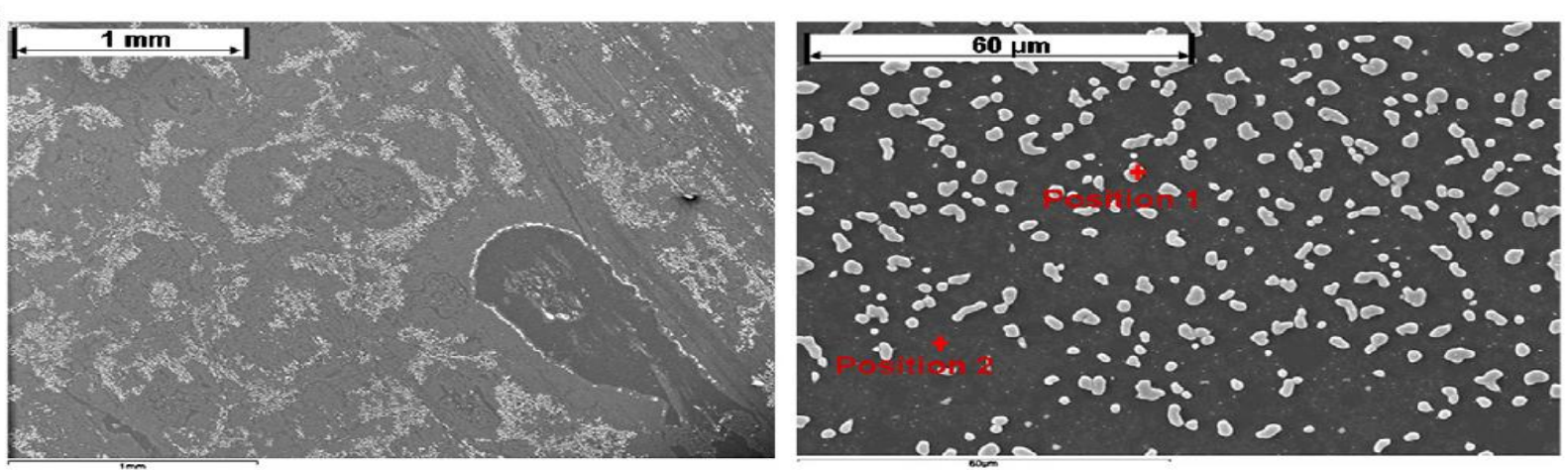

(b)
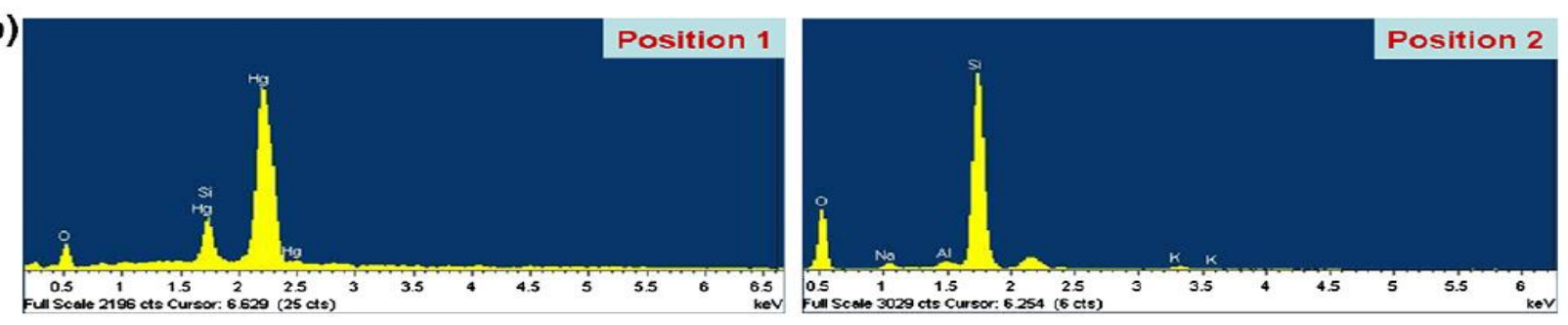

Figure 7. SEM-EDS analysis of the reactor (quartz) surface after using DBD reactor for 2 months without

cleaning procedure. (a) SEM images and (b) EDS spectra obtained at two positions 1 and 2 (Byun et al. 2011a).

Byun et al. 2011a also analyzed the deposited mercury species on the reactor surfaces of $\mathrm{Hg}^{0}$ removal in a

DBD reactor by scanning electron microscopy (SEM)-energy dispersive spectroscopy (EDS) and temperature-

programmed desorption and dissociation (TPDD). They continuously operated the DBD reactor for two months

without cleaning it and then found out yellow stains accumulated on the reactor surfaces. The authors analyzed the

seen that the yellow stains were conglomerated like islands on the reactor surfaces. For further comparison, two

higher temperature.

\subsubsection{Mechanism of $\mathrm{Hg}^{0}$ removal using non-thermal plasma}


601 McAdams et al. 2001; Li et al. 2014) showed that non-thermal plasma discharge process can produce a large

602

603

604

605

606

607

608

609

610

611

612

613

614

615

616

617

618

number of high-energy particles with high activity such as electrons, ions, free radicals and molecules under excited states. These high-energy particles can directly destroy the molecular bonds of background gases and gaseous pollutants. In the dissociation process of gas molecules, some active species such as $\cdot \mathrm{OH}, \cdot \mathrm{O}, \mathrm{O}_{3}$, etc. are generated. These reactive oxygen species can effectively oxidize and degrade various pollutants. The plasma removal process for $\mathrm{SO}_{2}, \mathrm{NO}_{\mathrm{x}}, \mathrm{H}_{2} \mathrm{~S}$ and VOCs mainly includes two reaction pathways, namely, the dissociations of pollutants by high-energy electrons followed by the oxidations by reactive species (Bogaerts et al. 2002; Chang et al. 2002; Tendero et al. 2002; Kogelschatz et al. 2004; McAdams et al. 2001; Li et al. 2014). However, elementary mercury $\left(\mathrm{Hg}^{0}\right)$ is mainly removed by direct oxidations rather than by dissociation (An et al. 2014a; Wang et al. 2010; Byun et al. 2011a; An et al. 2014b). Therefore, to date, research on $\mathrm{Hg}^{0}$ removal mechanism has focused on determining $\mathrm{Hg}^{0}$ oxidation pathways (An et al. 2014a; Byun et al. 2011a; Yang et al. $2012 \mathrm{a}$; An et al. 2014b).

An et al. 2014a investigated the reaction mechanism of $\mathrm{Hg}^{0}$ removal in a SDP reactor inserted in simulated flue duct using comparative studies, mercury mass balance and byproducts analysis using XPS and EPMA, and they found that the pathways for $\mathrm{Hg}^{0}$ removal include oxidations by several active substances $\left(\cdot \mathrm{OH}, \cdot \mathrm{O}, \mathrm{O}_{3}\right.$, $\mathrm{Cl}$. and $\mathrm{HOCl}$ ) as well as excitations from $\mathrm{UV}$-light generated by corona discharge with oxidation by $\mathrm{O}_{3}$ playing the dominant role. Byun et al. 2011a also investigated the reaction mechanism of $\mathrm{Hg}^{0}$ removal in a DBD reactor, and they found that the pathways of $\mathrm{Hg}^{0}$ removal in the DBD reactor mainly included gas-phase oxidations active oxidants $\left(\cdot \mathrm{OH}, \cdot \mathrm{O}, \mathrm{O}_{3}\right.$, etc., with $\mathrm{O}_{3}$ playing a pivotal role) and surface-induced reactions. It was also shown that mercury species deposited on the reactor surfaces acted as active sites and provided extra $\cdot \mathrm{O}$ to oxidize the adsorbed $\mathrm{Hg}^{0}$ on the surfaces, resulting in an acceleration of $\mathrm{Hg}^{0}$ removal as the oxidation process of $\mathrm{Hg}^{0}$ proceeded. The reaction mechanism of $\mathrm{Hg}^{0}$ removal in a DBD (SDP also belongs to DBD) reactor involving 
oxidants $\left(\cdot \mathrm{OH}, \cdot \mathrm{O}, \mathrm{Cl}^{-}, \mathrm{HOCl}, \mathrm{O}_{3}\right.$, etc., with $\mathrm{O}_{3}$ a major oxidation pathway), UV-induced excitations and surface reaction, is further described in Figure 8.

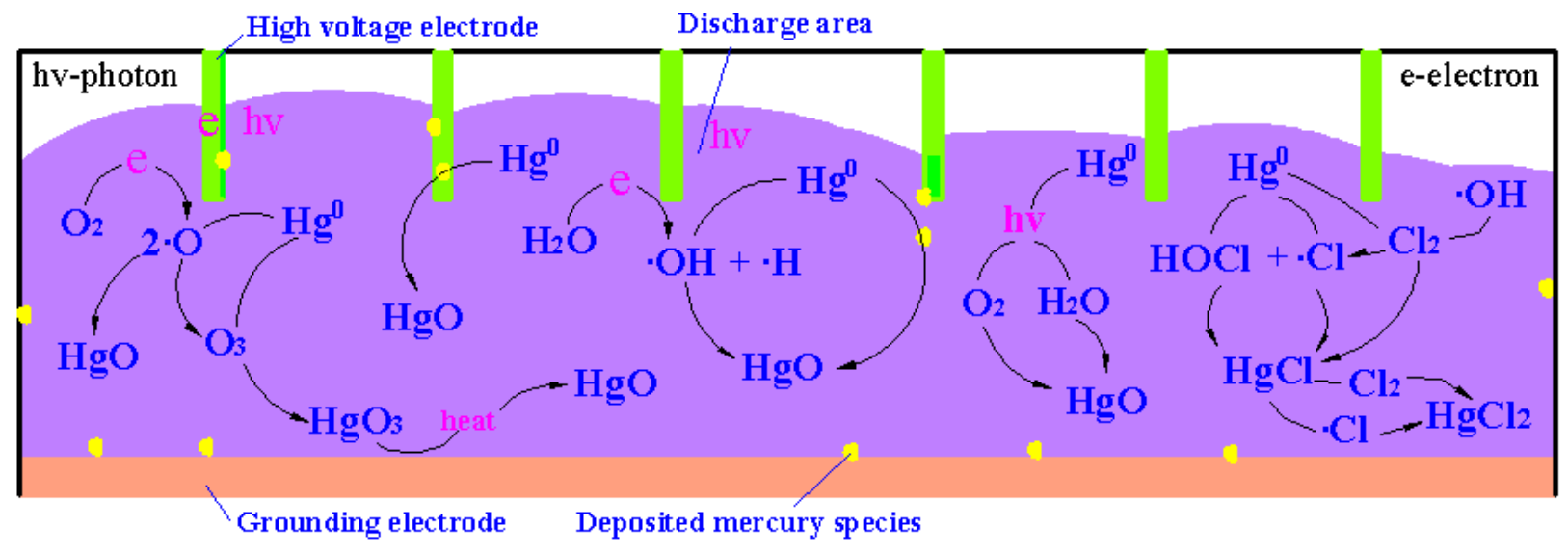

Figure 8. Schematic of $\mathrm{Hg}^{0}$ removal mechanism using DBD process.

It is worth noting that some potential factors may result in the changes of $\mathrm{Hg}^{0}$ removal pathways in different non-thermal plasma reactors involving several aspects. (1) Different plasma reactors, flue gas compositions or operating conditions will lead to potential differences in the yields and concentration distributions of active substances such as $\cdot \mathrm{OH}, \cdot \mathrm{O}, \mathrm{O}_{3}, \mathrm{Cl} \cdot$ and $\mathrm{HOCl}$ (An et al. 2014a; Liang et al. 2002; Xu et al. 2009; Wang et al. 2009; Byun et al. 2011a; Bo et al. 2009; Wang et al. 2011; An et al. 2014b), which may result in different pathways of $\mathrm{Hg}^{0}$ removal; (2) Due to the differences in the inner contact surface of reactor, different plasma reactors may result in the differences in surface-induced catalytic reactions (Byun et al. 2011a); (3) Different plasma reactors have different hydrodynamics as well as heat and mass transfer characteristics (Bo et al. 2009), which also will change the reaction pathways as well as the final forms and contents of the $\mathrm{Hg}^{0}$ removal products. These observations suggest complex reaction mechanisms, and require more efforts on comparative studies in the future.

\subsection{Kinetics of $\mathrm{Hg}^{0}$ removal using non-thermal plasma}

To date, the kinetic studies of $\mathrm{Hg}^{0}$ removal using non-thermal plasma are rare. Zhou et al. 2009 developed a kinetic mechanistic model of $\mathrm{Hg}^{0}$ removal, consisting of 30 elementary reactions, in $\mathrm{NO} / \mathrm{O}_{2} / \mathrm{N}_{2}$ gas stream using a 
DBD reactor. The model equations were solved by collision reaction cross section method, and the results successfully used to predict the concentration distribution of radicals and $\mathrm{Hg}^{0}$ in the reactor.

\subsection{Non-thermal plasma reactor and process flow of $\mathrm{Hg}^{0}$ removal}

\subsubsection{Non-thermal plasma reactor}

As previously discussed the non-thermal plasma reactor types for $\mathrm{Hg}^{0}$ oxidation mainly include corona discharge and dielectric barrier discharge. Corona discharge is initiated by partial breakdown of a gas gap in a strong inhomogeneous electric field (Bogaerts et al. 2002; Chang et al. 2002; Tendero et al. 2002; Kogelschatz et al. 2004; McAdams et al. 2001; Li et al. 2014). The active ionization region is restricted to a small volume around the corona electrodes with a small radius of curvature. A passive zone of low conductivity connects the active zone to the opposite electrode and stabilizes the low current discharge (Bogaerts et al. 2002; Chang et al. 2002; Tendero et al. 2002; Kogelschatz et al. 2004; McAdams et al. 2001; Li et al. 2014). The charge carriers in this drift region can be used to charge solid particles and droplets or to induce the formation of chemically reactive species. The corona discharge plasma reactors mainly include three types, namely, needle-plate, wire-plate and wire-cylinder (Bogaerts et al. 2002; Chang et al. 2002; Tendero et al. 2002; Kogelschatz et al. 2004; McAdams et al. 2001; $\mathrm{Li}$ et al. 2014). The structure and principle of the three typical corona discharge plasma reactors are shown in Figure 9. The corona discharge plasma reactor with wire-cylinder structure is used widely for $\mathrm{Hg}^{0}$ oxidation in laboratory studies because of its simple structure and good sealing. The corona discharge plasma reactor with wire-plate structure has better adaptability for flue gas treatment volume, richer industrial design experience and more systematic theoretical foundation because plasma reactor first evolves from electrostatic precipitator (ESP), which widely uses wire-plate structure, and hence, more adaptable for industrial applications

(Wu et al. 2006; Lin et al. 2002). Compared with the corona discharge plasma reactor with wire-cylinder and wire-plate structures, the corona discharge plasma reactor with needle-plate structure has a smaller and more 

plasma reactor with needle-plate structure for $\mathrm{Hg}^{0}$ oxidation are rare.

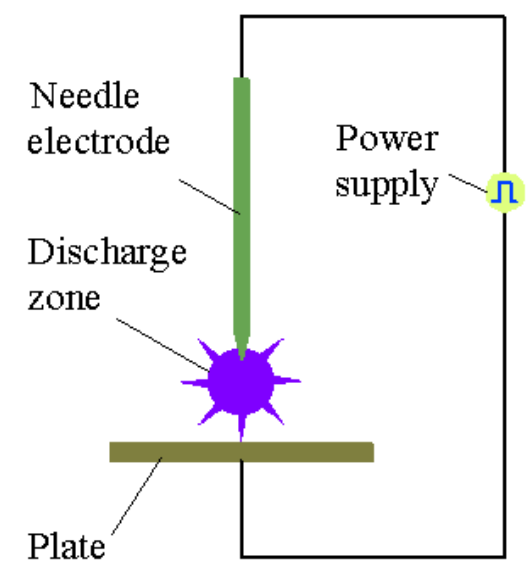

electrode
665 (a)

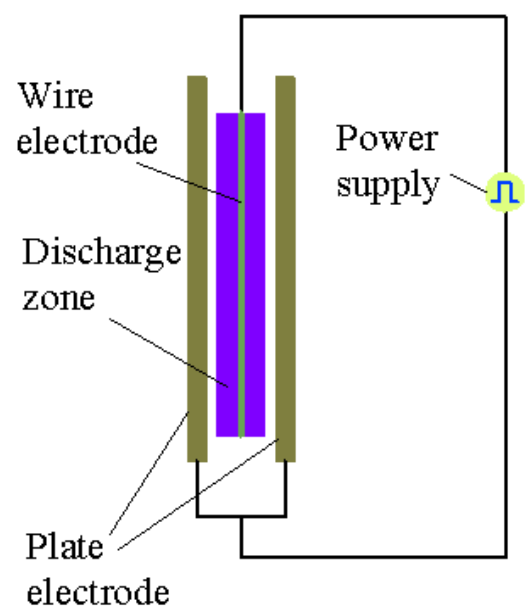

(b)

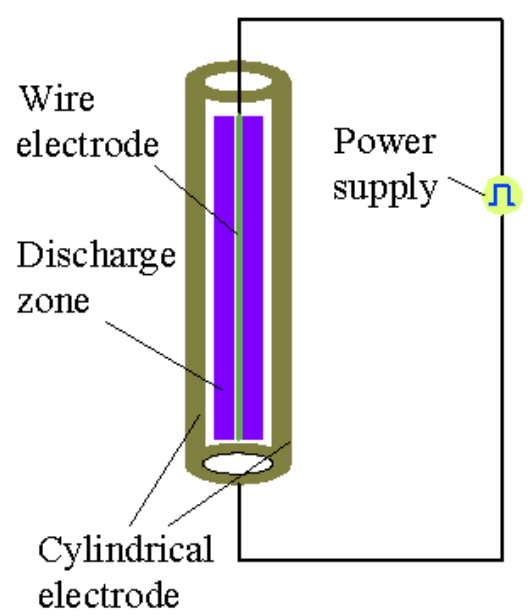

(c)

Figure 9. Structure and principle of corona discharge plasma reactors: (a) needle-plate; (b) wire-plate; (c) wire-cylinder.

The corona discharge has large discharge space and low onset voltage, but has low electron density and small discharge area. Compared to the corona discharge, the dielectric barrier discharge (DBD) can generate higher electron density as well as more high energy active species that are needed in chemical reactions (Zhou et al. 2013). DBD, also referred to silent discharge, is another main way of generating non-thermal plasma at atmospheric pressure. The electrode configuration is characterized by the presence of at least one dielectric barrier or insulator in the current path in addition to the gas gap used for discharge initiation (Tendero et al. 2002;

Kogelschatz et al. 2004; McAdams et al. 2001). The discharge is maintained by a large number of short-lived localized current filaments called microdischarges in gases. At least one of these electrodes is covered by a dielectric layer or insulator. To ensure stable plasma discharge operation, the gap which separates the electrodes is limited to a few millimeters wide (Tendero et al. 2002; McAdams et al. 2001). 


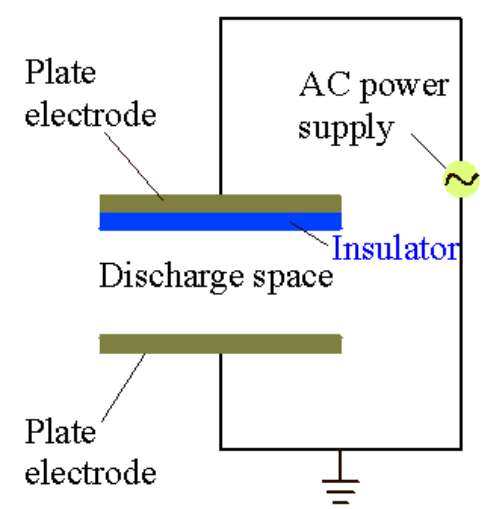

(a)

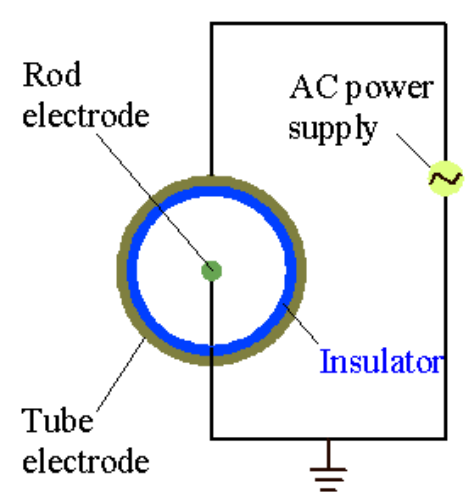

(d)

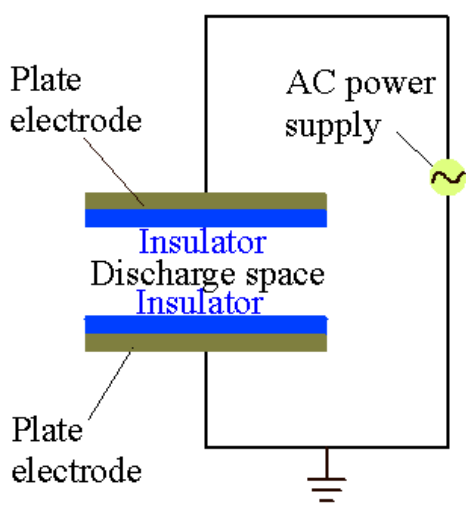

(b)

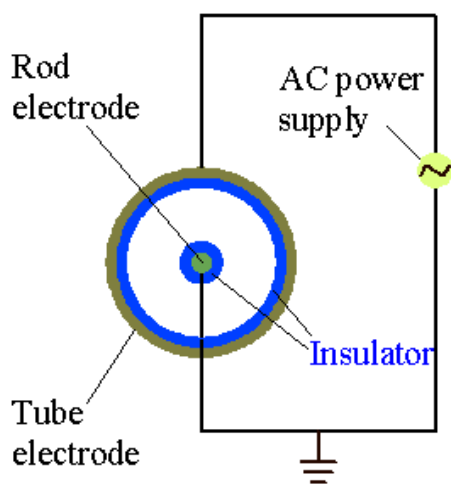

(e)

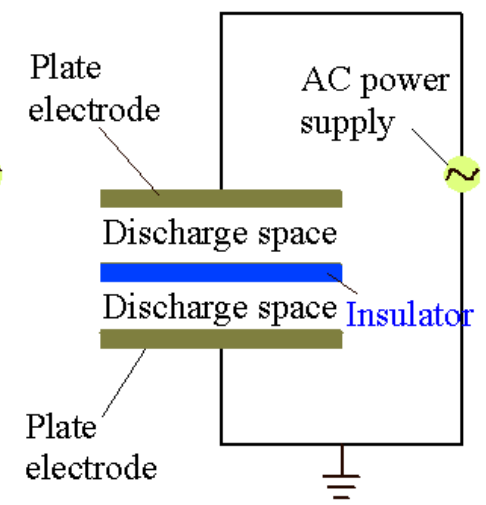

(c)

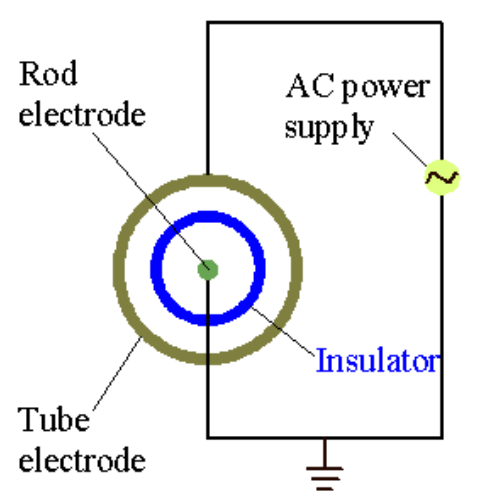

(f)

Figure 10. Schematic diagram of specific configuration of several DBD reactors: (a) plate type with a insulator; (b) plate type with two insulator; (c) plate type with a suspended insulator; (d) cylinder type with a insulator; (b) cylinder type with two insulator; (c) cylinder type with a suspended insulator. removal efficiency and environmental compatibility (Kogelschatz et al. 2004; Li et al. 2014). Based on the differences in reactor geometry, DBD can be divided into four types, namely, typical DBD, surface discharge, coplanar discharge and packed-bed discharge. The typical DBD reactor often consists of two plane-parallel metal electrodes with one or two insulators (Kogelschatz et al. 2004; Li et al. 2014). Also, some DBD reactors with rod-tube electrodes have been recently developed for oxidation of $\mathrm{Hg}^{0}$ in flue gas (Ko et al. 2008; Byun et al. 2011; Chen et al. 2006). Depending on the different placed locations and numbers of insulators, these plane-parallel or rod-tube DBD reactors may be further subdivided into three types (Tendero et al. 2002; 
691 Kogelschatz et al. 2004; McAdams et al. 2001; Li et al. 2014): (a) an insulator adhered to the high voltage

692

693

694

695

696

697

698

699

700

701

702

703

704

705

706

707

708

709

710

711

712

electrode; (b) two insulators respectively adhered to the high voltage electrode and ground electrode; (c) an insulator suspended in the space between the two electrodes. The schematic diagram of configuration of these DBD reactors is depicted in Figure 10.

As shown Figure 10, the discharge process of these DBD reactors occurs in the space between the two electrodes. However, An et al. 2014a and 2014b and Yang et al. 2012a recently reported studies using surface discharge plasma (SDP) and packed-bed discharge plasma (PDDP) reactors for oxidation of $\mathrm{Hg}^{0}$ in flue gas, respectively. The schematic diagram of typical SDP and PDDP reactors are shown in Figure 11. It can be seen from Figure 11 that although both of the SDP and PDDP also belong to the category of the typical DBD, there is some significant differences between them. The discharge process of the SDP occurs mainly at the electrode surface, while the discharge process of the PDDP occurs in the interspaces between fillers, not the common gas space between two electrodes. SDP reactors have aroused considerable interest because of their unique features and characteristics. For example, they are easily manufactured than other DBD reactors, and result in a decrease in the breakdown voltages, and hence better energy efficiency (Malik et al. 2011). Moreover, the flue gas resistance in SDP reactors is much less than those in other DBD reactors due to its much larger electrode gap (An et al. 2014a and 2014b). An et al. 2014b recently reported the application of SDP reactor for $\mathrm{Hg}^{0}$ oxidation, comparing $\mathrm{Hg}^{0}$ removal efficiency and energy yield in different plasma reactors, as summarized in Table 2. As can be observed from Table 2 the concentric cylinder discharge (CCD) reactor and wire-plate reactor showed lower $\mathrm{Hg}^{0}$ oxidation efficiency and energy yield compared to SDP reactor. $\mathrm{Hg}^{0}$ oxidation efficiencies obtained by wire-cylinder reactor were comparable with those of SDP reactor, but the energy yields were far lower than that of SDP reactor. Thus, SDP is a more cost-effective method for oxidizing $\mathrm{Hg}^{0}$ in flue gas.

Table 2. Comparison of $\mathrm{Hg}^{0}$ removal efficiency and energy yield in different plasma reactors (An et al. 2014b). 


\begin{tabular}{|c|c|c|c|c|c|}
\hline Reactor type & $\begin{array}{l}\text { Gas flow } \\
\left(\mathrm{L} \mathrm{min}{ }^{-1}\right)\end{array}$ & $\begin{array}{l}\mathrm{Hg}^{0} \text { concentration } \\
\left(\mu \mathrm{g} \mathrm{m}^{-3}\right)\end{array}$ & $\begin{array}{l}\text { SED } \\
\left(\mathrm{J} \mathrm{L}^{-1}\right)\end{array}$ & $\begin{array}{l}\text { Oxidation } \\
\text { efficiency }(\%)\end{array}$ & $\begin{array}{c}\text { Energy yield } \\
\left(\mu \mathrm{g} \mathrm{kJ}^{-1}\right)\end{array}$ \\
\hline $\mathrm{CCD}$ reactor & 2.5 & 300 & 23.7 & 59 & 7.5 \\
\hline Wire-plate reactor & 2.0 & 50 & 18.0 & 80 & 2.2 \\
\hline \multirow[t]{2}{*}{ Wire-cylinder reactor } & 6.0 & 110 & 894.0 & 98 & 0.1 \\
\hline & & & 80.0 & 98 & 1.3 \\
\hline SDP reactor & 4.5 & 110 & 7.9 & 98 & 13.7 \\
\hline
\end{tabular}

713

The major characteristic of PDDP reactors is the presence of contact points between pellets and pellets/ electrodes (Chen et al. 2008). Because of the short distance near these contact points, the electric field strength is significantly higher than the mean value in the reactor (Chen et al. 2008). The fact that PDDP reactor could achieve higher electric fields has been confirmed in various simulation studies. Chen et al. 2008 reviewed the current progress in PDDP reactor for ozone generation and abatement of air pollutants, mainly including $\mathrm{NO}_{\mathrm{x}}$, VOCs and greenhouse gases. Yang et al. 2012b measured the spectrum of dielectric barrier discharge process at atmospheric pressure in a coaxial reactor, and found that the typical spectrum of $\mathrm{N}_{2}$ molecule under dielectric barrier discharge was identified in wavelength range of $200-400 \mathrm{~nm}$, which covered the most UV-light wavelengths that are suitable for photocatalytic activity. Based on the theories of photocatalysis and PDDP reactor, Yang et al. 2012a recently developed a PDDP reactor, also called combined plasma-photocatalysis reactor, for oxidation of $\mathrm{Hg}^{0}$ in flue gas by filling $\mathrm{TiO}_{2}$ in a typical DBD reactor. Compared with the typical DBD process, $\mathrm{Hg}^{0}$ oxidation efficiency increased by $18.7-26.3 \%$ with the addition of $\mathrm{TiO}_{2}$ photocatalyst in this kind of combined plasma-photocatalysis reactor.

Liu et al. 2015d developed a plasma-catalyst reactor which was used for the adsorption of elemental mercury at low temperatures. $\mathrm{SiO}_{2}, \mathrm{TiO}_{2}$ and $\mathrm{SiO}_{2} / \mathrm{TiO}_{2}$ supported transitionmetal oxide catalysts were packed in the plasma discharge zone for adsorption enhancement. The results showed that the plasma-catalyst system displayed 


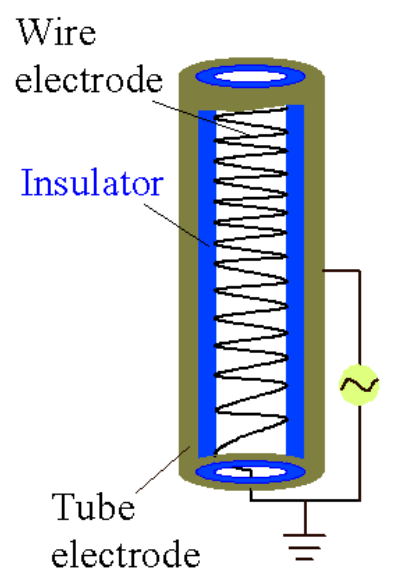

(a)

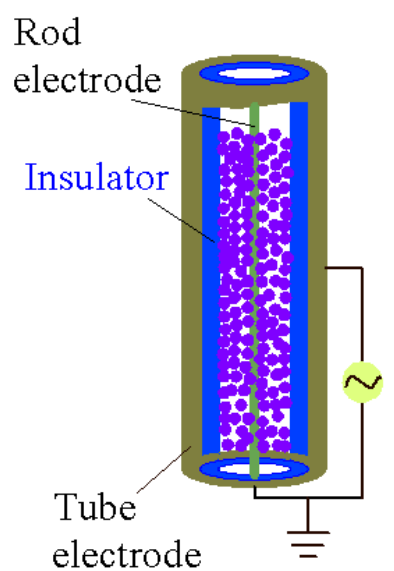

(b)

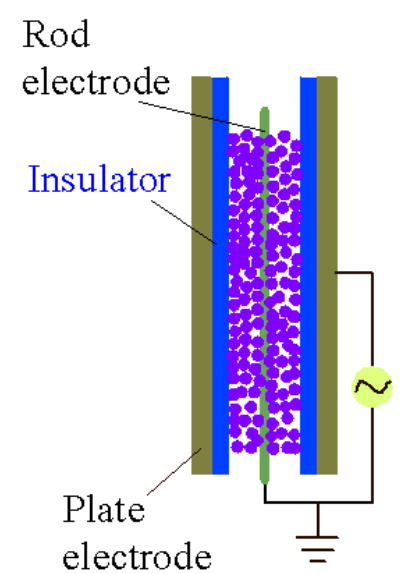

(c)

Figure 11. Schematic diagram of surface discharge plasma reactor (a) and packed-bed plasma reactor: (b) cylindrical style and (c) plate style. energy consumption is one of the main obstacles for the commercial applications of flue gas purification using non-thermal plasma. In order to reduce the energy consumption of non-thermal plasma process for flue gas mercury removal, an "indirect oxidation" plasma reactor based on plasma discharge was developed for flue gas purification by several researchers (An et al. 2014a; Wu et al. 2006; Lin et al. 2002). For this kind of plasma reactor, the removal process of contaminants mainly includes two steps: (1) Active substances were first produced by plasma discharge of oxygen-enriched gas stream; (2) Active substances produced were injected into the flue gas stream to oxidize contaminants. This type of plasma reactor consists of two common structures, which are 


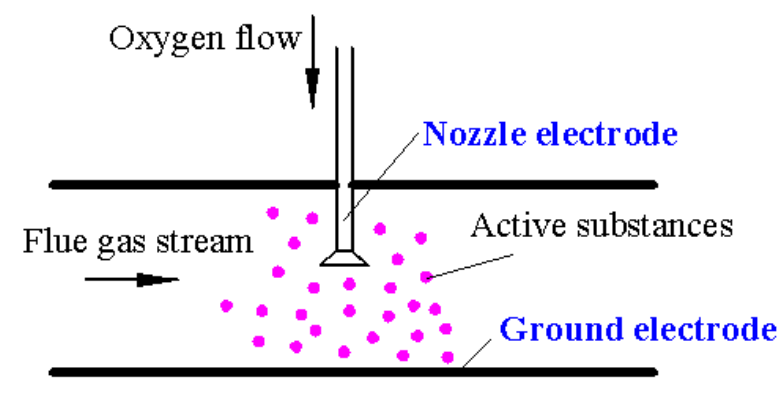

(a)

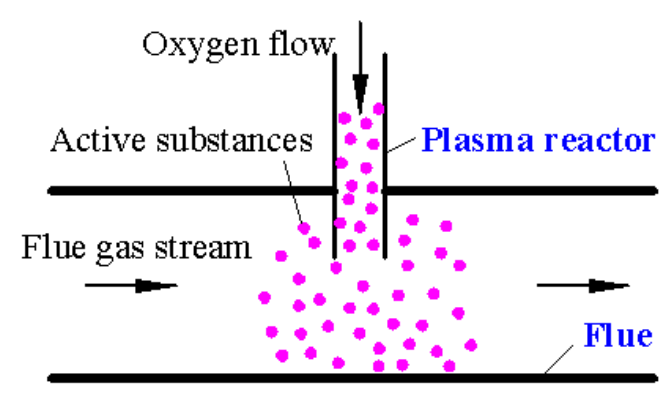

(b)

Figure 12. Schematic diagram of "indirect oxidation" plasma reactors: (a) nozzle electrode type and (b) SDP type.

755 2014a investigated the performance and energy consumption of $\mathrm{Hg}^{0}$ removal using "indirect oxidation" in the

756 latter reactor. The results indicated that for the same $\mathrm{Hg}^{0}$ oxidation efficiency, the energy yield of "indirect

757 oxidation" was approximately 7.5 times higher than that of the "direct oxidation", where the polluted flue gas

758 directly flows through the discharge space of the plasma reactor. The energy yields under different SEDs for

759 “indirect oxidation” and “direct oxidation’ are listed in Table 3.

Table 3. Comparison of energy yields under different SEDs for "indirect oxidation" and "direct oxidation" (An et

761 al. 2014a).

\begin{tabular}{ccc}
\hline $\operatorname{SED}\left(\mathrm{J} \cdot \mathrm{L}^{-1}\right)$ & Energy yields $(\mu \mathrm{g} / \mathrm{kJ})$ & \\
\hline & "indirect oxidation" & "direct oxidation" \\
\hline 2.0 & 27.8 & 3.7 \\
\hline
\end{tabular}




\begin{tabular}{lll}
\hline 3.0 & 24.6 & 3.3 \\
\hline 3.9 & 20.5 & 2.7 \\
\hline
\end{tabular}

\subsubsection{Process flow of $\mathrm{Hg}^{0}$ removal using non-thermal plasma}

Due to the very low concentrations of mercury in flue gas and the huge amount of flue gas, using an

independent device to control mercury emission is considered to be an uneconomical method (Wang et al. 2007;

Hutson et al. 2008; Su et al. 2013; Adewuyi et al. 2013; Ding et al. 2014; Obradović et al. 2011). Simultaneous

removal of multi-pollutants has been recognized as a cost-effective control strategy and has showed very good

2014; Obradović et al. 2011). Currently, the representative process flows of mercury removal using non-thermal

plasma involve two strategies. One is the simultaneous removal of $\mathrm{Hg}^{0}, \mathrm{NO}_{\mathrm{x}}$ and $\mathrm{SO}_{2}$ in a single non-thermal 
have reported (Yang et al. 2007; Hower et al. 2010; Ahmaruzzaman et al. 2010) that coal-fired fly ash is an effective sorbent for gaseous $\mathrm{Hg}^{2+}$. If the flue gas containing $\mathrm{NO}_{2} / \mathrm{HNO}_{2} / \mathrm{HNO}_{3} / \mathrm{SO}_{3} / \mathrm{H}_{2} \mathrm{SO}_{4} / \mathrm{Hg}^{2+}$ firstly flows through ESP, $\mathrm{Hg}^{2+}$ will be captured by coal-fired fly ash through adsorption. The mercury resources may be recovered by high-temperature desorption using flue gas heat or other methods in an additional desorption tower. The remaining $\mathrm{NO}_{2} / \mathrm{HNO}_{2} / \mathrm{HNO}_{3} / \mathrm{SO}_{3} / \mathrm{H}_{2} \mathrm{SO}_{4}$ in flue gas could then be converted into $\mathrm{NH}_{4} \mathrm{NO}_{3}$ and $\left(\mathrm{NH}_{4}\right)_{2} \mathrm{SO}_{4}$ with the injection of $\mathrm{NH}_{3}$ in the back container or flue. However, it is worth noting that this kind of arrangement also has inherently significant deficiencies. For example, untreated flue gas contains large amounts of particulate matters and corrosive substances such as acid gases and alkali metal vapor, which could have detrimental effects on the electrodes in the plasma reactor, including eroding and wearing them out, and accumulation of particulate matter blocking the small discharge space between the electrodes. It is interesting that "flue injection" or "indirect oxidation" method, which has been mentioned in the previous Section 2.4-(1), may provide a potential solution to this problem. The related process flow is illustrated in the Figure 13 (c) and (d), indicating that the electrodes in plasma reactor does have direct contact with the dust-containing/corrosive substances in the flue gas. This kind of arrangement strategy would effectively avoid the clogging, scouring and corrosion problems of the electrodes and discharge spaces. An et al. 2014a have tested the performance and energy consumption of this process, and they found that with $80 \% \mathrm{Hg}^{0}$ removal efficiency, the energy consumption of this kind of "flue injection" or "indirect oxidation" method was lower than that of several common "direct oxidation" methods, with very good prospects for industrial applications. 


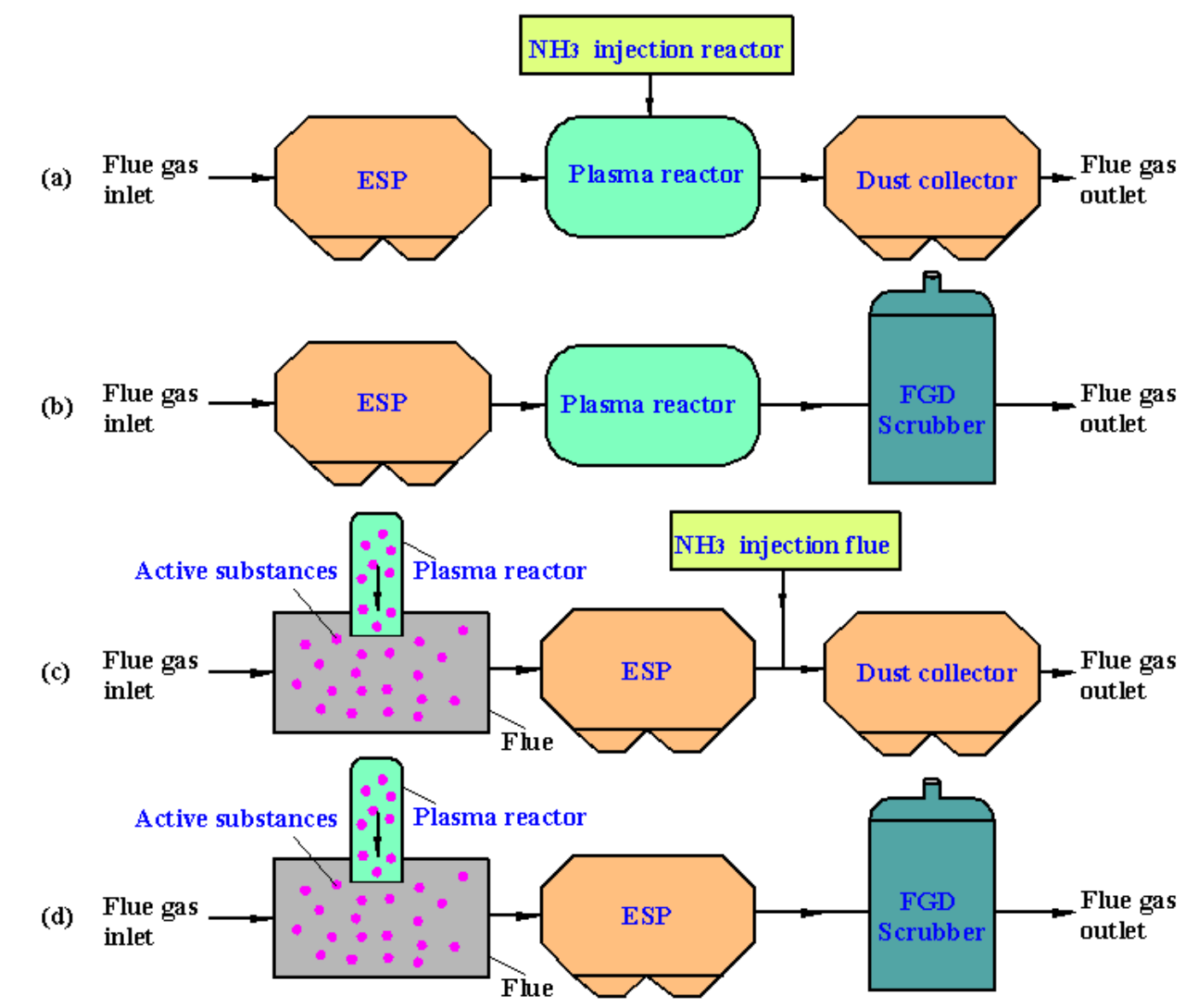

Figure 13. Several potential process flows of mercury removal using non-thermal plasma: (a) Typical plasma removal process; (b) Typical plasma "direct oxidation" \& wet scrubbing; (c) SDP plasma "indirect oxidation" \& dust; (d) SDP plasma "indirect oxidation" \& wet scrubbing.

\subsection{Overview of $\mathrm{TiO}_{2}$ photocatalytic AOTs for removing $\mathrm{Hg}^{0}$ in flue gas}

In the past few decades, photocatalytic technologies, as one of AOTs, have received more and more attention 
812 but also the most promising because of its high activity and stability, low cost as well as nontoxicity (Hashimoto 813 et al. 2005; Meng et al. 2007; Thiruvenkatachari et al. 2008; Biswas et al. 1988; Lee et al. 2010; Daghrir et al.

814 2013; Kumar et al. 2011; Fujishima et al. 1972).

815 Table 4. Common semiconductors used in photocatalysis (Daghrir et al. 2013; Kumar et al. 2011, Qi et al. 2016; ).

\begin{tabular}{cccc}
\hline Photocatalysts & band gap $(\mathrm{eV})$ & $\begin{array}{r}\text { Valence band } \\
(\mathrm{V} \text { vs NHE })\end{array}$ & $\begin{array}{c}\text { Conduction band } \\
\text { (V vs NHE) }\end{array}$ \\
\hline $\mathrm{TiO}_{2}$ & 3.2 & +3.1 & -0.1 \\
$\mathrm{ZnO}$ & 3.2 & +3.0 & -0.2 \\
$\mathrm{ZnS}$ & 3.7 & +1.4 & -2.3 \\
$\mathrm{SnO}_{2}$ & 3.8 & +4.1 & +0.3 \\
$\mathrm{WO}_{3}$ & 2.8 & +3.0 & +0.4 \\
$\mathrm{CdSe}$ & 2.5 & +1.6 & -0.1 \\
$\mathrm{CdS}^{\mathrm{BiOIO}}$ & 2.5 & +2.1 & -0.4 \\
& 3.1 & +4.1 & -0.97
\end{tabular}

$\mathrm{TiO}_{2}$ photoanode in combination with a Pt counter electrode immersed in an aqueous electrolytic solution. Since then, this great discovery has led to a powerful and long-lasting research boom for $\mathrm{TiO}_{2}$ photocatalytic technology all over the world. $\mathrm{TiO}_{2}$ photocatalytic technology has been widely studied and applied in the field of wastewater,

821 air pollution purification as well as energy conversion (Hashimoto et al. 2005; Meng et al. 2007; Thiruvenkatachari et al. 2008; Biswas et al. 1988; Lee et al. 2010; Daghrir et al. 2013; Kumar et al. 2011; Fujishima et al. 1972). In 1971, Kaluza and Boehm 1971 applied titania as a thin film on a glass slide with a drop of $\mathrm{Hg}^{0}$, and yellow color (mercury oxide) was observed after $1.5 \mathrm{~h}$ under UV irradiation in the range of 390-410 
$\mathrm{nm}$, demonstrating the feasibility of mercury removal using $\mathrm{TiO}_{2}$ photocatalytic AOTs. Wu, Lee and Biswas et al. 1998 and 2001 made important contribution in utilizing $\mathrm{TiO}_{2}$ photocatalytic technology for oxidation of $\mathrm{Hg}^{0}$ in flue gas with good results. Since then, a number of such studies have been conducted world-wide involving the use of pure $\mathrm{TiO}_{2}$, composite $\mathrm{TiO}_{2}$, and other doped or coupled $\mathrm{TiO}_{2}$ with other materials, which have been developed (Worathanakul et al. 2008; Suriyawong et al. 2009; Wang et al. 2011; Lee et al. 2004; Lee et al. 2005; Tsai et al. 2011; His et al. 2012; Pitoniak er al. 2005; Yuan et al. 2011; Jeon et al. 2008; Granite et al. 2008; Chen et al. 2007; Hong et al. 2005; Zhou et al. 2008; Zhuang et al. 2014; Chen et al. 2014). The effectiveness of these materials for $\mathrm{Hg}$ removal, details of the mechanisms, kinetics and processes involved, and recent progress on these technologies will be examined in the next sections.

\subsection{Pure $\mathrm{TiO}_{2}$}

$\mathrm{TiO}_{2}$ photocatalytic AOTs have been extensively studied in the field of wastewater treatment and flue gas purification because of its very strong oxidizing and environmentally friendly feature (Chen et al. 2007; Zhou et al. 2008; Zhuang et al. 2014; Chen et al. 2014; Seery et al. 2007; Grabowska et al. 2010; Dozzi et al. 2012; Binitha et al. 2009). $\mathrm{Wu}$ and Lee 1998 developed in situ-generated $\mathrm{TiO}_{2}$ photocatalyst with ultraviolet (UV) irradiation to capture $\mathrm{Hg}^{0}$ in flue gas, and obtained a $96 \% \mathrm{Hg}^{0}$ capture efficiency, which confirmed the feasibility of $\mathrm{Hg}^{0}$ removal from flue gas using $\mathrm{TiO}_{2} \mathrm{AOTs}$, and spurred further research and developmental studies. Lee and Biswas 2001 used three common sorbents $\left(\mathrm{TiO}_{2}, \mathrm{SiO}_{2}\right.$ and $\left.\mathrm{CaO}\right)$ to contrast their $\mathrm{Hg}^{0}$ capture capabilities in an entrained flow reactor, and the results showed that $\mathrm{TiO}_{2}$ in the presence of $\mathrm{UV}$ irradiation was most effective for $\mathrm{Hg}^{0}$ capture, resulting in a greater than $98 \% \mathrm{Hg}^{0}$ capture efficiency. $\mathrm{CaO}$ particles only had a $33 \% \mathrm{Hg}^{0}$ capture efficiency, while $\mathrm{SiO}_{2}$ was completely ineffective for $\mathrm{Hg}^{0}$ capture. Worathanakul et al. 2008 evaluated the performance of commercially available (four types of iron oxide, $\mathrm{TiO}_{2}$, titania pillared clay) and in-house synthesized (magnetite and SUZ-4 zeolite) sorbents for $\mathrm{Hg}^{0}$ capture in a differential bed reactor, and they found that $\mathrm{TiO}_{2}$ showed the 
greatest potential for capturing $\mathrm{Hg}^{0}$ with UV irradiation due to the high capture efficiency.

Related studies (Linsebigler et al. 1995; Kwon et al. 2008) verified that $\mathrm{TiO}_{2}$ from different synthesis methods often had different $\mathrm{Hg}^{0}$ removal performances. Suriyawong et al. 2009 tested the performance of $\mathrm{Hg}^{0}$ capture by nano-structured $\mathrm{TiO}_{2}$ with different synthesis methods under UV irradiation, and they found that the pre-synthesized nano-structured $\mathrm{TiO}_{2}$ demonstrated the highest $\mathrm{Hg}^{0}$ capture efficiency because of its larger surface area and higher proportion of anatase to rutile, followed by in-situ generated and commercial $\mathrm{TiO}_{2}(\mathrm{Degussa}, \mathrm{P} 25)$. Wang et al. 2011 prepared a novel titania nanotube (TNT) with vast surface area and high porosity by hydrothermal method to remove $\mathrm{Hg}^{0}$ in flue gas, and their results showed that the TNT exhibited an excellent $\mathrm{Hg}^{0}$ removal efficiency. In addition, Lee et al. 2004 and 2005 tested the removal performance of $\mathrm{Hg}^{0}$ using various light sources, and they found that $\mathrm{Hg}^{0}$ removal was significantly affected by different light sources. Tsai and His 2011 and 2012 synthesized oxygen-vacant titanium dioxide $\left(\mathrm{TiO}_{2-\mathrm{x}}\right)$ nanoparticles using $\mathrm{N}_{2} / \mathrm{Ar} / \mathrm{He}$ and $\mathrm{He} / \mathrm{Ar}$ thermal plasma as two heating sources and evaluated their photocatalytic activity for capturing gaseous $\mathrm{Hg}^{0}$. The results showed that both $\mathrm{TiO}_{2-\mathrm{x}}$ nanoparticles demonstrated good photocatalytic activity for capturing $\mathrm{Hg}^{0}$ under UV-light and visible-light because of the formation of oxygen-vacant sites. Granite et al. 2008 used commercially available self-cleaning windows (titania-coated glass) to sequester mercury from oxygen-nitrogen mixtures in a specially designed photo-reactor, and verified the possibility of removing mercury using the self-cleaning windows. Wu et al. 2015 b synthesized $\mathrm{TiO}_{2}$ hollow sphere by hydrothermal method, and studied the the removal performance of gaseous elemental mercury under UV light. The results showed that the mercury removal efficiency reached up to $82.75 \%$.

\subsection{Composite of $\mathrm{TiO}_{2}$ with other materials}

$\mathrm{TiO}_{2}$ powders with UV irradiation have proven to be an effective mercury sorbent/catalyst in the laboratory

(Wu et al. 1998; Lee et al. 2001). However, $\mathrm{TiO}_{2}$ powders were easily washed away with the flue gas stream and 
also lightly agglomerate together to form larger clusters due to the presence of water vapor in coal-fired flue gas (Hashimoto et al. 2005; Thiruvenkatachari et al. 2008). reover, pure $\mathrm{TiO}_{2}$ powders have a very low adsorption capacity for gaseous pollutants, which is not conducive to photocatalytic reaction because the adsorption process is often the rate-controlling step (Hashimoto et al. 2005; Thiruvenkatachari et al. 2008; Lee et al. 2001). Therefore, to avoid the loss and agglomeration of $\mathrm{TiO}_{2}$ powders and to provide stronger adsorption capacity, $\mathrm{TiO}_{2}$ powders typically need to be coated on a variety of support materials with larger specific surface area and stronger adsorption capacity, also referred to as the carriers, to be more adaptable for future industrial applications. Common $\mathrm{TiO}_{2}$ support materials or carriers include reactor walls, glass beads, metal oxides, carbon-based materials, zeolites, silicone, natural mineral materials, and even some organic materials (Hashimoto et al. 2005; Meng et al. 2007; Thiruvenkatachari et al. 2008; Biswas et al. 1998).

Nanostructured silica gel has excellent adsorption capacity and good light transmission, and is one of the most common sorbents/carriers (Hashimoto et al. 2005; Thiruvenkatachari et al. 2008). Pitoniak et al. 2003, 2004 and 2005 developed $\mathrm{SiO}_{2}-\mathrm{TiO}_{2}$ composites using a sol-gel method to remove $\mathrm{Hg}^{0}$ from flue gas with UV irradiation. The results showed that the composites achieved a more than $99 \% \mathrm{Hg}^{0}$ removal efficiency due to the synergistic adsorption and photocatalytic oxidation roles of the catalyzer and carrier. Yuan et al. 2011 and 2012 prepared a $\mathrm{TiO}_{2}$-aluminum silicate fiber nanocomposite by sol-gel method to capture $\mathrm{Hg}^{0}$ in flue gas under UV irradiation, and obtained a $84 \% \mathrm{Hg}^{0}$ removal efficiency. Jeon et al. 2008 developed several nanotitanosilicates by three different carrier gases (air, $\mathrm{N}_{2}$, and Ar) in a diffusion flame reactor, and achieved a $88 \% \mathrm{Hg}^{0}$ capture efficiency. Wu et al. 2015a prepared a low cost $\mathrm{CuO} / \mathrm{TiO}_{2}$ photocatalysts and test the removal performance of gaseous elemental mercury under UV light and visible light (both xenon lamp and LED), respectively. The results showed that the $\mathrm{CuO} / \mathrm{TiO}_{2}$ photocatalysts were highly efficient in oxidizing $\mathrm{Hg}^{0}$, reaching above $70 \%$ in all cases under UV light, peaking at $57.8 \%$ with 1.25 wt. $\% \mathrm{CuO}$ under visible light and peaking at about $60 \%$ with 1.25 
wt.\% CuO under LED light.

Activated carbon fiber (ACF) is a promising sorbent/carrier due to its huge surface area, developed gap structure and good thermal conductivity (Hashimoto et al. 2005; Thiruvenkatachari et al. 2008). Hsi et al. 2012 developed a $\mathrm{TiO}_{2-\mathrm{x}} / \mathrm{ACF}$ composite via a $\mathrm{N}_{2} / \mathrm{Ar} / \mathrm{He}$ thermal plasma system, and also achieved an efficient $\mathrm{Hg}^{0}$ removal with UV irradiation. Biomass coke is the byproduct from gasification process of biomass materials, and has been widely studied for flue gas purification because of its good pore structure and surface properties as well as low cost and wide sources (De et al. 2013; Tan et al. 2011). Tan et al. 2010 prepared a novel char $/$ nano-TiO 2 photocatalyst by sol-gel method to remove $\mathrm{Hg}^{0}$ in flue gas, and obtained a $86 \% \mathrm{Hg}^{0}$ removal efficiency in the presence of $10 \%$ oxygen. Fly ash, generated during coal combustion, is an industrial by-product, and has been proven to be an effective and potential mercury sorbent because of its low costs and huge reserves (Yang et al. 2007; Hower et al. 2010; Ahmaruzzaman et al. 2010). Fang et al. 2013 developed a $\mathrm{TiO}_{2} /$ coal fly ash by impregnation method to capture $\mathrm{Hg}^{0}$ in flue gas, and achieved a $63.8 \% \mathrm{Hg}^{0}$ conversion. Shen et al. 2016 prepared the $\mathrm{WO}_{3} / \mathrm{TiO}_{2}$ photocatalysts by sol-gel synthesis, which are immobilized on the surfaces of glass beads. The authors studied the photo-oxidation efficiencies of elemental mercury at high temperatures, and the results showed that the photo-oxidation efficiency of $\mathrm{Hg}^{0}$ was greatly enhanced by $\mathrm{WO}_{3}$ dopant at a high temperature of 160 Celsius. The improvement was due to the modification of $\mathrm{WO}_{3}$ that enlarged the band gap energy of $\mathrm{TiO}_{2}$ and effectively promoted the separation of photo-induced electrons and holes.

\subsection{Doped or coupled $\mathrm{TiO}_{2}$ using other materials}

Although $\mathrm{TiO}_{2}$ has been recognized as a promising photocatalyst, the large band gap and the fast recombination of photogenerated electron-hole pairs limit its further development (Daghrir et al. 2013). Results of related studies (Kumar et al. 2011) suggest that $\mathrm{TiO}_{2}$ could only be activated in the UV irradiation region with a lower than $387 \mathrm{~nm}$ wavelength due to its large band gap ( $3.2 \mathrm{eV}$ for anatase and brookite, $3.0 \mathrm{eV}$ for rutile). The 

band structure of $\mathrm{TiO}_{2}$ using various strategies including coupling with a narrow band gap semiconductor, cation/anion doping, co-doping with two or more, surface sensitization by organic dyes or metal complexes, and noble or poor metal deposition. The latter can be improved by changing the surface properties of $\mathrm{TiO}_{2}$ by fluorination or sulfation, or by adding suitable electron acceptors besides molecular oxygen in the reaction mediums (Hashimoto et al. 2005; Meng et al. 2007; Thiruvenkatachari et al. 2008; Biswas et al 1998; Lee et al.

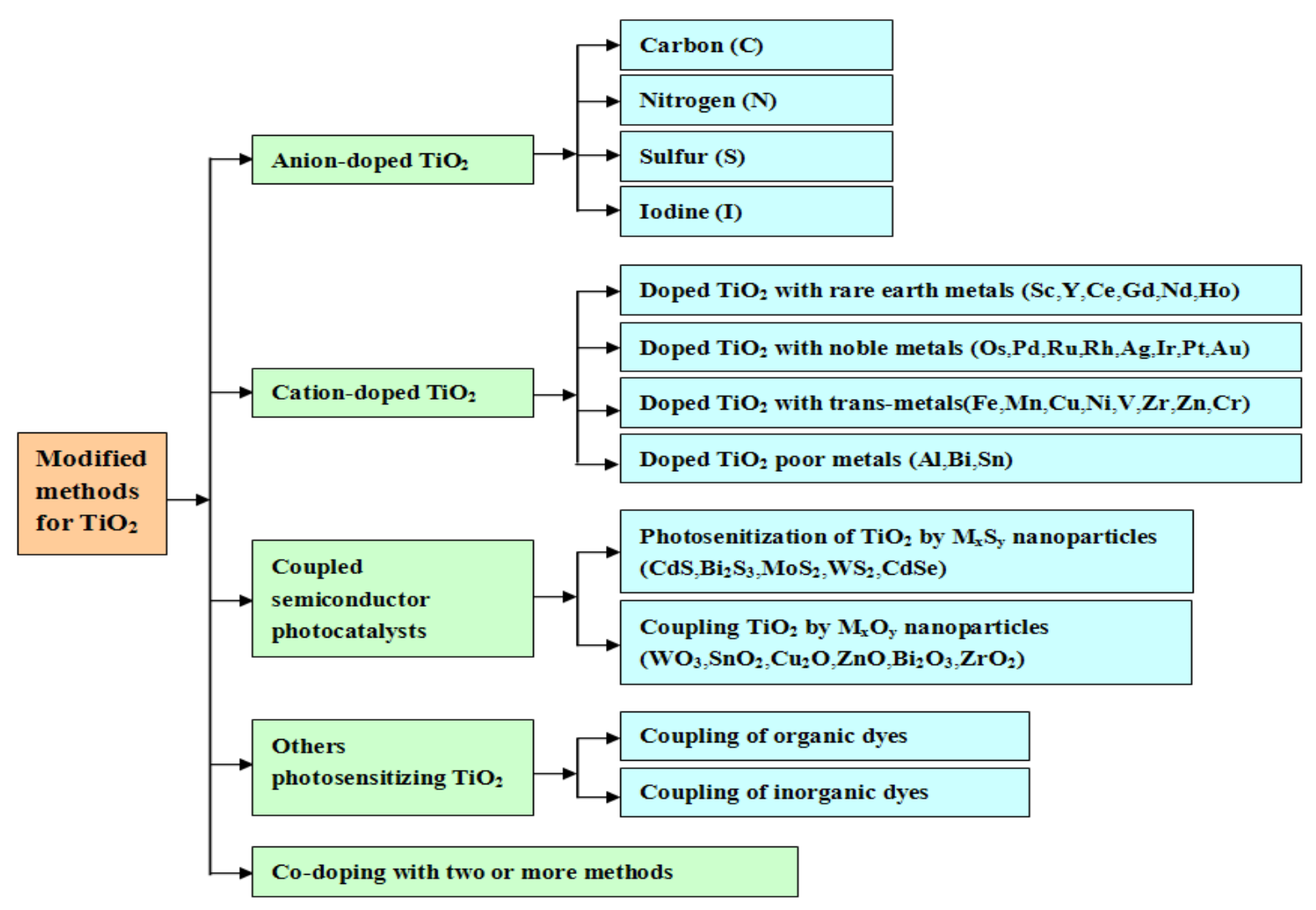

Figure 14. Some common modified methods for $\mathrm{TiO}_{2}$. 


\subsubsection{Anion-doped $\mathrm{TiO}_{2}$}

A large number of doping methods recently have been used to extend the spectral response of $\mathrm{TiO}_{2}$ into the visible region and to enhance its photocatalytic activity. Doping $\mathrm{TiO}_{2}$ with anionic nonmetals such as carbon (C) (Chen et al. 2004; Ren et al. 2007), nitrogen (N) (Asahi et al. 2001; Burda et al. 2003; Diwald et al. 2004), sulfur (S) (Ohno et al. 2003; Umebayashi et al. 2002; Umebayashi et al. 2003), and iodine (I) (Hong et al. 2005) or co-doping with these anionic nonmetals (Chen et al. 2007; Zhou et al. 2008) have received an increasing attention.

Related studies (Chen et al. 2004; Ren et al. 2007) showed that carbon doping of $\mathrm{TiO}_{2}$ was an acceptable choice for improving the above problems. The substitution of $\mathrm{C}$ atoms in $\mathrm{TiO}_{2}$ photocatlyst introduces new states $(\mathrm{C} 2 \mathrm{p})$ close to the valence band edge of $\mathrm{TiO}_{2}(\mathrm{O} 2 \mathrm{p})$. Accordingly, the conduction band edge shifts and narrows the band gap. The incorporation of $\mathrm{C}$ into $\mathrm{TiO}_{2}$ may form carbonaceous species on the surface of photocatalyst, which has been reported to facilitate the absorption for visible light (Wu et al. 1998; Chen et al. 2007; Ren et al. 2007). Hsi et al. 2012 developed an oxygen-vacant $\mathrm{TiO}_{2-\mathrm{x}} /$ activated carbon fiber composite via a $\mathrm{N}_{2} / \mathrm{Ar} / \mathrm{He}$ thermal plasma system, and achieved an effective removal of $\mathrm{Hg}^{0}$ from flue gas under visible-light irradiation. Zhuang et al. 2014 synthesized a carbon-modified $\mathrm{TiO}_{2}$ nanotubes (CTNTs) via a hydrothermal method to capture $\mathrm{Hg}^{0}$ in flue gas under the irradiation of white light LED lamps, and they found that the catalyst exhibited a high visible-light photocatalytic performance for $\mathrm{Hg}^{0}$ in flue gas, and achieved a $90 \% \mathrm{Hg}^{0}$ oxidation. Doping $\mathrm{TiO}_{2}$ with nonmetals such as $\mathrm{N}$ element can effectively change the refraction index, hardness, electrical conductivity, elastic modulus, and the photocatalytic activity toward the visible light absorption (Daghrir et al. 2013; Kumar et al. 2011; Asahi et al. 2011; Burda et al. 2003; Diwald et al. 2004). Chen et al. 2014 prepared a N-doped $\mathrm{TiO}_{2}$ nanoparticles that exhibited a narrow band gap by calcining a mixture of Degussa $\mathrm{P}-25 \mathrm{TiO}_{2}$ and $\mathrm{NH}_{4} \mathrm{Cl}$ for $\mathrm{Hg}^{0}$ removal in flue gas. XPS and UV/Vis diffuse reflectance spectra indicated that the molecular state $\mathrm{N}$ was incorporated into a $\mathrm{TiO}_{2}$ lattice, causing an observable shift of the absorption edge to along wavelength of $441 \mathrm{~nm}$. Moreover, the N-doped 
$\mathrm{TiO}_{2}$ nanoparticles not only have a high photocatalytic activity for $\mathrm{Hg}^{0}$ capture but also can effectively resist the competitive adsorption from moisture and negative photocatalytic effects caused by other flue gas components.

\subsubsection{Cation-doped $\mathrm{TiO}_{2}$}

$\mathrm{TiO}_{2}$ doped with cations such as noble metals (Seery et al. 2007; Grabowska et al. 2010; Dozzi et al. 2012; Binitha et al. 2009), poor metals (Depero et al. 2000; Ji et al. 2009; Sui et al. 2010; Fresno et al. 2006), rare earth metals (Stengl et al.2009; El-Bahy et al. 2009; Fan et al. 2006; Shi et al. 2009) and transition metals (Kment et al. 2010; Paola et al. 2002; Sun et al. 2009; Asilturk et al. 2009) or co-doped with these cations (Zhang et al. 2011a; Hsieh et al. 2009) have been widely studied in many research fields including mercury capture, and the results have shown that cations doping or co-doping $\mathrm{TiO}_{2}$ broadened the light absorption range, increased the redox potential of photogenerated free radicals, as well as strengthened the quantum efficiency by inhibiting the fast recombination of photogenerated electron-hole pairs. Tsai et al. 2013 successfully prepared transition metal $\mathrm{Cu}$-doped $\mathrm{TiO}_{2}$ nanoparticles via a single-step process using $\mathrm{Cu}$ powder and Degussa P-25 nanoparticles in a non-transferred plasma torch system, and they found that the $\mathrm{Cu}$-doped $\mathrm{TiO}_{2}$ exhibited a good photocatalytic activity for $\mathrm{Hg}^{0}$ removal under visible-light irradiation. Dai et al. 2012 prepared Fe-doped $\mathrm{TiO}_{2}$ nanocomposites for $\mathrm{Hg}^{0}$ removal by direct dissolution method, and obtained a higher $\mathrm{Hg}^{0}$ conversion as compared to pure $\mathrm{TiO}_{2}$. Related studies (Kment et al. 2010; Paola et al. 2002) showed that doping $\mathrm{TiO}_{2}$ with transition metals could effectively tune the electronic structure and shift the light absorption region from the UV to the visible-light, enhancing the photocatalytic activity. The shift of the absorption edge to the visible light region was mainly caused by the charge-transfer transition between the d electrons of the transition metals and the conduction or valence band of $\mathrm{TiO}_{2}$ (Wu et al. 1998; Lee et al. 2001; Kment et al. 2010; Paola et al. 2002). The coping generated a new electron state in the electronic structure of $\mathrm{TiO}_{2}$, which was able to capture the excited electrons from $\mathrm{TiO}_{2}$ valence band and prevented the recombination of charge carriers (Kment et al. 2010; Sun et al. 2009; Asilturk et al. 
2011). Aluminum is one of the most abundant metals found in Earth's crust, and classified as poor metal. Tsai and coworkers (2012) developed a $\mathrm{Al}$-doped $\mathrm{TiO}_{2}$ visible-light photocatalyst via a single step using vaporized $\mathrm{Ti}, \mathrm{Al}$, and $\mathrm{O}_{2}$ in a non-transferred plasma torch system. Results showed that the formed $\mathrm{Al}$-doped $\mathrm{TiO}_{2}$ nanoparticles were a mixture of anatase and rutile phase and had a size between 10 and $105 \mathrm{~nm}$, with the absorption spectra shifting towards the visible light region. $\mathrm{Hg}^{0}$ breakthrough tests revealed that the nanoparticles had an appreciable $\mathrm{Hg}^{0}$ removal under visible-light irradiation. The results of a related study (Depero et al. 2000), indicate doping $\mathrm{TiO}_{2}$ with $\mathrm{Al}$ hinders the phase transformation of $\mathrm{TiO}_{2}$ from anatase to rutile by stabilizing the surface state and inhibiting the grain growth of $\mathrm{TiO}_{2}$ particles.

\subsubsection{Coupled $\mathrm{TiO}_{2}$ with other semiconductors or metallic oxides}

Coupling with other semiconductors or metallic oxides with different energy levels is another effective approach to extend the absorption wavelength range and to hinder the recombination of photogenerated charge carriers (Daghrir et al. 2013; Kumar et al. 2011; Zhang et al. 2009). A large number of studies (Daghrir et al. 2013; Kumar et al. 2011; Robert et al. 2007; Zhang et al. 2009; Hernàndez-Alons et al. 2009; Ilieva et al. 2012; Bessekhouad et al. 2004; Kannaiyan et al. 2010; Shang et al. 2004; Ho et al. 2004; Coehoorn et al. 1987; Lo et al. 2004) have shown that an appropriate coupling between conduction band and valence band of two kinds of semiconductors or metallic oxides often could achieve an effective transfer of charge carriers from one to another. When the large band gap of $\mathrm{TiO}_{2}$ is coupled with a small band gap semiconductor with more negative conduction band level, the electron could be injected from the small band gap of the semiconductor used as a sensitizer to the $\mathrm{TiO}_{2}$, thereby promoting the separation between the photogenerated electron-holes (Robert et al. 2007; Zhang et al. 2009; Hernàndez-Alons et al. 2009; Ilieva et al. 2012; Bessekhouad et al. 2004; Kannaiyan et al. 2010; Shang et al. 2004; Ho et al. 2004; Coehoorn et al. 1987; Lo et al. 2004). Yuan et al. 2012a, 2012b and 2012c prepared several coupled $\mathrm{TiO}_{2}$ nanofibers with semiconductors and metal oxides, including $\mathrm{CuO}, \mathrm{In}_{2} \mathrm{O}_{3}, \mathrm{~V}_{2} \mathrm{O}_{5}, \mathrm{WO}_{3}$ and $\mathrm{Ag}_{2} \mathrm{O}$, by 
an electrospinning method, and tested them for $\mathrm{Hg}^{0}$ removal from flue gas under dark, visible light and UV irradiation, respectively. The results indicated that, compared to pure $\mathrm{TiO}_{2}$, the UV-vis absorption intensities of coupled $\mathrm{TiO}_{2}$ nanofibers significantly increased and the absorption bandwidth also expanded, especially for $\mathrm{Ag}_{2} \mathrm{O}-\mathrm{TiO}_{2}$ and $\mathrm{V}_{2} \mathrm{O}_{5}-\mathrm{TiO}_{2}$. $\mathrm{WO}_{3}$-doped $\mathrm{TiO}_{2}$ exhibited the highest $\mathrm{Hg}^{0}$ removal efficiency of $100 \%$ under $\mathrm{UV}$ irradiation. Doping $\mathrm{V}_{2} \mathrm{O}_{5}$ into $\mathrm{TiO}_{2}$ enhanced $\mathrm{Hg}^{0}$ removal efficiency greatly from $6 \%$ to $63 \%$ under visible light irradiation.

\subsection{Effects of flue gas components on $\mathrm{Hg}^{0}$ removal using $\mathrm{TiO}_{2}$ photocatalytic AOTs}

Coal-fired flue gas is a complex mixture containing fly ash particles, moisture, $\mathrm{CO}$, and many acid gases (Granite et al. 2002). Therefore, studying the influences of several flue gas components, including $\mathrm{H}_{2} \mathrm{O}, \mathrm{O}_{2}, \mathrm{SO}_{2}$ and $\mathrm{NO}$, on $\mathrm{TiO}_{2}$ photocatalytic removal of $\mathrm{Hg}^{0}$ in flue gas deserves important consideration.

\subsubsection{Effects of $\mathrm{H}_{2} \mathrm{O}$}

Pitoniak et al. 2003 studied the effects of relative humidity on $\mathrm{Hg}^{0}$ capture using $\mathrm{SiO}_{2}-\mathrm{TiO}_{2}$ composite with UV irradiation, and they found that the relative humidity impeded $\mathrm{Hg}^{0}$ adsorption, thereby decreasing $\mathrm{Hg}^{0}$ removal efficiency. Based on the results of Pitoniak et al. 2003, Li et al. 2006, 2007 and 2008 further investigated the role of moisture on $\mathrm{Hg}^{0}$ removal as well as the corresponding mechanism, and they found that water vapor dramatically suppressed both $\mathrm{Hg}^{0}$ adsorption and photocatalytic oxidation because of the significant reemission of captured $\mathrm{Hg}^{0}$ on the nanocomposite. This phenomenon was ascribed to the repellant effect of the adsorbed water vapor to the captured $\mathrm{Hg}^{0}$ on $\mathrm{TiO}_{2}$ surface because of the super-hydrophilic properties of $\mathrm{TiO}_{2}$ surface $(\mathrm{Li}$ et al. 2006, 2007 and 2008). Tsai et al. 2011 and 2012a and Hsi et al. 2012 also found that the presence of moisture had a negative impact on $\mathrm{Hg}^{0}$ removal using two kinds of oxygen-vacant $\mathrm{TiO}_{2-\mathrm{x}}$ nanoparticles and $\mathrm{TiO} \mathrm{O}_{2-\mathrm{x}} / \mathrm{ACF}$ composite with UV and visible light irradiation, respectively; and verified these results to be due to the reemission of $\mathrm{Hg}$ species from these photocatalysts surface due the competitive adsorption for the active sites between $\mathrm{Hg}$ 
1014

1015

1016

1017

1018

1019

1020

1021

1022

1023

1024

1025

1026

1027

1028

species and $\mathrm{H}_{2} \mathrm{O}$. Tsai et al. 2012b and 2013, Chen et al. 2014 and Cho et al. 2012 also obtained the similar results in studying the photocatalytic removal of $\mathrm{Hg}^{0}$ using $\mathrm{Cu}$-doped, Al-doped, $\mathrm{N}$-doped $\mathrm{TiO}_{2}$ and pure $\mathrm{TiO}_{2}$ nanoparticles with UV, visible light and household fluorescent lighting irradiation. The results suggest that moisture could suppress $\mathrm{Hg}^{0}$ removal using pure or doped $\mathrm{TiO}_{2}$ photocatalytic AOTs due to the reemission of $\mathrm{Hg}$ species from $\mathrm{TiO}_{2}$ surface. A typical coal-fired flue gas often contains 5\%-7\% $\mathrm{H}_{2} \mathrm{O}$ (Granite et al. 2002), therefore, the need to suppress the negative effects of $\mathrm{H}_{2} \mathrm{O}$ is an important research issue. Related studies (Chen et al. 2014; Tsai et al. 2012b) have verified that doped $\mathrm{TiO}_{2}$ with metal or non-metallic materials was one of the effective methods for suppressing the reemission of captured $\mathrm{Hg}^{0}$ on catalyst surface. Tsai et al. 2012b prepared Cu-doped $\mathrm{TiO}_{2}$ nanoparticles, and found it to effectively suppress $\mathrm{Hg}$ reemission from $\mathrm{TiO}_{2}$ surface. Chen et al. 2014 prepared $\mathrm{N}$-doped $\mathrm{TiO}_{2}$ nanoparticles for $\mathrm{Hg}^{0}$ removal and showed that the reemission of adsorbed $\mathrm{Hg}$ on $\mathrm{TiO} 2$ surface caused by $\mathrm{H}_{2} \mathrm{O}$ competition for active sites was markedly inhibited by $\mathrm{N}$ modification, possibly due to the strong bonding between $\mathrm{Hg}, \mathrm{N}$, and $\mathrm{O}$ groups.

\subsubsection{Effects of $\mathrm{O}_{2}$}

The results of Hsi (2012) and Tsai (2011 and 2012a) using two kinds of oxygen-vacant $\mathrm{TiO}_{2-\mathrm{x}}$ nanoparticles and a kind of $\mathrm{TiO}_{2-\mathrm{x}} / \mathrm{ACF}$ composite with UV and visible light irradiation, respectively, showed that the presence of $\mathrm{O}_{2}$ enhanced $\mathrm{Hg}^{0}$ removal. Tsai et al. 2013 found that $\mathrm{Hg}$ capture was enhanced with increasing $\mathrm{O}_{2}$ concentration using $\mathrm{Cu}$-doped $\mathrm{TiO}_{2}$ photocatalyst under visible-light irradiation. The results of Yuan et al. 2012a and $2012 \mathrm{~b}$ indicated that $\mathrm{O}_{2}$ exhibited a promotional effect on $\mathrm{Hg}^{0}$ removal using $\mathrm{TiO}_{2}$-aluminum silicate fiber under UV irradiation. Chen et al. 2014 also obtained similar results in studying the photocatalytic removal of $\mathrm{Hg}^{0}$ using N-doped $\mathrm{TiO}_{2}$ under UV and visible-light irradiation. Related results (His et al. 2012; Yuan et al. 2012d; Li et al. 2006) also showed that the promotional effect of $\mathrm{O}_{2}$ on photocatalytic removal of $\mathrm{Hg}^{0}$ was mainly attributed to the formation of lattice oxygen and the enhancement of catalytic oxidation. 


\subsubsection{Effects of $\mathrm{SO}_{2}$}

$\mathrm{Li}$ et al. 2007 and 2008 studied the effect of $\mathrm{SO}_{2}$ on $\mathrm{Hg}^{0}$ removal using $\mathrm{SiO}_{2}-\mathrm{TiO}_{2}$ composite with UV irradiation showed that $\mathrm{SO}_{2}$ promoted the oxidation of $\mathrm{Hg}^{0}$ to $\mathrm{Hg}^{2+}$, resulting in a higher $\mathrm{Hg}^{0}$ removal efficiency. Yuan et al. 2012a, 2012d and 2012e also tested the effects of $\mathrm{SO}_{2}$ on $\mathrm{Hg}^{0}$ removal using $\mathrm{TiO}_{2}$-aluminum silicate fiber with UV irradiation, and also found that $\mathrm{SO}_{2}$ had a promotional effect on $\mathrm{Hg}^{0}$ oxidation. The results of Chen et al. 2014 using $\mathrm{N}$-doped $\mathrm{TiO}_{2}$ under $\mathrm{UV}$ and visible-light irradiation, showed that $\mathrm{SO}_{2}$ had a negative impact $\mathrm{Hg}^{0}$ removal Lee et al. 2004 and Cho et al. 2012 also obtained similar negative results in studying $\mathrm{TiO}_{2}$ photocatalytic removal of $\mathrm{Hg}^{0}$ using UV and household fluorescent lighting irradiation, respectively. However, Zhuang et al. 2014 obtained a more complex result which showed that low concentrations of $\mathrm{SO}_{2}$ had almost no effect on $\mathrm{Hg}^{0}$ oxidation, but high concentrations of $\mathrm{SO}_{2}$ reduced $\mathrm{Hg}^{0}$ oxidation when using carbon modified $\mathrm{TiO}_{2}$ nanotubes under irradiation of visible-light LED. The multiple effects of $\mathrm{SO}_{2}$ on photocatalytic removal of $\mathrm{Hg}^{0}$ are attributed mainly to two factors. On the one hand, the presence of appropriate $\mathrm{SO}_{2}$ may enhance $\mathrm{Hg}^{2+}$ transform into more stable $\mathrm{HgSO}_{4}$, which can effectively suppress $\mathrm{Hg}$ reemission from the $\mathrm{TiO}_{2}$ surface (Yuan et al. 2012b; Li et al. 2007; Li et al. 2008; Yuan et al. 2012e). However, on the other hand, the presence of excess $\mathrm{SO}_{2}$ may substantially consume $\mathrm{O}_{2}{ }^{-}$and $\cdot \mathrm{OH}$ and occupy the active sites on $\mathrm{TiO}_{2}$ surface by competing with $\mathrm{Hg}^{0}$ (Suriyawong et al. 2009; Zhuang et al. 2014; Chen et al. 2014; Cho et al. 2012), thereby reducing removal of $\mathrm{Hg}^{0}$. The impact of $\mathrm{SO}_{2}$ on $\mathrm{Hg}^{0}$ oxidation will show different results depending on the experimental conditions and reaction systems.

\subsubsection{Effects of NO}

$\mathrm{Li}$ et al. 2007 and 2008 examined the effects of $\mathrm{NO}$ on $\mathrm{Hg}^{0}$ removal using $\mathrm{SiO}_{2}-\mathrm{TiO}_{2}$ composite with $\mathrm{UV}$ irradiation, and showed that NO had a dramatic inhibitory effect on $\mathrm{Hg}^{0}$ removal. Also, Yuan et al. 2012a and 2012e, Chen et al. 2014, Zhuang et al. 2014 and Cho et al. 2012 found that NO inhibited $\mathrm{Hg}^{0}$ removal using 
1058

1059

1060

1061

1062

1063

1064

1065

1066

1067

1068

1069

1070

1071

1072

1073

1074

1075

1076

$\mathrm{TiO}_{2}$-aluminum silicate fiber, $\mathrm{N}$-doped $\mathrm{TiO}_{2}$, carbon modified $\mathrm{TiO}_{2}$ nanotubes and $\mathrm{TiO}_{2}$-coated glass beads under UV-light, visible-light, visible-light LED and household fluorescent lighting irradiation, respectively. Other researchers (Zhuang et al. 2014; Chen et al. 2014; Li et al. 2007 and 2008; Cho et al. 2012; Yuan et al. 2012e) suggested that the negative effect of NO on photocatalytic removal of $\mathrm{Hg}^{0}$ should be attributed to NO occupying the adsorption sites on $\mathrm{TiO}_{2}$ surface and consuming $\mathrm{O}_{2}^{-} \cdot$ and $\cdot \mathrm{OH}$ free radicals by competing with $\mathrm{Hg}^{0}$.

\subsubsection{Effects of other components such as $\mathrm{HCl}$ and $\mathrm{NO}_{2}$}

$\mathrm{HCl}$ and $\mathrm{NO}_{2}$ are also widely present in the actual coal-fired flue gas (Granite et al. 2002), and have been shown to have significant impacts on $\mathrm{Hg}^{0}$ oxidation in other combustion chemistry fields (Hou et al. 2014; Tan et al. 2010; Ko et al. 2008). Cho et al. 2012 studied the effects of $\mathrm{HCl}$ on the photocatalytic removal of $\mathrm{Hg}^{0}$ using $\mathrm{TiO}_{2}$-coated glass beads under household fluorescent lighting irradiation, and they found that $\mathrm{Hg}^{0}$ removal efficiency slightly decreased with increasing $\mathrm{HCl}$ concentration from $30 \mathrm{ppm}$ to $120 \mathrm{ppm}$. The results of Chen et al. 2014 indicated that $\mathrm{HCl}$ also had a negative impact on $\mathrm{Hg}^{0}$ removal using $\mathrm{N}$-doped $\mathrm{TiO}_{2}$ under $\mathrm{UV}$ and visible-light irradiation. $\mathrm{Li}$ et al. 2007 and 2008 examined the effects of $\mathrm{HCl}$ and $\mathrm{NO}_{2}$ on $\mathrm{Hg}^{0}$ removal using

$\mathrm{SiO}_{2}-\mathrm{TiO}_{2}$ composite with UV irradiation and determined that $\mathrm{NO}_{2}$ had no significant effect on $\mathrm{Hg}^{0}$ removal, while $\mathrm{HCl}$ promoted $\mathrm{Hg}^{0}$ removal. The dual effects of $\mathrm{HCl}$ were attributed mainly to two phenomena (Chen et al. 2014; $\mathrm{Li}$ et al. 2007 and 2008; Cho et al. 2012): (1) $\mathrm{HCl}$ can occupy the adsorption sites on $\mathrm{TiO}_{2}$ surface and consume $\mathrm{O}_{2}^{-}$. and $\cdot \mathrm{OH}$ free radicals; (2) $\mathrm{HCl}$ can effectively promote the heterogeneous catalytic oxidation of $\mathrm{Hg}^{0}$, which has been widely reported by in many studies (Hou et al. 2014; Tan et al. 2010; Ko et al. 2008).

\subsection{Effects of process parameters on $\mathrm{Hg}^{0}$ removal using $\mathrm{TiO}_{2}$ photocatalytic $\mathrm{AOTs}$}

\subsubsection{Effects of calcination temperature}

Calcination temperature often has a significant influence on physical and chemical properties of adsorbent/ catalyst, as widely reported in the field of catalysis and adsorption (Yang et al. 2007; Gao et al. 2011). Lee and his 
1080

1081 1082

group (2006) examined the effects of calcination temperature for the photocatalytic activity and the ability of in situ generated $\mathrm{TiO}_{2}$ to capture $\mathrm{Hg}^{0}$ under UV irradiation. The results showed that $\mathrm{Hg}^{0}$ capture efficiencies for $\mathrm{TiO}_{2}$ particles generated at $500^{\circ} \mathrm{C}, 650^{\circ} \mathrm{C}, 750^{\circ} \mathrm{C}, 850^{\circ} \mathrm{C}$ and $1000^{\circ} \mathrm{C}$ were $3.3 \%, 14.2 \%, 25.3 \%, 41.4 \%$, and $62.5 \%$, respectively. It was found that $\mathrm{Hg}^{0}$ capture efficiency increased with increasing calcination temperature. It was suggested that, with increasing calcination temperature, the overall $\mathrm{TiO}_{2}$ aggregate size increased, which made $\mathrm{TiO}_{2}$ become more open-structured, resulting in easier access to $\mathrm{Hg}^{0}$ and $\mathrm{UV}$ light, and subsequently leading to an improved $\mathrm{Hg}^{0}$ capture (Lee et al. 2006). It has also been demonstrated that the anatase phase in $\mathrm{TiO}_{2}$ was the preferred crystalline for photocatalytic reaction because of its more excellent photocatalytic capability as compared to rutile phase (Lee et al. 2010; Kumar et al. 2011). Yuang et al. 2012d and 2012e tested the effects of calcination temperature on photocatalytic activity of $\mathrm{TiO}_{2}$-aluminum silicate fiber for capturing $\mathrm{Hg}^{0}$ in flue gas under UV irradiation by detecting the changes in anatase and rutile contents. It was observed that the anatase was the exclusive phase of $\mathrm{TiO}_{2}$ at calcination temperature below $500^{\circ} \mathrm{C}$. However, the anatase phase turned gradually into the rutile phase when calcination temperature further increased, resulting a lower $\mathrm{Hg}^{0}$ capture efficiency. Zhuang et al. 2014 also studied the effects of calcination temperature in the $200-500^{\circ} \mathrm{C}$ range on $\mathrm{Hg}^{0} \mathrm{removal}$ using carbon modified titanium dioxide nanotubes under visible-light LED irradiation, and found that, the catalyst calcinated at $300^{\circ} \mathrm{C}$ exhibited the best photocatalytic activity, with $90 \% \mathrm{Hg}^{0}$ oxidation capability in a long time light-on test. The superior activity of the catalyst calcinated at $300^{\circ} \mathrm{C}$ was ascribed to the expanded light adsorption spectrum resulting from carbon doping, the high surface area and the well sustained structure of the nanotubes (Zhuang et al. 2014).

Wang et al. 2011 tested the effects of calcination temperature in the $0-600^{\circ} \mathrm{C}$ on $\mathrm{Hg}^{0}$ removal using titania nanotubes (TNTs) under UV irradiation, and showed that the catalyst calcinated at $500^{\circ} \mathrm{C}$ exhibited the best removal performance for $\mathrm{Hg}^{0}$. The results of XRD patterns of the calcined TNTs showed that anatase crystals 
were few in the original nanotubes, and could not be formed at $300^{\circ} \mathrm{C}$, but were formed and enlarged at $400^{\circ} \mathrm{C}$ and $500^{\circ} \mathrm{C}$, enhancing photocatalytic activity. However, with further increase in calcination temperature to $600^{\circ} \mathrm{C}$, the nanotubes were completely transformed to rodlike particles, indicating the sintering of tubes, greatly reducing photocatalytic activity. Yang et al. 2009 also tested the removal performance of $\mathrm{Hg}^{0}$ using $\mathrm{TiO}_{2}-\mathrm{AC}$ and $\mathrm{TiO}_{2}$-fiber with UV irradiation at $500^{\circ} \mathrm{C}$ and $700^{\circ} \mathrm{C}$, found that the catalyst calcined at $500^{\circ} \mathrm{C}$ has better $\mathrm{Hg}^{0}$ removal performance than that at $700^{\circ} \mathrm{C}$. The results of XRD, SEM and BET indicated that the anatase with higher activity was observed to be the only phase of $\mathrm{TiO}_{2}$ at $500^{\circ} \mathrm{C}$, while the mixture of anatase and rutile co-existed in $\mathrm{TiO}_{2}$ at $700^{\circ} \mathrm{C}$. In addition, increasing the heat treatment temperature promoted the growth of $\mathrm{TiO}_{2}$ particles and agglomerates, destroying the nanostructures of the catalyst. The authors suggested (Yang et al. 2009) that the different results observed at $500^{\circ} \mathrm{C}$ and $700^{\circ} \mathrm{C}$ are attributable to the changes of the anatase phase contents and the properties of the nanostructures. Based on the above comments, it can be seen that calcination temperature has a very significant impact on the physical (surface and structural characteristics) and chemical (crystal type and proportion) properties of $\mathrm{TiO}_{2}$, and typically there is an optimum value.

\subsubsection{Effects of doping or coupling amount with other materials}

Based on the results of prior studies (Wu et al. 1988; Lee et al. 2001; Chen et al. 2007; Asahi et al. 2001; Diwald et al. 2004; Zhang et al. 2011; Yuan et al. 2012d) and as indicated earlier, the doped $\mathrm{TiO}_{2}$ using other materials can broaden the absorption range of light and enhance the quantum efficiency by inhibiting the fast recombination of the photogenerated electrons and holes. Related studies (Wu et al. 1988; Lee et al. 2001; Chen et al. 2007; Zhang et al. 2011; Yuan et al. 2012d) have demonstrated that the concentration of dopant substantially influenced the $\mathrm{TiO}_{2}$ photocatalytic activity. Yuan et al. 2012b prepared $\mathrm{TiO}_{2}-\mathrm{WO}_{3}$ nanofibers by electrospinning method and examined the effects of doping content of $\mathrm{WO}_{3}$ on $\mathrm{Hg}^{0}$ capture. The results indicated that the UV-Vis absorption intensity, specific surface area and pore volume of $\mathrm{TiO}_{2}-\mathrm{WO}_{3}$ nanofibers significantly increased with 
increasing $\mathrm{WO}_{3}$ doping content, compared to the pure $\mathrm{TiO}_{2}$. As a result, $\mathrm{Hg}^{0}$ removal efficiency was also greatly improved by doping $\mathrm{WO}_{3}$, up to $100 \%$ at a doping content of $7 \mathrm{wt} \% \mathrm{WO}_{3}$. Tsai et al. 2012 examined the effects of $\mathrm{Al}_{2} \mathrm{O}_{3} / \mathrm{Ti}$ mass ratios (0 to 0.5 ) on $\mathrm{Hg}^{0}$ capture using $\mathrm{Al}$-doped $\mathrm{TiO}_{2}$ nanoparticles under visible-light (VL) irradiation, and their results indicated that the absorption spectra of the nanoparticles shifted towards the visible light region with doping $\mathrm{Al}$, and showed a strong absorption in visible light range at the doping ratio of $\mathrm{Al}_{2} \mathrm{O}_{3} / \mathrm{Ti}=$ 0.5. Tsai et al. 2013 examined the effects of doping $\mathrm{Cu}$ content in the range of $0-5 \mathrm{wt} \% \mathrm{Cu} /\left(\mathrm{Cu}+\mathrm{TiO}_{2}\right)$ mass ratios on $\mathrm{Hg}^{0}$ removal using $\mathrm{Cu}$-doped $\mathrm{TiO}_{2}$ nanoparticles under visible-light, and they found that the crystal structure of the formed nanoparticles primarily consisted of anatase and rutile, but the mass fraction of anatase decreased with increasing doping $\mathrm{Cu}$ content. The result of UV-Vis spectrum indicated that the absorption wavelength extended to the visible light range with the addition of $\mathrm{Cu}$, and $5 \mathrm{wt} \%$ was found to be the optimal doping content. Pitoniak et al. 2003 tested the effects of $\mathrm{TiO}_{2}$ loading mass on $\mathrm{Hg}^{0}$ removal using $\mathrm{SiO}_{2}-\mathrm{TiO}_{2}$ composite, and they found that $13 \mathrm{wt} \% \mathrm{TiO}_{2}$ showed the best performance. Fang et al. 2010 examined the effects of $\mathrm{TiO}_{2}$ loading mass using $\mathrm{TiO}_{2} /$ coal fly ash, indicating that the loading of $3 \% \mathrm{TiO}_{2}$ on coal fly ash achieved the highest $\mathrm{Hg}^{0}$ removal efficiency.

\subsubsection{Effects of light sources}

Light source is regarded as one of three essential elements of a photocatalytic process (other two are photocatalyst and photoreactor), which not only affects photocatalytic efficiency, but also dominates energy consumption and cost of system (Worathanakul et al. 2008). Related studies (Worathanakul et al. 2008) showed that $\mathrm{Hg}^{0}$ removal using $\mathrm{TiO}_{2}$ photocatalysis was significantly affected by the light sources. Lee et al. 2004 investigated $\mathrm{Hg}^{0}$ removal by $\mathrm{TiO}_{2}$ photocatalysis using various light sources, including UV black light, UV sterilizing light, fluorescent light and the blue light, and their results showed that for the three types of commercially available $\mathrm{TiO}_{2}$, more than $99 \%$ of initial $\mathrm{Hg}^{0}$ was removed under all light sources tested except for 
the blue light which obtained only $85 \% \mathrm{Hg}^{0}$ removal efficiency. Yuan et al. 2012b and 2012d examined the effects of different light sources (visible light and UV light) using $\mathrm{TiO}_{2}-\mathrm{WO}_{3}$ nanofibers reported that $\mathrm{Hg}^{0}$ removal efficiency was up to $99 \%$ with UV light, and only reached $16 \%$ with visible light. Chen et al. 2014 and Hsi et al. 2012 also found that UV light had a better $\mathrm{Hg}^{0}$ removal performance than visible light using $\mathrm{N}$-doped $\mathrm{TiO}_{2}$ nanoparticles and $\mathrm{TiO}_{2-\mathrm{x}} / \mathrm{ACF}$ composites. It can be deduced from these results that UV light has a more favorable effect than the other light sources for photocatalytic removal of $\mathrm{Hg}^{0}$ because of its greater quantum energy. However, it's also worth noting that the other light sources such as visible light, accounts for about $43 \%$ of all sunlight (Kumar et al. 2011), and thus has much greater application prospects as compared to the UV light, which accounts for 5\% (Kumar et al. 2011).

\subsubsection{Effects of operating temperature}

Temperature often has an important impact for both chemical reaction and adsorption (Yang et al. 2007; Gao et al. 2013). Hsi et al. 2012 tested the effects of three operating temperatures, $25 / 50 / 100^{\circ} \mathrm{C}$, on $\mathrm{Hg}^{0}$ removal performance using oxygen-vacant $\mathrm{TiO}_{2-\mathrm{x}}$ nanoparticles under UV and visible light irradiations, respectively, and their results indicated that $\mathrm{Hg}^{0}$ removal performance at $50^{\circ} \mathrm{C}$ was better than those at $25^{\circ} \mathrm{C}$ and $100^{\circ} \mathrm{C}$. Yuan et al. 2012e also studied the effects of operating temperature on $\mathrm{Hg}^{0}$ removal using $\mathrm{TiO}_{2}$-aluminum silicate fiber with UV irradiation, and they found that with increasing temperature from $30^{\circ} \mathrm{C}$ to $120^{\circ} \mathrm{C}, \mathrm{Hg}^{0}$ removal efficiency reduced from $93 \%$ to $79 \%$. Chen et al. 2014 also found that increasing temperature decreased $\mathrm{Hg}^{0}$ removal effciency using $\mathrm{N}$-doped $\mathrm{TiO}_{2}$ nanoparticles under dark, UV light and visible light. Results of other studies (Chen et al. 2014; Yuan et al. 2012d; Yuan et al. 2012e) showed that increasing temperature can promote the reaction rate of $\mathrm{Hg}^{0}$ oxidation in accordance with Arrhenius equation, but will also negatively impact the adsorption process of involving $\mathrm{Hg}^{0}$ because of its exothermic nature (Chen et al. 2014).

\subsubsection{Effects of residence time}


Residence time is a key parameter for photocatalytic process and the design of photocatalytic reactor.

1169

Pitoniak et al. 2003 tested the effects of residence time on $\mathrm{Hg}^{0}$ removal using $\mathrm{SiO}_{2}-\mathrm{TiO}_{2}$ composite under UV irradiation, and they found that $\mathrm{Hg}^{0}$ removal efficiency drastically with decreasing residence time. The results of Cho et al. 2012 showed that $\mathrm{TiO}_{2}$ photocatalytic removal of $\mathrm{Hg}^{0}$ using household fluorescent lighting was improved by increasing residence time. Zhuang et al. 2014 also studied the effects of residence time on $\mathrm{Hg}^{0}$ removal using $\mathrm{C}$-modified $\mathrm{TiO}_{2}$ nanotubes under visible-light $\mathrm{LED}$ irradiation, and their results indicated that with increasing residence time, the photocatalytic efficiency of $\mathrm{Hg}^{0}$ greatly increased to nearly $90 \%$ within $4.5 \mathrm{~s}$, beyond which there was no further enhancement. A decrease in residence time will reduce reaction time between $\mathrm{Hg}^{0}$ and oxidants, resulting in more escape of $\mathrm{Hg}^{0}$ from reactor. However, increasing residence time will require a larger reactor volume, resulting in higher investment and operating costs. The choice of a cost-effective residence time requires joint consideration of both factors.

\subsubsection{Effects of other operating parameters}

In addition to the effects of the operating parameters described previously, Pitoniak et al. 2003 also tested the impact of gas flow on $\mathrm{Hg}^{0}$ removal using $\mathrm{SiO}_{2}-\mathrm{TiO}_{2}$ composite under UV irradiation, and it to drastically decrease efficiency with increasing gas flow. Lee et al. 2009 studied the effect of $\mathrm{TiO}_{2}$ feed rate on $\mathrm{Hg}^{0}$ capture under UV irradiation, and the results showed that with increasing $\mathrm{TiO}_{2}$ feed rate, and hence a higher concentration of $\mathrm{TiO}_{2}$ and more availability of active sites, resulted in an increase in $\mathrm{Hg}^{0}$ capture efficiency. In addition, Yuan et al. 2012d and 2012e investigated the effect of UV intensity on $\mathrm{Hg}^{0}$ removal using $\mathrm{TiO}_{2}$-aluminum silicate fiber with UV irradiation, and the results indicated that UV irradiation was critical to the successful oxidation of $\mathrm{Hg}^{0}$, and with the decrease of UV intensity, photocatalytic oxidation efficiency for $\mathrm{Hg}^{0}$ evidently reduced due to the reduction of photoexcited active species. In addition, Hsi (2012) and Tsai $(2011,2012)$ synthesized oxygen-vacant $\mathrm{TiO}_{2-\mathrm{x}}$ nanoparticles and $\mathrm{TiO}_{2-\mathrm{x}} / \mathrm{ACF}$ composite using $\mathrm{N}_{2} / \mathrm{Ar} / \mathrm{He}$ and $\mathrm{He} / \mathrm{Ar}$ thermal plasma as two heating sources, 
and they found that both of different applied plasma currents and atmospheres also have significant impacts on

1191 activity of these photocatalysts for $\mathrm{Hg}^{0}$ removal.

\subsection{Products, mechanism and kinetics of $\mathrm{Hg}^{0}$ removal using $\mathrm{TiO}_{2}$ photocatalytic AOTs}

\subsubsection{Products of $\mathrm{Hg}^{0}$ removal using $\mathrm{TiO}_{2}$ photocatalytic AOTs}

The products of $\mathrm{Hg}^{0}$ removal using $\mathrm{TiO}_{2}$ photocatalytic oxidation are important information for the recovery of mercury resources and avoiding new secondary mercury contamination. Wu et al. 1998 determined the reaction products of $\mathrm{Hg}^{0}$ removal by in situ-generated $\mathrm{TiO}_{2}$ with UV irradiation using the combination of XRD and electron dispersive X-ray spectroscopy (EDS). The formation of $\mathrm{HgO}$ on the collected particles as determined by

XRD is shown in Figure 15. In addition, $\mathrm{Ti}$ and $\mathrm{Hg}$ on the same particles were also further identified using EDS.

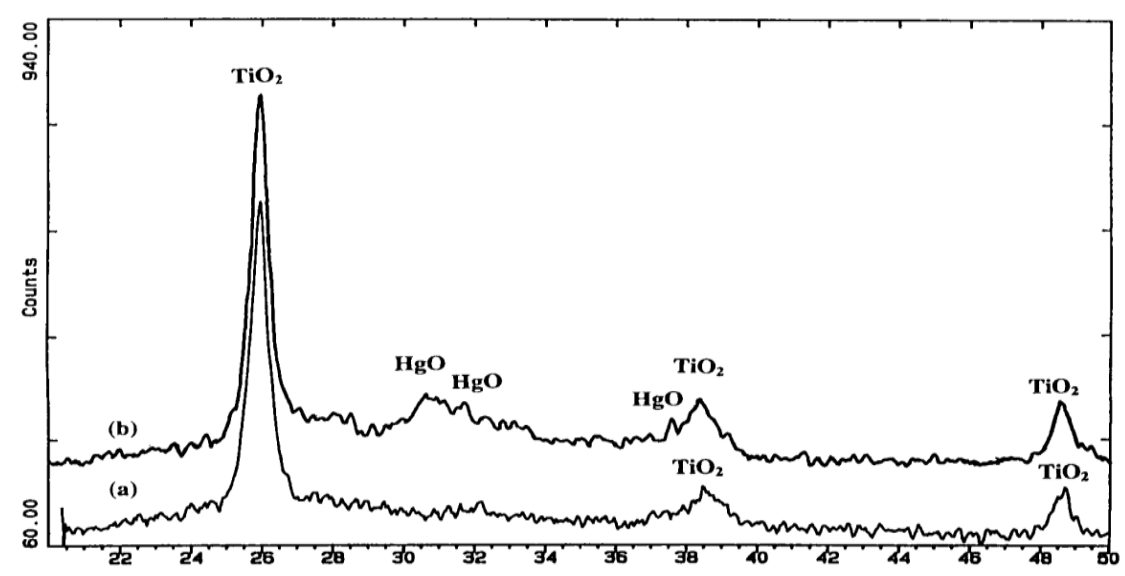

Figure 15. The X-ray diffraction patterns of the collected particles (Wu et al. 1998).

Using SEM and EDS, Snider et al. 2010 detected lightly white mercury deposits on the $\mathrm{TiO}_{2}$ particles as reaction products under UVA-irradiated $\mathrm{TiO}_{2}$ as illustrated in Figure 16 (a). Ti and $\mathrm{Hg}$ on the $\mathrm{TiO}_{2}$ particles were also detected by EDS as shown in Figure 16 (b). Pitoniak et al. 2003 and Yuan et al. 2012b also obtained similar results with EDS using $\mathrm{SiO}_{2}-\mathrm{TiO}_{2}$ composite and $\mathrm{TiO}_{2}-\mathrm{WO}_{3}$ nanofibers with $\mathrm{UV}$ irradiation, respectively. 

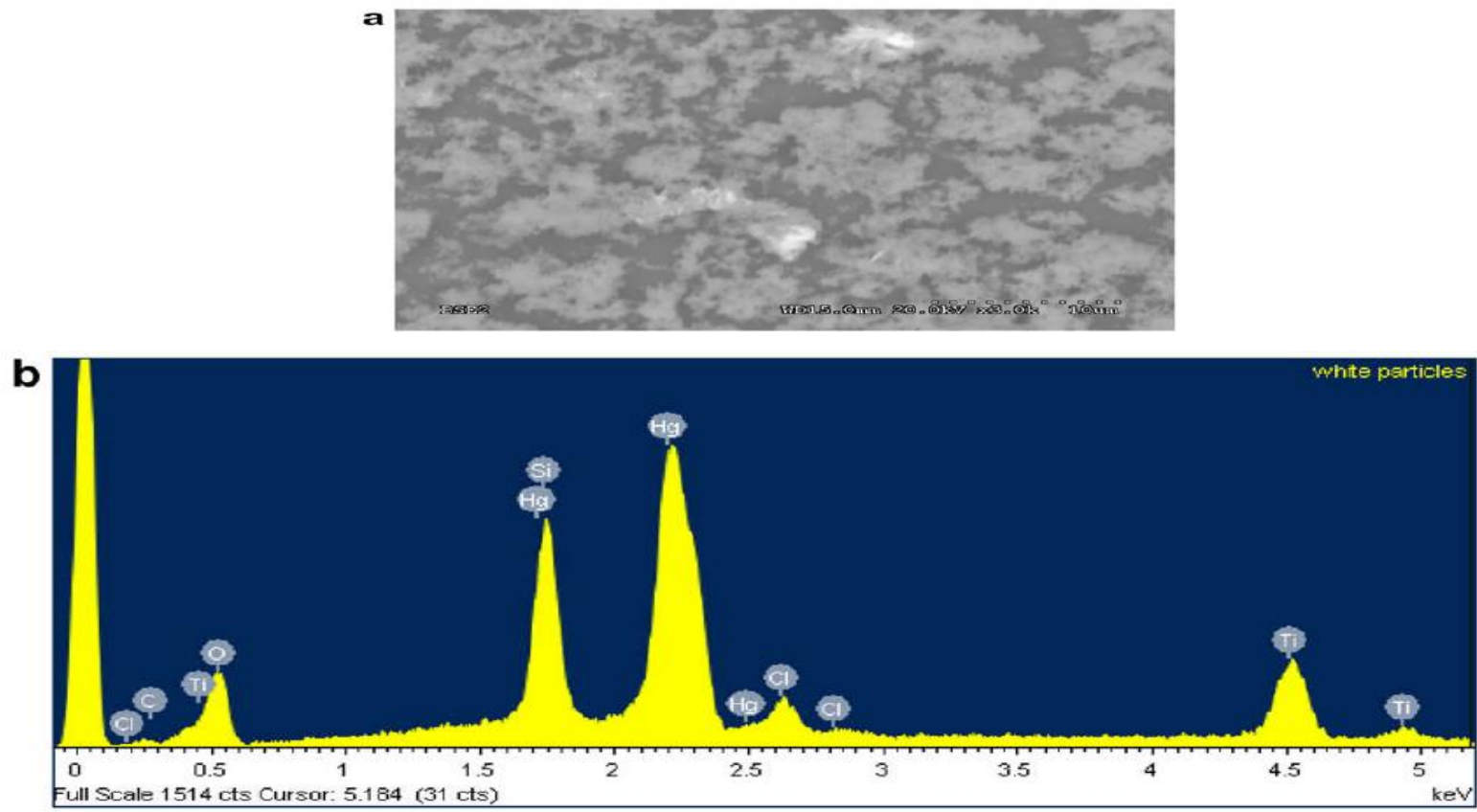

Figure 16. (a) SEM image (3000×magnification) of $\mathrm{TiO}_{2}$ displaying white paches and (b) EDS of marked area shows the presence of Ti and Hg (Snider et al. 2010). photocatalyst surface.
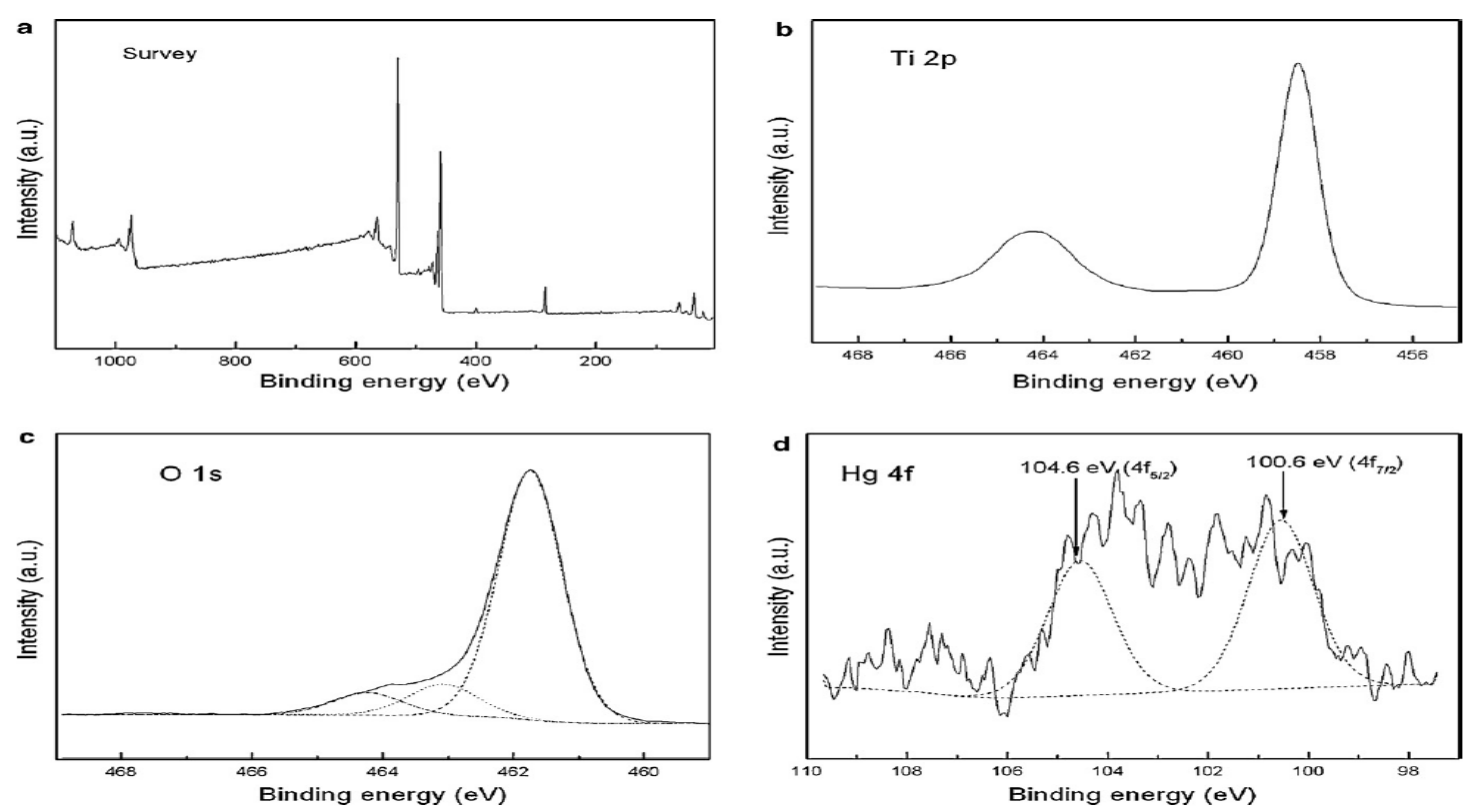

1214 Figure 17. XPS spectra of the used TNTs (a. survey spectra; b. Ti2p band; c. O1s band; d. Hg4f band) (Wang et al. 
While reported studies have focused on the analysis of reaction products on catalyst/adsorbed surfaces, 1217 analysis and verification of gaseous reaction products of $\mathrm{Hg}^{0}$ removal are rarely reported. Furthermore, the mass 1218 balance calculations for total $\mathrm{Hg}$, which are also important for elucidating $\mathrm{Hg}^{0}$ removal mechanism, recovery of 1219 mercury resources as well as avoiding new secondary contamination, are still missing in the open literature, and require serious attention in future studies.

\subsubsection{Removal mechanism of $\mathrm{Hg}^{0}$ using $\mathrm{TiO}_{2}$ photocatalytic AOTs}

situ-generated $\mathrm{TiO}_{2}$ and $\mathrm{SiO}_{2}-\mathrm{TiO}_{2}$ nanocomposite with $\mathrm{UV}$ irradiation identified three essential processes as the 


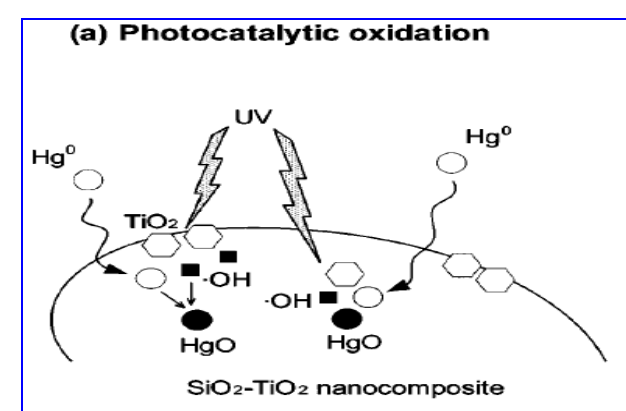

(c) Desorption

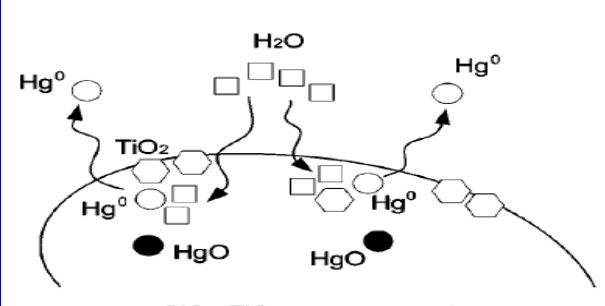

$\mathrm{SiO}_{2}-\mathrm{TiO}_{2}$ nanocomposite

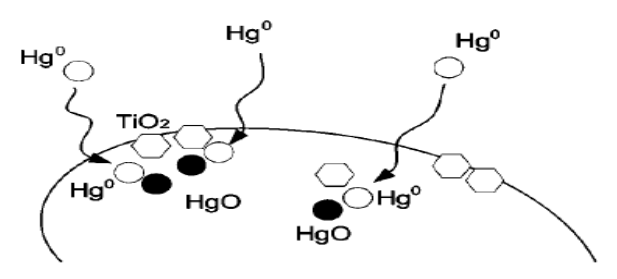

$\mathrm{SiO}_{2}-\mathrm{TiO}_{2}$ nanocomposite

(d) Photocatalytic reduction

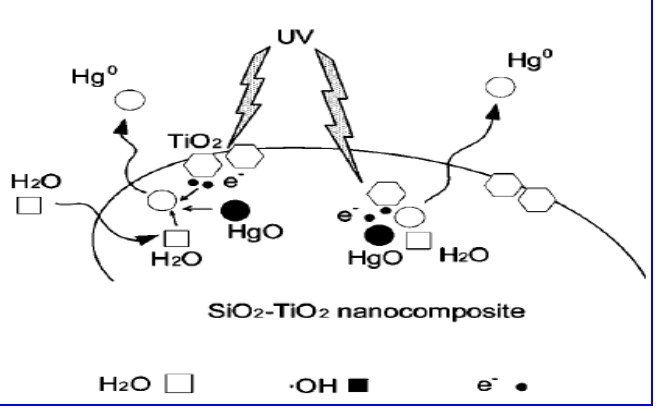

1233 Figure 18. Mechanisms of $\mathrm{Hg}^{0}$ capture and reemission on the surface of $\mathrm{SiO}_{2}-\mathrm{TiO}_{2}$ nanocomposite (Pitoniak et al. 1234 2003).

Table 5. $\mathrm{TiO}_{2}$ photocatalytic mechanism and scheme for removal of $\mathrm{Hg}^{0}$ in flue gas.

\begin{tabular}{ll}
\hline Overall removal process & Specific adsorption and chemical reaction \\
\hline Adsorption process & $\mathrm{TiO}_{2}(s)+\mathrm{O}_{2}(g) \rightarrow \mathrm{O}_{2, \text { ads }}(s) \quad\left(\right.$ adsorbed $\left.\mathrm{O}_{2}\right)$ \\
& $\mathrm{TiO}_{2}(s)+\mathrm{H}_{2} \mathrm{O}(g) \rightarrow \mathrm{H}_{2} \mathrm{O}_{\text {ads }}(s)$ (adsorbed $\left.\mathrm{H}_{2} \mathrm{O}\right)$ \\
& $\mathrm{TiO}_{2}(s)+\mathrm{Hg}^{0}(g) \rightarrow \mathrm{Hg}_{\text {ads }}^{0}(s) \quad\left(\right.$ adsorbed $\left.\mathrm{Hg}^{0}\right)$ \\
& $\mathrm{TiO}_{2}(s)+\mathrm{OH}^{-}(g) \rightarrow \mathrm{OH}_{\text {ads }}^{-}(s) \quad$ (adsorbed $\left.\mathrm{OH}^{-}\right)$ \\
Excitation process & $\mathrm{TiO}_{2}(s)+\mathrm{hv}^{-} \rightarrow \mathrm{e}^{-}+\mathrm{h}^{+}$ \\
Recombination process & $\mathrm{e}^{-}+\mathrm{h}^{+} \rightarrow \mathrm{heat}$ \\
Trapping process & $\mathrm{e}^{-}+\mathrm{O}_{2, \text { ads }}(s) \rightarrow \mathrm{O}_{2}^{-} \cdot(\mathrm{s})$ \\
& $\mathrm{h}^{+}+\mathrm{H}_{2} \mathrm{O}_{\text {ads }}(s) \rightarrow \cdot \mathrm{OH}(s)+\mathrm{H}^{+}(s)$ \\
& $\mathrm{h}^{+}+\mathrm{OH}_{\text {ads }}(s) \rightarrow \cdot \mathrm{OH}(\mathrm{s})$
\end{tabular}


Chain reaction transfer

$$
\begin{aligned}
& \mathrm{O}_{2}^{-} \cdot(\mathrm{s})+\mathrm{H}^{+}(\mathrm{s}) \rightarrow \mathrm{HO}_{2} \cdot(\mathrm{s}) \\
& \mathrm{HO}_{2} \cdot(\mathrm{s})+\mathrm{HO}_{2} \cdot(\mathrm{s}) \rightarrow \mathrm{H}_{2} \mathrm{O}_{2}(\mathrm{~s})+\mathrm{O}_{2}(\mathrm{~s}) \\
& \mathrm{H}_{2} \mathrm{O}_{2}(\mathrm{~s})+\mathrm{e}^{-} \rightarrow \cdot \mathrm{OH}(\mathrm{s})+\mathrm{OH}^{-}(\mathrm{s})
\end{aligned}
$$

Hydroxy attack process

$$
\begin{aligned}
& \mathrm{Hg}_{\text {ads }}^{0}(\mathrm{~s})+\cdot \mathrm{OH}(\mathrm{s}) \rightarrow \mathrm{HgOH}(\mathrm{s}) \\
& \mathrm{HgOH}(\mathrm{s})+\cdot \mathrm{OH}(\mathrm{s}) \rightarrow \mathrm{HgO}(\mathrm{s})+\mathrm{H}_{2}(\mathrm{~s}) \\
& \mathrm{HgOH}(\mathrm{s}) \rightarrow \mathrm{HgO}(\mathrm{s})+\mathrm{H}^{+}(\mathrm{s}) \\
& \mathrm{O}_{2}^{-} \cdot(\mathrm{s})+\mathrm{Hg}^{0}(\mathrm{~s}) \rightarrow \mathrm{HgO}(\mathrm{s})
\end{aligned}
$$

$\mathrm{Hg}^{0}$ reemission

$$
\mathrm{HgO}(\mathrm{s})+\mathrm{H}_{2} \mathrm{O}(\mathrm{s})+2 \mathrm{e}^{-} \rightarrow \mathrm{Hg}^{0}(\mathrm{~g})+2 \mathrm{OH}^{-}(\mathrm{s})
$$

much of what we know are derived from research results of other fields, and the key reaction pathways or main identification of some key reactive intermediates or radicals in the photocatalytic $\mathrm{Hg}^{0}$ removal process are still rarely reported. generated $\mathrm{TiO}_{2}$ in differential bed and entrained flow systems. The results showed that the overall reaction orders with respect to the gaseous $\mathrm{Hg}^{0}$ concentration and the UV intensity were found to be $1.4 \pm 0.1$ and $0.35 \pm 0.05$ for

\subsubsection{Kinetics of $\mathrm{Hg}^{0}$ removal using $\mathrm{TiO}_{2}$ photocatalytic AOTs}

Kinetic constants and kinetic models are the important basis for the optimization of adsorbent/catalyst, and the design of reactor. The kinetics of $\mathrm{Hg}^{0}$ removal using $\mathrm{TiO}_{2}$ photocatalytic oxidation was studied by several researchers (Yuanet al. 2012d; Snider et al. 2010; Lee et al. 2004; Rodri'guez et al. 2004; Li et al. 2007; Snider et al. 2012), and preliminary results reported. Lee et al. 2004 investigated the kinetics of $\mathrm{Hg}^{0}$ removal using in situ the differential bed reactor, whereas the two values were $1.1 \pm 0.1$ and 0.39 for the aerosol flow reactor. At the 
low-temperature range $\left(<80^{\circ} \mathrm{C}\right), \mathrm{Hg}^{0}$ removal was found to be a reaction-controlled process, while it was

adsorption-controlled process at the higher temperatures $\left(>110^{\circ} \mathrm{C}\right)$. Rodríguez et al. 2004 developed a mechanistic model to predict $\mathrm{Hg}$ oxidation rate on $\mathrm{TiO}_{2}$ surfaces with UV irradiation. The results showed that the model agreed well with experimental data for $\mathrm{Hg}$ capture rate and could effectively predict the effects of process parameters on $\mathrm{Hg}$ oxidation rate. $\mathrm{Li}$ et al. 2007 studied the kinetics using $\mathrm{SiO}_{2}-\mathrm{TiO}_{2}$ nanocomposite with $\mathrm{UV}$ irradiation in a fix-bed reactor. A Langmuir-Hinshelwood (L-H) model was used to analyze the kinetic data with a good agreement, indicating the validity of using the $\mathrm{L}-\mathrm{H}$ model to describe the kinetic process of $\mathrm{Hg}^{0}$ photocatalytic oxidation removal. Based on the L-H theory, Yuan et al. 2012d also established an L-H kinetic model of $\mathrm{Hg}^{0}$ removal using $\mathrm{WO}_{3}-\mathrm{TiO}_{2}$ nanofibers with $\mathrm{UV}$ irradiation, which also showed a good agreement with the experimental data. Snider et al. 2010 determined the L-H adsorption constant and apparent surface deposition rate kinetic parameters of $\mathrm{Hg}^{0}$ removal by UVA-irradiated $\mathrm{TiO}_{2}$ to be $\mathrm{K}_{\mathrm{Hg}}=(5.1 \pm 2.4) \times 10^{-14} \mathrm{~cm}^{3}$ and $\mathrm{k}=(7.4 \pm$ 2.5) $\times 10^{14} \mathrm{~min}^{-1} \mathrm{~cm}^{-2}$. Also, Snider et al. 2012 further determined the second-order rate constant of the gas-phase reaction of $\mathrm{NO}_{2}$ with $\mathrm{Hg}^{0}$ using $\mathrm{UVA}$-irradiated $\mathrm{TiO}_{2}$ to be $(3.5 \pm 0.5) \times 10^{-35} \mathrm{~cm}^{3}$.

\subsection{Reactor and process flow of $\mathrm{Hg}^{0}$ removal using $\mathrm{TiO}_{2}$ photocatalytic AOTs}

\subsubsection{Reactor of $\mathrm{Hg}^{0}$ removal using $\mathrm{TiO}_{2}$ photocatalytic AOTs}

Photocatalytic reactor type, photocatalyst and light source are three essential elements for a photocatalytic reaction system. An efficient photocatalytic reactor is extremely important for improving pollutant removal efficiency, increasing energy efficiency as well as reducing investment and operating costs. In recent years, a variety of photocatalytic reactors have been developed in flue gas purification field (Lee et al. 2010; Daghrir et al. 2013; Kumar et al. 2011; Worathanakul et al. 2008; Linsebigler et al. 1995; Kwon et al. 2008; Suriyawong et al. 2009), but the most commonly used include mainly the four types described in Figure 19 (a)-(d). The two reactors in Figure 19 (a) and (b) consist of a container and UV lamps, separately. The number of UV lamp may be changed 
from one to multiple according to the needs of the experiment. The reactor shell is often composed of glass (usually quartz glass) with high light transmission because UV-light has very low penetration ability in the vast majority of the mediums (Breault et al. 2006). To maximize the photocatalyst's exposure to the light source, the reactor in Figure 9(a) was sometimes also designed as a rotary structure (Lee et al. 2004; Lee et al. 2005). These reactors are the most widely used in laboratory research due to their simple structure and easy operation. However, it is difficult for them to realize large-scale applications due to the low utilization rate of light energy and the structural limitations of scale-up. The two photocatalytic reactors with built-in structure (Figure 19 (c) and (d)) are considered to have better developmental prospects because both of them are able to fully utilize UV light and easily realize amplification. The photocatalytic fixed bed reactor shown in Figure 19 (c), has received a wide range of applications in laboratory research due to its simple structure and easy operation. However, such reactors have several shortcomings such as low adsorption or mass transfer rate, small light irradiation surface for catalysts, easy agglomeration of catalysts, as well as poor heat transfer performance (Lee et al. 2010; Daghrir et al. 2013; Kumar et al. 2011; Fujishima et al. 1972; Kaluza et al. 1971; Wu et al. 1998; Lee et al. 2001; Worathanakul et al. 2008). Related results (Chen et al. 2014; Yuan et al. 2012b; Yuan et al. 2012d; Lee et al. 2004) have shown that the adsorption and mass transfer process, especially at high temperatures, is usually the rate-controlling step of photocatalytic removal of $\mathrm{Hg}^{0}$ in flue gas. Moreover, in the actual photocatalytic process, UV lamps often will release a lot of heat, thereby increasing the bed temperature in photocatalytic reactor. Prior studies (Kwon et al. 2008; Pitoniak et al. 2007; Chen et al. 2014; Yuan et al. 2012d; Yuan et al. 2012e) have confirmed that high temperature decreases the photocatalytic oxidation of $\mathrm{Hg}^{0}$ in flue gas, and greatly reduces the operating performance of the UV lamp (Breault et al. 2006). Thus enhancement of heat and mass transfer process is one of the most important ways to improve the photocatalytic efficiency of $\mathrm{Hg}^{0}$ removal.

Fluidized bed usually have much better heat and mass rate as compared to fixed bed, and has received 
widespread attention in many industries (Breault et al. 2006; Corella et al. 2006; Li et al. 2004; Berruti et al. 1995; Basu et al. 1999). In the field of air pollution purification, photocatalytic fluidized bed has also received considerable attention because of its excellent performances in enhancing heat and mass, improving gas-solid contact, preventing agglomeration of catalysts, as well as providing better light radiation (McCullagh et al. 2011; Geng et al. 2010; Kumazawa et al. 2003; Nelson et al. 2007; Lim et al. 2005; Satoru et al. 2005). Therefore, Figure 19 (d), may be regarded a good choice for enhancing photocatalytic removal of $\mathrm{Hg}^{0}$ in flue gas though studies using fluidized beds are yet to be reported. Related results (Chang et al. 2002; Tendero et al. 2006) showed that corona discharge process in electrostatic precipitator (ESP) could produce UV irradiation. Based on this feature of ESP, Biswas et al. 1998 and Wu et al. 1998 proposed a process of $\mathrm{Hg}^{0}$ capture using $\mathrm{TiO}_{2}$ injection in electrostatic precipitator (ESP), showing a better prospect due to its greater adsorption capacity for $\mathrm{Hg}^{0}$, lower processing costs, and potential multi-pollutants removal capability as compared to activated carbon injection technology. The related photocatalytic reactor and process flow are shown in Figure 19 (e) and Figure 20 (d), Unlike the application of UV light, if the sunlight is used as the light source of photocatalytic reaction, as shown in Figure 19 (b) and Figure 20 (c), a flat plate reactor is probably the most common structure for visible-light photocatalytic reaction. Depending on the amount of the flue gas to be treated, the flat plate reactor using sunlight may be one or more arranged in parallel. At present, for photocatalytic removal of $\mathrm{Hg}^{0}$ using visible light, the most commonly used light source is mainly an indoor simulation lamp light such as halogen lamp and xenon. Studies using sunlight is rare because of the uncertainty of climate conditions, but such a technology requires serious consideration because of its excellent prospects. 


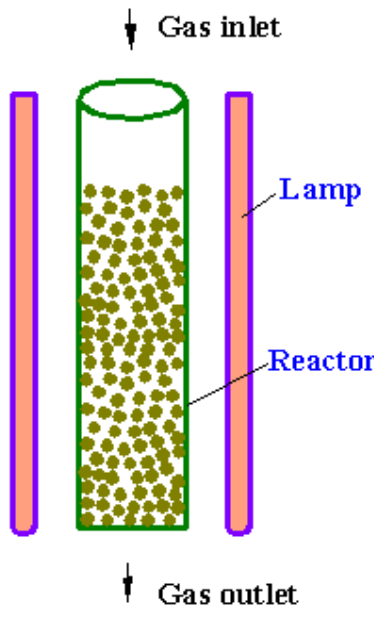

(a)

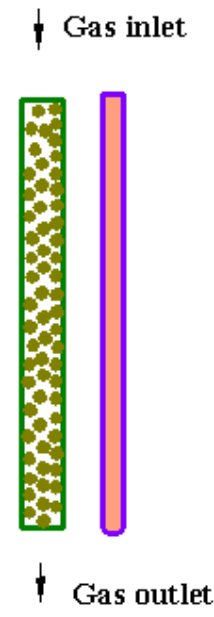

(b)

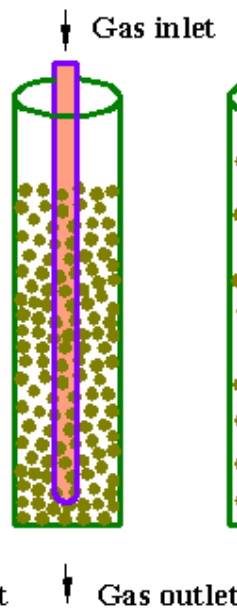

(c)

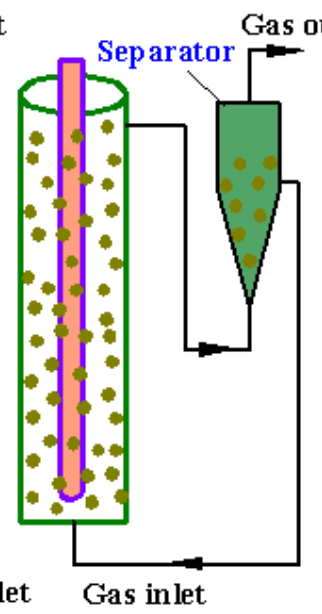

(d)

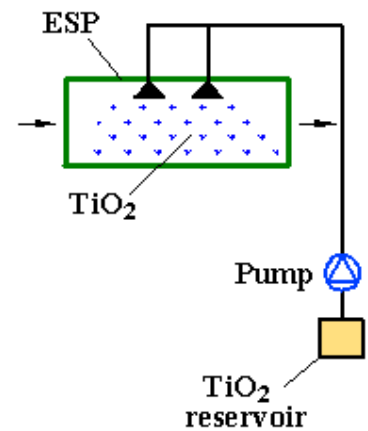

(e)
1313

Figure 19. Common and potential photocatalytic reactors for removing $\mathrm{Hg}^{0}$ from flue gas: (a) cylindrical fixed bed using external UV lamp; (b) plate-type fixed bed using external UV lamp or visible light; (c) cylindrical fixed bed using built-in UV lamp; (d) circulating fluidized bed using built-in UV lamp; (e) $\mathrm{TiO}_{2}$ injection in electrostatic precipitator (ESP).

\subsubsection{Process flow of $\mathrm{Hg}^{0}$ removal using $\mathrm{TiO}_{2}$ photocatalytic AOTs}

Related studies (Satoru et al. 2005; Zhao et al. 2008; Maggos et al. 2007; Todorova et al. 2014; Li et al. 2008; Zuo et al. 2006; Kima et al. 2002; Portela et al. 2010; Portela et al. 2012) have shown that $\mathrm{TiO}_{2}$ photocatalytic AOTs also have good removal performance for $\mathrm{SO}_{2}$ and $\mathrm{NO}_{\mathrm{x}}$ in coal-fired flue gas and VOCs and $\mathrm{H}_{2} \mathrm{~S}$ in exhaust. Simultaneous removal of multi-pollutants in flue gas has been recognized as a cost-effective control strategy for coal-fired flue gas purification (Wang et al. 2007; Hutson et al. 2008; Su et al. 2013; Adewuyi et al. 2013; Ding et al. 2014; Obradović et al. 2011). Therefore, in order to control application costs, $\mathrm{TiO}_{2}$ photocatalytic $\mathrm{AOTs}$ should also be fully considered for the simultaneous removal of $\mathrm{SO}_{2}, \mathrm{NO}_{\mathrm{x}}$ and $\mathrm{Hg}^{0}$ in coal-fired flue gas. The schematic diagram of this strategy is shown in Figure 20 (a)-(c). Figure 20 (a) and Figure 20 (b) respectively show the potential scale-up of photocatalytic fixed bed and photocatalytic circulating fluidized bed reactors, as well as the corresponding process flows using UV light as light source. Figure 20 (c) describes the potential photocatalytic 
horizontal flat plate reactor and the corresponding process flow using sunlight as light source.

Based on the existing results in product measurements (Kwon et al. 2008; Pitoniak et al. 2003; Yuan et al. 2012b; Snider et al. 2010; Zhao et al. 2008; Maggos et al. 2007; Todorova et al. 2014), the main gaseous products such as $\mathrm{NO}_{2}(\mathrm{~g}) / \mathrm{HNO}_{3}(\mathrm{~g}) / \mathrm{SO}_{3}(\mathrm{~g}) / \mathrm{H}_{2} \mathrm{SO}_{4}(\mathrm{~g}) / \mathrm{HgO}(\mathrm{g})$ and the main solid products such as $\mathrm{HNO}_{3}(\mathrm{~s}) / \mathrm{H}_{2} \mathrm{SO}_{4}(\mathrm{~s}) / \mathrm{HgO}(\mathrm{s})$ will be first produced from the oxidations of $\mathrm{NO}_{\mathrm{x}}, \mathrm{SO}_{2}$ and $\mathrm{Hg}^{0}$ from flue gas in photocatalytic reactor. According to the process flow, the gaseous products will be washed in the back WFGD device, and the solid products will be deposited on the surface of photocatalyst, and finally can be recovered by desorption and regeneration of photocatalyst. Related studies (Kwon et al. 2008; Pitoniak et al. 2003; Yuan et al. 2012b; Dou et al. 2008) have verified that with the continuous accumulation or deposition of solid products on the surface of the catalyst, the activity of catalyst will continue to decline, and may be deactivated.

(a)

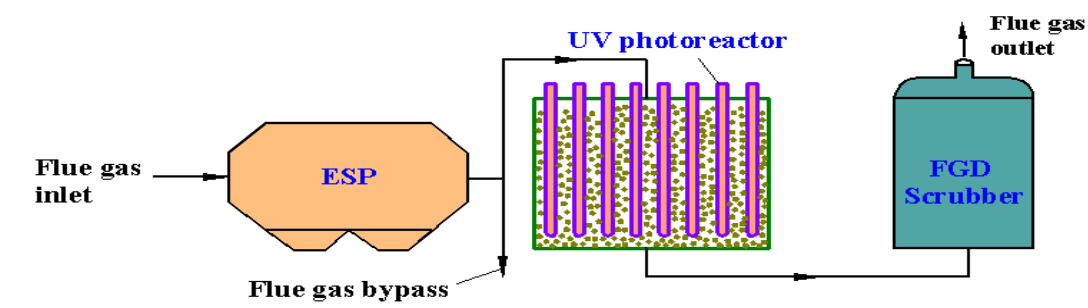

(b)

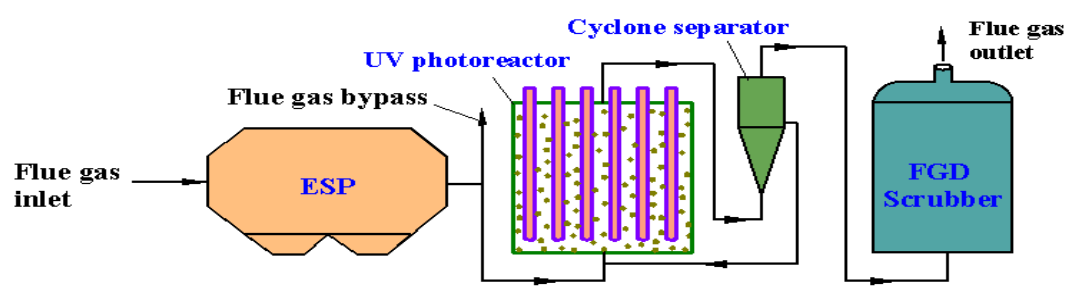

(c)

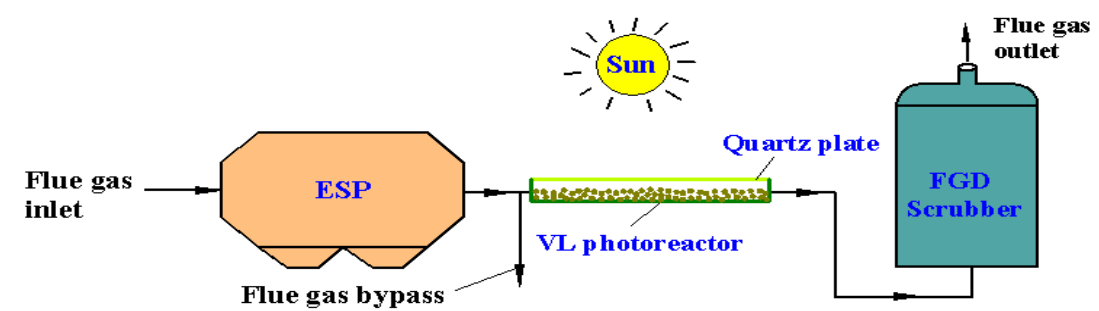

(d)

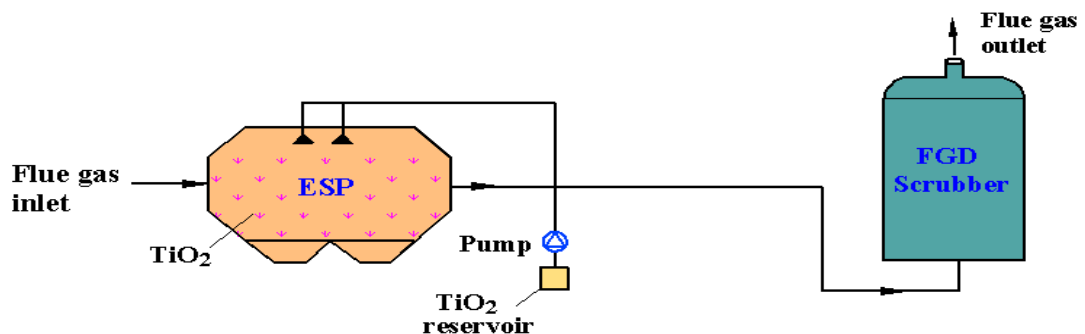


1341 Figure 20. Potential scale-up and process flow of $\mathrm{Hg}^{0}$ photocatalytic removal: (a) fixed bed using UV light; (b) 1342 circulating fluidized bed using UV light; (c) horizontal flat plate using sunlight; (d) electrostatic precipitator (ESP) 1343 injection. 
Asghar et al. 2014; Ye et al. 2014). In recent years, some researchers try to use several photochemical AOTs to remove gaseous pollutants such as $\mathrm{SO}_{2}, \mathrm{NO}_{\mathrm{x}}, \mathrm{VOCs}, \mathrm{Hg}^{0}$, etc., and also show a good prospect (Dickinson, et al. 1926; Granite et al. 1999; Granite et al. 2001; Jia et al. 2001; Liu et al. 2013a; Liu et al. 2014a; Liu et al. 2014c; Liu et al. 2013b; Zhan et al. 2013; Liu et al. 2010a; Liu et al. 2010b; Liu et al. 2010c; Ye et al. 2014). These gaseous pollutants can be oxidized or degraded by generated active substances such as $\cdot \mathrm{OH}, \cdot \mathrm{O}, \mathrm{HO}_{2} \cdot \mathrm{SO}_{4}{ }^{-} \cdot \mathrm{O}_{3}$, etc. in various gas phase reactors (homogeneous reaction) (Dickinson, et al. 1926; Granite et al. 1999; Granite et al. 2001; Jia et al. 2001; Ye et al. 2014) or gas-liquid reactors (heterogeneous) (Liu et al. 2013a; Liu et al. 2014a;

Liu et al. 2014c; Zhan et al. 2013; Liu et al. 2012a; Liu et al. 2010a; Liu et al. 2010b; Liu et al. 2010c). These photochemical AOTs for removing gaseous $\mathrm{Hg}^{0}$ can be divided into two categories of dry and wet methods.

\subsection{Dry photochemical AOTs for $\mathrm{Hg}^{0}$ removal}

In 1926, using oxygen/mercury mixtures, Dickinson and Sherrill demonstrated the photochemical formation of mercuric oxide (HgO) (Dickinson et al. 1926), and the experiments were reproduced by Granite and Pennline (Granite et al. 1999, 2000, 2001, 2002, 2003). The overall reaction between mercury and $\mathrm{O}_{2}$ in the presence of $253.7 \mathrm{~nm}$ UV can be described by the equation (42) (Dickinson et al. 1926; Granite et al. 1999, 2000, 2001, 2002, 2003).

$$
\mathrm{Hg}^{0}(g)+2 \mathrm{O}_{2}(g)+253.7 \mathrm{~nm} \text { light } \rightarrow \mathrm{HgO}(g)+\mathrm{O}_{3}(g)
$$

In this reaction, $\mathrm{Hg}^{0}$ serves as a sensitizer for the formation of $\mathrm{O}_{3}$, and $\mathrm{O}_{3}$ can oxidize $\mathrm{Hg}^{0}$ to form mercuric oxide (HgO), which has been confirmed by Granite et al. and Dickinson et al. (Dickinson et al. 1926; Granite et al. 1999, 2000, 2001, 2002, 2003). Based on this basic principle, Granite and coworkers, for the first time tried to use this novel technology to successfully remove mercury from coal-fired flue gas, and also obtained a US patent (Granite et al. 1999, 2000, 2001, 2002, 2003). Jia et al. 2010 and Liu et al. 2013a and 2013b have also done some related studies to improve this technology from the perspective of chemistry and reactor/process design, which are 
described in the following sections.

\subsubsection{Effects of flue gas components on $\mathrm{Hg}^{0}$ removal using dry photochemical AOTs}

Granite and Pennline (Granite et al. 1999, 2000, 2001, 2002, 2003) studied the effects of $\mathrm{O}_{2}$ and NO on photochemical oxidation of $\mathrm{Hg}^{0}$ using $253.7 \mathrm{~nm} \mathrm{UV}$ radiation, and their results showed that as an essential component for the formation of $\mathrm{O}_{3}, \mathrm{O}_{2}$ played a promotional role. However, the presence of $\mathrm{NO}$ decreased $\mathrm{Hg}^{0}$ removal, which was attributed to the loss of $\mathrm{O}_{3}$ due to the fast reaction between $\mathrm{NO}$ and $\mathrm{O}_{3}$. Jia et al. 2010 further investigated the effects of other flue gas components, including $\mathrm{O}_{2}, \mathrm{NO}, \mathrm{SO}_{2}, \mathrm{H}_{2} \mathrm{O}, \mathrm{CH}_{4}, \mathrm{CO}, \mathrm{CO}_{2}$ and alcohol vapor, and found that the addition of $\mathrm{SO}_{2}, \mathrm{NO}, \mathrm{H}_{2} \mathrm{O}$ or alcohol vapor adversely affected the photochemical oxidation of $\mathrm{Hg}^{0}$, whereas adding $\mathrm{O}_{2}, \mathrm{CH}_{4}, \mathrm{CO}$ or $\mathrm{CO}_{2}$ alone enhanced the process. Similar results were also obtained by Liu et al. 2013a and 2013b in studying the effects of $\mathrm{O}_{2}, \mathrm{NO}, \mathrm{SO}_{2}$ and $\mathrm{H}_{2} \mathrm{O}$ on the oxidation of $\mathrm{Hg}^{0}$ using $253.7 \mathrm{~nm}$ UV radiation.

\subsubsection{Effects of operating parameters on $\mathrm{Hg}^{0}$ removal using dry photochemical AOTs}

Granite and Pennline (Granite et al. 1999, 2000, 2001, 2002, 2003), studied the effects of UV radiation intensity and temperature and found that the UV intensity had a dramatic impact on $\mathrm{Hg}^{0}$ removal, with decrease in intensity resulting in a significant decrease in $\mathrm{Hg}^{0}$ capture, while increasing temperature had the opposite effect, consistent with the results of Jia and Anthony (Jia et al. 2010) and Liu et al. 2013a and 2013b. Liu et al. 2013a and $2013 \mathrm{~b}$ tested the effects of residence time and the results showed that increasing residence time initially increased $\mathrm{Hg}^{0}$ oxidation efficiency before leveling off (Liu et al. 2013a and 2013b). With the increase of $\mathrm{Hg}^{0}$ inlet concentration within the range of $10-80 \mu \mathrm{g} / \mathrm{m}^{3}$, photochemical oxidation efficiency of $\mathrm{Hg}^{0}$ only had a slight decrease, showing that this technology had a good adaptability for the changes of $\mathrm{Hg}^{0}$ concentrations in coal-fired flue gas.

\subsubsection{Products and mechanism of $\mathrm{Hg}^{0}$ removal using dry photochemical AOTs}


the reaction product of $\mathrm{Hg}^{0}$ photochemical oxidation, and found it to consist of gaseous and solid forms (Granite et al. 1999, 2000, 2001, 2002, 2003; Jia et al. 2010; Liu et al. 2013a and 2013b). The solid HgO deposited on the surface of lamp tube or reactor, white gaseous $\mathrm{HgO}$ remains in the flue gas stream to be captured in the back washing or adsorbing reactor (Granite et al. 2002, 2003; Liu et al. 2013a and 2013b). Based on these results, Granite and Pennline 1999, 2000, 2001, 2002, 2003) proposed for the first time, the following reaction mechanisms:

(A) $\mathrm{Hg}^{0}$ is first excited by UV photons from 254-nm mercury lamp according to the following equation (43);

$$
\mathrm{Hg}^{0}(g)+\mathrm{hv}(253.7 \mathrm{~nm} \text { light }) \rightarrow \mathrm{Hg}^{0} *(g)
$$

(B) Quenching of the excited state $\mathrm{Hg}^{0} *$ with $\mathrm{O}_{2}$ returns the excited state $\left(\mathrm{Hg}^{0} *\right)$ to its ground state $\left(\mathrm{Hg}^{0} *\right)$ and produces excited state oxygen $\left(\mathrm{O}_{2} *\right)$ according to the following equation (44);

$$
\mathrm{Hg}^{0} *(g)+\mathrm{O}_{2}(g) \rightarrow \mathrm{Hg}^{0}(g)+\mathrm{O}_{2} *(g)
$$

(C) The active substances used for oxidation of $\mathrm{Hg}^{0}$ are formed through quenching of $\mathrm{O}_{2} *$ and $\mathrm{O}_{2}$ and the reaction between $\cdot \mathrm{O}$ and $\mathrm{O}_{2}$ (Eq. 4) to form $\mathrm{O}_{3}$ and $\cdot \mathrm{O}$ (eq.45).

$$
\mathrm{O}_{2} *(g)+\mathrm{O}_{2}(g) \rightarrow \mathrm{O}_{3}(g)+\cdot \mathrm{O}(g)
$$

(D) Both of $\mathrm{O}_{3}$ and $\cdot \mathrm{O}$ can react with $\mathrm{Hg}^{0}$ to form $\mathrm{HgO}$ as in equations (5) and (6). The overall reaction can be described by equation (42) by superimposing reactions (4)-(6) and (43)-(45).

(E) The other compounds in flue gas may also oxidize $\mathrm{Hg}^{0}$ under the excitation of $254 \mathrm{~nm}$ UV light. For example, $\mathrm{Hg}^{0}$ can react with $\mathrm{H}_{2} \mathrm{O}$ in flue gas to form $\mathrm{HgO}$ according to reaction (46):

$$
\mathrm{Hg}^{0}(g)+\mathrm{H}_{2} \mathrm{O}(g)+\mathrm{hv}(g) \rightarrow \mathrm{HgO}(g)+\mathrm{H}_{2}(g)
$$

(F) $\mathrm{Hg}^{0}$ will be oxidized by $\mathrm{HCl}$ under the radiation of $254 \mathrm{~nm} \mathrm{UV}$ light as shown in reaction (47):

$$
2 \mathrm{Hg}^{0}(g)+2 \mathrm{HCl}(g)+\mathrm{hv} \rightarrow \mathrm{Hg}_{2} \mathrm{Cl}_{2}(g)+\mathrm{H}_{2}(g)
$$


(G) The photochemical oxidation of $\mathrm{Hg}^{0}$ by $\mathrm{NO}_{2}$ will result in the formation of $\mathrm{HgO}$ as shown in reaction (48):

$$
\mathrm{Hg}^{0}(g)+\mathrm{NO}_{2}(g)+\mathrm{hv} \rightarrow \mathrm{HgO}(g)+\mathrm{NO}(g)
$$

1431

(H) The slow sensitized oxidation of $\mathrm{Hg}^{0}$ by $\mathrm{CO}_{2}$ has also been reported with the $254 \mathrm{~nm} \mathrm{UV}$ radiation, and is described in reaction (49):

$$
\mathrm{Hg}(g)+\mathrm{CO}_{2}(g)+\mathrm{hv} \rightarrow \mathrm{HgO}(g)+\mathrm{CO}(g)
$$

(H) $\mathrm{Hg}^{0}$ will react with $\mathrm{SO}_{3}$ under the excitation of $254 \mathrm{~nm} \mathrm{UV} \mathrm{light} \mathrm{according} \mathrm{to} \mathrm{the} \mathrm{following} \mathrm{reaction} \mathrm{(50):}$

$$
\mathrm{Hg}(g)+\mathrm{SO}_{3}(g)+\mathrm{hv} \rightarrow \mathrm{HgO}(g)+\mathrm{SO}_{2}(g)
$$

(I) The results of Jia et al. 2010 also indicated that, compared with adding $\mathrm{O}_{2}$ alone (53.4\%), the joint addition of $\mathrm{CH}_{4}$ and $\mathrm{O}_{2}$ resulted in a much higher removal efficiency $(91.1 \%)$. Therefore, they speculated that when the excited state $\left(\mathrm{Hg}^{0}\right)$ collide with $\mathrm{CH}_{4}$ molecules, $\mathrm{H}$ atoms may be produced and, in turn, can further induce reactions as follows (51)-(53) (Jia et al. 2010).

$$
\begin{aligned}
& \mathrm{Hg}^{0} *(g)+\mathrm{CH}_{4}(g) \rightarrow \mathrm{Hg}^{0}(g)+\mathrm{CH}_{3} \cdot(g)+\cdot \mathrm{H}(g) \\
& \mathrm{O}_{2}(g)+\cdot \mathrm{H}(g) \rightarrow \cdot \mathrm{OH}(g)+\cdot \mathrm{O}(g) \\
& \mathrm{Hg}^{0}(g)+\cdot \mathrm{O}(g) \rightarrow \mathrm{HgO}(g)
\end{aligned}
$$

In addition, the elementary reactions between $\mathrm{Hg}^{0}$ and $\cdot \mathrm{OH}$ in gas phase also have been reported (Sommar et al. 2001; Jack et al. 2005) as previously described in reactions (8-11).

\subsection{Wet photochemical AOTs for $\mathrm{Hg}^{0}$ removal}

Although the dry photochemical AOTs have demonstrated good prospects for $\mathrm{Hg}^{0}$ removal, it also has some shortcomings in actual applications. As previously noted, a part of generated $\mathrm{HgO}$ will deposit on the surface of UV lamp tube to form white stains (Granite et al. 2002; Jia et al. 2010). This significantly reduces UV transmittance because of the very low penetration of 254nm UV light (254nm UV light cannot even pass through an ordinary glass) (Liu et al. 2011a). Also, due to the significant complexity of coal-fired flue gas system, slagging 
and fouling may inevitably occur on the surface of UV lamp tube, which is similar to the slagging and fouling of

1452

1453

1454

several heat transfer surfaces in coal-fired boilers, and finally will result in a decline in $\mathrm{Hg}^{0}$ removal. As a result of these shortcomings of dry photochemical AOTs, several novel wet photochemical AOTs for removing $\mathrm{Hg}^{0}$ in flue gas, including $\mathrm{UV} / \mathrm{H}_{2} \mathrm{O}_{2}$, homogeneous UV/Fenton, homogeneous UV/Fenton-like and heterogeneous UV/Fenton-like, have been proposed recently by Liu et al. 2010a, 2010b, 2014c, 2014d, 2014e, 2015a, Zhan et al. 2013 and Zhang et al. 2011b. Also, several novel gas-liquid photochemical reactors, including photochemical bubble reactor and photochemical spray reactor, and their removal processes have been reported by Liu et al. Liu et al. 2010a, 2010b, 2014c, 2014d, 2014e, 2015a and Zhan et al. 2013. These wet photochemical AOTs have shown some great promise for $\mathrm{Hg}^{0}$ removal.

\subsubsection{Effects of operating parameters on $\mathrm{Hg}^{0}$ removal using wet photochemical AOTs}

\section{(1) UV radiation intensity}

Liu et al. 2014a, 2014c, 2014d, 2015a investigated the effects of UV radiation intensity on $\mathrm{Hg}^{0}$ removal using $\mathrm{UV} / \mathrm{H}_{2} \mathrm{O}_{2}$ process in a photochemical bubble reactor and a photochemical spray reactor, respectively, and their results showed that $\mathrm{Hg}^{0}$ removal was greatly promoted with increasing UV radiation intensity. Similar results were also obtained by Liu et al. 2015a and Zhang et al. 2013 in studying $\mathrm{Hg}^{0}$ removal using homogeneous and heterogeneous Photo-Fenton-like reactions in a photochemical bubble reactor. Related studies (2014a, 2014c, 2014d, 2015a) showed that under UV radiation, $1 \mathrm{~mol} \mathrm{H}_{2} \mathrm{O}_{2}$ can produce $2 \mathrm{~mol} \cdot \mathrm{OH}$ to oxidize $\mathrm{Hg}^{0}$ in flue gas via equations (54) and (55).

$$
\mathrm{H}_{2} \mathrm{O}_{2}(l)+\mathrm{hv} \rightarrow 2 \cdot \mathrm{OH}(l)
$$

$$
\mathrm{Hg}^{0}(l)+2 \cdot \mathrm{OH}(l) \rightarrow \mathrm{Hg}(\mathrm{OH})_{2}(l) \stackrel{\text { heat }}{\longrightarrow} \mathrm{HgO}(l)+\mathrm{H}_{2} \mathrm{O}(l)
$$

Under $\mathrm{UV}$ radiation, $\mathrm{O}_{2}$ can also produce $\cdot \mathrm{O}$ and $\mathrm{O}_{3}$ by the reactions (56) and (57) as follows.

$$
\mathrm{O}_{2}(l)+\mathrm{hv} \rightarrow \cdot \mathrm{O}(l)+\cdot \mathrm{O}(l)
$$




$$
\cdot \mathrm{O}(l)+\mathrm{O}_{2}(l) \rightarrow \mathrm{O}_{3}(l)
$$

Both $\mathrm{O}_{3}$ and $\cdot \mathrm{O}$ have strong oxidants and can oxidize $\mathrm{Hg}^{0}$ by the reactions (58) and (59) as follows.

$$
\mathrm{Hg}^{0}(l)+\mathrm{O}_{3}(l) \rightarrow \mathrm{HgO}(l)+\mathrm{O}_{2}(l)
$$

$$
\mathrm{Hg}^{0}(l)+\cdot \mathrm{O}(l) \rightarrow \mathrm{HgO}(l)
$$

Under UV radiation, $\mathrm{O}_{3}$ can also react with $\mathrm{H}_{2} \mathrm{O}$ to produce $\mathrm{H}_{2} \mathrm{O}_{2}$ by the reaction (60) to provide additional source of $\cdot \mathrm{OH}$ through reactions (54) and (55) (Li et al. 2013).

$$
\mathrm{O}_{3}(l)+\mathrm{H}_{2} \mathrm{O}(l)+\mathrm{hv} \rightarrow \mathrm{H}_{2} \mathrm{O}_{2}(l)+\mathrm{O}_{2}(l)
$$

The results of Jia et al. 2010 and Granite et al. 2000, 2001, 2002 showed that under UV radiation, $\mathrm{Hg}^{0}$ also could directly react with $\mathrm{H}_{2} \mathrm{O}$ to produce $\mathrm{HgO}$ by the following photochemical reaction (61).

$$
\mathrm{Hg}^{0}(l)+\mathrm{H}_{2} \mathrm{O}(l)+\mathrm{hv} \rightarrow \mathrm{HgO}(l)+\mathrm{H}_{2}(l)
$$

An increase in $\mathrm{UV}$ radiation intensity can produce more effective $\mathrm{UV}$ photons, $\cdot \mathrm{OH}, \cdot \mathrm{O}$ and $\mathrm{O}_{3}$, thereby enhancing $\mathrm{Hg}^{0}$ removal. However, the results of Liu et al. 2014a, 2014c, 2014d, 2015a and Zhang et al. 2011b also found that $\mathrm{Hg}^{0}$ removal efficiency did not maintain a linear relationship with increasing UV radiation intensity, with the effect leveling off at excess intensity. Therefore, to reduce energy consumption of reaction system, an appropriate UV radiation intensity should be maintained in future industrial applications.

\section{(2) UV wavelength}

Based on the basic principles of photochemical reactions 2014a, 2014c, 2014d, oxidants such as $\cdot \mathrm{OH}, \cdot \mathrm{O}$ and $\mathrm{O}_{3}$ mainly derived from the photolysis of $\mathrm{O}_{2}$ and $\mathrm{H}_{2} \mathrm{O}_{2}$ molecules by $\mathrm{UV}$ photons by molecular bond breakage, and the energy of the UV light photons depends on the UV light wavelength as shown in the Planck's equation (62)

(Liu et al. 2011a):

$$
\varepsilon=h v=h \frac{c}{\lambda}
$$

where $\varepsilon$ - energy of photon, $\mathrm{J} ; \quad v$ - ultraviolet frequency, $1 / \mathrm{s} ; h$-Planck constant, $6.626 \times 10^{-34} \mathrm{~J} \cdot \mathrm{s} ; c$-speed of 
light, $2.998 \times 10^{8} \mathrm{~m} / \mathrm{s} ; \lambda$ - ultraviolet wavelength, $100-380 \mathrm{~nm}$. It can be inferred from this equation that as the UV wavelength becomes shorter, the energy of UV photon will become bigger. Liu et al. 2014a, 2014c, 2014d, 2015 studied the effects of UV wavelength on $\mathrm{Hg}^{0}$ removal using three most common UV wavelengths $(185 \mathrm{~nm}, 254$ $\mathrm{nm}, 365 \mathrm{~nm})$ and compared with visible light $(350-770 \mathrm{~nm})$ source. The results indicated that $254 \mathrm{~nm}$ UV-light obtained the highest $\mathrm{Hg}^{0}$ removal efficiency, and the visible light has almost no effect on $\mathrm{Hg}^{0}$ oxidation. Also, similar results were also obtained by Liu et al. 2015a and Zhang et al. 2011 in studying $\mathrm{Hg}^{0}$ removal using homogeneous and heterogeneous Photo-Fenton-like reactions in a photochemical bubble reactor. While shorter wavelength photons have the requisite energy to destroy the molecular bonds in $\mathrm{H}_{2} \mathrm{O}_{2}$ and $\mathrm{O}_{2}$ to produce more $\cdot \mathrm{OH}, \cdot \mathrm{O}$ and $\mathrm{O}_{3}$, they also have shorter propagation distance of UV light in solution because of the heat dissipation of UV-light in the propagation medium. By carefully considering both propagation distance and UV photon energy, $254 \mathrm{~nm}$ was found to achieve the best $\mathrm{Hg}^{0}$ removal performance (Liu et al. 2014a, 2014c, 2014d, 2015a; Zhang et al. 2011).

\section{(3) Effects of $\mathrm{H}_{2} \mathrm{O}_{2}$ concentration}

Liu et al. 2014a, 2014c, 2014d, 2015a investigated the effects of $\mathrm{H}_{2} \mathrm{O}_{2}$ concentration on $\mathrm{Hg}^{0}$ removal by $\mathrm{UV} / \mathrm{H}_{2} \mathrm{O}_{2}$ process in a photochemical bubble reactor and a photochemical spray reactor, respectively, and found that the addition of a small amount of $\mathrm{H}_{2} \mathrm{O}_{2}$ enhanced $\mathrm{Hg}^{0}$ removal but higher levels had the opposite effect. Liu et al. 2015a, Zhan et al. 2013 and Zhang et al. 2013 also obtained similar results in studying $\mathrm{Hg}^{0}$ removal using homogeneous UV/Fenton reaction, and homogeneous/heterogeneous Photo-Fenton-like reactions, respectively. As shown in reactions (54) and (55), UV photolysis of $\mathrm{H}_{2} \mathrm{O}_{2}$ produces additional $\cdot \mathrm{OH}$ to oxidize $\mathrm{Hg}^{0}$ in flue gas, in addition to oxidation by the added $\mathrm{H}_{2} \mathrm{O}_{2}$ as in reaction (63).

$$
\mathrm{Hg}^{0}(l)+\mathrm{H}_{2} \mathrm{O}_{2}(l) \rightarrow \mathrm{HgO}(l)+\mathrm{H}_{2} \mathrm{O}(l)
$$

However, excessive addition $\mathrm{H}_{2} \mathrm{O}_{2}$ also acts a scavenger of $\cdot \mathrm{OH}$, which has the stronger oxidation potential (Liu et 

removal.

\section{(4) Effects of $\mathrm{Fe}^{2+} / \mathrm{Fe}^{3+} / \mathrm{Cu}^{2+}$ concentration}

Related studies (Hsueh et al. 2005; Tony et al. 2009; Kwan et al. 2003; Cravotto et al. 2007; Ntampegliotis et al. 2006; Fan et al. 2009) showed that transition metal ions such as $\mathrm{Fe}^{2+}, \mathrm{Fe}^{3+}, \mathrm{Cu}^{2+}, \mathrm{Mn}^{2+}, \mathrm{Co}^{2+}$, etc. could effectively improve the yield of $\cdot \mathrm{OH}$ in UV/Fenton and Photo-Fenton-Like (PFL) systems, therefore enhancing oxidation of pollutants. Zhan et al. 2013 examined the effects of $\mathrm{Fe}^{2+}$ concentration on $\mathrm{Hg}^{0}$ removal using homogeneous UV/Fenton reaction, and the results showed that $\mathrm{Hg}^{0}$ removal was greatly enhanced by adding low concentration of $\mathrm{Fe}^{2+}$, but was greatly reduced by adding high concentration of $\mathrm{Fe}^{2+}$. Liu et al. 2015 obtained similar results using $\mathrm{Fe}^{3+}$-induced homogeneous PFL reaction. However, Liu et al. 2015a also obtained different results using $\mathrm{Cu}^{2+}$-induced homogeneous PFL reaction, indicating that $\mathrm{Hg}^{0}$ removal was monotonically enhanced by adding $\mathrm{Cu}^{2+}$. In general, increasing $\mathrm{Fe}^{2+}, \mathrm{Fe}^{3+}$ and $\mathrm{Cu}^{2+}$ concentrations increase the yield of $\cdot \mathrm{OH}$ in UV/Fenton and PTL systems via reactions (65)-(73), thereby promoting removal of $\mathrm{Hg}^{0}$ (Liu et al. 2015a; Zhan et al. 2013; Hsueh et al. 2005; Tony et al. 2009; Kwan et al. 2003; Cravotto et al. 2007; Ntampegliotis et al. 2006; Fan et al. 2009).

$\mathrm{Fe}^{2+}(l)+\mathrm{H}_{2} \mathrm{O}_{2}(l) \rightarrow \mathrm{Fe}^{3+}(l)+\cdot \mathrm{OH}(l)+\mathrm{OH}^{-}(l)$
$\mathrm{Fe}^{3+}(l)+\mathrm{H}_{2} \mathrm{O}_{2}(l) \rightarrow\left[\mathrm{Fe}\left(\mathrm{HO}_{2}\right)\right]^{2+}(l)+\mathrm{H}^{+}(l)$
$\left[\mathrm{Fe}\left(\mathrm{HO}_{2}\right)\right]^{2+}(l) \stackrel{\mathrm{uv}}{\longrightarrow} \mathrm{Fe}^{2+}(l)+\mathrm{HO}_{2} \cdot(l)$
$\mathrm{Cu}^{2+}(l)+\mathrm{H}_{2} \mathrm{O}_{2}(l) \rightarrow \mathrm{Cu}^{+}(l)+\mathrm{HO}_{2} \cdot(l)+\mathrm{H}^{+}(l)$
$\mathrm{Cu}^{+}(l)+\mathrm{H}_{2} \mathrm{O}_{2}(l) \rightarrow \mathrm{Cu}^{2+}(l)+\cdot \mathrm{OH}(l)+\mathrm{OH}^{-}(l)$
$\left[\mathrm{Cu}\left(\mathrm{HO}_{2}\right)\right]^{+}(l) \stackrel{\mathrm{uv}}{\longrightarrow} \mathrm{Cu}^{+}(l)+\mathrm{HO}_{2} \cdot(l)$




$$
\mathrm{Fe}^{3+}(l)+\mathrm{H}_{2} \mathrm{O}_{2}(l) \rightarrow \mathrm{Fe}^{2+}(l)+\mathrm{HO}_{2} \cdot(l)+\mathrm{H}^{+}(l)
$$

$$
\mathrm{Fe}^{2+}(l)+\mathrm{H}_{2} \mathrm{O}_{2}(l) \rightarrow \mathrm{Fe}^{3+}(l)+\cdot \mathrm{OH}(l)+\mathrm{OH}^{-}(l)
$$

$$
\left[\mathrm{Fe}\left(\mathrm{HO}_{2}\right)\right]^{2+}(l) \stackrel{\mathrm{UV}}{\longrightarrow} \mathrm{Fe}^{2+}(l)+\mathrm{HO}_{2} \cdot(l)
$$

1542

However, adding excessive $\mathrm{Fe}^{2+}$ will result in scavenging of $\cdot \mathrm{OH}$ by $\mathrm{Fe}^{2+}$ and radical recombination through the side reactions (74)-(77) with very large reaction rates (Liu et al. 2015a; Zhan et al. 2013; Hsueh et al. 2005; Tony et al. 2009; Kwan et al. 2003; Cravotto et al. 2007; Ntampegliotis et al. 2006; Fan et al. 2009), thereby inhibiting $\mathrm{Hg}^{0}$ removal.

$$
\begin{array}{ll}
\mathrm{Fe}^{2+}(l)+\cdot \mathrm{OH}(l) \rightarrow \mathrm{Fe}^{3+}(l)+\mathrm{OH}^{-}(l) & \mathrm{k}=3.0 \times 10^{8} \mathrm{M}^{-1} \mathrm{~s}^{-1} \\
\cdot \mathrm{OH}(l)+\cdot \mathrm{OH}(l) \rightarrow \mathrm{H}_{2} \mathrm{O}_{2}(l) & \mathrm{k}=5.5 \times 10^{9} \mathrm{M}^{-1} \mathrm{~s}^{-1} \\
\cdot \mathrm{OH}(l)+\mathrm{HO}_{2} \cdot(l) \rightarrow \mathrm{H}_{2} \mathrm{O}(l)+\mathrm{O}_{2}(l) & \mathrm{k}=1.0 \times 10^{10} \mathrm{M}^{-1} \mathrm{~s}^{-1} \\
\mathrm{HO}_{2} \cdot(l)+\mathrm{HO}_{2} \cdot(l) \rightarrow \mathrm{H}_{2} \mathrm{O}_{2}(l)+\mathrm{O}_{2}(l) & \mathrm{k}=3.4 \times 10^{7} \mathrm{M}^{-1} \mathrm{~s}^{-1}
\end{array}
$$

\section{(4) Effects of temperature}

Heterogeneous gas-liquid reacting systems are affected by temperature via the coupled effects of a chemical reaction rate, solubility of gas in solution and mass transfer rate. Liu et al. 2014a, 2014c, 2014d, 2015a and Zhang et al. 2013 studied the effects of temperature on $\mathrm{Hg}^{0}$ removal using $\mathrm{UV} / \mathrm{H}_{2} \mathrm{O}_{2}$ process, homogeneous/heterogeneous PTL reactions, and found oxidation of $\mathrm{Hg}^{0}$ to be slightly reduced with increasing reaction temperature. On the other hand, Zhan et al. 2013 found $\mathrm{Hg}^{0}$ removal using homogeneous UV/Fenton reaction to be promoted by low temperature, but was significantly inhibited by high temperature. Liu et al. 2014a, 2014c, 2014d, 2015a, Zhan et al. 2013 and Zhang et al. 2013 suggested that increasing temperature increased chemical reaction rate of $\mathrm{Hg}^{0}$ removal, and accelerated the decomposition of $\mathrm{H}_{2} \mathrm{O}_{2}$ but also reduced the solubility of $\mathrm{Hg}^{0}$ in water with the net effect of reducing $\mathrm{Hg}^{0}$ removal.

\section{(5) Effects of solution $\mathrm{pH}$}


removal by $\mathrm{UV} / \mathrm{H}_{2} \mathrm{O}_{2}$ process and homogeneous/heterogeneous PFL reactions, respectively, found that $\mathrm{Hg}^{0}$

Increasing solution $\mathrm{pH}$ promotes higher $\mathrm{OH}^{-}$concentration which neutralizes $\mathrm{H}^{+}$, and shifts reaction (78) to the left to further raise the yield of $\mathrm{HO}_{2}{ }^{-}$and reduce the effectiveness of $\mathrm{Hg}$ removal. Some studies have also confirmed that $\mathrm{H}_{2} \mathrm{O}_{2}$ and Fenton-Like reagents often provide stronger oxidizing environment under acidic conditions (Liu et al. 2014a, 2014b, 2014c, 2015a).

\section{(6) Effects of gas flow/liquid-gas ratio}

The gas flow/liquid-gas ratio is an important parameter for the design and operation of reactor. Related studies (Liu et al. 2011a) indicated that a small gas flow or large liquid-gas ratio generally helped improve removal efficiency of pollutants. However, a small gas flow or large liquid-gas ratio generally also requires a larger reactor volume, thereby increasing the investment and operating costs of systems. Liu et al. 2014a, 2014c, 2014d, 2015a and Zhang et al. 2013 investigated the effects of gas flow/liquid-gas ratio on $\mathrm{Hg}^{0}$ removal using homogeneous/heterogeneous PTL reactions and $\mathrm{UV} / \mathrm{H}_{2} \mathrm{O}_{2}$ process in a photochemical bubble reactor and a photochemical spray reactor, and showed that $\mathrm{Hg}^{0}$ oxidation efficiency significantly decreased with increasing gas flow or reducing liquid-gas ratio.

\section{(7) Effects of $\mathrm{Hg}^{0}$ inlet concentration}

Liu et al. 2014a, 2014c, 2014d, 2015a and Zhang et al. 2013 studied the effects of $\mathrm{Hg}^{0}$ inlet concentration on 
$\mathrm{Hg}^{0}$ oxidation in $\mathrm{UV} / \mathrm{H}_{2} \mathrm{O}_{2}$ process and homogeneous/ heterogeneous PFL reactions reported that the changes of $\mathrm{Hg}^{0}$ inlet concentration had only a slight effect on $\mathrm{Hg}^{0}$ oxidation, suggesting that wet photochemical AOTs have an excellent adaptability to changes in $\mathrm{Hg}^{0}$ concentration in the flue gas.

\subsubsection{Effects of flue gas components on $\mathrm{Hg}^{0}$ removal using wet photochemical AOTs}

Liu et al. 2014a, 2014c, 2014d, 2015a and Zhang et al. 2013 investigated the effects of $\mathrm{O}_{2}, \mathrm{SO}_{2}, \mathrm{CO}_{2}$ and $\mathrm{NO}$ on $\mathrm{Hg}^{0}$ removal by $\mathrm{UV} / \mathrm{H}_{2} \mathrm{O}_{2}$ process and homogeneous/heterogeneous PFL reactions, and found the addition of $\mathrm{SO}_{2}$ or $\mathrm{NO}$ to reduce $\mathrm{Hg}^{0}$ oxidation, while $\mathrm{O}_{2}$ slightly enhanced the reaction but $\mathrm{CO}_{2}$ has no noticeable effect. Zhan et al. 2013 also investigated the effects of $\mathrm{O}_{2}, \mathrm{SO}_{2}$ and $\mathrm{NO}$ on $\mathrm{Hg}^{0}$ removal using UV/Fenton process, and they found that an appropriate $\mathrm{O}_{2}$ concentration promoted $\mathrm{Hg}^{0}$ oxidation, but $\mathrm{O}_{2}$ concentration higher than $9 \%$ inhibited the reaction. $\mathrm{SO}_{2}$ had an inhibitory effect on $\mathrm{Hg}^{0}$ oxidation, but the inhibition was slower with further increase in $\mathrm{SO}_{2}$ concentration, while $\mathrm{NO}$ had no obvious effect on $\mathrm{Hg}^{0}$ oxidation.

In the presence of $\mathrm{O}_{2}$ in the flue gas, the yield of $\mathrm{O}_{3}$ and $\cdot \mathrm{O}$ would increase by the above reactions (56)-(60) (Liu et al. 2014a, 2014c, 2014d, 2015a), thereby promoting $\mathrm{Hg}^{0}$ removal. However, addition of excess $\mathrm{O}_{2}$ would also result in the excessive consumption of active free radicals, negatively impacting $\mathrm{Hg}^{0}$ removal (Liu et al. 2014a, 2014c, 2014d, 2015a). On the other hand, NO could compete with Hg for available oxidants such as $\cdot \mathrm{OH}, \cdot \mathrm{O}, \mathrm{O}_{3}$ and $\mathrm{H}_{2} \mathrm{O}_{2}$ via reactions (80)-(86), reducing the oxidation rate of $\mathrm{Hg}^{0}$ (Liu et al. 2014a, 2014c, 2014d, 2015a). 
Similarly, $\mathrm{SO}_{2}$ would compete with the oxidants via reactions (87)-(94) to reduce $\mathrm{Hg}^{0}$ removal (Liu et al. 2014a,

\subsubsection{Products and active intermediates of $\mathrm{Hg}^{0}$ removal using wet photochemical AOTs}

Liu et al. 2014a, 2014c, 2014d, 2015a, using a fluorescence spectrometry method, determined the reaction products of $\mathrm{Hg}^{0}$ removal from flue gas in $\mathrm{UV} / \mathrm{H}_{2} \mathrm{O}_{2}$ process and homogeneous PFL reactions and observed that $\mathrm{Hg}^{2+}$ was the main reaction product in solution resulting from almost complete oxidation of $\mathrm{Hg}^{0}$. The result was also verified by mass balance calculation of total $\mathrm{Hg}$ in different reaction systems and are summarized in Table 6 .

Table 6. Comparison of products and mass balance of total $\mathrm{Hg}$ in different reaction systems. 


\begin{tabular}{|c|c|c|c|c|c|c|c|c|c|c|}
\hline Reaction systems & \multicolumn{2}{|c|}{$\mathrm{UV} / \mathrm{H}_{2} \mathrm{O}_{2}$ (Liu et } & \multicolumn{2}{|c|}{$\mathrm{UV} / \mathrm{H}_{2} \mathrm{O}_{2}$ (Liu et } & \multicolumn{2}{|c|}{$\mathrm{UV} / \mathrm{H}_{2} \mathrm{O}_{2}$ (Liu et } & \multicolumn{2}{|c|}{$\mathrm{Fe}^{3+}$-induced (Liu } & \multicolumn{2}{|c|}{$\mathrm{Cu}^{2+}$-induced (Liu et } \\
\hline \multirow[t]{3}{*}{ and Reactors } & \multicolumn{2}{|c|}{ al. 2014a) } & \multicolumn{2}{|c|}{ al. 2014c) } & \multicolumn{2}{|c|}{ al. 2014d) } & \multicolumn{2}{|c|}{ et al. 2015a) } & \multicolumn{2}{|c|}{ al. 2015a ) } \\
\hline & \multicolumn{2}{|c|}{ Spray reactor } & \multicolumn{2}{|c|}{ Bubbling reactor } & \multicolumn{2}{|c|}{ Spray reactor } & \multicolumn{2}{|c|}{ Photo-Fenton-like } & \multicolumn{2}{|c|}{ Photo-Fenton-like } \\
\hline & & & & & & & \multicolumn{2}{|c|}{ Bubbling reactor } & \multicolumn{2}{|c|}{ Bubbling reactor } \\
\hline Type of mercury & $\mathrm{Hg}^{0}$ & Total $\mathrm{Hg}$ & $\mathrm{Hg}^{0}$ & Total $\mathrm{Hg}$ & $\mathrm{Hg}^{0}$ & Total Hg & $\mathrm{Hg}^{0}$ & Total Hg & $\mathrm{Hg}^{0}$ & Total $\mathrm{Hg}$ \\
\hline Mea-value ( $\mu \mathrm{g} / \mathrm{L})$ & 0 & 3.41 & 0 & 5.46 & 0 & 3.48 & 0 & 1.73 & 0 & 1.77 \\
\hline Cal-value $(\mu \mathrm{g} / \mathrm{L})$ & - & 3.73 & - & 6.19 & - & 3.83 & - & 2.07 & - & 1.96 \\
\hline Relative error (\%) & - & $8.58 \%$ & - & $11.79 \%$ & - & $9.1 \%$ & - & $16.4 \%$ & - & $9.0 \%$ \\
\hline
\end{tabular}

1629 key active intermediate, $\cdot \mathrm{OH}$ in the $\mathrm{UV} / \mathrm{H}_{2} \mathrm{O}_{2}$ process, which is difficult to detect in solution due to its high 1630 reactivity and short life span, using "indirect capture" method. The basic principle of this method is the addition of 1631 a capturing agent to react with $\cdot \mathrm{OH}$ to product more stable intermediates, thereby indirectly detecting the presence 1632 of $\cdot \mathrm{OH}$ (Liu et al. 2014a and 2014c). The capturing agent, salicylic acid (SA), was used to capture $\cdot \mathrm{OH}$ by a 1633 hydroxylation reaction, which produced relatively more stable hydroxylated products, 2,3-DHBA and 2,5-DHBA. 1634 The 2,3-DHBA and 2,5-DHBA, with a relatively longer life than $\cdot \mathrm{OH}$, were determined by liquid-mass 1635 spectrometry (LC-MS) with UV and MS detectors (Liu et al. 2014a and 2014c). The relevant reaction is given in equation (95), and the resulting LC-MS chromatograph is illustrated in Figure 21:<smiles>C[C+](C)c1cc(O)c(C(=O)O)c(C(=O)O)c1</smiles> 

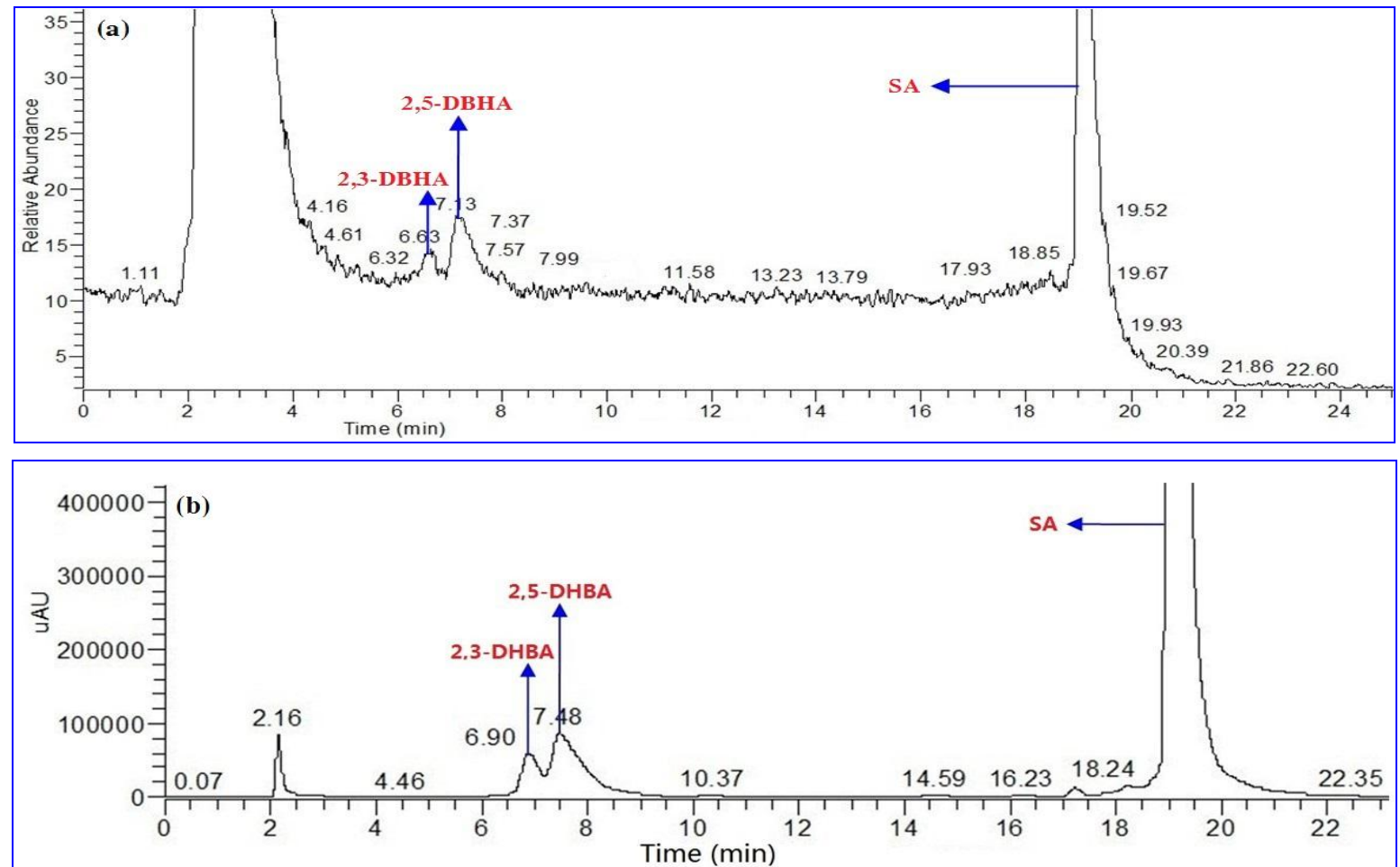

1641 Figure 21. Determination of hydroxylated products 2,3-DHBA and 2,5-DHBA by the MS detector (a) and the UV 1642 detector (b) in liquid-mass spectrometry (LC-MS) (Liu et al. 2014a and 2014c).

As shown in Figure 22, under catalysis of $\mathrm{Fe}^{3+}$ and $\mathrm{Cu}^{2+}$, both of the typical four-line ESR spectrums were detected in solution. The hyperfine splitting constants $\mathrm{a}_{\mathrm{N}}=15.2 \mathrm{G}$ and $\mathrm{a}_{\mathrm{H}}=14.7 \mathrm{G}$ were in good agreement with the literature data $\mathrm{a}_{\mathrm{N}}=15.0 \mathrm{G}$ and $\mathrm{a}_{\mathrm{H}}=14.8 \mathrm{G}$ (Liu et al. 2014b), showing that $\cdot \mathrm{OH}$ was also produced in homogeneous Photo-Fenton-Like reactions. These results provided powerful supports for studying the reaction mechanism and pathways of $\mathrm{Hg}^{0}$ removal by wet photochemical AOTs. 

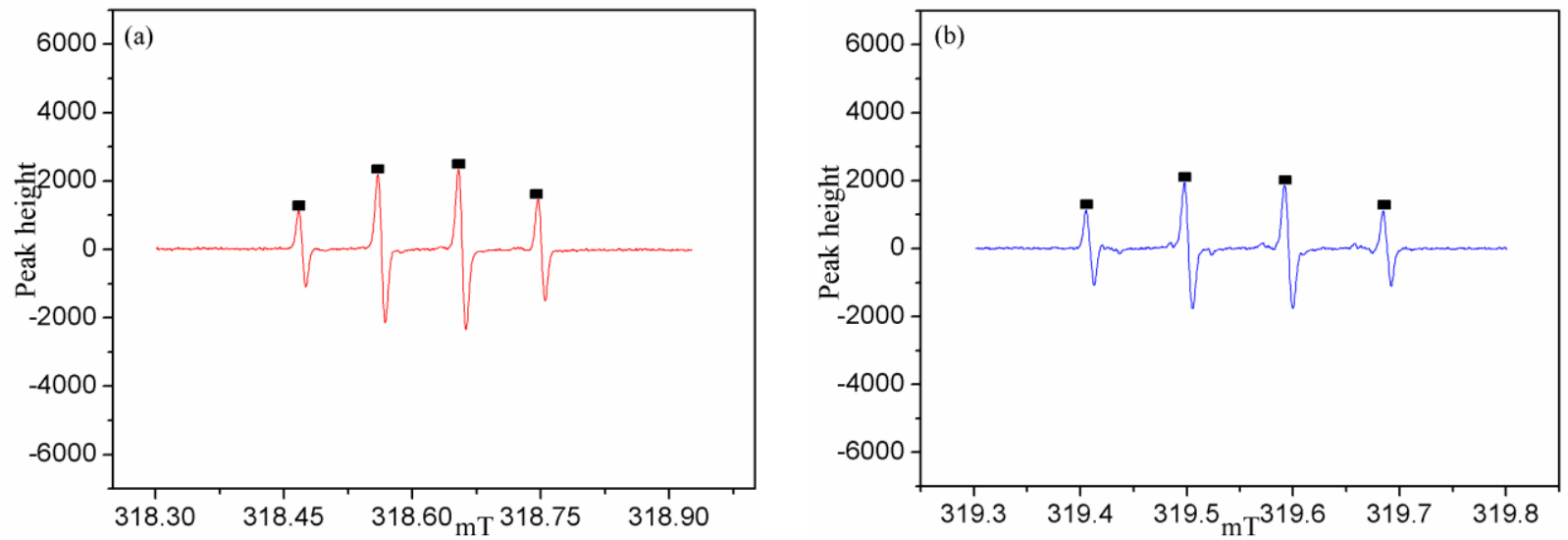

1651 Figure 22. ESR spectrums of $\cdot \mathrm{OH}$ radical adducts in two homogeneous Photo-Fenton-Like reactions: (a) catalysis

of $\mathrm{Fe}^{3+}$; (b) catalysis of $\mathrm{Cu}^{2+}$ (Liu et al. 2015a).

\subsubsection{Mechanism of $\mathrm{Hg}^{0}$ removal using wet photochemical AOTs}

Liu et al. (2014a, 2014c, 2014d) studied the reaction mechanism and pathways of $\mathrm{Hg}^{0}$ removal in the $\mathrm{UV} / \mathrm{H}_{2} \mathrm{O}_{2}$ process systematically based on the determination of the reactive intermediates and reaction products.

The reaction mechanism and pathways are hypothesized to consist of the following five steps: (a) active substances such as $\cdot \mathrm{OH}, \cdot \mathrm{O}$ and $\mathrm{O}_{3}$ are produced through $\mathrm{UV}$ photolysis of $\mathrm{O}_{2}$ and $\mathrm{H}_{2} \mathrm{O}_{2}$; (b) removals of $\mathrm{Hg}^{0}$ by oxidations of $\cdot \mathrm{OH}, \cdot \mathrm{O}$ and $\mathrm{O}_{3}$; (c) removal of $\mathrm{Hg}^{0}$ by photoexcitation reaction of $\mathrm{Hg}^{0}$ with $\mathrm{H}_{2} \mathrm{O}$; (d) removal of $\mathrm{Hg}^{0}$ by oxidation of $\mathrm{H}_{2} \mathrm{O}_{2}$; (e) termination of radical chain reactions (Liu et al. 2014a, 2014c, 2014d, 2015a). 


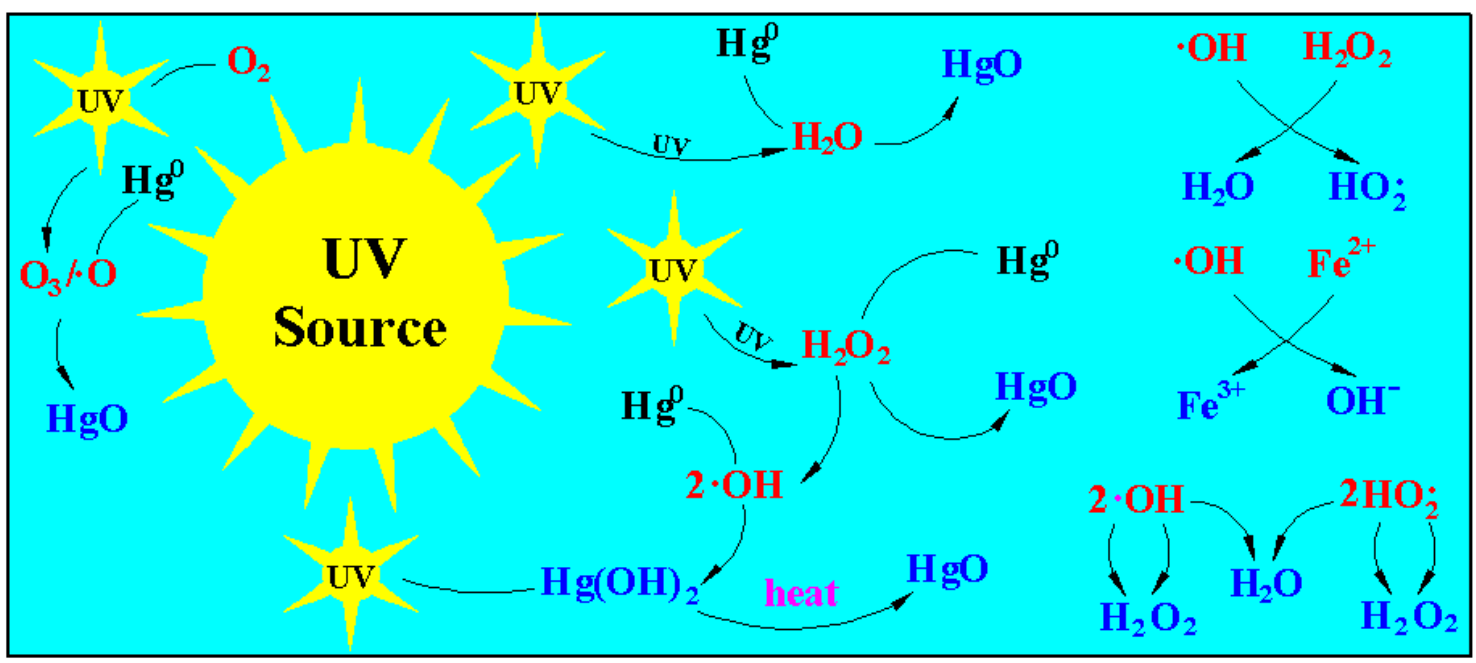

Figure 23. Schematic diagram of reaction mechanism and pathways of $\mathrm{Hg}^{0}$ removal by $\mathrm{UV} / \mathrm{H}_{2} \mathrm{O}_{2}$ process.

\subsection{Reactor and process flow of $\mathrm{Hg}^{0}$ removal using wet photochemical AOTs}

\subsubsection{Reactor of $\mathrm{Hg}^{0}$ removal using wet photochemical AOTs} photochemical reactors for $\mathrm{Hg}^{0}$ removal. A dry photochemical reactor with external $\mathrm{UV}$ lamp for removing $\mathrm{Hg}^{0}$ in photochemical reactors have demonstrated a good mercury removal performance. 

described in Figure 24(d) and (e).

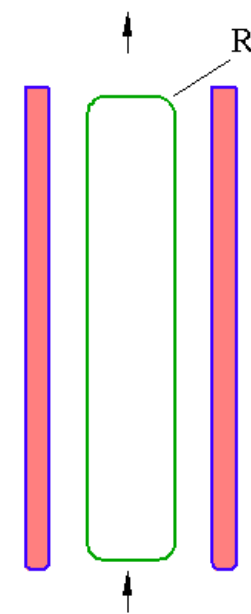

(a)

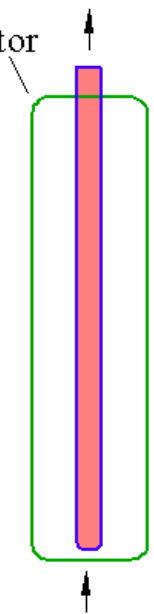

(b)
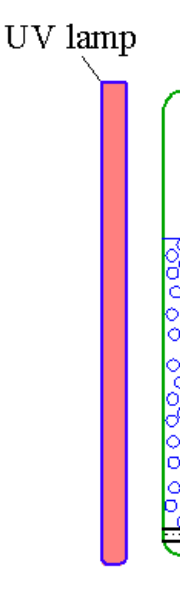

(c)

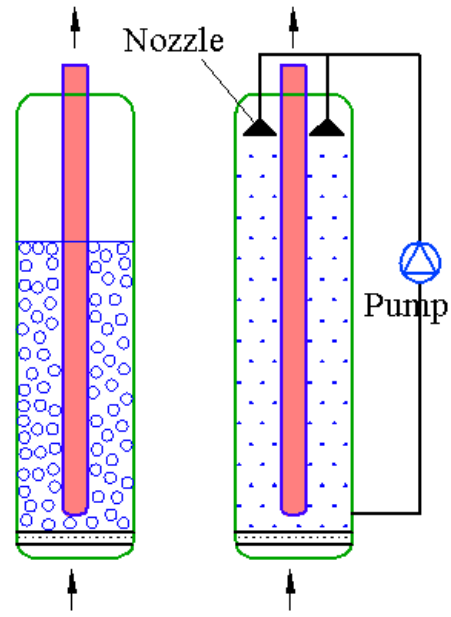

(e)

Figure 24. Dry and wet photochemical reactors for removing $\mathrm{Hg}^{0}$ in flue gas: (a) Dry photochemical reactor with external UV lamp; (b) Dry photochemical reactor with built-in UV lamp; (c) Wet photochemical bubbling reactor with external UV lamp; (d) Wet photochemical bubbling reactor with built-in UV lamp; (e) Wet photochemical 
(a)

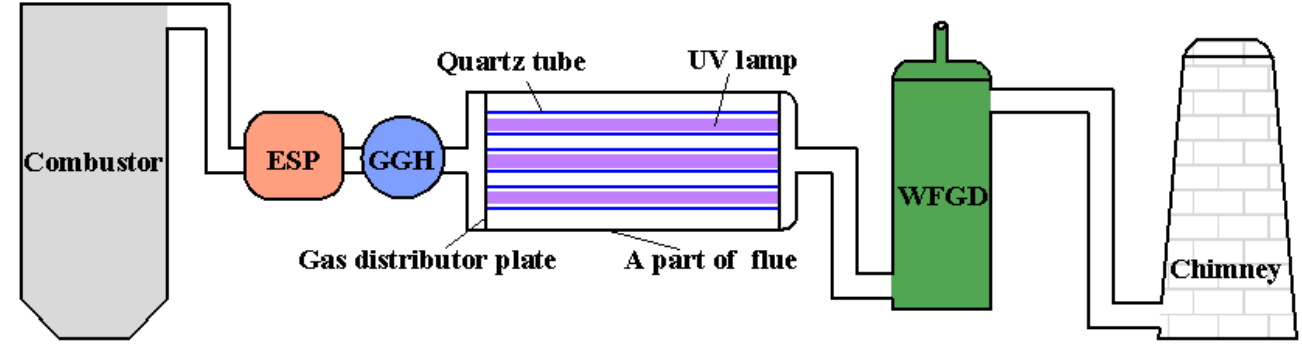

(b)

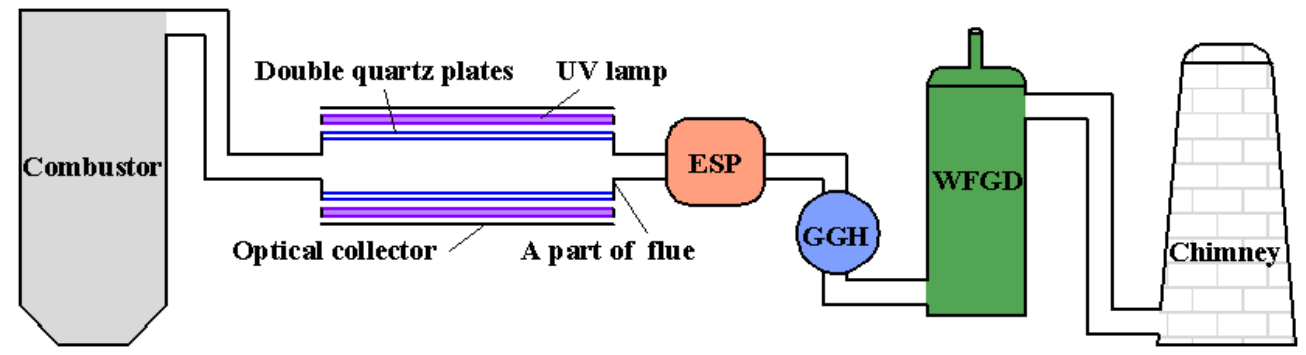

Figure 25. Process flow of $\mathrm{Hg}^{0}$ removal using dry photochemical oxidation: (a) Low temperature arrangement of dry photochemical reactor; (b) High temperature arrangement of dry photochemical reactor.

Liu et al. 2013a and 2013b suggested that UV-light source should be installed after the GGH and before the inlet of WFGD device because $254 \mathrm{~nm}$ UV lamp was only suitable for operating at low temperatures. The optimum operating temperature is $5-50^{\circ} \mathrm{C}$, and high temperature will greatly reduce the operational efficiency of $254 \mathrm{~nm}$ UV lamp) (Liu et al. 2011a), which is described in Figure 25(a) (low temperature arrangement of reactor). However, to take advantage of $\mathrm{Hg}^{2+}$ removal via adsorption by fly ash in the precipitator, the UV-light source could also be installed before the precipitator/GGH. In this case, flue gas temperature is usually higher than $130^{\circ} \mathrm{C}$ (Liu et al. 2011a), using a built-in arrangement in Figure 25(a) is inappropriate due to the adverse effects of high temperature on UV lamp operation. Compared to the built-in arrangement in the Figure 25(a), an external arrangement in Figure 25(b) not only can make full use of removal capacity of $\mathrm{Hg}^{2+}$ by fly ash in the precipitator, but also avoids the adverse influence of high temperature on UV lamp operation. To prevent the loss of heat in flue gas, a double quartz plate with vacuum sandwich may be used to separate the high temperature flue gas and UV lamps (Liu et al. 2013a and 2013b). An optical collector is also necessary to make full use of UV light. Besides, based on the treatment amount of flue gas, this kind of external photochemical reactor may be amplified 
by using parallel connection of several same reactors (Liu et al. 2013a and 2013b).

The $\mathrm{Hg}^{0}$ in flue gas from combustor will be oxidized into gaseous and solid $\mathrm{HgO}$. A large number of studies (Liu et al. 2014a, 2014c, 2014d, 2015a) has shown that, compared with $\mathrm{Hg}^{0}, \mathrm{HgO}$ is easier to remove in a dust collector or a WFGD device through adsoprtion on fly ash or solution washing. This method has a simple process and low cost, and can be easily used to revamp the existing thermal power units to achieve mercury removal in combination with electrostatic/bag type dust collector or WFGD device. At present, the application of this technology still faces some problems. For example, the product $\mathrm{HgO}$, particulate matters or some other substances in actual flue gas may deposite on the surface of UV lamp or quartz glass, and significantly reduce UV transmittance because of the very low penetration capacity of 254nm UV light (254nm UV light can not even pass novel techniques, which are described in Figure 26(a) and (b). It can be seen that the two kinds of processes have similar process flows and devices, but the key photochemical reactors are different. In Figure 26(a), a photochemical bubbling reactor is used to remove pollutants. In Figure 26(b), the photochemical bubbling reactor is replaced by a photochemical spray reactor. Liu et al., demonstrated that both of two photochemical reactors are very effective in removing $\mathrm{Hg}^{0}$ and $\mathrm{SO}_{2}$ in flue gas, but the latter has a higher efficiency for NO removal than the former because of its far greater surface area and better light transmission efficiency (Liu et al. 2010c, 2010d, 2014a, 2014c, 2014d, 2015a). Given the current and urgent need for the simultaneous removal of $\mathrm{NO}_{\mathrm{x}}, \mathrm{SO}_{2}$ and 
(a)

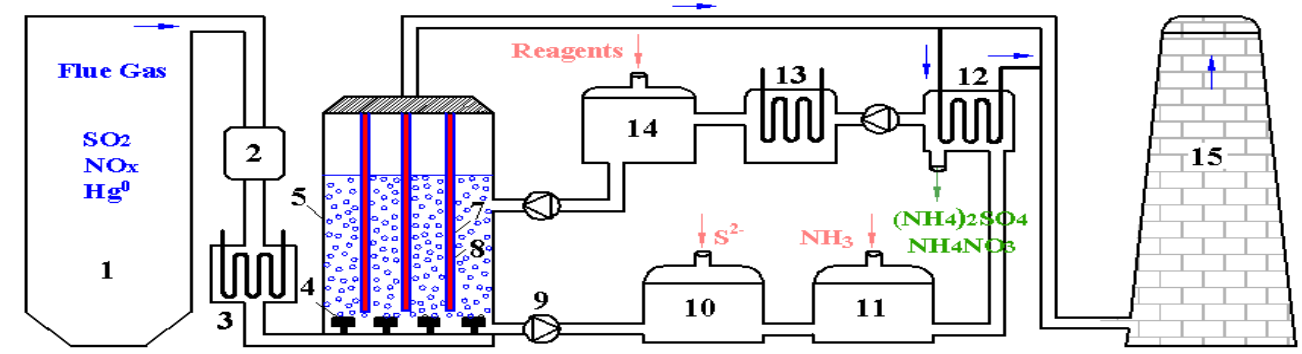

(b)

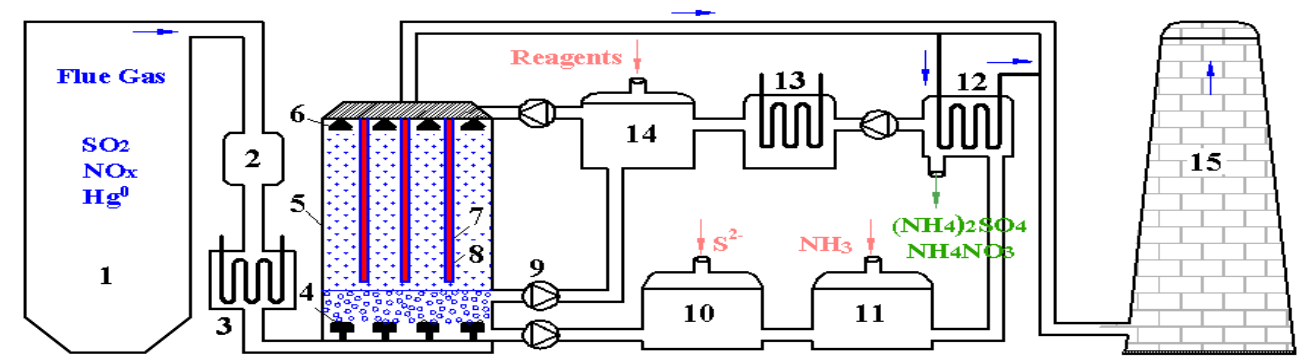

1. Boiler, Furnace or Incinerator; 2. Deduster; 3. Heat Exchanger; 4. Gas Distribution Nozzles; 5. Photochemical Spray Reactor; 6.

Atomizing Nozzles; 7. UV Lamps; 8. Quartz Tubes; 9. Circulation Pumps; 10. Hg Separation Tower; 11. $\mathrm{NH}_{3}$ Neutralizing Tower; 12.

Evaporating and Crystallizing Tower; 13. Water Vapor Vondensing Tower; 14. Reagent Addition Tower; 15. Chimney.

1734

1735

1736

Figure 26. Process flow of $\mathrm{Hg}^{0}$ removal using wet photochemical oxidation: (a) wet photochemical bubbling reactor; (b) wet photochemical spray reactor (Liu et al. 2010c, 2010d and Zhang et al. 2013).

The process flow for the simultaneous removal of $\mathrm{NO}_{\mathrm{x}}, \mathrm{SO}_{2}$ and $\mathrm{Hg}^{0}$ from flue gas in a photochemical spray reactor is shown in Figure 26 and described as follows: The flue gas system containing $\mathrm{SO}_{2} / \mathrm{NO}_{\mathrm{x}} / \mathrm{Hg}$ generated by Boiler, Furnace or Incinerator 1 enters Deduster 2 and Heat Exchanger 3 to remove dust and reduce flue gas temperature, and proceeds to the Photochemical Spray Reactor 5 through Gas Distribution Nozzles 4 to make a gas-liquid reaction with the oxidizing medium from Atomizing Nozzles 6 and Reagent Addition Tower 14. As reported by Liu et al. Liu et al. 2010a, 2010c, 2010d, 2014a, 2014c, 2014d, 2015a, the $\mathrm{SO}_{2}, \mathrm{NO}_{\mathrm{x}}$ and $\mathrm{Hg}$ can be oxidized to $\mathrm{H}_{2} \mathrm{SO}_{4}, \mathrm{HNO}_{3}$ and $\mathrm{Hg}^{2+}$, respectively, by a series of oxidation reactions. $\mathrm{The}^{2+}$ in mixed solutions can be separated in $\mathbf{H g}$ Separation Tower 10 by the addition of $\mathrm{S}^{2+}$ to react with $\mathrm{Hg}^{2+}$ producing $\mathrm{HgS}$ precipitates, which can be recycled by simple precipitation separation. The remaining $\mathrm{H}_{2} \mathrm{SO}_{4}$ and $\mathrm{HNO}_{3}$ mixed solution can be used to manufacture fertilizers, $\left(\mathrm{NH}_{4}\right)_{2} \mathrm{SO}_{4}$ and $\mathrm{NH}_{4} \mathrm{NO}_{3}$, by adding $\mathrm{NH}_{3}$ in $\mathbf{N H}_{3}$ Neutralizing Tower 11 with 
evaporation and crystallization in Evaporating and Crystallizing Tower 12 using flue gas waste heat. The produced water vapor can be condensed into water in Water Vapor Vondensing Tower 13, and is recycled back to the Reagent Addition Tower 14. The cleaned flue gas is discharged into the atmosphere by Chimney $\mathbf{1 5}$.

Liu et al. 2010c and 2010d suggested that the process has several advantages: (1) It can achieve the simultaneous removal of multi-gaseous pollutants, including $\mathrm{SO}_{2}, \mathrm{NO}_{\mathrm{x}}$ and $\mathrm{Hg}^{0}$; (2) The reaction products can be recycled by producing agricultural fertilizers such as $(\mathrm{NH} 4)_{2} \mathrm{SO}_{4}$ and $\mathrm{NH}_{4} \mathrm{NO}_{3}$; (3) The dirt on the surface of quartz tube of UV lamp is easily washed by high-speed liquid spray, avoiding the attenuation of UV-light in wet photochemical AOTs due to the deposition of dirt; (4) Removal process has no secondary pollution, and even water can also be recycled; and (5) most of the devices such as light source, spray tower and product post-processing system are very mature products, which have been widely applied in water treatment and flue gas purification industries, and can be almost applied directly on this technology. There are about more than 800000 widely used small and medium size coal-fired boilers, industrial furnaces and refuse incinerators in China alone (Liu et al. 2011a). It is economical to install individual desulfurization, denitrification or mercury removal equipment for flue gas cleanup. Therefore, this process has a good prospect for multicomponent pollution control for small- and medium-scale burners and a pilot scale construction is currently underway under the supervision of the author (Liu and collaborators).

\section{Activated oxidant AOTs}

While plasma oxidation, photocatalytic oxidation and photochemical oxidation processes have excellent technological prospects, to date, they have not achieved large-scale applications due to several unresoved issues. Among these issues, the instability of system operation and the high energy consumption of electrical installations such as plasma and light source are two of the main obstacles preventing large-scale applications (Liu et al. 2011a). Meanwhile, alternative AOTs involving ion-activated and heat-activated $\mathrm{H}_{2} \mathrm{O}_{2}$ and persulfate are gaining 
popularity due to some good laboratory results in removing $\mathrm{Hg}^{0}$ from flue gas using various reactor types (Xu et al.2008; Liu et al. 2014b; Lu et al. 2007; Zhao et al. 2014b; Zhao et al. 2014c; Martinezm et al. 2007; Ye et al. 2006; Tan et al. 2007; Liu et al. 2015b).

\subsection{An overview of $\mathrm{Hg}^{0}$ removal using activated $\mathrm{H}_{2} \mathrm{O}_{2}$ AOTs}

\subsubsection{Homogeneous Fenton-(like) processes}

Fenton reaction $\left(\mathrm{H}_{2} \mathrm{O}_{2} / \mathrm{Fe}^{2+}\right)$ was discovered in 1894 by H. J. H. Fenton, who reported that $\mathrm{H}_{2} \mathrm{O}_{2}$ could be activated by $\mathrm{Fe}^{2+}$ to oxidize tartaric acid (Fenton et al. 1984). Following this discovery, Fenton-Like reactions with similar characteristics, mainly including $\mathrm{H}_{2} \mathrm{O}_{2} / \mathrm{Fe}^{3+}, \mathrm{H}_{2} \mathrm{O}_{2} / \mathrm{Cu}^{2+}, \mathrm{H}_{2} \mathrm{O}_{2} / \mathrm{Mn}^{2+}, \mathrm{H}_{2} \mathrm{O}_{2} / \mathrm{Co}^{2+}$, etc., have been reported and received world-wide applications in the field of wastewater treatment and soil remediation, as well as flue gas purification, due to their very strong oxidative capabilities and environmentally benign features (Bokare et al. 2014; Babuponnusamiet al. 2014; Garrido-Ramírez et al. 2010; Pouran et al. 2014a; Bagal et al. 2014; Pouran et al. 2014b).

Recently, $\mathrm{Lu}$ et al. 2007 investigated for the first time $\mathrm{Hg}^{0}$ oxidation using $\mathrm{Fe}^{3+}$-based and $\mathrm{Cu}^{2+}$-based Fenton-Like reactions in both bench-scale and pilot-scale wet scrubbers, and found that $\mathrm{Fe}^{3+}$-based Fenton-Like gave better results compared to $\mathrm{Cu}^{2+}$-based ones, obtaining on the average, $75 \% \mathrm{Hg}^{0}$ oxidation. Based on the bench-scale results, a pilot-scale testing for mercury removal based on $\mathrm{Fe}^{3+}$-based Fenton reaction was further carried out by Tan et al. 2007, and a 30-40\% of $\mathrm{Hg}^{0}$ oxidation was achieved in optimized testing conditions. Although Lu et al. 2007 conducted initial research for this technology, but most of the process parameters were not optimized, and $\mathrm{Hg}^{0}$ removal mechanisms were not studied in depth. Liu et al. $2015 \mathrm{~b}$ further improved on the studies using $\mathrm{Fe}^{3+}$-based and $\mathrm{Cu}^{2+}$-based Fenton-Like reactions in a spray reactor, and reported that $100 \%{\mathrm{of} \mathrm{Hg}^{0}}^{0}$ oxidation was achieved in optimized conditions. Furthermore, both $\mathrm{Fe}^{3+}$-based and $\mathrm{Cu}^{2+}$-based Fenton-Like reactions showed good performance for the simultaneous removal of multi-pollutants. The highest simultaneous 
removal efficiencies of $\mathrm{Hg}^{0}, \mathrm{SO}_{2}$ and $\mathrm{NO}$ were up to $100 \%, 100 \%, 85.3 \%$ and $100 \%, 100 \%, 75.3 \%$ using catalysis

1791 of $\mathrm{Fe}^{3+}$ and $\mathrm{Cu}^{2+}$ catalysts, respectively. In addition, Liu et al. $2015 \mathrm{c}$ further studied the $\mathrm{Hg}^{0}$ removal using 1792 Fenton reagent in a bubble reactor, and also obtianed a good result. absorption to remove $\mathrm{Hg}^{0}$ in flue gas. The basic experimental procedure and devices are described in Figure 27. It can be seen from the Figure 27 that the vaporized Fenton-based liquid-phase complex absorbent (LCA) initially oxidized $\mathrm{Hg}^{0}$ in a preoxidation device, and then the produced $\mathrm{Hg}^{2+}$ was absorbed in a $\mathrm{Ca}(\mathrm{OH})_{2}$ in adsorbent bed or $\mathrm{CaCO}_{3}$ slurry in a WFGD device. Zhao et al. 2014a noted that the semi-dry two-stage-treatment process can effectively decrease the consumption of water and expensive oxidant, greatly reducing flue gas purification costs. In addition to ion activation, thermal activation of $\mathrm{H}_{2} \mathrm{O}_{2}$ also show a good prospect for flue gas purification because this technique can apply the high temperature waste heat from boiler to decompose $\mathrm{H}_{2} \mathrm{O}_{2}$ to generate $\cdot \mathrm{OH}$ (Martinez et al. 2007). Martinez et al. 2007 investigated the feasibility of using $\mathrm{H}_{2} \mathrm{O}_{2}$ injection for oxidation of $\mathrm{Hg}^{0}$ in flue gas and established a detailed kinetic mechanism modeling, and the results demonstrated that the application of $\mathrm{H}_{2} \mathrm{O}_{2}$, as source of $\cdot \mathrm{OH}$ radicals, accelerated the oxidation of $\mathrm{Hg}^{0}$ into $\mathrm{Hg}^{2+}$.

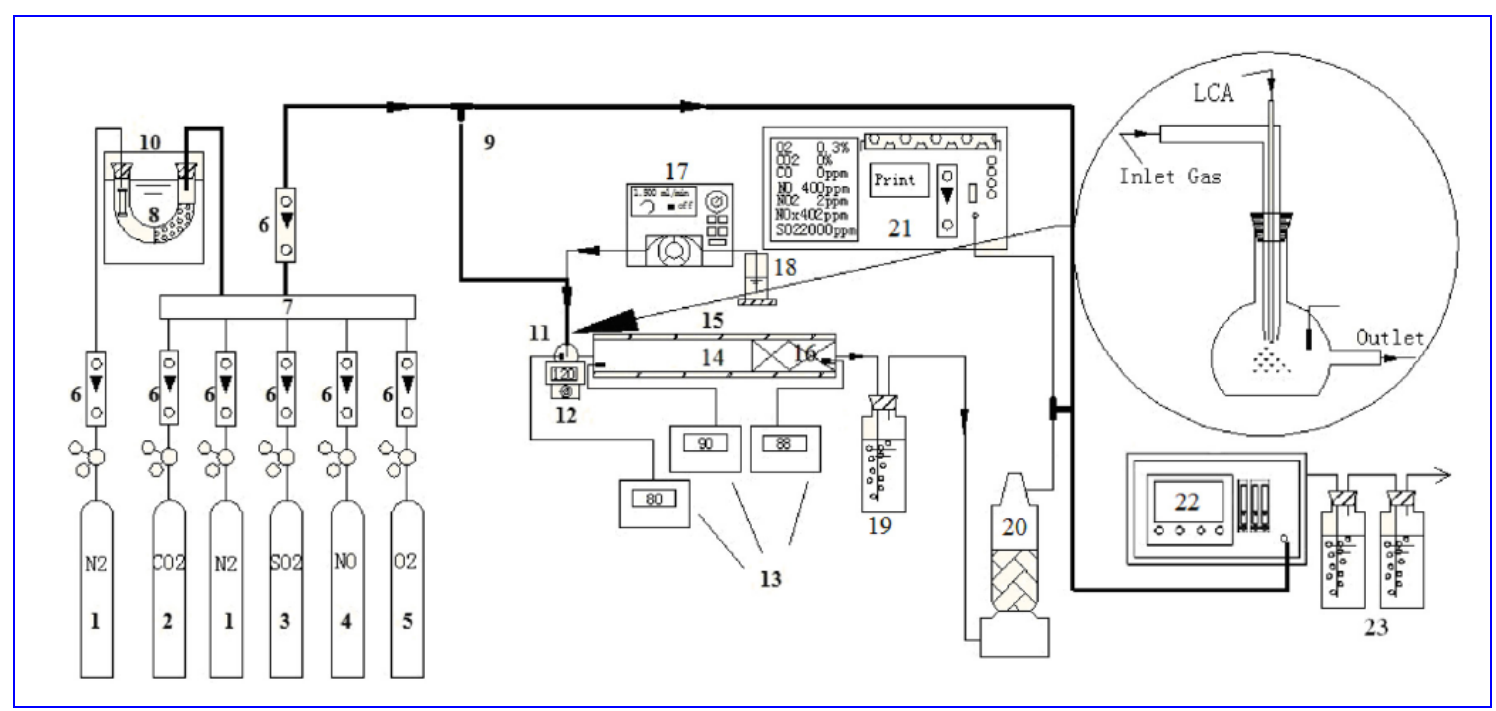

Figure 27. Schematic diagram of the experimental apparatus (Zhao et al. 2014c). (1-5) $\mathrm{N}_{2}, \mathrm{CO}_{2}, \mathrm{SO}_{2}, \mathrm{NO}, \mathrm{O}_{2}$ gas 

type resistance furnace; (16) Ca-based absorbent; (17) Peristaltic pump; (18) LCA solution; (19) KCl solution; (20) Dry tower; (21) Flue gas analyzer; (22) Cold atom fluorescence mercury detector; (23) $\mathrm{H}_{2} \mathrm{SO}_{4}-\mathrm{KMnO}_{4}$ solution.

\subsubsection{Heterogeneous Fenton-(like) processes} have several significant disadvantages that constitute the major limitations. First, additional post-treatment processes have to be used to separate the transition metal ions at the end of removal process, which will increase the costs. Second, the homogeneous Fenton solution requires quite low $\mathrm{pH}$ value to maintain high reactivity, which is not easy to be controlled. In recent years, the heterogeneous Fenton-like processes have been used widely to degrade organic pollutants from wastewater treatment because of its several advantages in broad $\mathrm{pH}$ window and without request for separation of ions (Wang et al. 2016). Zhou et al. 2015a, 2015b, 2015c recently developed several heterogeneous catalysts, such as $\mathrm{Cu}_{0.3} \mathrm{Fe}_{2.7-\mathrm{x}} \mathrm{Ti}_{\mathrm{x}} \mathrm{O}_{4}, \mathrm{Fe}_{3-\mathrm{x}} \mathrm{Cu}_{\mathrm{x}} \mathrm{O}_{4}, \mathrm{Fe}_{2.45} \mathrm{Ti}_{0.55} \mathrm{O}_{4}$ composites. Based on these catalysts the authors constituteed several novel heterogeneous Fenton-like oxidation systems to remove $\mathrm{Hg}^{0}$ from coal-fired flue gas, and the results showed that these heterogeneous Fenton-like oxidation systems have good

\subsubsection{The main influencing factors of $\mathrm{Hg}^{0}$ removal using activated $\mathrm{H}_{2} \mathrm{O}_{2}$ AOTs}

In studying $\mathrm{Hg}^{0}$ oxidation using $\mathrm{Fe}^{3+}$-based and $\mathrm{Cu}^{2+}$-based Fenton-Like reactions, Lu et al. 2007 found that solution $\mathrm{pH}$ had a significant effect on oxidation of $\mathrm{Hg}^{0}$ and a suitable $\mathrm{pH}$ window was found to be 1.0 to 3.0. Better $\mathrm{Hg}$ removal results were achieved by combining sulfur removal and $\mathrm{Hg}$ removal, and $\mathrm{Hg}$ removal capability using the Fenton-Like reactions was not dependent on the configuration of the wet scrubber. Liu et al. 2015b further studied the effects of several factors on $\mathrm{Hg}^{0}$ removal using $\mathrm{Fe}^{3+}$ - and $\mathrm{Cu}^{2+}$-based Fenton-Like reactions in spray reactor and $\mathrm{Fe}^{2+}$-based Fenton in bubble reactor, and the results indicated that $\mathrm{H}_{2} \mathrm{O}_{2}, \mathrm{Fe}^{2+}, \mathrm{Fe}^{3+}$ 
and $\mathrm{Cu}^{2+}$ concentration and liquid-gas ratio significantly promoted $\mathrm{Hg}^{0}$ removal. Solution $\mathrm{pH}, \mathrm{NO}$ and $\mathrm{SO}_{2}$ concentration significantly reduced $\mathrm{Hg}^{0}$ removal, but inlet $\mathrm{Hg}^{0}$ concentration and reaction temperature only had a small impact on $\mathrm{Hg}^{0}$ removal.

Zhao et al. 2014c also studied the influence of process parameters on $\mathrm{Hg}^{0}$ in flue gas using the above-mentioned semi-dry two-stage-treatment process, and showed that $\mathrm{Hg}^{0}$ removal efficiency to increase with increasing oxidant addition rate and reaction temperature, and then decreased with exceeding a certain value. $\mathrm{Hg}^{0}$ oxidation was inhibited with increasing solution $\mathrm{pH}$ and $\mathrm{Hg}^{0}$ inlet concentration. Zhou et al. 2015a, 2015b, 2015c studied the effects of several factors on $\mathrm{Hg}^{0}$ removal using several novel heterogeneous Fenton-like oxidation systems, and the results showed that several factors, such as reaction temperature, solution $\mathrm{pH}$, catalyst dosage, $\mathrm{H}_{2} \mathrm{O}_{2}$ dosage, $\mathrm{NO}$ content, etc., had significant effect on $\mathrm{Hg}^{0}$ removal. However, changing the content of $\mathrm{SO}_{2}$ in flue gas often only had little impact on the $\mathrm{Hg}^{0}$ removal.

\subsubsection{Product, intermediate, mechanism of $\mathrm{Hg}^{0}$ removal using activated $\mathrm{H}_{2} \mathrm{O}_{2}$ AOTs}

Martinez et al. 2007 studied the kinetic reaction mechanism of $\mathrm{Hg}^{0}$ oxidation using $\mathrm{H}_{2} \mathrm{O}_{2}$ injection through a plug flow reactor model from CHEMKIN 4.0, and carried out a sensitivity analysis to determine the dependence of model solution on the model input parameters. The sensitivity analysis of the reaction mechanism indicated that the pathway for the oxidation of $\mathrm{Hg}^{0}$ followed the interactions between $\mathrm{Cl}_{2}$ and the added supply of $\mathrm{H}_{2} \mathrm{O}_{2}$. The majority of $\mathrm{Cl}_{2}$ in flue gas was converted into atomic $\mathrm{Cl}$. and $\mathrm{HOCl}$ through the reaction with $\cdot \mathrm{OH}$ radicals. The added $\cdot \mathrm{OH}$ radicals converted $\mathrm{Cl}_{2}$ into $\mathrm{Cl}$, which triggered the formation of $\mathrm{HgCl}_{2}$ through $\mathrm{HgCl}$ as an intermediate substance. Hence, the authors concluded that the supply of $\cdot \mathrm{OH}$ radicals through $\mathrm{H}_{2} \mathrm{O}_{2}$ dissociation enhanced the oxidation of $\mathrm{Hg}^{0}$ by the aforementioned pathway. Zhao et al. 2014c determined the products and reaction mechanism of $\mathrm{Hg}^{0}$ removal using the two-stage-treatment process, and verified them to be $\mathrm{Hg}_{2}(\mathrm{OH})_{2}$, $\mathrm{HgCl}$ and $\mathrm{HgCl}_{2}$ by using XRD and atomic fluorescence spectrometry (AFS). The reaction mechanism of $\mathrm{Hg}^{0}$ 
removal was found to include several steps: (1) generation of active species such as $\cdot \mathrm{OH}, \mathrm{Cl} \cdot \mathrm{ClOH}{ }^{-}$, etc. by the initiation of Fenton reaction; (2) pre-oxidation of $\mathrm{Hg}^{0}$ in flue gas by these active species; and (3) generation of reaction products, $\mathrm{Hg}_{2}(\mathrm{OH})_{2}, \mathrm{HgCl}$ and $\mathrm{HgCl}_{2}$, by the back absorption.

Liu et al. 2015b also measured the products and intermediates of $\mathrm{Hg}^{0}$ removal in $\mathrm{Fe}^{2+}$-based and $\mathrm{Cu}^{2+}$-based Fenton-Like reactions using liquid fluorescence spectrometer and ESR spectrometer, and determined that $\mathrm{Hg}^{2+}$ was the final product of $\mathrm{Hg}^{0}$ removal and $\cdot \mathrm{OH}$ produced in solution. Liu et al. $2015 \mathrm{~b}$ also suggested the following mechanistic steps by analyzing reaction products and monitoring $\cdot \mathrm{OH}:(\mathbf{A}) \cdot \mathrm{OH}$ is produced in solution through a series of catalytic and free radical chain reactions according to the equations (65),(66),(68) and (69); (B) $\mathrm{Hg}^{0}$ is removed by $\cdot \mathrm{OH}$ and $\mathrm{H}_{2} \mathrm{O}_{2}$ oxidations according to equations (55) and (63). In the two removal pathways, $\mathrm{Hg}^{0}$ removal by oxidation of $\cdot \mathrm{OH}$ plays a major role, and $\mathrm{Hg}^{0}$ removal by oxidation of $\mathrm{H}_{2} \mathrm{O}_{2}$ only plays a secondary role in removal of $\mathrm{Hg}^{0}$; (C) radical chain reactions will terminate by reactions (64) and (74)-(77) discussed earlier. Zhou et al. 2015a, 2015b, 2015c also studied the removal mechanism of $\mathrm{Hg}^{0}$ removal using several novel heterogeneous Fenton-like oxidation systems based on the preliminary experimental analysis and discussions.

\subsubsection{Kinetics of $\mathrm{Hg}^{0}$ removal using activated $\mathrm{H}_{2} \mathrm{O}_{2}$ AOTs}

At present, the reports related to kinetics of $\mathrm{Hg}^{0}$ removal using activated $\mathrm{H}_{2} \mathrm{O}_{2}$ oxidation are rare. Zhao et al. 2014d evaluated the macrokinetics of $\mathrm{Hg}^{0}$ oxidation using a two-stage-treatment process, and they found that the reaction was a pseudo first-order with respect to $\mathrm{Hg}^{0}$, and the apparent activation energy was $14.3 \mathrm{~kJ} / \mathrm{mol}$.

\subsection{An overview of $\mathrm{Hg}^{0}$ removal using activated persulfate AOTs}

Persulfate or peroxydisulfate anion $\left(\mathrm{S}_{2} \mathrm{O}_{8}{ }^{2-}\right)$ is a strong oxidant with a redox potential of $2.01 \mathrm{~V}$, and is considered as a promising choice for clean-up applications because of the ease of storage and transport, pH-independence, stability and low cost (Khan et al. 2010). Persulfate is a strong oxidizing agent, but it is kinetically slow under ordinary conditions (Adewuyi et al. 2013; Adewuyi et al. 2010; Fang et al. 2012). Related 
studies showed that $\mathrm{S}_{2} \mathrm{O}_{8}{ }^{2-}$ can be activated to generate $\cdot \mathrm{OH}$ and sulfate radicals $\left(\mathrm{SO}_{4}{ }^{-}\right)$with higher redox potential of 2.6-3.1V either by the homolysis of the oxidant bond using heat (Tan et al. 2013; Ji et al. 2015), ultrasound (Hao et al. 2014; Wang et al. 2014; ), microwave (Chou et al. 2015; Qi et al. 2014) or light (Wang et al. 2014; Lin et al. 2011), or by a redox reaction caused by catalysis of various substances (Oncu et al. 2015; Yan et al. 2015; Yang et al. 2011; Liang et al. 2013; Lee et al. 2013; Li et al. 2014c; Li et al. 2014d; Usman et al. 2012) as summarized in Figure 28. Compared to $\cdot \mathrm{OH}, \mathrm{SO}_{4} \cdot{ }^{-}$is more selective and demonstrate higher standard reduction potential at neutral pH (Adewuyi et al. 2010; Hao et al. 2014; Oncu et al. 2015; Yang et al. 2011). In recent years, activated persulfate technologies have rapidly evolved with successful applications in the field of wastewater treatment, remediation of contaminated soils and groundwater as well as flue gas purification.

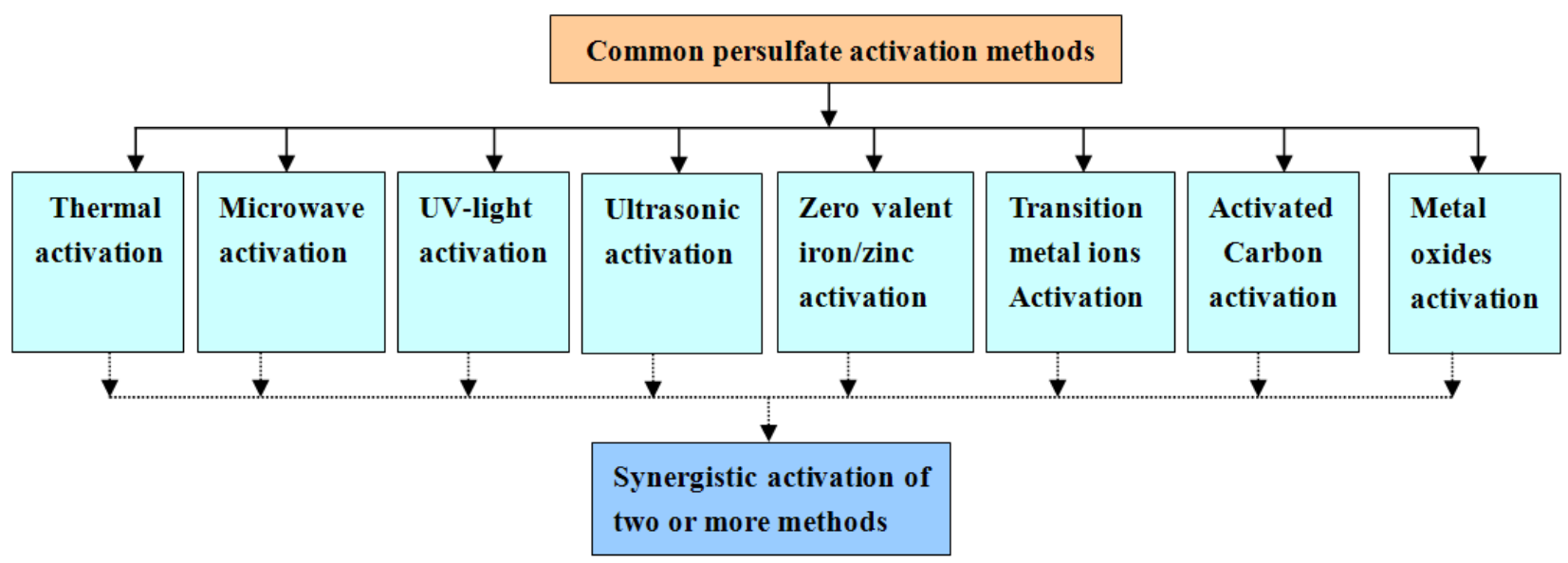

Figure 28. Common activated persulfate methods

Ye et al. 2006 and Xu et al. 2008 used $\mathrm{Ag}^{+}$-activated and $\mathrm{Cu}^{2+}$-activated $\mathrm{K}_{2} \mathrm{~S}_{2} \mathrm{O}_{8}$ to oxidize $\mathrm{Hg}^{0}$ from flue gas in a simple bubbler, and their results showed that $97.0 \%$ and $81.9 \%$ of $\mathrm{Hg}^{0}$ conversion were achieved by $\mathrm{Ag}^{+}-$and $\mathrm{Cu}^{2+}$-activated $\mathrm{K}_{2} \mathrm{~S}_{2} \mathrm{O}_{8}$, respectively. Liu et al. 2014b developed a novel technique on removal of $\mathrm{Hg}^{0}$ from flue gas by heat-activated $\left(\mathrm{NH}_{4}\right)_{2} \mathrm{~S}_{2} \mathrm{O}_{8}$ in a bubbling reactor, which uses the flue gas waste heat from boilers (usually above $130^{\circ} \mathrm{C}$ ) to provide free heat for activation of persulfate. They reported the highest removal efficiency for $\mathrm{Hg}^{0}$ up to $99.6 \%$, with reaction product recyclable, and deemed this process to have a good prospect. Zhao et al. 
2014b proposed an integrative process of preoxidation of $\mathrm{Hg}^{0}$ to $\mathrm{Hg}^{2+}$ by a vaporized liquid-phase multi-component oxidant made up of $\mathrm{H}_{2} \mathrm{O}_{2}$ and $\mathrm{Na}_{2} \mathrm{~S}_{2} \mathrm{O}_{8}$ coupled with $\mathrm{Ca}(\mathrm{OH})_{2}$ absorption for removing $\mathrm{Hg}^{0}$ in flue gas. This technique has a process and apparatus similar to Figure 27, but the radical chain reactions were induced by heat-activated persulfate. Zhao et al. 2014b also showed that this method is effective for the simultaneous removal of $\mathrm{SO}_{2}, \mathrm{NO}$ and $\mathrm{Hg}^{0}$ in flue gas, with efficiencies of $100,83.2$ and $91.5 \%$ for $\mathrm{SO}_{2}, \mathrm{NO}$ and $\mathrm{Hg}^{0}$, respectively, under optimal conditions.

\subsubsection{The main influencing factors of $\mathrm{Hg}^{0}$ removal using activated persulfate AOTs}

Ye et al. 2006 and $\mathrm{Xu}$ et al. 2008 examined the effects of several factors on $\mathrm{Hg}^{0}$ removal using $\mathrm{Ag}^{+}$- and $\mathrm{Cu}^{2+}$-activated $\mathrm{K}_{2} \mathrm{~S}_{2} \mathrm{O}_{8}$ in a bubbler, and found that $\mathrm{Hg}^{0}$ conversion efficiency increased with increasing $\mathrm{K}_{2} \mathrm{~S}_{2} \mathrm{O}_{8}$, $\mathrm{Ag}^{+}$or $\mathrm{Cu}^{2+}$ concentration. Low temperature and neutral solution were more conducive to $\mathrm{Hg}^{0}$ conversion. Liu et al. $2014 \mathrm{~b}$ also tested the effects of several factors on $\mathrm{Hg}^{0}$ removal by heat-activated $\left(\mathrm{NH}_{4}\right)_{2} \mathrm{~S}_{2} \mathrm{O}_{8}$ in a bubbling reactor, and found that $\left(\mathrm{NH}_{4}\right)_{2} \mathrm{~S}_{2} \mathrm{O}_{8}$ concentration and the activation temperature significantly promoted, while solution $\mathrm{pH}$ greatly inhibited $\mathrm{Hg}^{0}$ removal, but the concentrations of $\mathrm{Hg}^{0}$, $\mathrm{NO}$ and $\mathrm{SO}_{2}$ had insignificant effect.

Zhao et al. 2014b investigated the effects of several factors on $\mathrm{Hg}^{0}$ removal using an integrative process of preoxidation and absorption previously described and showed that $\mathrm{Hg}^{0}$ removal efficiency significantly increased with increasing molar ratio of $\mathrm{Na}_{2} \mathrm{~S}_{2} \mathrm{O}_{8}$ to $\mathrm{H}_{2} \mathrm{O}_{2}$, reaction temperature or addition rate of mixed oxidant; and then almost kept constant, greatly decreased and slightly reduced when molar ratio, reaction temperature or addition rate exceeded a certain value, respectively. $\mathrm{Hg}^{0}$ removal was almost unaffected by $\mathrm{pH}$ of mixed oxidant when the $\mathrm{pH}$ was between 1.5 and 5.5 , but was significantly reduced as $\mathrm{pH}$ increased from 5.5 to 7.5 . The effect of $\mathrm{NO}$ was either promotional or inhibitory depending on its concentration, while the influences of other gases such as $\mathrm{O}_{2}$, $\mathrm{CO}_{2}$ and $\mathrm{SO}_{2}$ could be neglected.

\subsubsection{Product, intermediate and mechanism of $\mathrm{Hg}^{0}$ removal using activated persulfate AOTs}



products and mechanism of $\mathrm{Hg}^{0}$ removal between $\mathrm{Ag}^{+}$- and $\mathrm{Cu}^{2+}$-activated $\mathrm{K}_{2} \mathrm{~S}_{2} \mathrm{O}_{8}$ using cold vapor generation atomic absorption spectrometry (CVAAS) and the addition of tert-butanol inhibitors. The results showed that $\mathrm{Hg}^{0}$ oxidation was achieved simultaneously via "direct oxidation" by $\mathrm{K}_{2} \mathrm{~S}_{2} \mathrm{O}_{8}$ and "indirect reaction" by free radicals, and the final product was $\mathrm{Hg}^{2+}$ in liquid phase. Zhao et al. 2014b investigated the product and mechanism of $\mathrm{Hg}^{0}$ removal using an integrative process of preoxidation and absorption basing on the analysis of XPS for the deposited mercury species, and they found that both $\mathrm{HgO}$ and $\mathrm{HgSO}_{4}$ were the main products of $\mathrm{Hg}^{0}$ removal. The radical chain reactions of $\mathrm{Hg}^{0}$ removal were induced by heat-activated persulfate, and $\mathrm{H}_{2} \mathrm{O}_{2}$ played an important role in the free radical chain reactions, improving the yield of free radicals. The reaction mechanism and pathways 1922 of $\mathrm{Hg}^{0}$ removal using this integrative process of pre-oxidation and absorption is also described in Figure 29. 2014a).

Liu et al. 2014b studied the reaction mechanism and pathways of $\mathrm{Hg}^{0}$ removal by heat-activated $\left(\mathrm{NH}_{4}\right)_{2} \mathrm{~S}_{2} \mathrm{O}_{8}$,

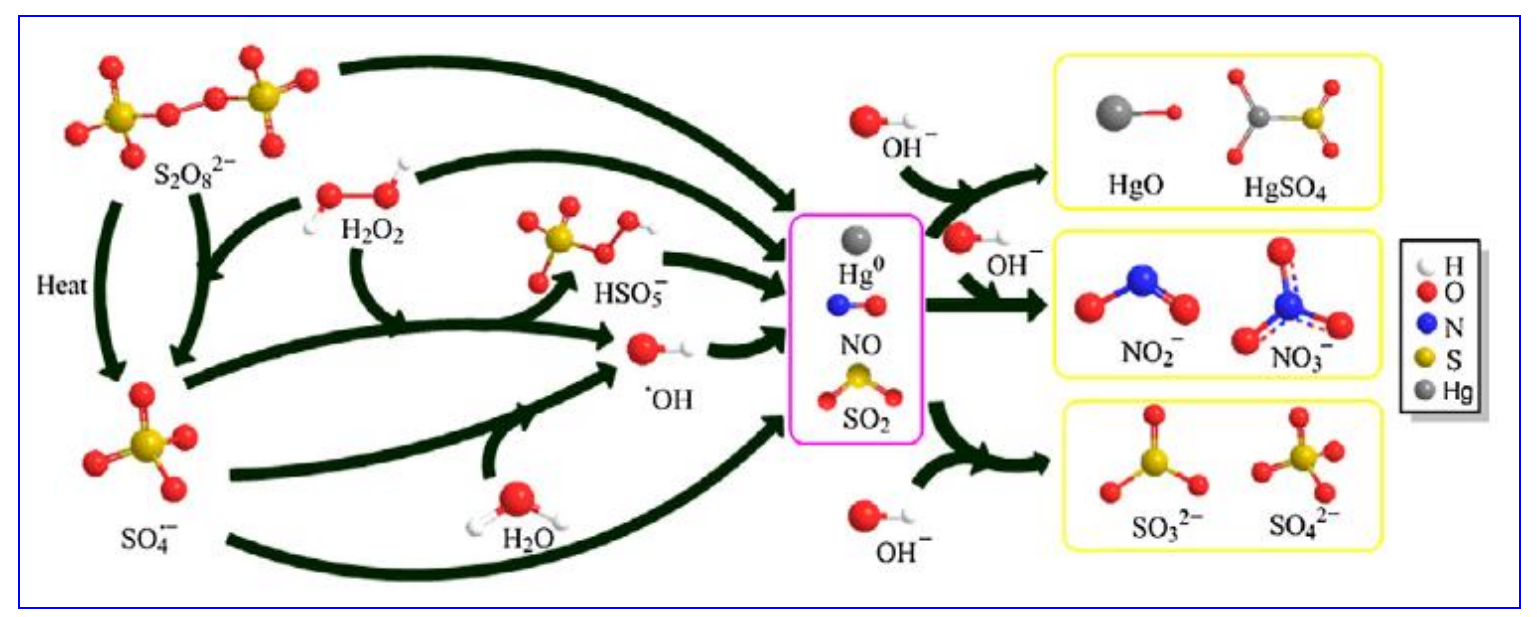

Figure 29. Mechanism of $\mathrm{Hg}^{0}$ removal using integrative process of preoxidation and absorption (Zhao et al. and measured the reaction products and intermediates using liquid fluorescence spectrometer, ion chromatography (IC) and ESR spectrometer. The results indicated that $\mathrm{SO}_{4}{ }^{-} \cdot$ and $\cdot \mathrm{OH}$ in solution were successfully captured using ESR spectrometer, which are shown in Figure $30 . \mathrm{Hg}^{2+}$ was the main product of $\mathrm{Hg}^{0}$ removal, and $\mathrm{Hg}^{0}$ was mainly 

heat-activated $\left(\mathrm{NH}_{4}\right)_{2} \mathrm{~S}_{2} \mathrm{O}_{8}$ proposed are as in reactions (96)-(99).

1932 (A) Generation of $\mathrm{SO}_{4}^{-} \cdot$ and $\cdot \mathrm{OH}$ by reactions (96) and (97).

$$
\mathrm{S}_{2} \mathrm{O}_{8}^{2-}(l) \stackrel{\text { heat }}{\longrightarrow} 2 \mathrm{SO}_{4}^{-} \cdot(l)
$$

$$
\mathrm{SO}_{4}^{-} \cdot(l)+\mathrm{H}_{2} \mathrm{O}(l) \rightarrow \cdot \mathrm{OH}(l)+\mathrm{HSO}_{4}^{-}(l) \quad k=6.6 \times 10^{2} s^{-1}
$$

(B) Oxidative removal of $\mathrm{Hg}^{0}$ by $\mathrm{SO}_{4}^{-}$. and $\cdot \mathrm{OH}$ via reactions (55) and (98).

$$
2 \mathrm{SO}_{4}^{-} \cdot(l)+\mathrm{Hg}^{0}(l) \rightarrow \mathrm{Hg}^{2+}(l)+2 \mathrm{SO}_{4}^{2-}(l)
$$

(C) Oxidative removal of $\mathrm{Hg}^{0}$ by $\mathrm{S}_{2} \mathrm{O}_{8}^{2-}$ via reaction (99).

$$
\mathrm{S}_{2} \mathrm{O}_{8}^{2-}(l)+\mathrm{Hg}^{0}(l) \rightarrow \mathrm{Hg}^{2+}(l)+2 \mathrm{SO}_{4}^{2-}(l)
$$

(D) Termination of radical reactions via reactions (64), (74)-(77) and (100)-(102).

1940

$$
\begin{array}{ll}
\cdot \mathrm{OH}(l)+\mathrm{S}_{2} \mathrm{O}_{8}^{2-}(l) \rightarrow \mathrm{OH}^{-}(l)+\mathrm{S}_{2} \mathrm{O}_{8}^{-} \cdot(l) & k=1.2 \times 10^{7} M^{-1} s^{-1} \\
\mathrm{SO}_{4}^{-} \cdot(l)+\mathrm{S}_{2} \mathrm{O}_{8}^{2-}(l) \rightarrow \mathrm{SO}_{4}^{2-}(l)+\mathrm{S}_{2} \mathrm{O}_{8}^{-} \cdot(l) & k=6.1 \times 10^{5} M^{-1} s^{-1} \\
\mathrm{SO}_{4}^{-} \cdot(l)+\mathrm{SO}_{4}^{-} \cdot(l) \rightarrow \mathrm{S}_{2} \mathrm{O}_{8}^{2-}(l) & k=4.0 \times 10^{8} M^{-1} s^{-1}
\end{array}
$$
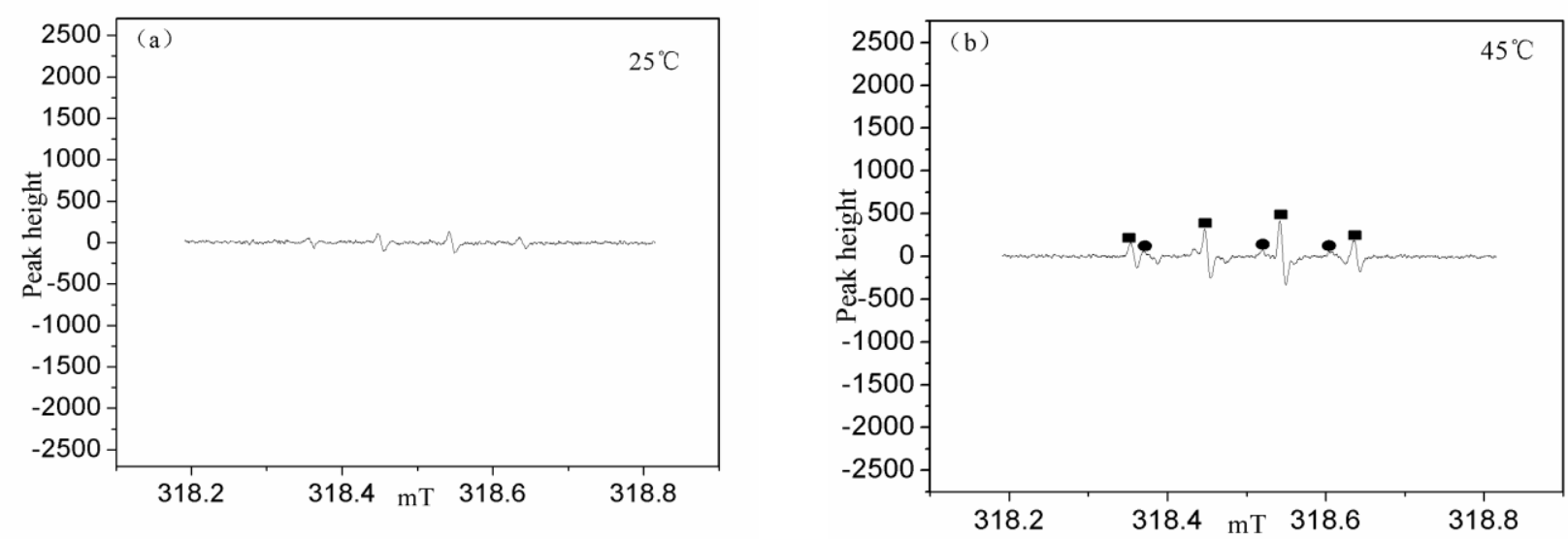

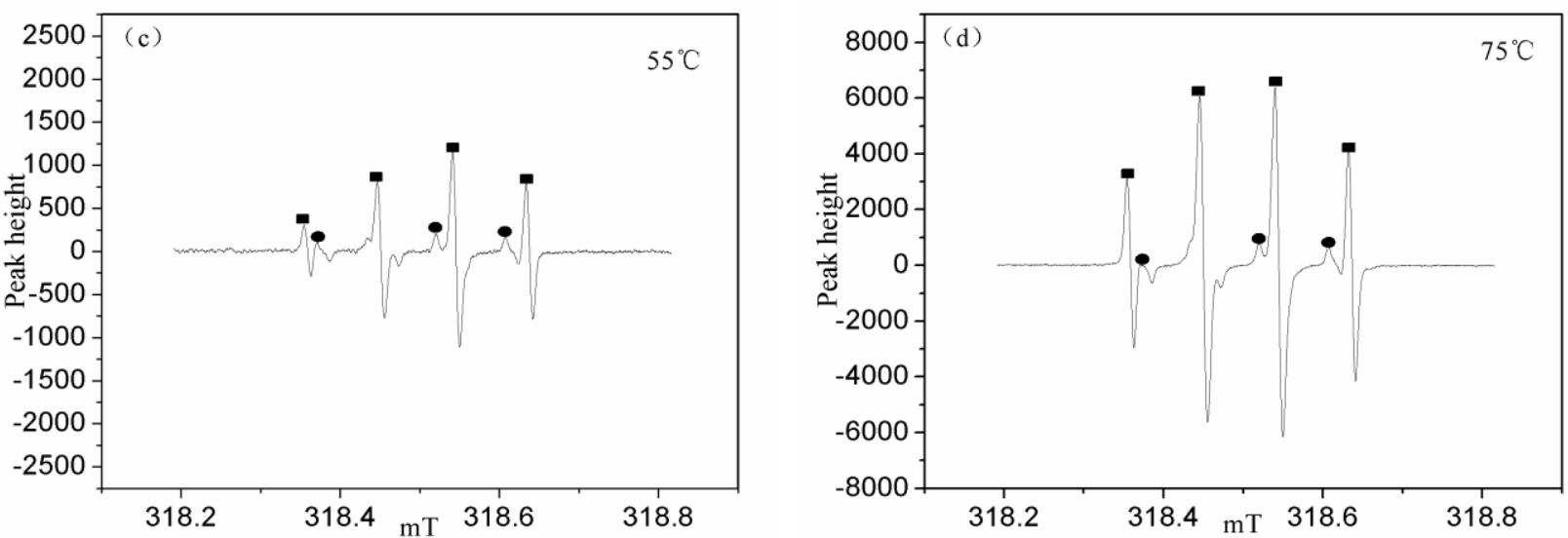

1944

1945

1946

1947

1948

1949

1950

1951

1952

1953

1954

1955

1956

1958

1959

1960

Figure 30. ESR spectra of $\mathrm{SO}_{4}{ }^{-} \cdot$ and $\cdot \mathrm{OH}$ radical adducts at $25^{\circ} \mathrm{C}$ (a), $45^{\circ} \mathrm{C}$ (b), $55^{\circ} \mathrm{C}$ (c) and $75^{\circ} \mathrm{C}$ (e). (Circles represent the DMPO-SO 4 and triangles represent the DMPO-OH.) (Liu et al. 2014b).

\subsubsection{Kinetics of $\mathrm{Hg}^{0}$ removal using activated persulfate AOTs}

The kinetic parameters and kinetic model are the essential basis for the design and amplification of reactor as well as the numerical simulation of $\mathrm{Hg}^{0}$ removal process. Ye et al. 2006 studied the kinetics of $\mathrm{Hg}^{0}$ removal using $\mathrm{Ag}^{+}$-activated $\mathrm{K}_{2} \mathrm{~S}_{2} \mathrm{O}_{8}$ was studied, and determined the kinetic rate constants and activation energy. They found the chemical reaction to be the rate-controlling step for $\mathrm{Hg}^{0}$ removal. Zhao et al. 2014b studied the macrokinetics of $\mathrm{Hg}^{0}$ oxidation using an integrative process of preoxidation and absorption, and they found that the reaction was a pseudo first-order with respect to $\mathrm{Hg}^{0}$, and the apparent activation energy was $14.3 \mathrm{~kJ} / \mathrm{mol}$. Liu et al. 2014b investigated the mass-transfer reaction kinetics of $\mathrm{Hg}^{0}$ removal using heat-activated $\left(\mathrm{NH}_{4}\right)_{2} \mathrm{~S}_{2} \mathrm{O}_{8}$ in a bubbling reactor. Their results indicated that when $\left(\mathrm{NH}_{4}\right)_{2} \mathrm{~S}_{2} \mathrm{O}_{8}$ concentration was more than $0.1 \mathrm{~mol} / \mathrm{L}$ and solution $\mathrm{pH}$ was lower than 9.71, $\mathrm{Hg}^{0}$ removal was a pseudo-first-order rapid reaction for $\mathrm{Hg}^{0}$, and the $\mathrm{Hg}^{0}$ absorption process could be represented by the following kinetic model (103):

$$
N_{\mathrm{Hg}^{0}}=p_{\mathrm{Hg}^{0}, G}\left(\frac{1}{k_{\mathrm{Hg}^{0}, G}}+\frac{1}{H_{H^{0}, L}\left(k_{o v 1} \cdot D_{H^{0}, L}\right)^{1 / 2}}\right)^{-1}
$$

where $N_{\mathrm{Hg}^{0}}$ is $\mathrm{Hg}^{0}$ absorption rate, $\mathrm{mol} / \mathrm{m}^{2} \cdot s ; k_{\mathrm{Hg}^{0}, \mathrm{G}}$ is gas phase mass transfer coefficient, $\mathrm{mol} / \mathrm{s} \cdot \mathrm{m}^{2} \cdot \mathrm{Pa}$; $p_{\mathrm{Hg}^{0}, G}$ is $\mathrm{Hg}^{0}$ partial pressure in gas phase body, $\mathrm{Pa} ; \mathrm{H}_{\mathrm{Hg}^{0}, L}$ is solubility coefficient of $\mathrm{Hg}^{0}$ in liquid phase, 
1961

$\mathrm{mol} /(\mathrm{L} \cdot \mathrm{Pa}) ; k_{o v 1, \mathrm{Hg}^{0}}$ is pseudo-first-order reaction with respect to $\mathrm{Hg}^{0}, \mathrm{~s}^{-1} ; D_{\mathrm{Hg}^{0}, L}$ is the diffusion coefficient of $\mathrm{Hg}^{0}$ in liquid phase, $m^{2} / s$.

Based on the results of reaction mechanism previously described in section 5.2.2 and mass-transfer reaction kinetics, Liu et al. 2014b further proposed a macroscopic kinetic mechanism model of $\mathrm{Hg}^{0}$ removal involving mass transfer and chemical reaction, which include mainly the following several parts: (1) $\mathrm{Hg}^{0}(\mathrm{~g})$ in gas-phase body firstly reaches the gas-liquid interface by diffusion through gas film, and keep a gas-liquid equilibrium in gas-liquid interface; (2) $\mathrm{Hg}^{0}$ (1), which has been dissolved in liquid phase enters the liquid film by diffusion through gas-liquid interface, and reacts with $\mathrm{S}_{2} \mathrm{O}_{8}{ }^{2-} / \mathrm{SO}_{4}{ }^{-} \cdot / \mathrm{OH}$ from liquid phase body in a reaction surface; (3) In the reaction surface, a series of chemical reactions (55) and (96)-(99) for $\mathrm{Hg}^{0}$ removal will occur, other side reactions including (64), (74)-(77) and (100)-(102) occur; and (4) The gaseous products will return to the gas phase body by diffusion through two-film. However, the liquid product such as $\mathrm{Hg}^{2+}$ will enter liquid phase body by diffusion through liquid film. The macroscopic kinetic mechanism model of $\mathrm{Hg}^{0}$ removal from flue gas by thermally activated $\left(\mathrm{NH}_{4}\right)_{2} \mathrm{~S}_{2} \mathrm{O}_{8}$ in a bubbling reactor also can be presumably described as in Figure 31 .

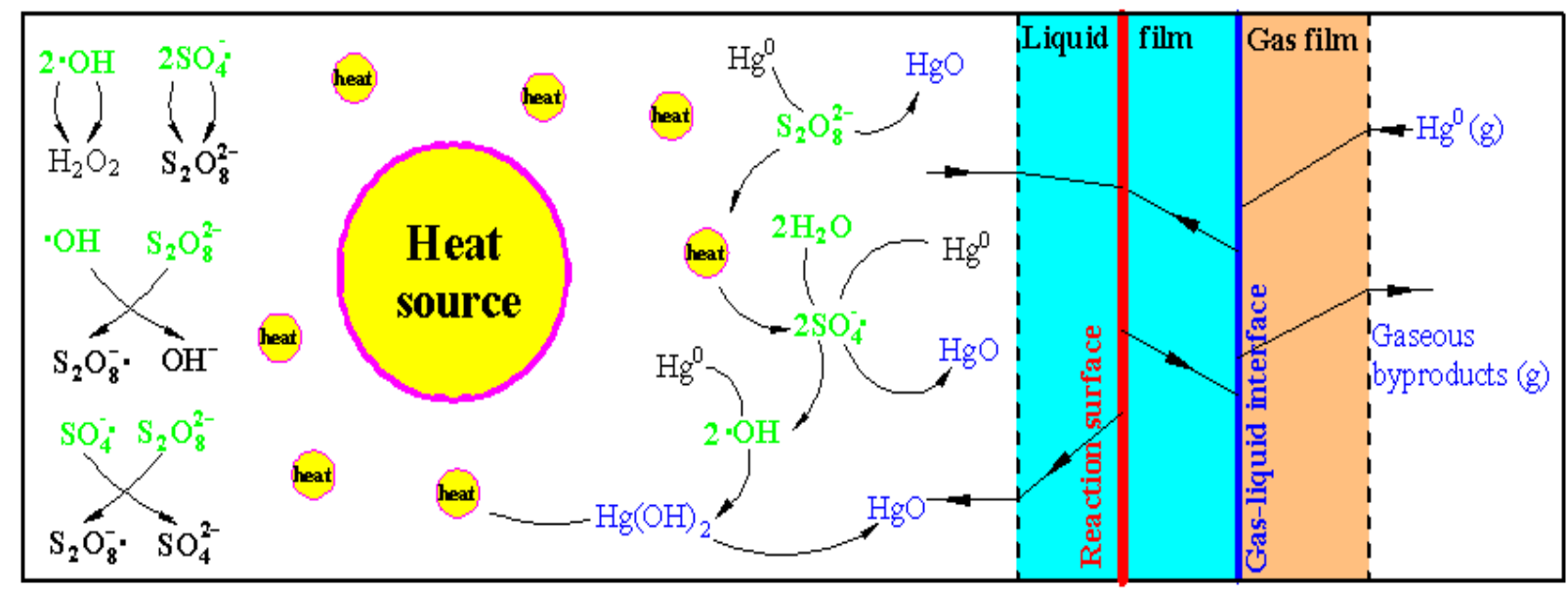

Figure 31. Macroscopic kinetic mechanism model of $\mathrm{Hg}^{0}$ removal from flue gas by thermally activated $\left(\mathrm{NH}_{4}\right)_{2} \mathrm{~S}_{2} \mathrm{O}_{8}$ in a bubbling reactor (Liu et al. 2014b).

\subsection{An overview of $\mathrm{Hg}^{0}$ removal using activated $\mathrm{O}_{3} \mathrm{AOTs}$}


2009; Wen et al. 2008). To improve utilization rate of $\mathrm{O}_{3}$ and oxidation ability of process, $\mathrm{O}_{3}$ is often activated to

generate $\cdot \mathrm{OH}, \cdot \mathrm{O}, \mathrm{HO}_{2}$, etc. with stronger oxidizing power for removing pollutants using a variety of methods

very similar with those used for activating persulfate as illustrated in Figure 28 (Umar et al. 2013; Ding et al. 2014;

Sun et al. 2011; Sun et al. 2013; Wang et al. 2005; Wang et al. 2007; Wen et al. 2009; Wen et al. 2008; Einaga et al.

2015; Oh et al. 2014; Lucas et al. 2014; Moussavi et al. 2009; Medellin-Castillo et al. 2013; Kim et al. 2011; Song

ozone injection process to oxidize $\mathrm{Hg}^{0}, \mathrm{NO}$ and $\mathrm{SO}_{2}$ from flue gas, and proposed a reaction mechanism of $\mathrm{Hg}^{0}$

removal with 70 elementary reactions. The results showed that $\mathrm{Hg}^{0}$ oxidation was enhanced by adding more $\mathrm{O}_{3}$, a key role in $\mathrm{Hg}^{0}$ oxidation. 
low flow resistance and large gas-liquid contact area (Zhang et al. 1985). The bubble column tower, Figure 32 (b),

2001 is also popular in laboratory settings due to its simple structure and easy operation, but so far, of limited industrial 2002 applications. In these reactors, the chemical reaction rate caused by free radicals is usually very fast, and hence, the mass transfer process is often the rate-controlling step (Liu et al. 2012b, 2012c, 2013d; Khan et al. 2010; 2004 Adewuyi et al. 2014) Liu et al. 2014b recently investigated the mass-transfer reaction kinetics of $\mathrm{Hg}^{0}$ removal reactor with a larger specific interfacial area was the most effective method for enhancing $\mathrm{Hg}^{0}$ removal (Liu et al. 2014b). The gas-liquid specific surface area of the spray tower $\left(200 \mathrm{~m}^{-1}\right)$ is about ten times that of the bubble column tower $\left(20 \mathrm{~m}^{-1}\right)$, therefore, it was suggested that the spray tower might be more suitable for $\mathrm{Hg}^{0}$ removal using heat-activated $\left(\mathrm{NH}_{4}\right)_{2} \mathrm{~S}_{2} \mathrm{O}_{8}$ (Zhu et al. 2005). As described in Figure 33(a), the corresponding process flows are very similar to typical WFGD process. While industrial applications of flue injection of activated carbon for waste incineration flue gas purification are well-known, its application as oxidizer for flue gas purification is rare tower, this kind of flue injection reactor as shown in Figure 32(c) appears to be more suitable for the revamping of 


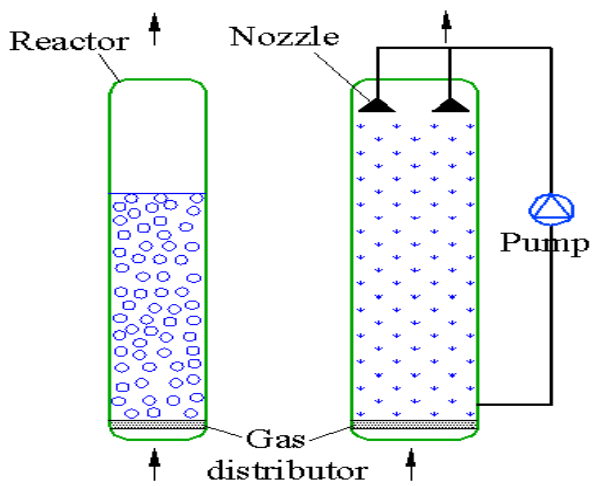

(a)

(b)

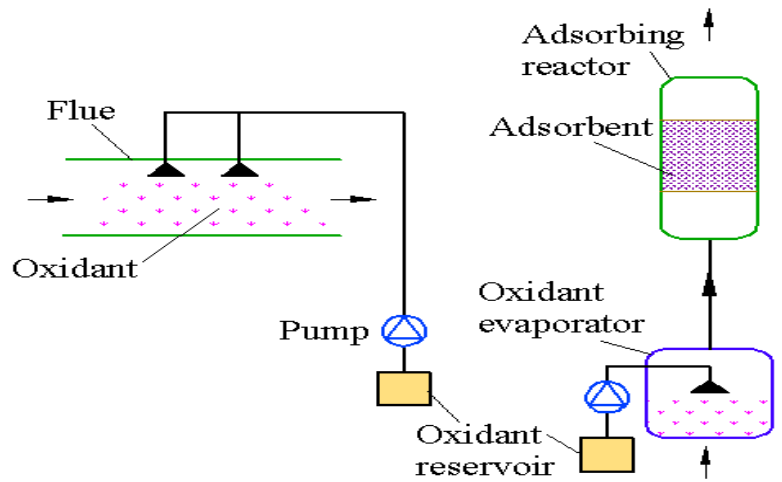

(c)

(d)

Figure 32. Reactor of $\mathrm{Hg}^{0}$ removal using activated oxidizer AOTs: (a) bubble column tower; (b) spray tower

(a)

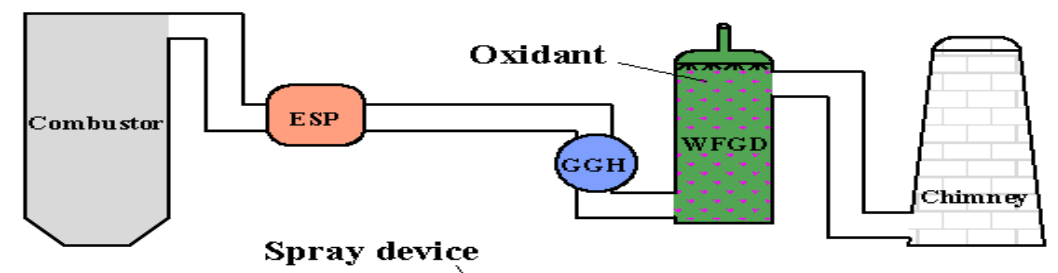

(b)

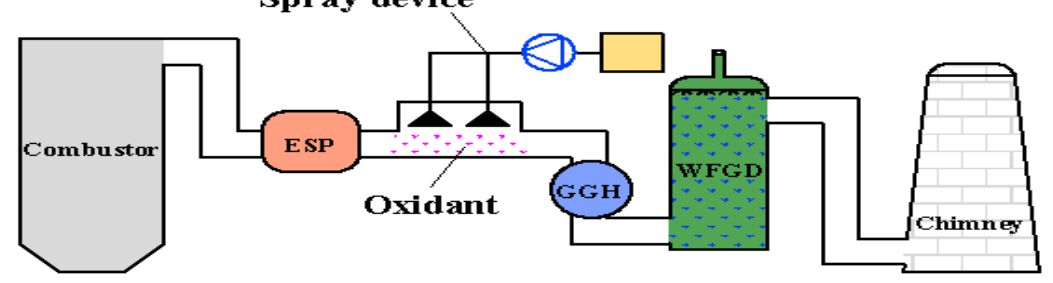

(c)

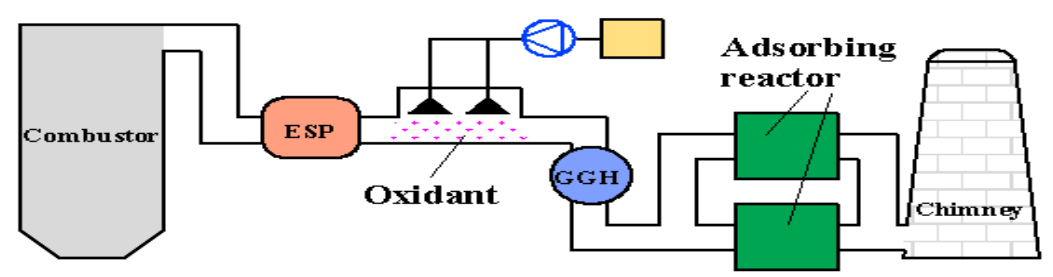

Figure 33. Process flow of $\mathrm{Hg}^{0}$ removal using activated oxidizer AOTs: (a) spray tower reactor process; (b) flue injection process of oxidizer; (e) pre-oxidation \& adsorption process.

At present, although adsorption removal of mercury has demonstrated good prospects, almost all of the adsorbents have very low adsorption performance for $\mathrm{Hg}^{0}$ and NO (Liu et al. 2008; Liu et al. 2010d). However, a large number of modified methods have been recently developed to enhance performance of adsorbents for $\mathrm{Hg}^{0}$ and NO in flue gas, which appear to have demonstrated significant progress (Liu et al. 2008; Ahmaruzzaman et al. 
2010; Wilcox et al. 2012; Liu et al. 2010d). Unfortunately, these lab-scale studies are still difficult to be adapted for industrial applications due to unstable performance and high modification costs. Zhao et al. 2014b and 2014c have proposed the preoxidation \& absorption reactor shown in Figure 32 (d), and the corresponding two-stage integrative process shown in Figure 33(c), and similar to Figure 33 (b), which effectively avoid the aforementioned dual problems. In these processes, both $\mathrm{Hg}^{0}$ and $\mathrm{NO}$ in flue gas are oxidized to $\mathrm{Hg}^{2+}$ and $\mathrm{NO}_{2} / \mathrm{HNO}_{2} / \mathrm{HNO}_{3}$, which are then easily adsorbed in the back adsorption reactor. It should be noted tha,t to achieve continuous operation of the removal process, it might be necessary to install two parallel adsorption reactors; one for the regeneration of adsorbent and the recovery of products, and the other for the adsorption of pollutants. For this kind of oxidizer flue injection method, it is very necessary to take some effective anti-corrosion measures to protect heat transfer surfaces as well as other rear-mounted devices in flue gas duct due to the inevitable destruction of equipment resulting from erosion and the process oxidants.

\section{Summary, concluding remark and future research directions}

Recently, AOTs have received significant world-wide attention for multicomponent gas purification and control of air toxics. It is obvious from these discussions that AOTs have great potential for further development and application in the field of $\mathrm{Hg}^{0}$ control and multicomponent flue gas purification. However, there are still a number of technical issues to be resolved before the realization of the ultimate goal of industrial applications. Major challenges for broader application of $\mathrm{AOPs}$ for $\mathrm{Hg}^{0}$ removal include further development of fundamental understanding of the reaction pathways and dynamics and engineering advancement in materials and equipment to counter the corrosive and erosive effects of reaction products to make these processes more energy-sustainable.

These issues are briefly discussed here and some potential research directions also proposed.

(1) Due to very strong oxidizing environment induced by free radicals, AOTs have demonstrated good prospects for the development of clean processes, especially in the field of water treatment, soil remediation as 
well as flue gas purification, including the simultaneous and multi-pollutant removal of mainly $\mathrm{Hg}^{0}, \mathrm{SO}_{2}, \mathrm{NO}_{\mathrm{x}}$,

$\mathrm{H}_{2} \mathrm{~S}$ and VOCs in flue gas. This review has discussed a number of new AOTs for effective purification of $\mathrm{Hg}^{0}$-containing flue gas and outlined new research opportunities and directions. However, due to the very low concentration of mercury in flue gas and huge amount of flue gas, using an independent device to control mercury emission is considered to be an uneconomical method. It is almost impossible, especially for a large number of small/medium-scale burners in civil and industrial sectors, to simultaneously install desulfurization, denitrification and demercurization equipment due to the huge cost. Simultaneous removal of multi-pollutants in flue gas has been recognized as a cost-effective control strategy, which has shown excellent prospects. As previously discussed, AOTs often have excellent removal capability of multi-pollutants due to the non-selectivity and strong oxidation potential of the hydroxyl radical $(\cdot \mathrm{OH})$. Therefore, further studies are necessary in the future to demonstrate the potential of AOPs for the simultaneous removal of $\mathrm{SO}_{2}, \mathrm{NO}_{\mathrm{x}}$ and $\mathrm{Hg}^{0}$ in a single reactor of separation vessel. Such technologies could make a single wet flue gas desulfurization (WFGD) scrubber more cost-effective and could obviate the need to install additional costly equipment as SCR and carbon adsorption for multicomponent gas purification.

(2) Actual flue gas components are extremely complex, and current studies have mostly considered $\mathrm{Hg}^{0}$ removal only and evaluated the effects of limited components of the flue gas, mainly other gas constituents, and not solid components. For example, fly ash particles or alkali metal salts in actual flue gas may corrode and block the electrodes and discharge spaces of plasma reactor as well as photocatalysts. Deposition of particles and oxidation products on the surface of photocatalysts, plasma electrode and UV lamp quartz tube also result in the decline of photocatalyst activity and system operating efficiency, and even system failure. In future studies, effects of more practical flue gas components should be addressed, and some suitable anti-corrosion and anti-blocking measures developed. 
(3) Reaction products of $\mathrm{Hg}^{0}$ removal using AOTs are very important information for recovery of mercury resources, avoiding new mercury secondary pollution and revealing reaction mechanism. For example, $\mathrm{Hg}^{0}$ removal using plasma AOTs involves complex reaction pathways and product mixtures. In addition, for AOTs, capture and identification of reactive intermediates are very useful for understanding the reaction mechanism of

$\mathrm{Hg}^{0}$ removal. To date, studies on the determination of products are limited and often involve a single solid, liquid or gaseous phase. However, the removal products of $\mathrm{Hg}^{0}$ may simultaneously exist in two or three phases. 
system. Kinetic parameters and kinetic model are the essential basis for the design and amplification of reactor as

2096 well as the numerical simulation of $\mathrm{Hg}^{0}$ removal process. For gas-liquid (wet AOPs) and gas-solid $\left(\mathrm{TiO}_{2}\right.$ 2097 photocatalytic AOPs) systems where the removal process are affected by simultaneous mass transfer (or adsorption) and chemical reaction, detailed investigations to determine the extent of mass transfer intensification as a function of process and operating parameters are needed. Mathematical models should be developed and solved numerically to obtain species and product concentrations and distribution, correlate experimental data, estimate mass transfer and kinetic rate parameters, and predict process performance and appropriate practical limits. However, for plasma, photocatalytic and photochemical reactors for $\mathrm{Hg}^{0}$ removal, studies on reactor design and amplification are very limited, and require more attention.

\section{Acknowledgments}




\section{Reference}

An, J.T., Shang. K.F., Lu, N., Jiang, Y.Z., Wang, T.C., Li, J., Wu, Y., 2014a. Performance evaluation of non-thermal plasma injection for elemental mercury oxidation in a simulated flue gas. J. Hazard. Mater. 268, 237-245.

Ahmaruzzaman, M., 2010. A review on the utilization of fly ash. Prog. Energ. Combust. 36, 327-363.

Ayoub, K., Hullebusch, E.D.V., Cassir, M., Bermond, A., 2010. Application of advanced oxidation processes for TNT removal, A review. J. Hazard. Mater. 2010, 10-28.

Antonopoulou, I.M., Evgenidou, E., Lambropoulou, D., Konstantinou, I., 2014. A review on advanced oxidation processes for the removal of taste and odor compounds from aqueous media. Water. Res. 53, 215-234.

Asghar, A., Raman, A.A.A., Daud, W.M.A.W., 2014. Advanced oxidation processes for in-situ production of hydrogen peroxide/hydroxyl radical for textile wastewater treatment, a review. J. Clean. Prod. 2, 1-13.

Adewuyi, Y.G., Sakyi, N.Y., 2013. Simultaneous Absorption and Oxidation of Nitric Oxide and Sulfur Dioxide by Aqueous Solutions of Sodium Persulfate Activated by Temperature. Ind. Eng. Chem. Res. 52, 11702-11711.

An, J.T., Shang, K.F., Lu, N., Jiang, Y.Z., Wang, T.C., Li, J., Wu, Y., 2014b. Oxidation of Elemental Mercury by Active Species Generated From a Surface Dielectric Barrier Discharge Plasma Reactor. Plasma Chem. Plasma Process. 34, $217-228$.

Asahi, R., Morikawa, T., Ohwaki, T., Aoki, K., Taga, Y., 2001. Visible light photocatalysis in nitrogen-doped titanium oxides. Science 293, 269-271.

Asilturk, M., Sayilkan, F., Arpac, E., 2009. Effect of $\mathrm{Fe}^{3+}$ ion doping to $\mathrm{TiO}_{2}$ on the photocatalytic degradation of Malachite Green dye under UV and vis-irradiation. J. Photochem. Photobiol. A 203, 64-71.

Adewuyi, Y.G., Sakyi, N.Y., 2010. Removal of Nitric Oxide by Aqueous Sodium Persulfate Simultaneously Activated by Temperature and $\mathrm{Fe}^{2+}$ in a Lab-scale Bubble Reactor. 49, 8749-8760.

Adewuyi, Y.G., Khan, M.A., Sakyi, N.Y., 2014. Kinetics and Modeling of the Removal of Nitric Oxide by Aqueous Sodium Persulfate Simultaneously Activated by Temperature and $\mathrm{Fe}^{2+}$. Ind. Eng. Chem. Res. 53, 828-839. 
Barnea, Z., Sachs, T., Chidambaram, M., Sasson, Y., 2013. A novel oxidative method for the absorption of $\mathrm{Hg}^{0}$ from flue gas of coal fired power plants using task specific ionic liquid scrubber. J. Hazard. Mater. 244-245, 495-500.

Bokare, A.D., Choi, W.Y., Review of iron-free Fenton-like systems for activating $\mathrm{H}_{2} \mathrm{O}_{2}$ in advanced oxidation processes. J. Hazard.

Bagal, M.V., Gogate, P.R., 2914. Wastewater treatment using hybrid treatment schemes based on cavitation and Fenton chemistry, A

Babuponnusami, A., Muthukumar, K., 2014. A review on Fenton and improvements to the Fenton process for wastewater treatment.

Bogaerts, A., Erik, N., Gijbels, R., 2002. Gas discharge plasmas and their applications. Spectrochim. Acta B 57, 609-658.

Basfar, A.A., Fageeh, O.I., Kunnummal, N., Al-Ghamdi, S., Chmielewski, A.G., Lickid, J., Pawelec, A., 2008. Electron beam flue gas treatment (EBFGT) technology for simultaneous removal of $\mathrm{SO}_{2}$ and $\mathrm{NO}_{\mathrm{x}}$ from combustion of liquid fuels. Fuel 8-9, 1446-1452.

Byun, Y., Koh, D.J., Shin, D.N., 2011a. Removal mechanism of elemental mercury by using non-thermal plasma. Chemosphere 83, 69-75.

Byun, Y.C., Ko, K.B., Cho, M.Y., Namkung, W., Shin, D.N., 2008. Oxidation of elemental mercury using atmospheric pressure non-thermal plasma. Chemosphere 72, 652-658.

Byun, Y., Koh, D.J., Shin, D.N., Cho, M., Namkung, W., 2011b. Polarity effect of pulsed corona discharge for the oxidation of gaseous elemental mercury. Chemosphere 84, 1285-1289.

Bo, Z., Fen, L.W., Gang, Y., Min, Y.H., 2009. Kinetic simulation of $\mathrm{NO} / \mathrm{N}_{2} / \mathrm{O}_{2} / \mathrm{Hg}_{0}$ streamer under dielectric barrier discharge. J. Eng. Thermophys 2, 343-346.

Biswas, P., Wu, C.Y., 1998. Control of Toxic Metal Emissions from Combustors Using Sorbents, A Review. J. Air \& Waste Manage. 
Burda, C., Lou, Y., Chen, X,, Samia, A.C.S., Stout, J., Gole, J.L., 2003. Enhanced nitrogen doping in $\mathrm{TiO}_{2}$ nanoparticles. Nano. Lett. $3,1049-1051$.

Binitha, N.N., Yaakob, Z., Reshmi, M.R., Sugunan, S., Ambili, V.K., Zetty, A.A., 2009. Preparation and characterization of nano-silver doped mesoporous titania photocatalysts for dye degradation. Catal. Today 147,S76-S80.

Bessekhouad, Y., Robert, D., Weber, J.V., 2004. $\mathrm{Bi}_{2} \mathrm{~S}_{3} / \mathrm{TiO}_{2}$ and $\mathrm{CdS} / \mathrm{TiO}_{2}$ heterojunctions as an available configuration for photocatalytic degradation of organic pollutant. J. Photochem. Photobiol. A 163,569-580.

Berruti, F., Pugsley, T.S., Godfroy, L., Chaouki, J., Patience, G.S., 1995. Hydrodynamics of circulating fluidized bed risers, A review. Can. J. Chem. Eng. 5,579-602.

Basu, P., 1999. Combustion of coal in circulating fluidized-bed boilers, a review. Chem. Eng. Sci. 22,5547-5557.

Bagal, M.V., Gogate, P.R., 2014. Wastewater treatment using hybrid treatment schemes based on cavitation and Fenton chemistry, A review. Ultrason. Sonochem. 21,1-14.

Cheng, G.W., Bai, B.F., Zhang, Q., Cai, M., 2014. $\mathrm{Hg}^{0}$ removal from flue gas by ionic liquid/ $\mathrm{H}_{2} \mathrm{O}_{2}$. J. Hazard. Mater. $280,767-773$.

Chi, Y., Yan, N.Q., Qu, Z., Qiao, S.H., Jia, J.P., 2009. The performance of iodine on the removal of elemental mercury from the simulated coal-fired flue gas. J. Hazard. Mater. 166,776-781.

Chiu, C.H., His, H.C., Lin, C.C., 2014. Control of mercury emissions from coal-combustion flue gases using $\mathrm{CuCl}_{2}$-modified zeolite and evaluating the cobenefit effects on $\mathrm{SO}_{2}$ and NO removal. Fuel Process. Technol. 126,138-144.

Chen, W.M., Ma, Y.P., Yan, N.Q., Qu, Z., Yang, S.J., 2014. The co-benefit of elemental mercury oxidation and slip ammonia abatement with SCR-Plus catalysts. Fuel 133,263-269.

Cheng, G.W., Zhang, Q., Bai, B.F., 2014. Removal of $\mathrm{Hg}^{0}$ from flue gas using Fe-based ionic liquid. Chem. Eng. J. 252,159-165.

Chang, J.S., 2001. Recent development of plasma pollution control technology, a critical review. Sci. Technol. Adv. Mater.

$$
\text { 2,571-576. }
$$

Chen, H.L., Lee, H.M., Chen, S.H., Chang, M.B., Yu, S.J., Li, S.N., 2009. Removal of Volatile Organic Compounds by Single-Stage 
and Two-Stage Plasma Catalysis Systems, A Review of the Performance Enhancement Mechanisms, Current Status, and

Chang, J.S., Lawless, P.A., 2002. Corona discharge process. Plasma Sci. IEEE Transaction 6,1152-1166.

Chmielewski, A.G., 2007. Industrial applications of electron beam flue gas treatment-From laboratory to the practice. Radiation Phys.

Chmielewski, A.G., Iller, E., Zimek, Z., Licki, J., 1992. Pilot plant for electron beam flue gas treatment. Int. J. Radiation

Chmielewski, A.G., Sun, Y.X., Licki, J., Bułka, S., Kubica, K., Zimek, Z., 2003. $\mathrm{NO}_{\mathrm{x}}$ and PAHs removal from industrial flue gas by using electron beam technology with alcohol addition. Radiation Phys. Chem. 3-4,555-560.

Chang, M.B., Kushner, M.J., Rood, M.J., 1992. Removal of $\mathrm{SO}_{2}$ and the simultaneous removal of $\mathrm{SO}_{2}$ and NO from simulated flue gas streams using dielectric barrier discharge plasmas. Plasma Chem. Plasma Process 4,565-580.

Chang, J.S., Urashima, K., Tong, Y.X., Liu, W.P., Wei, H.Y., Yang, F.M., Liu, X.J., 2003. Simultaneous removal of $\mathrm{NO}_{\mathrm{x}}$ and $\mathrm{SO}_{2}$ from coal boiler flue gases by DC corona discharge ammonia radical shower systems, pilot plant tests. J. Electrosta 3-4,313-323.

Chen, S.S., His, H.C., Nian, S.H., Chiu, C.H., 2014. Synthesis of N-doped $\mathrm{TiO}_{2}$ photocatalyst forlow-concentration elemental 
mercury removal under various gas conditions. App. Catal. B, Environ. 160-161,558-565.

Coehoorn, R., Haas, C., De, G.R.A., 1987. Electronic structure of $\mathrm{MoSe}_{2}, \mathrm{MoS}_{2}$, and $\mathrm{WSe}_{2}$. II. The nature of the optical band gaps. Phys. Rev. B35,6203-6206.

Cho, J.H., Lee, T.G., Eom, Y.J., 2012. Gas-phase elemental mercury removal in a simulated combustion flue gas using $\mathrm{TiO}_{2}$ with fluorescent light. J. Air Waste Manage. 10,1208-1213.

Corella, J., Toledo, J.M., Molina, G., 2007. A Review on Dual Fluidized-Bed Biomass Gasifiers. Ind. Eng. Chem. Res. 46, 6831-6839.

Cravotto, G., Carlo, S.D., Ondruschka, B., Tumiattic, V., Roggero, C.M., 2007. Decontamination of soil containing POPs by the combined action of solid Fenton-like reagents and microwaves. Chemosphere 8,1326-1329.

Chou, Y.C., Lo, S.L., Kuo, J., Yeh, C.J., 2015. Microwave-enhanced persulfate oxidation to treat mature landfill leachate. J. Hazard.

Careya, T.R., Hargrove, O.W., 2011.Richardson CF, Chang R, Meserole FB. Factors Affecting Mercury Control in Utility Flue Gas 
Dozzi, M.V., Saccomanni, A., Selli, E., 2012. Cr(VI) photocatalytic reduction, Effects of simultaneous organics oxidation and of

gold nanoparticles photodeposition on $\mathrm{TiO}_{2}$. J. Hazard. Mater. 211-212,188-195.

Depero, L.E., Marino, A., Allieri, B., Bontempi, E., Sangaletti, L., Casale, C., Notaro, M., 2000. Morphology and microstructural properties of $\mathrm{TiO}_{2}$ nanopowders doped with trivalent $\mathrm{Al}$ and Ga cations. J. Mater. Res.15,2080-2086.

Dai, X.W., Wang, T.T., Fang, J.H., Wu, J., 2012. Experimental study of titanium-based photocatalysts and catalytic oxidation of mercury in the flue gas. 2012 Thermal Power Plant Pollution Removal and Energy Saving Technology Seminar. WuXi.

Dou, B.L., Hui, C., Ge, H.H., Chen, B.B., Ting, W., 2008. Preparation of $\mathrm{TiO}_{2}$ Nanoparticles by Sol-gel Method and Its Application in Mercury Pollutant Removal. J. Power Eng. 5,779-782.

Dickinson, R.G., Sherrill, M.S., 1926. Formation of Ozone by Optically Excited Mercury Vapor. Proc. Natl. Acad. Sci. 12 , 175 -178.

Ding, J., Zhong, Q., Zhang, S.L., 2014. Simultaneous desulfurization and denitrification of flue gas by catalytic ozonation over Ce-Ti catalyst. Fuel Process Technol. 128, 449-455.

Evans, D., Rosocha, L.A., Anderson, G.K., John, J., 1993. Plasma remediation of trichloroethylene in silent discharge plasmas. J. Appl. Phys. 74, 5378-5385.

El-Bahy, Z.M., Ismail, A.A., 2009. Mohamed RM. Enhancement of titania by doping rare earth for photodegradation of organic dye (Direct blue). J. Hazard. Mater. 166,138-143.

Einaga, H., Yamamoto, S., Maeda, N., Teraoka, Y., 2015. Structural analysis of manganese oxides supported on $\mathrm{SiO}_{2}$ for benzene oxidation with ozone. Catal. Today 242, 287-293.

Fuente-Cuesta, A., Diaz-Somoano, M., Lopez-Anton, M.A., Cieplik, M., Fierro, J.L.G., Martínez-Tarazona, M.R., 2012. Biomass gasification chars for mercury capture from a simulated flue gas of coal combustion. J. Environl. Manage. 98,23-28.

Fang, J.J., 2013. The mechanism study on the photocatalytic removal effect of coal fly ash on $\mathrm{Hg}$ and NO in the coal-fired derived flue gas. ShangHai, Shanghai University of Electric Power. 
Fang, P., Cen, C.P., Tang, Z.J., 2012. Experimental Study on the Oxidative Absorption of $\mathrm{Hg}^{0}$ by $\mathrm{KMnO}_{4}$ Solution. Chem. Eng. J. $102,198-199$.

Fang, P., Cen, C.P., Wang, X.M., Tang, Z.J., Tang, Z.X., Chen, D.S., 2014. Simultaneous removal of $\mathrm{SO}_{2}$, $\mathrm{NO}$ and $\mathrm{Hg}^{0}$ by wet scrubbing using urea+KMnO 4 solution. Chem. Eng. J. 249,72-78. 46,8976-8983. 
Granite, E.J., Pennline, H.W., 2002. Photochemical Removal of Mercury from Flue Gas. Ind. Eng. Chem. Res. 41,5470-5476.

Gultekin, I., Ince, N.H., 2007. Synthetic endocrine disruptors in the environment and water remediation by advanced oxidation

Gasparik, R., Ihara, S., Yamabe, C., Satoh, S., 2000. Effect of $\mathrm{CO}_{2}$ and Water Vapors on $\mathrm{NO}_{\mathrm{x}}$ Removal Efficiency under Conditions of DC Corona Discharge in Cylindrical Discharge Reactor. Jpn. J. Appl. Phys. 39,306-312.

Goodsite, M.E., Plane, J.M.C., Skov, H., 2004. A theoretical study of the oxidation of $\mathrm{Hg}^{0}$ to $\mathrm{HgBr}_{2}$ in the troposphere. Environ. Sci. Technol. 38,1772-1776.

Granite, E.J., King, W.P., Stanko, D.C., Pennline, H.W., 2008. Implications of mercury interactions with band-gap semiconductor oxides. Main Group Chem.7,227-237.

Grabowska, E., Remita, H., Zaleska, A., 2010. Photocatalytic activity of $\mathrm{TiO}_{2}$ loaded with metal clusters. Physicochem. Probl. Miner Process. 45,29-38.

Geng, Q.J., Guo, Q.J., Yue, X.H., 2010. Adsorption and Photocatalytic Degradation Kinetics of Gaseous Cyclohexane in an Annular Fluidized Bed Photocatalytic Reactor. Ind. Eng. Chem. Res. 49, 4644-4652.

Granite, E.J., Pennline, H.W., Hoffman, J.S., 1999. Effects of Photochemical Formation of Mercuric Oxide. Ind. Eng. Chem. Res. 38, $5034-5037$.

Granite, E.J., Pennline, H.W., Stanko, D.C., 2000. Photochemical Removal of Mercury from Flue Gas. In Proceedings of the $17^{\text {th }}$ Annual International Pittsburgh Coal Conference. University of Pittsburgh, Pittsburgh, PA.

Granite, E.J., Pennline, H.W., 2001. Photochemical Removal of Mercury from Flue Gas. Proceedings of the 11th International Conference on Coal Science. National Energy Technology Laboratory, Pittsburgh, PA.

Granite, E.J., Pennline, H.W., 2002. Photochemical Removal of Mercury from Flue Gas. In Proceedings of 223rd ACS National 
Meeting; American Chemical Society, Washington, DC.

Garrido-Ramírez, E.G., Theng, B.K.G., Mora, M.L., 2010. Clays and oxide minerals as catalysts and nanocatalysts in Fenton-like reactions-A review. App. Clay Sci. 47,182-192.

Hou, W.H., Zhou, J.S., Qi, P., Gao, X., Luo, Z.Y., 2014. Effect of $\mathrm{H}_{2} \mathrm{~S} / \mathrm{HCl}$ on the removal of elemental mercury in syngas over $\mathrm{CeO}_{2}-\mathrm{TiO}_{2}$. Chem. Eng. J. 241,131-137.

Hutson, N.D., Krzyzynska, R., Srivastava, R.K., 2008. Simultaneous Removal of $\mathrm{SO}_{2}, \mathrm{NO}_{\mathrm{x}}$, and $\mathrm{Hg}$ from Coal Flue Gas Using a coal-fired power plants. Prog. Energ. Combust. 36,510-529. $\mathrm{NaClO}_{2}$ - Enhanced Wet Scrubber. Ind. Eng. Chem. Res. 47,5825-5831.

Hower, J.C., Senior, C.L., Suuberg, E.M., Hurt, R.H., Wilcox, J.L., Olson, E.S., 2010. Mercury capture by native fly ash carbons in

Hussain, M., Russo, N., Saracco, G., 2011. Photocatalytic abatement of VOCs by novel optimized $\mathrm{TiO}_{2}$ nanoparticles. Chem. Eng, J. $1,138-149$. 12,8269-8285. 
His, H.C., Tsai, C.Y., 2012b. Preparation of oxygen-vacant $\mathrm{TiO}_{2-\mathrm{x}}$ and activated carbon fiber composite using a single-step thermal plasma method for low-concentration elemental mercury removal. Chem. Eng. J 200-202,18-24.

Hong, X., Wang, Z., Cai, W., Lu, F., Zhang, J., Yang, Y., Ma, N., Liu, Y., 2005. Visible light activated nanoparticle photocatalyst of iodinedoped titanium dioxide. Chem. Mater. 17,1548-1552. 
Jani, M.A., Takaki, K., Fujiwara, T., 1999. Streamer Polarity Dependence of $\mathrm{NO}_{\mathrm{x}}$ Removal by Dielectric Barrier Discharge with a Multipoint-to-Plane Geometry. J. Phys. D, Appl. Phys. 32,2560-2566.

Jeon, S.H., Eom, Y.J., Lee, T.G., 2008. Photocatalytic oxidation of gas-phase elemental mercury by nanotitanosilicate fibers.

Ji, T., Yang, F., Lv, Y., Zhou, J., Sun, J., 2009. Synthesis and visible light photocatalytic activity of Bi-doped $\mathrm{TiO}_{2}$ nanobelts. Mater. Lett. 63,2044-2046.

Jia, L., Dureau, R., Ko, V., Anthony, E.J., 2010. Oxidation of Mercury under Ultraviolet (UV) Irradiation. Energ. Fuel removal from exhaust gases by electron beam irradiation. Radiation Phy. Chem. 1-2,5-12.

Calvert, J.G., Lindberg, S.E., 2005. Mechanisms of mercury removal by $\mathrm{O}_{3}$ and $\cdot \mathrm{OH}$ in the atmosphere. Atmospheric Environment 39 , $3355-3367$.

Ji, Y.F., Dong, C.X., Kong, D.Y., Lu, J.H., Zhou, Q.S., 2015. Heat-activated persulfate oxidation of atrazine, Implications for remediation of groundwater contaminated by herbicides. Chem. Eng. J. 263,45-54.

Klasson, K.T., Boihem, L.L., Uchimiya, J.M., Lima, I.M., 2014. Influence of biochar pyrolysis temperature and post-treatment on the uptake of mercury from flue gas. Fuel ProcessTechnol. 123,27-33.

Klavarioti, M., Mantzavinos, D., Kassinos, D., 2009. Removal of residual pharmaceuticals from aqueous systems by advanced oxidation processes. Environ. Int. 35,402-417.

Kim, H.H., 2004. Nonthermal Plasma Processing for Air-Pollution Control, A Historical Review, Current Issues, and Future Prospects. Plasma Process Polym. 2,91-110.

Kogelschatz, U., 2004. Atmospheric-pressure plasma technology. Plasma Phys. Control Fusion 46,B63-B75.

Kawamura, K., Hirasawa, A., Aoki, S., Kimura, H., Fujii, T., Mizutani, S., Higo, T., 1979. Pilot plant experiment of $\mathrm{NO}_{\mathbf{x}}$ and $\mathrm{SO}_{2}$

Kawamura, K., Katayama, T., Kawamura, K., 1981. The pilot plant experiment of electron beam irradiation process for removal of 
Kawamura, K., Aoki, S.J., Kimura, H., Adachi, K., Kawamura, K., Katayama, T., Kengaku, K., Sawada, Y., 1980. Pilot plant

Kogelschatz, U., 2003. Dielectric-Barrier Discharges, Their History, Discharge Physics, and Industrial Applications. Plasma Chem. Plasma Process 1,1-46.

Koutsospyros, A.D., Yin. S.M., Christodoulatos, C., Becker, K., 2005. Plasmochemical degradation of volatile organic compounds (VOC) in a capillary discharge plasma Reactor. Plasma Sci. IEEE Transaction 2,42-49.

Ko, K.B., Byun, Y., Cho, M., Namkung W, Dong, N.S., 2008a. Influence of HCl on oxidation of gaseous elemental mercury by dielectric barrier discharge process. Chemosphere 71,1674-1682.

Ko, K.B., Byun, Y., Cho, M., Namkung, W., Hamilton, I.P., Shin, D.N., Koh, D.J., Kim, K.T., 2008b. Pulsed corona discharge for oxidation of gaseous elemental mercury. Appl. Phy. Let. 92,251503-3-251503-3.

Ko, K.B., Byun, Y., Cho, M., Namkung, W., 2008c. Influence of gas components on the oxidation of elemental mercury by positive pulsed corona discharge. Main Group Chem. 3,69-75.

Kumar, S.G., Devi, L.G., 2011. Review on Modified $\mathrm{TiO}_{2}$ Photocatalysis under UV/Visible Light, Selected Results and Related Mechanisms on Interfacial Charge Carrier Transfer Dynamics. J. Phys. Chem. A 115,13211-13241.

Kaluza, U., Boehm, H. P., 1971. Titanium dioxide catalyzed photooxidation of mercury. J. Catal. 22,347-358.

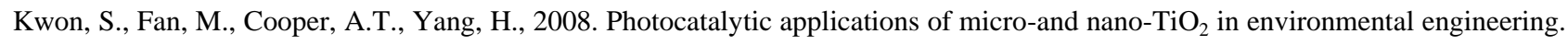
Crit. Rev. Env. Sci. Tec. 3,197-226. 

$20,677-682$.

Kumazawa, H., Inoue, M., Kasuya, T., 2003. Photocatalytic Degradation of Volatile and Nonvolatile Organic Compounds on Titanium Dioxide Particles Using Fluidized Beds. Ind. Eng. Chem. Res. 42,3237-3244.

Kima, S. B., Hwang, H.T., Hong, S.C., 2002. Photocatalytic degradation of volatile organic compounds at the gas-solid interface of a $\mathrm{TiO}_{2}$ photocatalyst. Chemosphere 4,437-444.

Kwan, W.P., Voelker, B.M., 2003. Rates of Hydroxyl Radical Generation and Organic Compound Oxidation in Mineral-Catalyzed

Khan, N.E., Adewuyi, Y.G., 2010. Absorption and Oxidation of Nitric Oxide (NO) by Aqueous Solutions of Sodium Persulfate in a Bubble Column Reactor. Ind. Eng. Chem. Res.;49,8749-8760.

Kim, S.J., Kim, S.C., Seo, S.G., Lee, D.J., Lee, H., Park, S.H., Jung, S.C., 2011. Photocatalyzed destruction of organic dyes using microwave $/ \mathrm{UV} / \mathrm{O}_{3} / \mathrm{H}_{2} \mathrm{O}_{2} / \mathrm{TiO}_{2}$ oxidation system. Catal. Today $164,384-390$.

Li, H.L., Wu, C.Y., Li, Y., Li, L.Q., Zhao, Y.C., Zhang, J.Y., 2013. Impact of $\mathrm{SO}_{2}$ on elemental mercury oxidation over $\mathrm{CeO}_{2}-\mathrm{TiO}{ }_{2}$ catalyst. Chem. Eng. J. 219,319-326.

Li, X., Liu, Z.Y., Kim, J.S., Lee, J.Y., 2014a. Theoretical study of mercury species adsorption mechanism on $\mathrm{MnO}_{2}(110)$ surface. Chem. Eng. J. 256,93-100.

Liu, Y.X., Pan, J.F., Wang, Q., 2014a. Removal of $\mathrm{Hg}^{0}$ from Containing- $\mathrm{SO}_{2} / \mathrm{NO}$ Flue Gas by Ultraviolet/ $\mathrm{H}_{2} \mathrm{O}_{2}$ Process in a Novel Photochemical Reactor. AIChE Journal 6,2275-565.

Liu, Y.X., Qian, W., 2014b. Removal of Elemental Mercury from Flue Gas by Thermally Activated Ammonium Persulfate in A Bubble Column Reactor. Environ. Sci. Technol. 48,12181-12189.

Lu, D., Anthony, E.J., Tan, Y.W., Dureau, R., Ko, V., Douglas, M.A., 2007. Mercury removal from coal combustion by Fenton reactions-Part A, Bench-scale tests. Fuel 86,2789-2797. 
Liu, S.Y., Nengzi, L.C., Qu, B., Liu, P., Ye, Z.X.,2010b. Simultaneous Removal of Elemental Mercury in Aqueous Potassium Hypochlorite by Oxidation. Environ. Eng. Sci. 4,323-327.

Liu, Y.X., Zhang, J., Sheng, C.D., Zhang, Y.C., Yuan, S.J., 2008. New research progress in sorbents for removal of mercury in coal-fired flue gas. Modern. Chem. Ind.11,19-25.

Liu, Y.X., Zhang, J., Pan, J.F., 2014c. Photochemical Oxidation Removal of $\mathrm{Hg}^{0}$ from Flue Gas Containing $\mathrm{SO}_{2} / \mathrm{NO}$ by an Ultraviolet Irradiation/Hydrogen Peroxide $\left(\mathrm{UV} / \mathrm{H}_{2} \mathrm{O}_{2}\right)$ Process. Energy Fuels 28,2135-2143.

Liu, Y.X., 2011a. Study on integrated desulfurization and denitrification by $\mathrm{UV} / \mathrm{H}_{2} \mathrm{O}_{2}$ advanced oxidation process. Nanjing, Southeast University 1, 6-15.

Liu, Y.X., Zhang, J., Sheng, C.D., Zhang, Y.C., Zhao, L., 2010a. Simultaneous removal of NO and $\mathrm{SO}_{2}$ from coal-fired flue gas by UV/ $\mathrm{H}_{2} \mathrm{O}_{2}$ advanced oxidation process. Chem. Eng. J. 3,1006-1011.

Lin, T.S., Hong, M., Lei, J., Ping, N., 2008. Purification of $\mathrm{H}_{2} \mathrm{~S}$-containing gas stream by aqueous oxidation with Fenton agent. China Environ. Sci. 28,1052-1056.

Li, S.R., Huang, Y.F., Wang, F.F., Liu, J., Feng, F.D., Shen, X.J., Yan, K.P., 2014b. Multi-pollutants Emission from Coal-Fired Flue Gas. Fundamentals and Environmental Applications of Non-thermal Plasmas, Multi-pollutants Emission Control from Coal-Fired Flue Gas. Plasma Chem. Plasma Process 34,579-603.

Licki, J., Chmielewski, A.G., Zimek, E., Mazurek, Z.J., Sobolewski, L., 2003. Electron-beam flue-gas treatment for multicomponent air-pollution control. App. Energ. 3-4,145-154.

Liang, X.H., Looy, P.C., Jayaram, S., 2002. Mercury and Other Trace Elements Removal Characteristics of DC and Pulse-Energized Electrostatic Precipitator. IEEE T Ind. Appl. 1,69-76.

Lin, W.F., Zhang, B., Hou, W.H., Zhou, Q., Yang, H.M., 2010. Enhanced Oxidation of Elemental Mercury in Simulated Flue gas by Non-Thermal Plasma. Proceedings of the CSEE 2010;2,72-76

Li, L.C., Deng, P., Tian, A.M., Xu, M.H., Zheng, C.G., Wong, N.B., 2003. A study on the reaction mechanism and kinetic of 
mercury oxidation by chlorine species. J. Mol. Struc-Theochem. 625,277-281.

Lin, H., 2002. Experimental and theoretical study on flue gas denitrification with radical shower induced by DC Corona discharge. Hang Zhou, Zhejiang University.

Lin, W.F., Zhang, B., Yang, H.M., 2009. Characteristics of emissive spectrum and the removal of nitric oxide in $\mathrm{N}_{2} / \mathrm{O}_{2} / \mathrm{NO}$ plasma with argon additive. J. Environ. Sci. 21,790-794.

Lee, T.G., 2010. Photocatalytic Removal of Gas-Phase Elemental Mercury Using $\mathrm{TiO}_{2}$. Environmentally Benign Photocatalysts-Nanostructure Science and Technology 437-449.

Lee, T.G., Biswas, P., 2001. Comparison of $\mathrm{Hg}^{0}$ Capture Efficiencies of Three in situ Generated Sorbents. AIChE Journal 4,954-961.

Linsebigler, A.L., Lu, G.Q., Yates, J.T., 1995. Photocatalysis on $\mathrm{TiO}_{2}$ Surfaces, Principles, Mechanisms, and Selected Results. Chem. Rev. 95,735-758.

Lee, Y.G., Park, J.W., Kim, J.H., Min, B.R., Jurng, J., Kim, J., Lee, T.G., 2004. Comparison of Mercury Removal Efficiency from a Simulated Exhaust Gas by Several Types of $\mathrm{TiO}_{2}$ under Various Light Sources. Chem. Let. 1,36-37.

Lee, Y.G., Lee, T.G., Kim, W.S., 2005. Comparison of the Mercury Removal Efficiency using $\mathrm{TiO}_{2}$ Powder under Various Light Sources. Korean. Chem. Eng. Res. 43, 65-69.

Lo, S.F., Lin, C.F., Wu, C.H., Hsieh, P.H., 2004. Capability of coupled $\mathrm{CdSe}_{\mathrm{TiO}} 2$ for photocatalytic degradation of 4-chlorophenol. J. Hazard. Mater. B114,183-190.

Li, Y., Wu, C.Y., 2006. Role of Moisture in Adsorption, Photocatalytic Oxidation, and Reemission of Elemental Mercury on a $\mathrm{SiO}_{2}-\mathrm{TiO}_{2}$ Nanocomposite. Environ. Sci. Technol. 40,6444-6448.

Li, Y., 2007a. Removal of elemental mercury from flue gas using nanostructured silica/titania/vanadia composites. Florida, University of Florida.

Li, Y., Murphy, P., Wu, C.Y., 2008. Removal of elemental mercury from simulated coal-combustion flue gas using a $\mathrm{SiO}_{2}-\mathrm{TiO}_{2}$ nanocomposite. Fuel Process. Technol. 89,567-573 
Lee, T.G., Hyun, J.E., 2006. Structural effect of the in situ generated titania on its ability to oxidize and capture the gas-phase elemental mercury. Chemosphere 62,26-33.

Lee, T.G., Biswas, P., Hedrick, E., 2004. Overall Kinetics of Heterogeneous Elemental Mercury Reactions on $\mathrm{TiO}_{2}$ Sorbent Particles with UV Irradiation. Ind. Eng. Chem. Res. 43,1411-1417. (CFB) photoreactor. Chem Eng Process 2,327-334.

Li, D.Z., Chen, Z.X., Chen, Y.L., Li, W.J., Huang, H.J., He, Y.H., Fu, X.Z.,2008. A New Route for Degradation of Volatile Organic Compounds under Visible Light, Using the Bifunctional Photocatalyst $\mathrm{Pt} / \mathrm{TiO}_{2-\mathrm{x}} \mathrm{N}_{\mathrm{x}}$ in $\mathrm{H}_{2}-\mathrm{O}_{2}$ Atmosphere. Environ. Sci. Technol. 6,2130-2135.

Liu, Y.X, Zhang, J, Pan, J.F., 2013a. A mercury removal method and system basing on UV irradiation with flue gas cooling unit. China Patent, CN201310684668.

Liu, Y.X., Pan, J.F., Tang, A.K.,2013b. A method and system for flue gas mercury removal basing on coupling flue and UV lamp. China Patent, CN201310683054.

Liu, Y.X., Zhang, J., Yin, Y.S., 2014d. Study on Absorption of Elemental Mercury from Flue Gas by UV/ $\mathrm{H}_{2} \mathrm{O}_{2}$, Process Parameters and Reaction Mechanism. Chem. Eng. J.191,482-494.

Liu, Y.X., Zhang, J., Yin, Y.S., 2015a. Removal of $\mathrm{Hg}^{0}$ from flue gas Using Two Homogeneous Photo- Fenton-Like Reactions. AIChE Joural, 2015, 61, 1322-1333. 
Liu, Y.X., Zhang, J., Pan, J.F., Tang, A.K., 2012a. Investigation on Removal of $\mathrm{NO}$ from $\mathrm{SO}_{2}$-Containing Simulated Flue Gas by UV/Fenton-Like Reaction. Energ Fuels 26,5430-5436.

Liu, Y.X., Pan, J.F., Tang, A.K., Wang, Q., 2013d. A Study on Mass Transfer-Reaction Kinetics of NO Absorption by Using $\mathrm{UV} / \mathrm{H}_{2} \mathrm{O}_{2} / \mathrm{NaOH}$ Process. Fuel 108,254-260.

Liu, Y.X., Zhang, J., Wang, Z.L., 2012b. A Study on Kinetics of NO Absorption from Flue Gas by Using UV/Fenton Wet Scrubbing. Chem. Eng. J. 197,468-474.

Liu, Y.X., Pan, J.F., Zhang, J., Tang, A.K., Liu, Y.,2012c. Study on Mass Transfer-Reaction Kinetics of NO Removal from Flue Gas by Using UV/Fenton-Like Reaction. Ind. Eng. Chem. Res. 51,12065-12072.

Liu, Y.X., Zhang, J., Sheng, C.D., 2011c. Study on Kinetics of NO Removal from Simulated Flue Gas by Wet UV/ $\mathrm{H}_{2} \mathrm{O}_{2}$ Advanced 
Liu, Y.X., Wang, Y., Wang, Q., Pan, J.F., Zhang,Y.C., Zhang, J., 2015c. A Study on Removal of Elemental Mercury in Flue Gasusing Fenton Solution. J. Hazard. Mater. 292, 164-172.

Liu, L., Zheng, C.G., Chen, J.H., Zhou, J.S., Gao, X., Ni, M.J., Cen, K.F., 2015d. Plasma-induced adsorption of elemental mercury

Li, H., Wan, J.Q., Ma, Y.W., Wang, Y., Huang, M.Z., 2014c. Influence of particle size of zero-valent iron and dissolved silica on the

Lee, Y.C., Lo, S.L., Kuo, J., Huang, C.P., 2013. Promoted degradation of perfluorooctanic acid by persulfate when adding activated carbon. J. Hazard. Mater. 261,463-469.

Lin, Y.T., Liang, C.J., Chen, J.H., 2011. Feasibility study of ultraviolet activated persulfate oxidation of phenol. Chemosphere 82, $1168-1172$.

Liang, H.Y., Zhang, Y.Q., Huang, S.B., Hussain, I., 2013. Oxidative degradation of p-chloroaniline by copper oxidate activated persulfate. Chem. Eng. J. 218,384-391.

\author{
(
} reactivity of activated persulfate for degradation of acid orange 7. Chem. Eng. J. 237,487-496.

Li, H., Guo, J., Yang, L.J., Lan, Y.Q., 2014d. Degradation of methyl orange by sodium persulfate activated with zero-valent zinc. Sep. Purif. Technol. 132,168-173.

Liu, Y., Bisson, T.M., Yang, H.Q., Xu, Z.H., 2010d. Recent developments in novel sorbents for flue gas clean up. Fuel Process. Technol. 10,1175-1197.

Lucas, M.S., Peres, J.A., Puma, G.L., Treatment of winery wastewater by ozone-based advanced oxidation processes $\left(\mathrm{O}_{3}, \mathrm{O}_{3} / \mathrm{UV}\right.$ and $\mathrm{O}_{3} / \mathrm{UV} / \mathrm{H}_{2} \mathrm{O}_{2}$ ) in a pilot-scale bubble column reactor and process economics. Sep. Purif. Technol. 72,235-241.

Martinezm A.I., Deshpande, B.K., 2007. Kinetic modeling of $\mathrm{H}_{2} \mathrm{O}_{2}$-enhanced oxidation of flue gas elemental mercury. Fuel Process. Technol. 88,982-987.

Matilainena, A., Sillanpää, M., 2010. Removal of natural organic matter from drinking water by advanced oxidation processes. 
McAdams, R., 2001. Prospects for non-thermal atmospheric plasmas for pollution abatement. J. Phys. D, Appl. Phys. 34, $2810-2821$.

Ma, H.B., Chen, P., Zhang, M.L., Lin, X.Y., Ruan, R.,2002. Study of $\mathrm{SO}_{2}$ Removal Using Non-thermal Plasma Induced by Dielectric Barrier Discharge (DBD). Plasma Chem. Plasma Process 2,239-254.

Mok, Y.S., Nam, C.M., Cho, M.H., Nam, I.S., 2002. Decomposition of volatile organic compounds and nitric oxide by nonthermal plasma discharge processes. Plasma Sci. IEEE Transaction 7,408-416.

Mok, Y.S., Nam, I.S., 1998. Positive pulsed corona discharge process for simultaneous removal of $\mathrm{SO}_{2}$ and $\mathrm{NO}_{\mathrm{x}}$ from iron-ore sintering flue gas. Plasma Sci. IEEE Transaction 8,1188-1196.

Mok, Y.S., Nam, I.S., 1999. Positive pulsed corona discharge process for simultaneous removal of $\mathrm{SO}_{2}$ and $\mathrm{NO}_{\mathrm{x}}$ from iron-ore sintering flue gas. Plasma Sci. IEEE Transaction 8,1188-1196.

Masuda, S., Wu, Y., Urabe, T., Ono, M., 1987. DeNO x and control of mercury vapor combustion gas by pulse corona induced plasma chemical process, in, Proc. 8th Int. Symp. Plasma Chemistry, Tokyo.

Mannava, P.C.D, 2004. Mercury Remediation by Dielectric Barrier Discharge. Master's Thesis, University of New Hampshire, Durham, NH.

Malik, M.A., Kolb, J.F., Sun, Y., Schoenbach, K.H., 2011. Comparative study of NO removal in surface-plasma and volume-plasma reactors based on pulsed corona discharges. J. hazard. mater.197,220-228.

Meng, N., Leung, M.K.H., Leung, D.Y.C., 2007. Sumathy K. A review and recent developments in photocatalytic water-splitting using $\mathrm{TiO}_{2}$ for hydrogen production. Renew. Sust. Energ. Rev. 11,401-425.

McCullagh, C., Skillen, N., Adams, M., Robertson, P.K.J.,2011. Photocatalytic reactors for environmental remediation, a review. J. Chem. Technol. Biotechnol. 8,1002-1017.

Maggos, T., Bartzis, J.G., Liakou, M., Gobin, C.,2007. Photocatalytic degradation of $\mathrm{NO}_{\mathrm{x}}$ gases using $\mathrm{TiO}_{2}$-containing paint, A real scale study. J. Hazard. Mater. 146,668-673.

Medellin-Castillo, N.A., Ocampo-Pérez, R., Leyva-Ramos, R., Sanchez-Polo, M., Rivera-Utrilla, J., Méndez-Díaz, J. D., 2013. 
Moussavi, G., Yazdanbakhsh, A., Heidarizad, M., 2009. The removal of formaldehyde from concentrated synthetic wastewater using $\mathrm{O}_{3} / \mathrm{MgO} / \mathrm{H}_{2} \mathrm{O}_{2}$ process integrated with the biological treatment. J. Hazard. Mater. 171,907-913.

Niksa, S., Naik, C.V., Berry, M.S., Monroe, L., 2009. Interpreting enhanced Hg oxidation with Br addition at Plant Miller. Fuel Process. Technol. 90,1372-1377.

Nelson, R.J., Flakker, C.L., Muggli, DS., 2007. Photocatalytic oxidation of methanol using titania-based fluidized beds. App. Catal. B Environ. 69,189-195.

Ntampegliotis, K., Riga, A., Karayannis, V., Bontozoglou, V., Papapolymerou, G., 2006. Decolorization kinetics of Procion H-exl dyes from textile dyeing using Fenton-like reactions. J. Hazard. Mater. 1,75-84.

Oller, I., Malato, S., Sánchez-Pérez, J.A., 2011. Combination of Advanced Oxidation Processes and biological treatments for wastewater decontamination-A review. Sci. Total. Environ. 409,4141-4166.

Obradović, B.M., Sretenović, G.B., Kuraica, M.M., 2011. A dual-use of DBD plasma for simultaneous $\mathrm{NO}_{\mathrm{x}}$ and $\mathrm{SO}_{2}$ removal from coal-combustion flue gas. J. Hazard. Mater. 2-3, 1280-1286.

Ohno, T., Mitsui, T., Matsumura, M., 2003. Photocatalytic activity of S-doped $\mathrm{TiO}_{2}$ photocatalyst under visible light. Chem. Lett. $32,364-365$.

Oncu, N.B., Mercan, N., Balcioglu, I.A., 2015. The impact of ferrous iron/heat-activated persulfate treatment on waste sewage sludge constituents and sorbed antimicrobial micropollutants. Chem. Eng. J. 259,972-980.

Oh, B.T., Seo, Y.S., Sudhakar, D., Choe, J.H., Lee, S.M., Park, Y.J., Cho, M., 2014. Oxidative degradation of endotoxin by advanced oxidation process $\left(\mathrm{O}_{3} / \mathrm{H}_{2} \mathrm{O}_{2} \& \mathrm{UV} / \mathrm{H}_{2} \mathrm{O}_{2}\right)$. J. Hazard. Mater. 279,105-110.

Pavlish, J.H., Sondreal, E.A., Mann, M.D., Olson, E.S., Galbreath, K.C., 2003. Status review of mercury control options for coal-fired power plants. Fuel Process. Technol. 82,89-165. 
Presto, A., Granite, E. J., 2006. Survey of Catalysts for Oxidation of Mercury in Flue Gas. Environ. sci. technol. 18,5601-5609.

Portland's Handbook of Chemistry (15th Edition), Section 8, 8,124-8.139.

Park, J.Y., Tomicic, I., Round, G.F., Chang, J.S., 1999. Simultaneous removal of $\mathrm{NO}_{\mathrm{x}}$ and $\mathrm{SO}_{2}$ from $\mathrm{NO}^{-} \mathrm{SO}_{2}-\mathrm{CO}_{2}-\mathrm{N}_{2}-\mathrm{O}_{2}$ gas mixtures by corona radical shower systems. J. Phy. D App. Phy. 32,1006-1013.

Penetrante, B.M., Hsiao, M.C., Merrit, B.T., Vogtlin, G.E., 1996. Pulsed corona and dielectric-barrier discharge processing of NO in

$$
\mathrm{N}_{2} \text {. App. Phy. Let. 6,3719-3781. }
$$

Pitoniak, E.R., 2004. Evaluation of nanostructured silica-titania composites in an adsorption/photocatalytic oxidation system for elemental mercury vapor control. Florida, University of Florida.

Pitoniak, E., Wu, C.Y., Londeree, D., Mazyck, D., Bonzongo, J.C., Powers, K., Sigmund, W., 2003. Nanostructured silica-gel doped with $\mathrm{TiO}_{2}$ for mercury vapor control. J. Nanopart. Res. 3-4, 281-292.

Pitoniak, E., Wu, C.Y., Mazyck, D., Powers, K., Sigmund, W. Adsorption Enhancement Mechanisms of Silica-Titania Nanocomposites for Elemental Mercury Vapor Removal. Environ. Sci. Technol. 39,1269-1274.

Paola, D., Garcia-Lopez, A., Ikeda, E., Marc, S., Ohtani, G., Palmisano, B.L.,2002. Photocatalytic degradation of organic compounds in aqueous systems by transition metal-doped polycristalline $\mathrm{TiO}_{2}$. Catal. Today 75,87-93.

Portela, R., Suárez, S., Rasmussen, S.B., Arconada, N., Castro, Y., 2010. Photocatalytic-based strategies for $\mathrm{H}_{2} \mathrm{~S}$ elimination. Catal. Today $151,64-70$.

Portela, R., Sánchez, B., Coronado, J.M., Candal, R., Suárez, S., 2012. A parametric study of the UV-A photocatalytic oxidation of $\mathrm{H}_{2} \mathrm{~S}$ over $\mathrm{TiO}_{2}$. App. Catal. B Environ.115-116,209-218.

Pouran, S.R., Abdul, A.A.R., Daud, W.M.A.W., 2014. Review on the main advances in photo-Fenton oxidation system for recalcitrant wastewaters. J Ind Eng Chem 2014;xxx,xxx-xxx.

Pouran, S.R., Raman, A.A.A., Daud, W.M.A.W., 2014. Review on the application of modified iron oxides as heterogeneous catalysts in Fenton reactions. J. Clea. Prod. 64,24-35. 
Qi, C.D., Liu, X.T., Lin, C.Y., Zhang, X.H., Ma, J., Tan, H.B., Ye, W., 2014. Degradation of sulfamethoxazole by microwave-activated persulfate, Kinetics, mechanism and acute toxicity. Chem. Eng. J. 49,6-14.

Qi, X.M., Gu, M.L., Zhu, X.Y., Wu, J., 2016. Fabrication of $\mathrm{BiOIO}_{3}$ nanosheets with remarkable photocatalytic oxidation removal

Reddy, B.M., Durgasri, N., Kumar, T.V., Bhargava, S.K., 2012. Abatement of Gas-Phase Mercury-Recent Developments. $3,344-398$.

Rodríguez-Pérez, J., López-Antón, M.A., Díaz-Somoano, M., García, R., Martínez-Tarazona, M.R., 2013. Regenerable sorbents for mercury capture in simulated coal combustion flue gas. J. Hazard. Mater. 260,869-877.

Rupp, E.C., Wilcox, J., 2014. Mercury chemistry of brominated activated carbons-Packed-bed breakthrough experiments. Fuel 117,

Ren, J.L., Zhou, J.S., Luo, Z.Y., Xu, Z., Zhang, X.M., 2006. Ca-based sorbents for mercury vapor removal from flue gas. J. Fuel

Ribeiroa, A.R., Nunes, O.C., Pereira, M.F.R., Silva, A.M.T., 2015. An overview on the advanced oxidation processes applied for the

Ren, W., Ai, Z., Jia, F., Zhang, L., Fan, X., Zou, Z., 2007. Low temperature preparation and visible light photocatalytic activity of mesoporous carbon-doped crystalline $\mathrm{TiO}_{2}$. Appl. Catal. B 69,138-144.

Robert, D., 2007. Photosensitization of $\mathrm{TiO}_{2}$ by $\mathrm{M}_{\mathrm{x}} \mathrm{O}_{\mathrm{y}}$ and $\mathrm{M}_{\mathrm{x}} \mathrm{S}_{\mathrm{y}}$ nanoparticles for heterogeneous photocatalysis applications. Catal.

$$
\text { Today122,20-26. }
$$

Rodri'guez, S., Almquist, C., Lee, T.G., 2044. Masami Furuuchi, Elizabeth Hedrick, Pratim Biswas. J. Air \& Waste Manage

Stolle, R., Koeser, H., Gutberlet, H., 2014. Oxidation and reduction of mercury by SCR DeNO catalysts underflue gas conditions in 
coal fired power plants. App. Catal. B Environ. 144,486-497.

Shu, T., Lu, P., He, N., 2013. Mercury adsorption of modifiedmulberry twig chars inasimulated flue gas. Bioresource Technol. 136, $182-187$.

Shen, B.X., Cai, J., Chen, J.H., Li, Z., He, C., 2014. Removal of element mercury from simulated flue gas by clay modified with KBr and KI. CIESC Jorunal 2,711-717.

Su, C.Y., Ran, X., Hu, J.L., Shao, C.L., 2013. Photocatalytic Process of Simultaneous Desulfurization and Denitrification of Flue Gas by $\mathrm{TiO}_{2}-$ Polyacrylonitrile Nanofibers. Environ. Sci. Technol. 47,11562-11568.

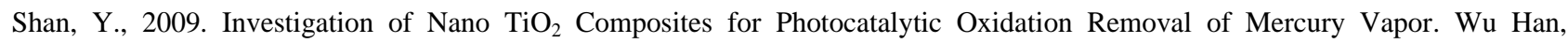
Huazhong University of Science and Technology.

Stergaršek, A., Horvat, M., Frkal, P., Stergaršek, J., 2010. Removal of $\mathrm{Hg}^{0}$ from flue gases in wet FGD by catalytic oxidation with air -An experimental study. Fuel 89,3167-3177.

Serpone, N., Horikoshi, S., Emeline, A.V., 2010. Microwaves in advanced oxidation processes for environmental applications. A brief review. J. Photochem. Photobiolo. C 11,114-131.

Sharma, V.K., Triantis, T.M., Hiskia, A., Dionysiou, D.D., 2012. Destruction of microcystins by conventional and advanced oxidation processes, A review. Sep. Puri. Technol. 91,3-17

Sillanpääa, M.E.T., Kurniawan, T.A., Lo, W.H., 2011. Degradation of chelating agents in aqueous solution using advanced oxidation process (AOP). Chemosphere 83,1443-1460.

Sun, W., Pashaie, B.J., Dhali, S.K., Honea, F.I., 1996. Non-thermal plasma remediation of $\mathrm{SO}_{2} / \mathrm{NO}$ using a dielectric-barrier discharge. J. Appl. Phys. 79,3438-3445.

Suriyawong, A., Smallwood, M., Li, Y., Zhuang, Y., Biswas, P., 2009. Mercury Capture by Nano-structured Titanium Dioxide Sorbent during Coal Combustion, Lab-scale to Pilot-scale Studies. Aerosol Air Qual Res. 9,394-403.

Seery, M.K., George, R., Floris, P., Pillai, S.C., 2007. Silver-doped titanium dioxide nanomaterials for enhanced visible light 
photocatalysis. J. Photochem. Photobiol. A 189,258-263.

Sui, R., Young, J.L., Berlinguette, C.P., 2010. Sol-gel synthesis of linear Sn-doped $\mathrm{TiO}_{2}$ nanostructures. J. Mater. Chem. 20, 498-503.

Stengl, V., Bakardjieva, S., Murafa, N., 2009 Preparation and photocatalytic activity of rare earth-doped $\mathrm{TiO}_{2}$ nanoparticles. Mater.

Chem. Phys. 114,217-226.

Sommar, J., Katarina, G., Feng, X.B., 2001. A kinetic study of the gas-phase reaction between the hydroxyl radical and atomic

Shi, J.W., Zheng, J.T., Wu, P., 2009. Preparation, characterization and photocatalytic activities of holmium-doped titanium dioxide nanoparticles. J. Hazard. Mater. 161,416-422.

Sun, L., Li, J., Wang, C.L., Li, S.F., Chen, H.B., Lin, C.J., 2009. An electrochemical strategy of doping $\mathrm{Fe}^{3+}$ into $\mathrm{TiO}_{2}$ nanotube array films for enhancement in photocatalytic activity. Sol. Energy Mater. Sol. Cells 93,1875-1880.

Shang, J., Yao, W., Zhu, Y., Wu, N., 2004. Structure and photocatalytic performance of glass $/ \mathrm{SnO}_{2} / \mathrm{TiO}_{2}$ interface composite film. Appl. Catal. A 257,25-32.

Snider, G., Ariya, P., 2010. Photo-catalytic oxidation reaction of gaseous mercury over titanium dioxide nanoparticle surfaces. Chem. Phy. Lett. 491,23-28.

Snider, G., Ariya, P., 2012. Kinetic and Product Studies of the Reactions of $\mathrm{NO}_{2}$, with $\mathrm{Hg}^{0}$ in the Gas Phase in the Presence of Titania Micro-Particle Surfaces. Water Air Soil Pollut. 223,4397-4406.

Matsuda, S.; Hatano, H., 2005. Photocatalytic removal of $\mathrm{NO}_{\mathrm{x}}$ in a circulating fluidized bed system. Powder Technol. $1-3,61-67$. mercury. Atmosp. Environ. 35,3049-3054.

Scala, F., 2001. Simulation of Mercury Capture by Activated Carbon Injection in Incinerator Flue Gas. 1. In-Duct Removal. Environ. Sci. Technol. 35, 4367-4372

Sun, W.Y., Wang, Q.Y., Ding, S.L., Su, S.J., 2013. Simultaneous absorption of $\mathrm{SO}_{2}$ and $\mathrm{NO}_{\mathrm{x}}$ with pyrolusite slurry combined with 
gas-phase oxidation of $\mathrm{NO}$ using ozone, Effect of molar ratio of $\mathrm{O}_{2} /\left(\mathrm{SO}_{2}+0.5 \mathrm{NO}_{\mathrm{x}}\right)$ in flue gas. Chem. Eng. J. 228,700-707.

Sun, W.Y., Ding, S.L., Zeng, S.S., Su, S.J., Jiang, W.J., 2011. Simultaneous absorption of $\mathrm{NO}_{\mathrm{x}}$ and $\mathrm{SO}_{2}$ from flue gas with pyrolusite slurry combined with gas-phase oxidation of NO using ozone. J. Hazard. Mater. 192,124-130.

Song, S., He, Z.Q., Chen, J.M., 2007. US/O 3 combination degradation of aniline in aqueous solution. Ultrason. Sonochem. 14,84-88.

Shen, H.Z., Ie, I.R., Yuan, C.S., Hung, C.H., 2016. The enhancement of photo-oxidation efficiency of elemental mercuryby immobilized $\mathrm{WO}_{3} / \mathrm{TiO}_{2}$ at high temperatures. Applied Catalysis B: Environmental 195, 90-103.

Tan, Z.Q., Sun, L.S., Xiang, J., Zeng, H.C., Liu, Z.H., Hu, S., Qiu, J.R., 2012. Gas-phase elemental mercury removal by novel carbon-based sorbents. Carbon 50,362-371.

Tan, Z.Q., Qiu, J.R., Zeng, H.C., Liu, H., Xiang, J., 2011. Removal of elemental mercury by bamboo charcoal impregnated with $\mathrm{H}_{2} \mathrm{O}_{2}$. Fuel 90,1471-1475.

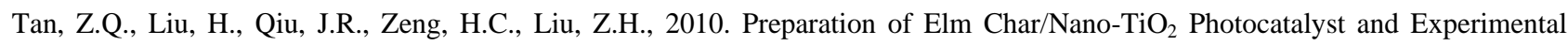
Studies on the Removal of Elemental Mercury. Proceedings of the CSEE. 29,37-41.

Tisa, F., Raman, A.A.A., Daud, W.M.A.W., 2014. Applicability of fluidized bed reactor in recalcitrant compound degradation through advanced oxidation processes, A review. J. Environ. Manage. 146,60-275.

Tokumura, M., Wada, Y., Usami, Y., Yamaki, T., Mizukoshi, A., Noguchi, M., Yanagisawa, Y., 2012. Method of removal of volatile organic compounds by using wet scrubber coupled with photo-Fenton reaction-Preventing emission of by-products. Chemosphere 10,1238-1242.

Tendero, C., Tixier, C., Tristant, P., Desmaison, J., Leprince, P., 2006. Atmospheric pressure plasmas, A review. Spectrochim. Acta B 61,2-30.

Tas, M.A., Hardeveld, R.V., Veldhuizen, E.M.V., 1997. Reactions of NO in a Positive Streamer Corona Plasma. Plasma Chem. Plasma Process 4,371-391.

Takaki K, Jani, M.A., Fujiwara, T., 1999. Removal of nitric oxide in flue gases by multi-point to plane dielectric barrier discharge. 
Tang, P., Zhu, T.L., Li, H., Luo, H.J., Li, J., 2008. Effects of Gas Compositions on the Oxidation of Gas Phase Elementary Mercury

Thiruvenkatachari, R., Vigneswaran, S., Moon, S., 2008. A review on $\mathrm{UV}^{\mathrm{TTiO}}{ }_{2}$ photocatalytic oxidation process. Korean J. Chem. Eng. 25,64-72.

by Non- thermal Plasma. Environ. Sci. 6,1749-1753.

Tsai, C.Y., His, H.C., Bai, H., Fan, K.S., Chen, C., 2011. $\mathrm{TiO}_{2-\mathrm{x}}$ nanoparticles synthesized using He/Ar thermal plasma and their effectiveness on low-concentration mercury vapor removal. J. Nanopart. Res. 2011, DOI 10.1007/s11051-011-0442-8.

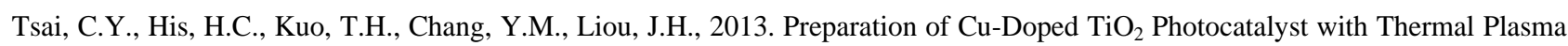
Torch for Low-Concentration Mercury Removal. Aerosol Air Qual Res.13,639-648.

Tsai, C.Y., Kuo, T.H., His, H.C., 2012. Fabrication of Al-Doped $\mathrm{TiO}_{2}$ Visible-Light Photocatalyst for Low-Concentration Mercury Removal. Int. J. Photoenergy 12,1-8.

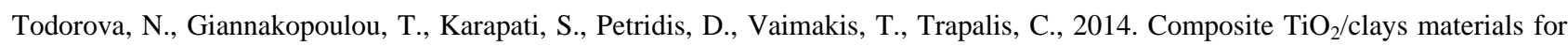
photocatalytic $\mathrm{NO}_{\mathrm{x}}$ oxidation. App. Surf. Sci. 319,113-120.

Tokumura, M., Wada, Y., Usami, Y., Yamaki, T., Mizukoshi, A., 2012. Method of removal of volatile organic compounds by using wet scrubber coupled with photo-Fenton reaction-Preventing emission of by-products. Chemosphere 89,1238-1242.

Tony, M.A., Zhao, Y.Q., Taye, A.M.,2009. Exploitation of Fenton and Fenton-like reagents as alternative conditioners for alum sludge conditioning. J. Environ. Sci. 1,101-105.

Tan, Y.W., Lu, D., Anthony, E.J., Dureau, R., Mortazavi, R., Douglas, M.A., 2007. Mercury removal from coal combustion by Fenton reactions. Paper B, Pilot-scale tests. Fuel 86,2798-2805.

Tan, C.Q., Gao, N.Y., Deng, Y., Rong, W.L., Zhou, S.D., 2013. Degradation of antipyrine by heat activated persulfate. Sep. Purif. Technol. 109,122-128.

Urashima, K., Chang, J.S., 2000. Removal of volatile organic compounds from air streams and industrial flue gases by non-thermal 
plasma technology. IEEE T Dielect El In. 5, 602-614.

Urabe, T., Wu, Y., Nagawa, T., 1998. Study on $\mathrm{Hg}, \mathrm{NO}_{\mathrm{x}}, \mathrm{SO}_{\mathrm{x}}$ behavior in municipal refuse incinerator furnace and removal of those by pulse corona discharge. Seiso. Giho. 13,12-29.

Umebayashi, T., Yamaki, T., Itoh, H., Asai, K., 2002. Analysis of electronic structures of 3d transition metal-doped $\mathrm{TiO}_{2}$ based on band calculations. J. Phys. Chem. Solids 63,1909-1920.

Umebayashi, T., Yamaki, T., Tanaka, S., Asai, K., 2003. Visible light induced degradation of methylene blue on $\mathrm{S}_{\text {-doped }} \mathrm{TiO}_{2}$. Chem. Lett. 32, 330-331.

Usman, M., Faure, P., Ruby, C., Hann, K., 2012. Application of magnetite-activated persulfate oxidation for the degradation of PAHs in contaminated soils. Chemosphere 87,234-240.

Umar, M., Roddick, F., Fan, L.H., Aziz, H.A., 2013. Application of ozone for the removal of bisphenol A from water and wastewater-A review. Chemosphere 90, 2197-2207.

Vaart, R.V.D., Akkerhuis, J., Feron, P., Jansen, B., 2001. Removal of mercury from gas streams by oxidative membrane gas absorption. J. Membrane Sci. 187,151-157.

Vallejo, M., Román, M.F.S., Ortiz, I., Irabien, A., 2015. Overview of the PCDD/Fs degradation potential and formation risk in the application of advanced oxidation processes (AOPs) to wastewater treatment. Chemosphere 118,44-56.

Wang, P.Y., Su, S., Xiang, J., You, H.W., Cao, F., Sun, L.S., Hu, S., Zhang, Y., 2014a. Catalytic oxidation of $\mathrm{Hg}^{0}$ by $\mathrm{MnOx}-\mathrm{CeO}_{2} / \gamma-\mathrm{Al}_{2} \mathrm{O}_{3}$ catalyst at low temperatures. Chemosphere 101,49-54.

Wiatros-Motyka, M.M., Sun, C.G., Stevens, L.A., Snape, C.E., 2013. High capacity co-precipitated manganese oxides sorbents for oxidative mercury capture. Fuel 109,559-562.

Wang, Z.H., Jiang, S.D., Zhu, Y.Q., Zhou, J.S., Zhou, J.H., Li, Z.S., Cen, K.F., 2010. Investigation on elemental mercury oxidation mechanism by non-thermal plasma treatment. Fuel Process. Technol. 91,1395-1400.

Wang, Z.H., Zhou, J.H., Zhu, Y.Q., Wen, Z.H., 2007. Simultaneous Removal of $\mathrm{NO}_{\mathrm{x}}, \mathrm{SO}_{2}$ and $\mathrm{Hg}$ in Nitrogen Flow in a Narrow 
Wilcox, J., Rupp, E., Ying, S.C., Lim, D.H., 2011. Negreira AS. Mercury adsorption and oxidation in coal combustion and gasification processes. Int. J. Coal Geol. 90-91,4-20.

Wols, B.A., Hofman-Caris, C.H.M., 2012. Review of photochemical reaction constants of organic micropollutants required for UV advanced oxidation processes in water. Water Res. 46,2815-2827.

Wang, M.Y., Zhu, T.L., Luo, H.J., Tang, P., Li, H., 2009. Oxidation of gaseous elemental mercury in a high voltage discharge reactor. J. Environ. Sci. 21,1652-1657.

Wang, M.Y., Zhu, T.L., Luo, H.J., Wang, H., Fan, W.Y., 2011. Effects of Reaction Conditions on Elemental Mercury Oxidation in Simulated Flue Gas by DC Nonthermal Plasma. Ind. Eng. Chem. Res. 50,5914-5919

Wang, N.N., Zheng, T., Zhang, G.S., Wang, P., 2016. A review on Fenton-like processes for organic wastewater treatment. J. Environ.Chem. Eng. 1, 762-787.

Wu, Y., 1996. Experimental study of mercury vapor removal using pulse discharge method. J. Environ. Sci. 2, 221-225.

Wu, Z.L., 2006.Study on removal mechanism of multi-pollutants in flue gas using DC corona radical shower. Hang Zhou, Zhejiang University.

Wu, C.Y., Lee, T.G., Tyree, G., Arar, E., Biswas, P., 1998. Capture of Mercury in Combustion Systems by In Situ-Generated Titania Particles with UV Irradiation. Environ. Eng. Sci. 15,137-148.

Worathanakul, P., Kongkachuichay, P., Noel, J.D., Suriyawong, A., Giammar, D.E., Biswas, P., 2008. Evaluation of Nanostructured Sorbents in Differential Bed Reactors for Elemental Mercury Capture. Environ. Eng. Sci. 7,1061-1070.

Wang, H.Q., Zhou, S.Y., Xiao, L., Wang, Y.J., Liu, Y., Wu, Z.B., 2011. Titania nanotubes-A unique photocatalyst and adsorbent for elemental mercury removal. Catal. Today 175,202-208.

Wang, X., Wang, L.G., Li, J.B., Qiu, J.J., Cai, C., Zhang, H., 2014b. Degradation of Acid Orange 7 by persulfate activated with zero valent iron in the presence of ultrasonic irradiation. Sep. Purif. Technol.122,41-46. 
Wang, C.W., Liang, C.J., 2014c. Oxidative degradation of TMAH solution with UV persulfate activation. Chem. Eng. J. 254, $472-478$.

Wang, Z.H., 2005. Mechanism study on multi-pollution control simultaneously during coal combustion and direct numerical

Wu, J., Li, X., Ren, J.X., Qi, X. M., 2015b. Experimental study of $\mathrm{TiO}_{2}$ hollow microspheres removal on elemental mercury in simulated flue gas. Journal of Industrial and Engineering Chemistry 32, 49-57.

Xu, W.Q., Wang, H.R., Zhou, X., Zhu, T.Y., 2014. CuO/TiO 2 catalysts for gas-phase $\mathrm{Hg}^{0}$ catalytic oxidation. Chem. Eng. J. 243, 380-385.

Xu, Y.L., Zhong, Q., Liu, X.Y., 2015. Elemental mercury oxidation and adsorption on magnesite powdermodified by Mn at low temperature. J. Hazard. Mater. 283,252-259.

Xu, X.H., Ye, Q.F., Tang, T.M., Wang, D.H., 2008. $\mathrm{Hg}^{0}$ oxidative absorption by $\mathrm{K}_{2} \mathrm{~S}_{2} \mathrm{O}_{8}$ solution catalyzed by $\mathrm{Ag}^{+}$and $\mathrm{Cu}^{2+} . \mathrm{J}$ Hazard. Mater. 158,410-416.

Xu, J.H., Li, C.L., Liu, P., He, D., Wang, J.F., Zhang, Q., 2014. Photolysis of low concentration $\mathrm{H}_{2} \mathrm{~S}$ under UV/VUV irradiation emitted from high frequency discharge electrodeless lamps. Chemosphere 109,202-207. 
Xu, F., Luo, Z.Y., Cao, W., Wang, P., Wei, B., Gao, X., 2009. Simultaneous oxidation of $\mathrm{NO}, \mathrm{SO}_{2}$ and $\mathrm{Hg}^{0}$ from flue gas by pulsed corona discharge. J. Environ. Sci. 3,328-332.

Yang, S.J., Yan, N.Q., Guo, Y.F., Wu, D.Q., He, H.P., Qu, Z., Li, J.F., Zhou, Q., Jia, J.P., 2011. Gaseous Elemental Mercury Capture from Flue Gas Using Magnetic Nanosized $\left(\mathrm{Fe}_{3}-\mathrm{xMn}_{\mathrm{x}}\right) 1-\delta \mathrm{O}_{4}$. Environ. Sci. Technol. 45,1540-1546.

Yang, H.Q., Xu, Z.H., Fan, M.H., Bland, A.E., Judkins, R.R., 2007. Adsorbents for capturing mercury in coal-fired boiler flue gas. J.

Yu, Y., Zhang, T.T., Zheng, L.Q., Yu, J., 2013. Photocatalytic degradation of hydrogen sulfide using $\mathrm{TiO}_{2}$ film under microwave electrodeless discharge lamp irradiation. Chem. Eng. J. 1,9-15.

Ye, J.H., Shang, J., Li, Q., Xu, W.W., Liu, J., Feng, X., Zhu, T., 2014. The use of vacuum ultraviolet irradiation to oxidize $\mathrm{SO}_{2}$ and $\mathrm{NO}_{\mathrm{x}}$ for simultaneous desulfurization and denitrification. J. Hazard. Mater.30,89-97.

Yan, K., Kanazawa, S., Ohkubo, T., Nomoto, Y., 1999. Oxidation and Reduction Processes During $\mathrm{NO}_{\mathrm{x}}$ Removal with Corona-Induced Nonthermal Plasma. Plasma Chem. Plasma Process 3,421-443.

Yoshida, K., Yamamoto, T., Kuroki, T., Okubo, M., 2009. Pilot-Scale Experiment for Simultaneous Dioxin and $\mathrm{NO}_{\mathrm{x}}$ Removal from Garbage Incinerator Emissions Using the Pulse Corona Induced Plasma Chemical Process. Plasma Chem. Plasma Process 5,373-386.

Yang, H.M., Hou, W.H., Zhang, H.R., Zhou, L.Y., 2012a. Oxidation of Elemental Mercury with Non-Thermal Plasma Coupled with Photocatalyst. J. Adv. Oxid. Technol. 2,321-327. 
Yuan, Y., Zhang, J.Y., Zhao, Y.C., Wang, Y.X, Zheng, C.G., 2012a. Effects of $\mathrm{SO}_{2}$ and NO on removal of elemental mercury using a $\mathrm{TiO}_{2}$-aluminum silicate fiber. J. Fuel Chem. Technol. 5,630-635.

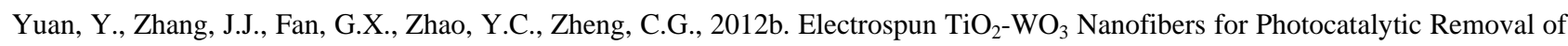
Mercury. Proceedings of the CSEE 32,44-49.

Yuan, Y., Zhao, Y.C., Li, H.L., Gao, X., Zheng, C.G., Zhang, J.Y., 2012c. Electrospun metal oxide-TiO ${ }_{2}$ nanofibers for elemental mercury removal from flue gas. J. Hazard. Mater. 227-228,427- 435. silicate fiber by photocatalysis. Chem. Eng. J. 192,21-28.

Ye, Q.F., 2006. Gaseous Mercury Absorption from Simulated Flue Gas. Hangzhou, Zhejiang university.

Yan, J.C., Han, L., Gao, W.G., Xue, S., Chen, M.F., 2015. Biochar supported nanoscale zerovalent iron composite used as persulfate activator for removing trichloroethylene. Bioresource Technol. 175,269-274.

Yang, S.Y., Yang, X., Shao, X.T., Niu, R., Wang, L.L., 2011. Activated carbon catalyzed persulfate oxidation of Azo dye acid orange 7 at ambient temperature. J. Hazard. Mater. 186,659-666.

Zheng, Y.J., Jensen, A.D., Windelin, C., Jensen, F., 2012. Dynamic measurement of mercury adsorption and oxidation on activated carbon in simulated cement kiln flue gas. Fuel 93,649-657.

Zhao, P.F., Guo, X., Zheng, C.G., 2010. Removal of elemental mercury by iodine-modified rice husk ash sorbents. J. Environ. Sci.

$$
22,1629-1636 .
$$

Zhao, B., Liu, X.W., Zhou, Z.J., Shao, H.Z., Wang, C., Si, J.P., Xu, M.H., 2014a. Effect of molybdenum on mercury oxidized by $\mathrm{V}_{2} \mathrm{O}_{5}-\mathrm{MoO}_{3} / \mathrm{TiO}_{2}$ catalysts. Chem. Eng. J. 253,508-517. 
Zhang, B.K., Liu, J., Zheng, C.G., Chang, M., 2014b. Theoretical study of mercury species adsorption mechanism on $\mathrm{MnO}_{2}(110)$ surface. Chem. Eng. J. 256,93-100.

Zhou, S.Y., 2011. Adsorption-Photocatalytic Oxidation performance of $\mathrm{TiO}_{2}$ based nanotubes in elemental mercury removal.

Zhao, Y., Hao, R.L., Guo, Q., 2014c. A novel pre-oxidation method for elemental mercury removalutilizing a complex vaporized HangZhou, Zhejiang University.

Zhao, Y., Hao, R.L., Zhang, P., Zhou, S.H., 2014b. An integrative process for $\mathrm{Hg}^{0}$ removal using vaporized $\mathrm{H}_{2} \mathrm{O}_{2} / \mathrm{Na}_{2} \mathrm{~S}_{2} \mathrm{O}_{8}$. Fuel $136,113-121$. absorbent. J. Hazard. Mater. 280,118-126.

Zhao, Y., Xue, F.M., Zhao, X.C., Guo, T.X., Li, X.L., 2013a. Experimental study on elemental mercury removal by diperiodatonickelate (IV) solution. J. Hazard. Mater. 260,383-388.

Zhao, Y., Xue, F.M., Ma, T.Z., 2013b. Experimental study on $\mathrm{Hg}^{0}$ removal by diperiodatocuprate (III) coordination ion solution. Fuel Process. Technol. 106,468-47.

Zheng, Y.J., Jensen, A.D., Windelin, C., Jensen, F., 2012. Review of technologies for mercury removal from flue gas from cement production processes. Prog. Energ. Combust. 5,599-629.

Zhong, Y., 2008. Experimental and theory study on synergy removal of sulfur, nitrogen, mercury contaminants using WFGD system. Hang Zhou, Zhejiang University.

Zhao, Y., Chen, Z.Y., Wang, L.D., Zhang, S.W., 2008. Study on simultaneous removal of $\mathrm{SO}_{2}$ and $\mathrm{Hg}$ in wet flue gas desulfurization. $1,64-68$.

Zhao, Y., Wen, X.Y., Guo, T.X., Zhou, J.H., 2014d. Desulfurization and denitrogenation from flue gas using Fenton reagent. Fuel Process. Technol. 128,54-60.

Zhou, Q., 2013. The research of reactor structural optimization as well as influence of power parameters and gas conditions on 
plasma denitrification. Wu Han, Wuhan Textile University.

Zhou, L.M., Wang, Y.P., Huang, Q.W., Liu, Z.R., 2008. Preparation and visible light activity of silver, sulfur, and carbon co-doped

Zhang, C. F., 1985. Gas-Liquid Reaction and Reactor. Beijing, Chemical Industry Press.

nano- $\mathrm{TiO}_{2}$. Semiconduct. Optoelect 29,365-369.

Zhuang, Z.K., Yang, Z.M., Zhou, S.Y., Wang, H.Q., Sun, C.L, Wu, Z.B., 2014. Synergistic photocatalytic oxidation and adsorption of elemental mercury by carbon modified titanium dioxide nanotubes under visible light LED irradiation. Chem. Eng. J. $253,16-23$.

Zhang, D., Zeng. F., 2011a. Photocatalytic oxidation of organic dyes with visible light driven codoped $\mathrm{TiO}_{2}$ photocatalysts. Russ. J. Phys. Chem. A 85,1077-1083.

Zhang, H.; Chen, G.; Behnemann, D. W., 2009. Photo-electrocatalytic materials for environmental applications. J. Mater. Chem. 19, 5089-5121.

Zhao, Y., Zhao, L., Han, J., Xu, Y.Y., Wang, S.Q., 2008. Study on method and mechanism for simultaneous desulfurization and denitrification of flue gas based on the $\mathrm{TiO}_{2}$ photocatalysis. Sci. China Ser. E 3,268-276.

Zuo, G.M., Cheng, Z.X., Chen, H., Li, G.W., Miao, T., 2006. Study on photocatalytic degradation of several volatile organic compounds. J. Hazard. Mater. 2-3,158-163.

Zhan, F., Li, C.T., Zeng, G.M., Tao, S.S., Xiao, Y.J., 2013. Experimental study on oxidation of elemental mercury by UV/Fenton system. Chem. Eng. J. 232,81-88.

Zhang, J., Liu, Y.X., Sheng, C.D., 2011b. An integrated flue gas purification system basing on heterogeneous UV/Fenton-like. China Patent, CN201110045887.

Zhao, Y., Hao, R.L., 2014d. Macrokinetics of $\mathrm{Hg}^{0}$ Removal by a Vaporized Multicomponent Oxidant. Ind. Eng. Chem. Res. $53,10899-10905$.

Zhu, K.H., 2003. Analysis introduction of industry reaction process. Beijing, China Petrochemical Press, 2003. 
Zhuang, Y., 2011. Martin, C., Pavlisha, J., Botha, F., 2011. Cobenefit of $\mathrm{SO}_{3}$ reduction on mercury capture with activated carbon in coal flue gas. Fuel 90,2998-3006.

Zhou C.S., Sun, L.S., Zhang, A.C., Wu, X.F., Ma, C., Su, S., 2015a. $\mathrm{Fe}_{3-\mathrm{x}} \mathrm{Cu}_{\mathrm{x}} \mathrm{O}_{4}$ as highly active heterogeneous Fenton-like catalysts toward elemental mercury removal. Chemosphere 125, 16-24.

Zhou, C.S., Wang, B., Ma, C., Song, Z.J., Zeng, Z., Xiang, J., Hu, S., Su, S., Sun, L.S., 2015b. Gaseous elemental mercury removal through heterogeneous Fenton-like processes using novel magnetically separable $\mathrm{Cu}_{0.3} \mathrm{Fe}_{2.7-\mathrm{x}} \mathrm{Ti}_{\mathrm{x}} \mathrm{O}_{4}$ catalysts. Fuel 161, $254-261$.

Zhou, C.S., Sun, L.S., Zhang, A.C., Ma, C., 2015c. Elemental mercury $\left(\mathrm{Hg}^{0}\right)$ removal from containing $\mathrm{SO}_{2} / \mathrm{NO}$ flue gas by magnetically separable $\mathrm{Fe}_{2.45} \mathrm{Ti}_{0.55} \mathrm{O}_{4} / \mathrm{H}_{2} \mathrm{O}_{2}$ advanced oxidation processes. Chemical Engineering Journal 273, 381-389. 